\title{
COMPORTAMENTO DE CONECTORES DE CISALHAMENTO EM VIGAS MISTAS AÇO-CONCRETO COM ANÁLISE DA RESPOSTA NUMÉRICA
}

\section{Gustavo Alves Tristão}

Dissertação apresentada à Escola de Engenharia de São Carlos da Universidade de São Paulo, como parte dos requisitos para obtenção do título de Mestre em Engenharia de Estruturas

ORIENTADOR: Prof. Dr. Jorge Munaiar Neto 
Aos meus pais, Joelson e Maria da Fé,

e aos meus irmãos Leonardo e Rodrigo 


\section{AGRADECIMENTOS}

Ao professor Jorge Munaiar Neto pelos constantes incentivos e aconselhamentos na procura de desenvolver sempre o melhor trabalho.

A o CNPQ pela concessão da bolsa de estudos.

A Nadir, bibliotecária do Departamento de Engenharia de Estruturas, pela contribuição na pesquisa bibliográfica e revisão das referências bibliográficas deste trabalho.

Ao professor Maximiliano Malite pela ajuda no entendimento e desenvolvimento do tema.

Ao professor e amigo Reginaldo Carneiro da Silva pelo acolhimento e conselhos desde o início do Mestrado.

Ao amigo Yuri Maggi e amiga Rejane Matins pela enorme colaboração para o entendimento do programa ANSYS.

Aos amigos e amigas do Departamento Ricardo, Fernando, Rodrigo Gustavo, Andrei, Clayton, Fábio, João de Deus, Romeu, Rodrigo, Joel, Valério, Luciano Barbosa, Júlio, Adilson, Alex, Josafá, Luciano, Arthur, Valentim, Bruce, Ângela, Suzana, Patrícia, Tatiana.

Aos amigos do QG (João Marcelo, Rômulo e Everton) e Base Aérea (Ricardo, Marcos Vinícios e Rafael), com também Mário Garrido, Cláudio, Alexandre, Renato e Lisiane pelas inúmeras horas de lazer que tivemos, o qual propiciou a construção de uma grande amizade.

Aos de mais professores e funcionários do Departamento de Engenharia de Estruturas. 
A todos aqueles que, embora não citados nominalmente, contribuíram direta ou indiretamente para execução deste trabalho.

Em especial, um agradecimento aos meus pais, irmãos e meu avô, os quais sempre lutaram para conclusão deste trabalho, bem como pelos constantes incentivos e apoio nos momentos mais difíceis. 


\section{SUMÁRIO}

LISTA DE FIGURAS............................................................................................... viii

LISTA DE TABELAS..................................................................................................... xii

LISTA DE GRÁFICOS.................................................................................................. xiii

LISTA DE SÍMBOLOS..................................................................................... xiv

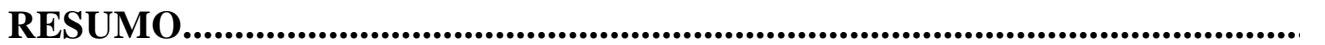

xviii

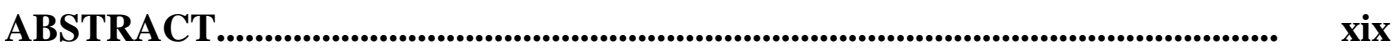

1 INTRODUÇÃ

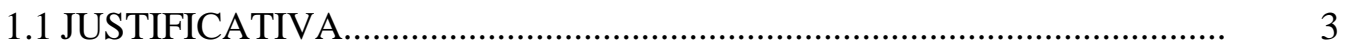

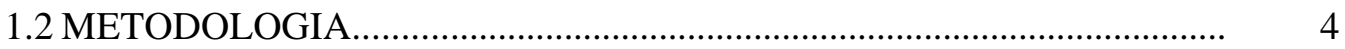

2 VIGAS MISTAS AÇO-CONCRETO_........................................................... 5

2.1 GRAU DE CONEXÃO E GRAU DE INTERAÇÃO.................................... 7

2.1.1 GRAU DE CONEXÃO ….......................................................................

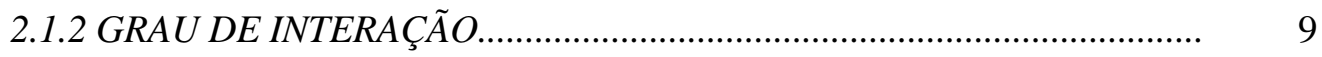

2.2 TIPOS DE CONECTORES DE CISALHAMENTO....................................... 10

2.3 ASPECTOS DA RUPTURA DO CONECTOR TIPO PINO COM

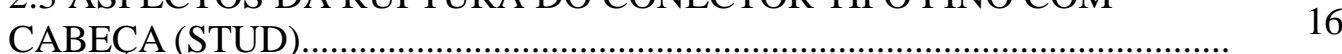

2.4 FORÇA DE CISALHAMENTO LONGITUDINAL NOS CONECTORES 17

2.5 ASPECTOS DA FISSURAÇÃO NA LAJE DE CONCRETO....................... 19

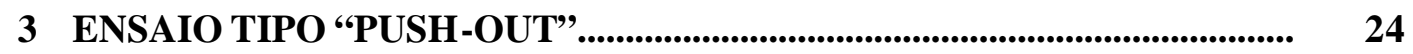

3.1 PROCEDIMENTOS PARA A REALIZAÇÃO DO ENSAIO E ANÁLISE DOS RESULTADOS OBTIDOS.

3.2 CONSIDERAÇÕES PARA O ENSAIO TIPO "PUSH-OUT".

3.3 ENSAIOS TIPO "PUSH-OUT" PARA CONECTORES FORMADOS A FRIO..... 
3.4 DETERMINAÇÃO DA RESISTÊNCIA AO CISALHAMENTO DOS CONECTORES EM VIGAS MISTAS AÇO-CONCRETO..

3.5 LOCAÇÃO E ESPAÇAMENTO DOS CONECTORES SEGUNDO ALGUMAS NORMAS.

4 ASPECTOS DA MODELAGEM NUMÉRICA DO ENSAIO TIPO "PUSH-OUT"

4.1 CONSIDERAÇÕES INICIAIS

4.2 MÉTODO ADOTADO PARA OS MODELOS NUMÉRICOS PROPOSTOS

4.2.1 ELEMENTOS FINITOS ADOTADOS PARA OS MODELOS PROPOSTOS.

4.2.1.1 ELEMENTO SOLID 65. 45

4.2.1.2 ELEMENTO SOLID 45. 46

4.2.1.3 ELEMENTO LINK 8. 47

4.2.1.4 TARGE 170 E CONTAC 173.

4.2.2 CRITÉRIOS GERAIS ADOTADOS NOS MODELOS NUMÉRICOS....... 48

4.2.2.1 DEFINIÇÃO DA MALHA DE ELEMENTOS FINITOS. 49

4.2.2.2 CONDIÇÕES DE CONTORNO ADOTADAS NO MODELO. 53

4.2.2.3 CONSIDERAÇÕES NA APLICAÇÃO DA SOLICITAÇÃO. 53

4.2.3 MODELOS COM NÃO-LINEARIDADE FÍSICA ADOTADOS PARA OS MATERIAIS AÇO E CONCRETO

4.2.3.1 COMPORTAMENTO ELASTO-PLÁSTICO PERFEITO ADOTADO PARA O AÇO DA ARMADURA.

4.2.3.2 COMPORTAMENTO ELASTO-PLÁSTICO MULTILINEAR COM ENCRUAMENTO ISÓTROPO PARA O AÇO DO CONECTOR E DO PERFIL.

4.2.3.3 COMPORTAMENTO NÃO-LINEAR DO MODELO CONCRETO....

4.2.3.4 MODELO DE COMPORTAMENTO ELÁSTICO NÃO-LINEAR....... 56 57 59

\section{ANÁLISE E DISCUSSÃO DOS RESULTADOS NUMÉRICOS}

5.1 MODELOS NUMÉRICOS COM CONECTOR TIPO PINO COM CABEÇA (STUD)

5.1.1 MODELO NUMÉRICO PHS-1.

5.1.1.1 CARACTERÍSTICAS ADOTADAS PARA OS MATERIAIS.

5.1.1.2 - CONFRONTO DA RELAÇÃO ENTRE FORÇA E DESLOCAMENTO PARA O MODELO NUMÉRICO PHS-1. 
5.1.1.3 - ANÁLISE DA RESPOSTA NUMÉRICA DE COMPONENTES QUE CONSTITUEM O MODELO PHS-1

5.1.2 MODELO NUMÉRICO PHS-2

5.1.2.1 CARACTERÍSTICAS DOS MATERIAIS, MODELO PHS-2.

5.1.2.2 CONFRONTO DA RELAÇÃO ENTRE FORÇA E DESLOCAMENTO PARA O MODELO NUMÉRICO PHS-2..

5.1.2.3 ANÁLISE DA RESPOSTA NUMÉRICA DE COMPONENTES QUE CONSTITUEM O MODELO PHS-2. 76

5.2 MODELOS NUMÉRICOS COM CONECTORES TIPO PERFIL "U" FORMADOS A FRIO.

5.2.1 ANÁLISE DO MODELO NUMÉRICO PHU-EI. 82

5.2.2 ANÁLISE DO MODELO NUMÉRICO PHU-EII. 86

5.2.3 ANÁLISE DO MODELO NUMÉRICO PHU-FI. 90

5.2.4 ANÁLISE DO MODELO NUMÉRICO PHU-FII. 95

5.3 CONFRONTO ENTRE RESULTADOS NUMÉRICOS DOS MODELOS COM CONECTOR TIPO PERFIL "U" FORMADO A FRIO.

5.3.1 INFLUÊNCIA DA POSIÇÃO DO CONECTOR 100

5.3.2 INFLUÊNCIA DA ESPESSURA DO CONECTOR 103

6 CONSIDERAÇÕES FINAIS. 105

REFERÊNCIAS BIBLIOGRÁFICAS

APÊNDICE I - CRITÉRIO DE RUPTURA DO MODELO DE NÃOLINEARIDADE CONCRETO. 


\section{LISTA DE FIGURAS}

FIGURA 2.1 Tipos usuais de vigas mistas, ALVA (2000) ................................... 6

FIGURA 2.2 Equilíbrio longitudinal de forças........................................................ 7

FIGURA 2.3 Interação entre o aço e o concreto no comportamento de viga mista, MALITE(1990)

FIGURA 2.4 Relação força-deslocamento para conectores de cisalhamento, ALVA (2000).

FIGURA 2.5

Tipos usuais de conectores de cisalhamento, MALITE (1990)

FIGURA 2.6 Detalhe da laje com forma de aço incorporada (laje mista), catálogo da CODEME Engenharia.

FIGURA 2.7 Dimensões mínimas para o conector tipo pino com cabeça (stud), (ECCS/1993)

FIGURA 2.8 Processo de soldagem do conector pino com cabeça (stud), QUEIROZ (2001)...

FIGURA 2.9 Resultado final da soldagem do conector tipo pino com cabeça (stud)

FIGURA 2.10 Soldagem do conector pino com cabeça (stud) "in loco", QUEIROZ (2001)...

FIGURA 2.11 Detalhe do Conector tipo perfil "U".

FIGURA 2.12 Conector da Hilti HVB, QUEIROZ (2001).................................... 15

FIGURA 2.13 Conector da Hilti HVB em fôrmas de aço, QUEIROZ (2001).......... 15

FIGURA 2.14 Transferência de forças de cisalhamento longitudinal do tipo pino com cabeça (stud)

FIGURA 2.15 Tipos de fissuração na laje devida à força concentrada

FIGURA 2.16

Disposição das armaduras transversais (adicionais) na laje de concreto.

FIGURA 2.17 Superfícies típicas de falha ao cisalhamento, EUROCODE 4 (1994)

FIGURA 3.1 Modelo do ensaio tipo "Push-out" proposto pelo EUROCODE 4 (1994).

FIGURA 3.2 Determinação da capacidade de deslocamento $\delta_{u}$, em correspondência a $\mathrm{P}_{\mathrm{rk}}$

FIGURA 3.3 Modos de ruptura do ensaio tipo "Push-out", EUROCODE 4 (1994).

FIGURA 3.4 Tensões de contato no conector tipo pino com cabeça. 
FIGURA 3.5 Esquema geral dos modelos ensaiados por MALITE (1993)

FIGURA 3.6 Tipos e posições dos conectores nos modelos de ensaio de MALITE (1993).

FIGURA 3.7 Rotação do conector junto á ligação com o perfil, modelo ensaiado por MALITE (1993).

FIGURA 3.8 Relação força $x$ deslocamento para os modelos com conector perfil "U" de 2,66 mm nas duas posições (EI e EII).

FIGURA 3.9 Comparação das recomendações das normas quanto à locação e espaçamento dos conectores.

FIGURA 4.1 a) modelo típico para o ensaio experimental "Push-out".

b) modelo utilizado para a simulação numérica.

FIGURA 4.2 Elemento finito tipo SOLID 65.

FIGURA 4.3 Elemento finito tipo SOLID 45

FIGURA 4.4 Elemento finito tipo LINK 8

FIGURA 4.5 Malha de elementos finitos para a laje de concreto referente ao modelo PHU-EI.

FIGURA 4.6 Detalhe dos acoplamentos dos nós entre a laje de concreto e o perfil metálico modelo PHU-EI.

FIGURA 4.7 Malha referente ao perfil metálico e conector tipo pino com cabeça (stud) modelo PHS-2.

FIGURA 4.8 Malha referente ao perfil metálico e conector tipo perfil " $U$ " modelo PHU-FI.

FIGURA 4.9 Detalhe da armadura na laje de concreto referente ao modelo PHUFI..

FIGURA 4.10 Detalhe dos elementos de contato para os conectores pino com cabeça (stud), modelo PHS-2

FIGURA 4.11 Detalhe dos elementos de contato para os conectores perfil "U", modelo PHU-FI.

FIGURA 4.12 Condições de contorno, modelo PHU-FI.......................................... 54

FIGURA 4.13 Aplicação da solicitação, modelo PHU-FI........................................... 54

FIGURA 4.14 Comportamento elasto-plástico perfeito............................................. 56

FIGURA 4.15 Comportamento elasto-plástico multilinear com encruamento isótropo.

FIGURA 4.16 Relação tensão x deformação do concreto, CEB-FIP (1991)............. 59

FIGURA 5.1 Visão geral do modelo PHS-1 …........................................................ 62

FIGURA 5.2 Dimensões do modelo PHS-1 1 ......................................................... 63

FIGURA 5.3 Detalhe da aplicação dos modelos de não-linearidade no concreto, modelo PHS-1. 
FIGURA 5.4 Tensão axial $\left(\mathrm{kN} / \mathrm{cm}^{2}\right)$ na armadura da laje de concerto para o modelo PHS-1.

FIGURA 5.5 Pressão de contato $\left(\mathrm{kN} / \mathrm{cm}^{2}\right)$ entre o conector e o concreto, modelo PHS-1.

FIGURA 5.6 Tensão $\left(\mathrm{kN} / \mathrm{cm}^{2}\right)$ na laje de concreto, região circundante ao conector, modelo PHS-1

FIGURA 5.7 Estado de tensão $\left(\mathrm{kN} / \mathrm{cm}^{2}\right)$ no pino com cabeça (stud), modelo PHS-1.

FIGURA 5.8 Progressão das fissuras na laje de concreto, modelo PHS-1.

FIGURA 5.9 Apresentação do modelo experimental utilizado por AN \& CEDERWALL (1996).

FIGURA 5.10 Visão geral do modelo numérico PHS-2

FIGURA 5.11 Progressão das fissuras na laje de concreto, modelo PHS-2 76

FIGURA 5.12 Pressão de contato $\left(\mathrm{kN} / \mathrm{cm}^{2}\right)$ entre o conector e o concreto, modelo PHS-2.

FIGURA 5.13 Tensão axial $\left(\mathrm{kN} / \mathrm{cm}^{2}\right)$ na armadura, modelo PHS-2.

FIGURA 5.14 Tensão $\left(\mathrm{kN} / \mathrm{cm}^{2}\right)$ no conector pino com cabeça (stud), modelo PHS-2.

FIGURA 5.15 Visão geral do modelo numérico denominado PHU-EI.....

FIGURA 5.16 Modelos de não-linearidade na laje de concreto, modelo PHU-EI.....

FIGURA 5.17 Tensão $\left(\mathrm{kN} / \mathrm{cm}^{2}\right)$ no concreto, região da laje com o modelo de nãolinearidade concreto(a) e modelo elástico não-linear (b)(região abaixo do conector), modelo PHU-EI.

FIGURA 5.18 Tensão axial $\left(\mathrm{kN} / \mathrm{cm}^{2}\right)$ na armadura da laje, modelo PHU-EI........... 84

FIGURA 5.19 Tensão $\left(\mathrm{kN} / \mathrm{cm}^{2}\right)$ no conector, modelo PHU-EI.............................. 85

FIGURA 5.20 Visão geral do modelo numérico denominado PHU-EII.................... 87

FIGURA 5.21 Modelos de não-linearidade na laje de concreto, modelo PHU-EII... 88

FIGURA 5.22 Tensão $\left(\mathrm{kN} / \mathrm{cm}^{2}\right)$ no concreto, região da laje com o modelo de nãolinearidade concreto(a) e modelo elástico não-linear (b), modelo PHU-EII..

FIGURA 5.23 Tensão axial $\left(\mathrm{kN} / \mathrm{cm}^{2}\right)$ na armadura da laje, modelo PHU-EII......... 89

FIGURA 5.24 Tensão $\left(\mathrm{kN} / \mathrm{cm}^{2}\right)$ no conector, modelo PHU-EII............................. 89

FIGURA 5.25 Visão geral do modelo numérico PHU-FI........................................ 90

FIGURA 5.26 Modelos de não-linearidade na laje de concreto, modelo PHU-FI..... 92

FIGURA 5.27 Tensão de Mises $\left(\mathrm{kN} / \mathrm{cm}^{2}\right)$ no concreto, região da laje com o modelo de não-linearidade concreto(a) e modelo elástico não-linear (b), modelo PHU-FI. 
FIGURA 5.28 Tensão axial $\left(\mathrm{kN} / \mathrm{cm}^{2}\right)$ na armadura da laje, modelo PHU-FI........... 93

FIGURA 5.29 Tensão $\left(\mathrm{kN} / \mathrm{cm}^{2}\right)$ no conector, modelo PHU-FI.............................. 94

FIGURA 5.30 Visão geral do modelo PHU-FII......................................................... 95

FIGURA 5.31 Modelos de não-linearidade na laje de concreto, modelo PHU-FII.... 96

FIGURA 5.32 Tensão $\left(\mathrm{kN} / \mathrm{cm}^{2}\right)$ no concreto, região da laje com o modelo de nãolinearidade concreto(a)(abaixo da alma do perfil’"U") e modelo elástico não-linear (b)

FIGURA 5.33 Tensão axial $\left(\mathrm{kN} / \mathrm{cm}^{2}\right)$ na armadura, modelo PHU-FII..................... 98

FIGURA 5.34 Tensão $\left(\mathrm{kN} / \mathrm{cm}^{2}\right)$ no conector, modelo PHU-FII............................... 99

FIGURA 5.35 Comparação da distribuição da tensão no conector entre os modelos (a) PHU-FI e (b) PHU-FII, referente às forças últimas de cada modelo

FIGURA 5.36 Comparação da pressão de contato entre os modelos (a) PHU-FI e (b) PHU-FII, referente à força de $139 \mathrm{kN}$.

FIGURA 5.37 Comparação da distribuição da tensão no conector entre os modelos (a) PHU-EII e (b) PHU-FII, referente às forças últimas de cada modelo.

FIGURA 5.38 Comparação da pressão de contato entre os modelos (a) PHU-EII e (b) PHU-FII, referente às forças últimas de cada modelo

FIGURA I.1 Superfície de ruptura no espaço das tensões principais

FIGURA I.2 Superfície de ruptura associado ao modelo concreto, em função de 
TABELA 3.1 Resistências últimas médias dos conectores para os modelos analisados.

TABELA 3.2 Capacidade nominal dos conectores tipo pino com cabeça em lajes maciças, BS 5950 (1990).

TABELA 3.3 Capacidade nominal dos conectores tipo perfil "U" laminado, BS 5400 (1979)

TABELA 4.1 Detalhe das características dos modelos numéricos

TABELA 4.2 Parâmetros do modelo de material concreto, de acordo com o manual do ANSYS.

TABELA 5.1 Propriedades do aço do conector pino com cabeça (stud) e do perfil metálico (referente à figura 4.14, capítulo 4), modelo PHS-1

TABELA 5.2 Propriedades do aço da armadura (referente à figura 4.13), modelo PHS-1

TABELA 5.3 Valores dos parâmetros para o modelo de não-linearidade concreto, modelo PHS-1

TABELA 5.4 Propriedades do aço do conector pino com cabeça (stud) e do perfil metálico (referente à figura 4.14, capítulo 4), modelo PHS-2.

TABELA 5.5 Propriedades do aço da armadura (referente à figura 4.13), modelo PHS-2

TABELA 5.6 Valores dos parâmetros para o modelo de não-linearidade concreto, modelo PHS-2

TABELA 5.7 propriedades do aço do conector perfil "U" formado a frio e do perfil metálico (referente à figura 4.14, capítulo 4).

TABELA 5.8 propriedades do aço da armadura (referente à figura 4.13, capítulo 4).

TABELA 5.9 Valores dos parâmetros para o modelo de não-linearidade concreto, modelos PHU-EI e PHU-EII.

TABELA 5.10 Valores dos parâmetros para o modelo de não-linearidade concreto, modelos PHU-FI e PHU-FII.

TABELA 6.1 Comparação da resistência última para os modelos PHS-1 e PHS-2.

TABELA 6.2 Comparação da resistência última para os modelos com conector perfil "U"

TABELA 6.3 Tipos de modos de falha detectados nos ensaios experimentais dos respectivos modelos numéricos 


\section{LISTA DE GRÁFICOS}

GRÁFICO 5.1 Relação tensão x deformação para compressão do concreto, modelo PHS-1

GRÁFICO 5.2 Relação força x deslocamento, modelo PHS-1.

GRÁFICO 5.3 Relação força $x$ deformação axial na região mais solicitada da armadura, modelo PHS-1

GRÁFICO 5.4 Relação força $x$ tensão no concreto na região da armadura, modelo PHS-1

GRÁFICO 5.5 Relação pressão de contato x força por conector, modelo PHS-1..

GRÁFICO 5.6 Relação tensão $x$ força no conector, modelo PHS-1.

GRÁFICO 5.7 Relação tensão x deformação para compressão do concreto, modelo PHS-2.

GRÁFICO 5.8 Relação força x deslocamento do conector, modelo PHS-2

GRÁFICO 5.9 Relação pressão de contato x força por conector, modelo PHS-2

GRÁFICO 5.10 Relação tensão $x$ força no conector, modelo PHS-2 .................... 79

GRÁFICO 5.11 Relação tensão x deformação para o concreto, modelos PHU-EI, PHU-EII, PHU-FI e PHU-FII

GRÁFICO 5.12 Relação força x deslocamento referente ao modelo PHU-EI.

GRÁFICO 5.13 Relação força x tensão na armadura, modelo PHU-EI.

GRÁFICO 5.14 Relação tensão $x$ força no conector, modelo PHU-EI...

GRÁFICO 5.15 Relação força $x$ deslocamento referente ao modelo PHU-EII........

GRÁFICO 5.16 Relação tensão x força no conector, modelo PHU-EII.....

GRÁFICO 5.17 Relação força $x$ deslocamento, modelo PHU-FI.

GRÁFICO 5.18 Relação força x tensão na armadura, modelo PHU-FI.................. 93

GRÁFICO 5.19 Relação tensão $x$ força no conector, modelo PHU-FI.................... 94

GRÁFICO 5.20 Relação força $x$ deslocamento, modelo PHU-FII........................... 96

GRÁFICO 5.21 Relação força $x$ tensão na armadura, modelo PHU-FII.................. 98

GRÁFICO 5.22 Relação tensão x força no conector, modelo PHU-FII................... 99

GRÁFICO 5.23 Comparação da força última do conector entre os modelos PHUEI, PHU-EII, PHU-FI e PHU-FII. 
GRÁFICO 5.24 Comparação da tensão no conector entre os modelos PHU-FI e PHU-FII.

GRÁFICO 5.25 Relação pressão de contato x força, modelos PHU-FI e PHU-FII 102

GRÁFICO 5.26 Relação pressão de contato $x$ força, modelo PHU-EII 


\section{LISTA DE SÍMBOLOS}

$\eta$

$\gamma_{\mathrm{a}} \quad$ - coeficiente de segurança do aço da viga (EUROCODE 4) (1994)

$\phi_{\mathbf{b}} \mathbf{M}_{\mathbf{a}} \quad$ - resistência de cálculo ao momento fletor da viga de aço isolada, baseada no estado limite FLA

$\sigma_{\mathbf{c}} \quad-$ tensão de compressão do concreto

$\varepsilon_{\mathbf{c}} \quad$ - deformação na compressão do concreto

$\gamma_{c} \quad$ - coeficiente de segurança do concreto (EUROCODE 4) (1994)

$\gamma_{c} ; \rho \quad-$ peso específico do concreto

$\varepsilon_{\mathbf{c 1}} \quad-$ deformação de pico do concreto

$\sigma_{\mathrm{e}} \quad$ - tensão equivalente de Von Mises

$\sigma_{\mathrm{h}} \quad-$ tensão hidrostática

$\sigma_{\mathrm{h}}^{\mathrm{a}} \quad$ - estado de tensão hidrostática ambiente

$v_{\text {pd }} \quad$ - contribuição da forma de aço para o cálculo da resistência ao esforço cisalhante da laje

$v_{\text {rd }} \quad-$ resistência ao esforço cisalhante na superfície considerada da laje

$\gamma_{\mathrm{s}} \quad$ - coeficiente de segurança do aço da armadura (EUROCODE 4) (1994)

$\phi_{\text {sc }} \quad$ - coeficiente de resistência, CAN/CSA-S16.1 (1994)

$\gamma_{\mathbf{u}} \quad$ - coeficiente de segurança para o estado limite último (EUROCODE 4) (1994)

a - distância do centro do conector à borda da forma

A $\quad$ - área da seção transversal da viga de aço

$\mathbf{A}_{\text {ap }} \quad$ - área eficiente de qualquer forma de aço nervurada, em caso de laje com forma de aço incorporada

$\mathbf{A}_{\mathbf{c}} \quad$ - área da largura efetiva do concreto 
$\mathbf{A}_{\mathbf{p}} \quad$ - área da seção transversal da forma por unidade de comprimento da viga

A $\quad$ - área eficiente da armadura longitudinal da laje

$\mathbf{A}_{\mathbf{s}} ; \mathbf{A}_{\mathbf{s c}} \quad$ - área da seção transversal do conector tipo pino com cabeça (stud)

A se $_{\text {se }} \quad$ área de qualquer armadura longitudinal na compressão que é incluída no cálculo da resistência à flexão

b - largura efetiva da laje de concreto

$\mathbf{b}_{\mathbf{F}} \quad$ - largura da nervura da forma de aço

$\mathbf{C}_{\text {red }} \quad$ - coeficiente de redução para o cálculo da resistência do conector tipo pino com cabeça (stud) em laje com forma de aço incorporada

d - diâmetro do conector tipo pino com cabeça (stud)

$\mathbf{E}_{\mathbf{a}} \quad$ - módulo de elasticidade do aço

$\mathbf{E}_{\mathbf{c}} \quad$ - módulo de elasticidade do concreto

$\mathbf{E}_{\mathbf{c 1}} \quad$ - módulo de elasticidade secante

$\mathbf{E}_{\mathrm{ci}} \quad$ - módulo de elasticidade tangente

$\mathbf{e}_{\max } \quad$ - espaçamento máximo entre linhas de centro de conectores

$\mathbf{e}_{\min } \quad$ - espaçamento mínimo entre linhas de centro de conectores

$\mathbf{E}_{\mathbf{p}} \quad$ - módulo plástico do material

F - função do estado de tensões principais

$\mathbf{f}_{1} \quad$ - resistência ultima a compressão para o estado biaxial de compressão superposta ao estado de tensão hidrostático ambiente

$\mathbf{f}_{2} \quad$ - resistência ultima a compressão para o estado uniaxial de compressão superposta ao estado de tensão hidrostático ambiente

f $\quad$ - resistência uniaxial à compressão do concreto

$\mathbf{F}_{\mathbf{c}} \quad$ - força de compressão na laje de concreto necessária para resistir o momento fletor positivo de cálculo $\left(\mathrm{M}_{\mathrm{sd}}\right)$

$\mathbf{f}_{\mathrm{cb}} \quad$ - resistência biaxial à compressão do material

$\mathbf{f}_{\mathrm{ck}} \quad-$ resistência característica à compressão do concreto

$\mathbf{F}_{\mathrm{sh}} \quad$ - somatório das forças dos conectores no vão considerado

$\mathbf{F}_{\text {sh }} \quad$ - força de cisalhamento

$\mathbf{f}_{\mathbf{u}} \quad-$ resistência última do aço 

$\mathbf{f}_{\mathrm{ut}} \quad-$ resistência última do conector obtida no ensaio experimental
f $\quad$ - tensão de escoamento do aço
$\mathbf{h} ; \mathbf{h}_{\mathrm{cs}} \quad$ - altura do conector tipo pino com cabeça (stud)
$\mathbf{h}_{\mathbf{a}} \quad$ - altura efetiva do conector
$\mathbf{h}_{\mathrm{cs}} \quad$ - altura total do conector tipo pino com cabeça (stud) depois de soldado
$\mathbf{h}_{\mathbf{F}} \quad$ - altura nominal da nervura da forma de aço
L - comprimento do conector perfil " $U$ " e "Z" formado a frio
$\mathbf{L}_{\mathbf{c}} \quad$ - comprimento do conector perfil "U" laminado
$\mathbf{L}_{\mathbf{s p}} \quad$ - comprimento do vão considerado
$\mathbf{M}_{\mathbf{d}} \quad$ - momento fletor de cálculo no ponto de força concentrada
$\mathbf{M}_{\text {apl,Rd }}$ - momento resistente de cálculo positivo à flexão da seção metálica com conexão completa
$\mathbf{M}_{\mathbf{d}} \quad$ - momento fletor máximo de cálculo
$\mathbf{M}_{\mathbf{p l} \mathbf{R d}} \quad$ - momento resistente de cálculo positivo à flexão da seção mista com conexão completa
$\mathbf{M}_{\mathrm{sd}} \quad$ - momento fletor positico de cálculo
$\mathbf{M}_{\mathrm{sh}} \quad$ - momento produzido por $\mathrm{F}_{\mathrm{sh}} \mathrm{e} \mathrm{z}$
n - número de conectores de cisalhamento colocados de cada lado da seção de momento fletor máximo e a seção de momento nulo adjacente
$\mathbf{n}_{\mathrm{cs}} \quad$ - número de conectores de cisalhamento na viga, por nervura
$\mathbf{n}_{\mathbf{r}} \quad$ - número de conectores que podem ser assumidos com a possibilidade de romperem em grupo (deslocamentos similares)
$\mathbf{P}_{\mathbf{c}} \quad$ - resultante axial no elemento de concreto
$\mathbf{P}_{\text {rd }} \quad$ - resistência de cálculo para o modelo de ensaio tipo "push-out"
$\mathbf{P}_{\mathrm{s}} \quad-$ resultante axial do elemento de aço
$\left(\mathbf{P}_{\text {sh }}\right)_{\text {fsc }} \quad$ - resistência da conexão de cisalhamento mínima, que se estabelece para situação de conexão de cisalhamento completa
$\mathbf{P}_{\mathrm{sh}} \quad$ - resistência da conexão de cisalhamento
$\mathbf{P}_{\mathbf{u}} \quad$ - força de colapso do conector
qn $\quad$ - resistência nominal do conector tipo pino com cabeça (stud) ou capacidade nominal do conector tipo perfil " $u$ " laminado e perfil " $u$ " e " $z$ " formado a frio


qrd - resistência de cálculo do conector tipo pino com cabeça (stud)

$\mathbf{Q}_{\mathbf{u}} \quad$ - resistência última do conector

Qu $\quad$ - resistência última do conector tipo pino com cabeça (stud)

S - superfície de ruptura

S - espaçamento longitudinal dos conectores

t - espessura da forma de aço

t - espessura da chapa do conector perfil "U" e "Z" formado a frio

$\mathbf{t}_{\mathbf{c}} \quad$ - espessura da laje de concreto

$\mathbf{t}_{\mathrm{f}} \quad$ - espessura da mesa do perfil metálico

$\mathbf{t}_{\mathbf{f}} \quad-$ espessura da mesa do conector tipo perfil " $U$ " laminado

$\mathbf{t}_{\mathrm{w}} \quad$ - espessura da alma do conector tipo perfil "U" laminado

$\mathbf{V}_{\mathbf{l}} \quad$ - força de cisalhamento longitudinal de cálculo

W - espessura do colarinho de solda entre o conector tipo pino com cabeça (stud) e o perfil metálico

z $\quad$ excentricidade da força de cisalhamento $\left(\mathrm{F}_{\mathrm{sh}}\right)$ 
TRISTÃO, G.A. (2002). Comportamento de conectores de cisalhamento em vigas mistas aço-concreto com análise da resposta numérica. São Carlos, 2002. 125p. Dissertação (Mestrado) - Escola de Engenharia de São Carlos, Universidade de São Paulo.

As vigas mistas aço-concreto têm sido bastante utilizadas na engenharia civil, tanto no Brasil como no contexto mundial. O comportamento adequado deste elemento estrutural faz-se pela interação entre ambos os materiais, a qual é garantida por conectores de cisalhamento. $\mathrm{O}$ presente trabalho apresenta uma visão geral do comportamento das vigas mistas aço-concreto, e, principalmente o estudo do comportamento estrutural de conectores de cisalhamento. Para tanto, faz-se uma simulação numérica dos conectores tipo pino com cabeça (stud) e perfil "U" formado a frio, por meio de uma modelagem do ensaio experimental tipo "Push-out", cujos resultados são confrontados com valores experimentais obtidos de ensaios realizados em laboratório. Para a simulação numérica utiliza-se um código de cálculo com base nos Método dos Elementos Finitos (MEF), cujas ferramentas disponibilizadas permitem análises dos modelos em regime de não-linearidade física e geométrica. Os modelos numéricos apresentam como variáveis de interesse o número de conectores na laje de concreto, a quantidade de armadura inserida no concreto, o diâmetro do conector tipo pino com cabeça (stud), a resistência do concreto, a espessura e posição de soldagem do conector tipo perfil " $U$ " formado a frio. A variação desses parâmetros tem como finalidade a determinação da resistência última e da relação força-deslocamento dos conectores, bem como avaliar a concentração de tensão e deformação nas partes constituintes dos modelos.

Palavras-chave: conector de cisalhamento, viga mista aço-concreto, análise numérica, nãolinearidade física 
TRISTÃO, G.A. (2002). Behaviour of shear connectors in steel-concrete composite beams with numerical analysis. São Carlos, 2002. 125p. Dissertação (Mestrado) - Escola de Engenharia de São Carlos, Universidade de São Paulo.

Composite steetconcrete beams have been used in civil engineering in Brazil as well other countries. A realistic determination of the behaviour of this structural element is estimated by considering the interaction between the two materials, which is safeguarded by providing shear connectors. The present research presents a general view of the behaviour of steel-concrete composite beams, and primarily the study of the behaviour of shear connectors. To meet this ends, a numerical analysis of stud bolt and cold formed U-channel under push-out test geometry was carried out and the results compared to experimental test results. The numerical analysis utilises a Finite Element Method (FEM) code that permits the analysis under non-linear material and geometric regimes. The main numerical variables in the study were the number of connectors used in the concrete plate, the quantity steel reinforcement, the diameter of stub bolt connector, concrete strength, the thickness and position of welding of the cold-formed U-channel. The main objective of varying these parameters was to determine the ultimate strength and the load-slip behaviour of the connectors as well as evaluate the stress and strain concentrations in certain parts that constitute the models.

Keywords: shear connector, steel-concrete composite beam, numerical analysis, non-linear material 


\section{INTRODUÇÃO}

Os sistemas estruturais mistos, citando-se como exemplos as lajes mistas aço-concreto (lajes de concreto com forma de aço incorporada), os pilares mistos açoconcreto (pilares de aço protegidos por concreto ou preenchidos com concreto) e as vigas mistas aço-concreto (lajes de concreto associadas a vigas de aço), têm sido bastante utilizados nas obras de engenharia civil, tanto no contexto mundial como no Brasil.

No contexto mundial, como citado em MALITE (1990), os estudos de sistemas compostos tiveram seu início antes da primeira guerra mundial, na Inglaterra, com base em uma série de ensaios para pisos. Entre os anos de 1922 e 1939, foram construídos edifícios e pontes que adotavam os sistemas de vigas compostas. Vale ressaltar ainda que a partir do ano de 1944, os sistemas compostos passaram a fazer parte das normas da AMERICAN ASSOCIATION OF HIGHWAY OFFICIALS (AASHO), a qual hoje é denominada por AASHTO.

No Brasil, a construção mista limitou-se a alguns edifícios e pequenas pontes, na década de 50. Atualmente, com o aumento considerável da produção de aço no Brasil e objetivando novas soluções arquitetônicas e estruturais, sua utilização vem crescendo consideravelmente na construção de edifícios industriais, comerciais, pontes, etc.

Pesquisas sobre o assunto em questão tiveram seu início no final da década de 80. No Departamento de Engenharia de Estruturas da EESC/USP, o comportamento de vigas mistas aço-concreto vem sendo estudado desde o mestrado de Maximiliano Malite, hoje professor do Departamento de Engenharia de Estruturas da EESC -USP, abordado em MALITE (1990), tendo seqüência em trabalho de doutorado do mesmo autor, MALITE 
(1993), com a realização de ensaios normalizados em conectores de cisalhamento e em vigas mistas.

Uma outra pesquisa sobre estruturas mistas foi realizada por ALVA (2000), também no Departamento de Engenharia de Estruturas da EESC/USP, na qual foram abordados aspectos sobre conectores de cisalhamento, lajes mistas e pilares mistos.

Portanto, têm-se atualmente trabalhos sobre sistemas mistos bastante amplos com vistas, na sua grande maioria, aos aspectos teórico e experimental, e conseqüientemente, sem abordagem com referência à análise numérica.

Para um comportamento estrutural adequado dos sistemas mistos açoconcreto, faz-se necessária uma interação entre ambos os materiais. No caso das vigas mistas, essa interação é garantida por meio de elementos metálicos denominados conectores de cisalhamento, cujas principais funções consistem em transferir forças de cisalhamento longitudinais do concreto para o aço na interface entre laje e viga, bem como impedir a separação vertical entre laje de concreto e perfil metálico, movimento conhecido como "uplift".

Nesse sentido, o presente trabalho tem como objetivo principal analisar numericamente o comportamento estrutural dos conectores de cisalhamento em vigas mistas aço-concreto. Para tanto, faz-se uma extensa pesquisa com base em referências bibliográficas, bem como é proposta a elaboração de um modelo numérico tridimensional objetivando simular o ensaio experimental tipo "Push-out", o qual é usualmente empregado para a determinação da resistência ao cisalhamento de conectores de cisalhamento. A modelagem numérica utiliza-se o código de cálculo ANSYS 5.7, elaborado com base nos Métodos dos Elementos Finitos.

Desta forma, o presente trabalho consiste de assuntos que abordam desde aspectos sobre o comportamento de vigas mistas, até a modelagem numérica do ensaio tipo "Push-out", os quais foram devidamente separados em capítulos.

No capítulo 2 tem-se uma visão geral do comportamento estrutural de vigas mistas aço-concreto, bem como a descrição de alguns conectores de cisalhamento geralmente empregados. Além disso, são mencionados alguns aspectos referentes à fissuração na laje de concreto, bem como os procedimentos para limitar essas fissurações.

No capítulo 3 é detalhado o ensaio experimental tipo "Push-out", mencionando os procedimentos adotados para a realização do ensaio. Além disso, apresentam-se os modelos experimentais e os principais resultados dos ensaios experimentais tipo "Push-out" em conectores formados a frio, realizado por MALITE 
(1993). Na parte final do capítulo em questão são apresentadas expressões para o cálculo da resistência última de alguns conectores, com base na maioria das normas, assim como procedimentos para locação e espaçamento de conectores em vigas mistas aço-concreto.

O capítulo 4 trata dos aspectos gerais para a modelagem numérica do ensaio tipo "Push-out", em que são mencionados os tipos de elementos finitos adotados nos modelos, as condições de contorno e solicitação, bem como um detalhamento dos modelos matemáticos com não-linearidade física, adotados para o aço e o concreto.

No capítulo 5 são analisados e discutidos resultados de seis modelos numéricos, em que dois desses modelos foram elaborados com conectores tipo pino com cabeça (stud) e quatro elaborados com conectores tipo perfil " $U$ " formados a frio.

Finalmente, no capítulo 6 são apresentadas as principais conclusões que aparecem em resposta tanto com relação à pesquisa bibliográfica, quanto com relação aos procedimentos adotados para a modelagem numérica, bem como com referência aos resultados das análises numéricas.

Vale ressaltar ao leitor que a análise numérica objetivou principalmente respostas com referência ao comportamento dos conectores, com vistas à determinação da relação entre força no conector e o correspondente deslocamento relativo entre viga de aço e laje de concreto. Adicionalmente, analisa-se a concentração de tensões e deformações nos conectores, nas armaduras e na laje de concreto, bem como as fissurações referentes à mesma laje.

Os resultados dos modelos numéricos do ensaio tipo "Push-out" elaborados com conectores tipo pino com cabeça (stud) serão confrontados com resultados experimentais extraídos de referências bibliográficas, enquanto que os resultados de modelagens com conectores tipo perfil " $U$ " formado a frio serão confrontados com os resultados experimentais obtidos e apresentados em MALITE (1993).

Os modelos numéricos têm como variáveis de interesse o número de conectores na laje de concreto, a quantidade de armadura inserida no concreto, o diâmetro do conector tipo pino com cabeça (stud), a resistência do concreto, a espessura e posição do conector tipo perfil " $U$ " formado a frio.

\section{1 - JUSTIFICATIVA}

Um dos aspectos de interesse para o cálculo das vigas mistas é a relação força no conector e deslocamento relativo aço-concreto, a qual é obtida por meio de ensaios 
experimentais em vigas mistas, ou por meio de um ensaio em modelo isolado, denominado de "Push-out".

O ensaio tipo "Push-out" tem sido bastante utilizado para a obtenção da referida relação, e tem as suas dimensões definidas por algumas normas, as quais serão devidamente mencionadas nos capítulos que seguem. Por meio desse ensaio, diversas expressões têm sido propostas por essas normas para a determinação da resistência ao cisalhamento dos conectores. No entanto, vale mencionar que os resultados experimentais proporcionam, em geral, uma avaliação do comportamento global do ensaio experimental tipo "Push-out".

Por outro lado, a análise da resposta numérica, realizada por meio da utilização de códigos de cálculo sofisticados, no caso do presente trabalho o ANSYS versão 5.7, possibilita ao usuário avaliações com relação aos níveis de tensões, de deformações e grau de fissuração em pontos específicos do modelo numérico.

Assim como nos ensaios experimentais, a modelagem numérica também objetiva uma avaliação satisfatória do comportamento do conector de cisalhamento em estado de utilização e último. A partir de resultados numéricos satisfatórios do ensaio tipo "Push-out", acredita-se que futuros pesquisadores poderão, desde que seja de interesse, adotar os parâmetros obtidos nas análises numéricas do presente trabalho para o estudo de outros assuntos que tenham relação direta com conectores de cisalhamento, como por exemplo, o estudo do comportamento de vigas mistas aço-concreto.

\section{2- METODOLOGIA DO TRABALHO}

Foi realizada uma extensa pesquisa bibliográfica sobre o comportamento dos conectores de cisalhamento, assim como a realização de simulação numérica de o ensaio experimental tipo "Push-out" por meio da utilização do código de cálculo ANSYS, objetivando avaliar o comportamento dos conectores de cisalhamento.

Os fatores importantes para o refinamento, quando da discretização dos modelos numéricos, consistem das dimensões e geometrias das partes constituintes dos modelos, bem como de uma análise criteriosa de prováveis regiões com maiores concentrações de tensões. A não-linearidade dos materiais também foi simulada com a utilização de modelos com não-linearidade física, disponíveis na biblioteca interna do mesmo código de cálculo. 
Apesar de algumas normas recomendarem a aplicação da solicitação de forma cíclica em algumas fases do ensaio experimental, aplicou-se a solicitação de forma monotônica durante toda a simulação numérica. A consideração nos modelos numéricos estudados da não-linearidade física, bem como a não-linearidade geométrica (elementos de contato), conduziram a uma forma de processamentos com solicitação aplicada ao modelo na forma de incrementos, adotando-se como critérios de convergência a comparação dos deslocamentos entre iterações sucessivas, com tolerância de 0,001 , bem como a penetração entre os elementos de contato, limitada em no máximo $1 \mathrm{~mm}$. 


\section{VIGAS MISTAS AÇO-CONCRETO}

Vigas mistas aço-concreto são elementos estruturais que consistem da associação de uma viga de aço (perfil I) com uma laje de concreto. A interação entre viga de aço e laje de concreto, estabelecida por meio de elementos metálicos denominados conectores de cisalhamento, deverá garantir que ambos os materiais funcionem em conjunto para resistir a esforços de flexão em torno do eixo perpendicular ao plano médio da alma da viga. A figura 2.1 apresenta os tipos mais usuais de vigas mistas, com conectores de cisalhamento tipo pino com cabeça (stud).

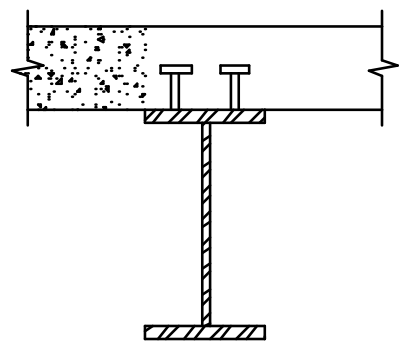

a) Laje com face inferior plana

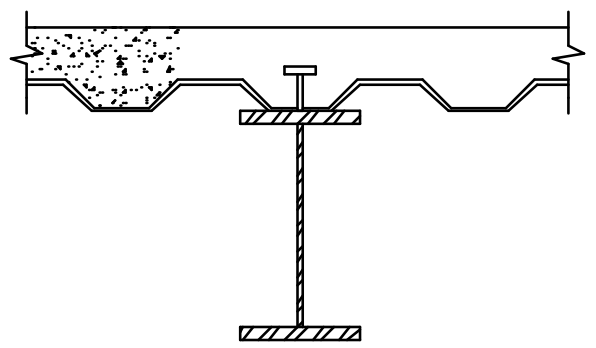

b) Laje com fôrma de aço incorporada (steel deck)

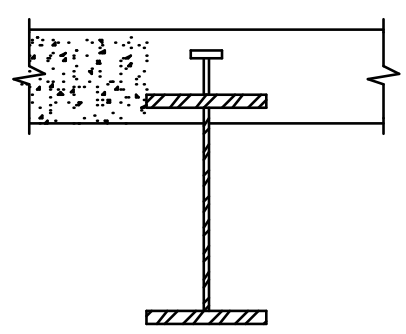

c) Viga de aço parcialmente embutida no concreto

FIGURA 2.1: Tipos usuais de vigas mistas, ALVA (2000) 
Os conectores de cisalhamento têm também como funções transferir esforços de cisalhamento longitudinais do concreto para o aço, na interface da viga mista, bem como impedir a separação vertical entre laje de concreto e perfil de aço, movimento conhecido como "uplift". Desta forma, a resistência e rigidez do material do conector de cisalhamento têm enorme influência no comportamento de uma viga mista.

\section{1 - GRAU DE CONEXÃO E GRAU DE INTERAÇÃO}

O comportamento de uma viga mista é bastante complexo, sendo necessário para o bom entendimento compreender dois conceitos que surgem como conseqüência do trabalho em conjunto de ambos os materiais: grau de conexão e grau de interação. Grau de conexão se divide em completo e parcial, enquanto que grau de interação de divide em total e parcial.

\subsection{1 - GRAU DE CONEX ̃̃O}

O grau de conexão está diretamente relacionado às resistências da viga de aço, da laje de concreto e da ligação aço-concreto, na forma de forças resultantes. A figura 2.2, elaborada com base em OEHLERS et al. (1997), ilustra o equilíbrio longitudinal de forças, considerando a análise rígido plástica.

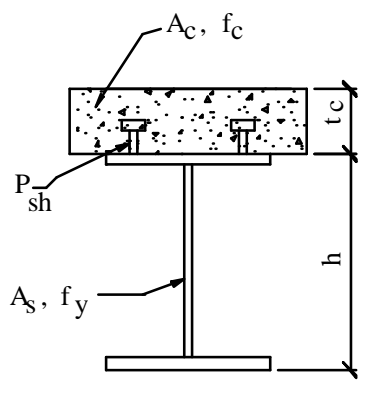

(a)

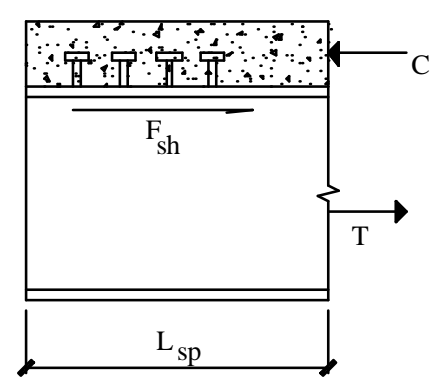

(b)

FIGURA 2.2: Equilíbrio longitudinal de forças

Uma conexão completa se verifica quando se tem uma quantidade de conectores, tal que qualquer aumento no número ou na resistência desses conectores não implica em aumento da resistência à flexão da viga mista. Nesse caso, a resistência da conexão de cisalhamento $\left(\mathrm{P}_{\mathrm{sh}}\right)$ obtida a partir da resistência de cálculo de um conector 
multiplicado pelo número de conectores existentes no vão analisado, deve ser maior ou igual que a menor das resultantes axiais obtidas nos elementos de concreto $\left(\mathrm{P}_{c}=0,85 \mathrm{f}_{\mathrm{c}} \mathrm{A}_{\mathrm{c}}\right)$ e de $\operatorname{aço~}\left(P_{s}=A_{s} f_{y}\right)$.

Desse modo, se $\mathrm{P}_{\mathrm{c}}>\mathrm{P}_{\mathrm{s}}$, o equilíbrio longitudinal de forças ocorre quando $\mathrm{T}=\mathrm{P}_{\mathrm{s}}$ e, conseqüentemente, $\mathrm{C}=\mathrm{P}_{\mathrm{s}}$. Caso contrário, se $\mathrm{P}_{\mathrm{s}}>\mathrm{P}_{\mathrm{c}}$, o equilíbrio longitudinal de forças é atingido quando $\mathrm{C}=\mathrm{P}_{\mathrm{c}} \mathrm{e}$, conseqüentemente, $\mathrm{T}=\mathrm{P}_{\mathrm{c}}$. É possível também ocorrer uma situação em que $\mathrm{Pc}=\mathrm{Ps}$, então o equilíbrio de forças é verificado quando $\mathrm{T}=\mathrm{P}_{\mathrm{s}}=\mathrm{P}_{\mathrm{c}} \mathrm{e}$, consequientemente, $C=P_{s}=P_{c}$. Portanto, na conexão completa a resistência da conexão de cisalhamento não interfere no cálculo da viga mista, ou seja, a seção mais solicitada da viga mista consegue atingir a sua capacidade máxima sem que ocorra a ruptura da conexão de cisalhamento.

Já na conexão parcial, a resistência da conexão de cisalhamento $\left(\mathrm{P}_{\mathrm{sh}}\right)$ é menor quando comparada que às resultantes axial do elemento de concreto $\left(\mathrm{P}_{c}=0,85 \mathrm{f}_{\mathrm{c}} \mathrm{A}_{\mathrm{c}}\right)$ e do elemento de aço $\left(\mathrm{P}_{\mathrm{s}}=\mathrm{A}_{\mathrm{s}} \mathrm{f}_{\mathrm{y}}\right)$, situação que ocorre como consequiência de uma quantidade de conectores menor que a mínima estabelecida para se ter conexão completa. Nesse caso, o equilíbrio longitudinal de forças é obtido quando $\mathrm{C}=\mathrm{P}_{\mathrm{sh}}$ e conseqüentemente $\mathrm{T}=\mathrm{P}_{\mathrm{sh}}$. Com isso, a resistência da conexão de cisalhamento controla a capacidade de flexão da viga mista.

O grau de conexão de cisalhamento é determinado pela expressão.

$$
\eta=\frac{P_{\text {sh }}}{\left(P_{\text {sh }}\right)_{\text {fsc }}}
$$

onde

$\eta$ é o grau da conexão;

$\mathrm{P}_{\mathrm{sh}}$ é a resistência da conexão de cisalhamento;

$\left(\mathrm{P}_{\mathrm{sh}}\right)_{\text {fsc }}$ é a resistência da conexão de cisalhamento mínima, que se estabelece para situação de conexão de cisalhamento completa.

De acordo com a expressão 2.1, quando $\eta=1$ tem-se conexão completa. Por outro lado, para 0,5 $\leq \eta<1,0$ tem-se conexão parcial, considerando que a NBR-8800 (1986) estabelece um grau de conexão $(\eta)$ mínimo igual a 0,5. Conforme estudos realizados por MALITE (1990) em vigas de aço tipo perfil I, com alturas de 300, 500 e 700 mm, adotando $\eta=0,5$ verificou-se uma máxima perda de resistência de $15 \%$ em relação à conexão completa $(\eta=1)$, confirmando a total viabilidade da conexão parcial, que possibilita reduzir em até $50 \%$ o número de conectores. 
Vale ressaltar que a escolha por parte dos projetistas entre conexão parcial ou conexão completa pode estar vinculada a outros aspectos que não apenas o econômico, como por exemplo, os aspectos construtivos.

Pode ser citado o caso de edifícios comerciais e residenciais, em que a opção por conexão parcial com $\eta=0,5$ objetivando maior economia pode, eventualmente, comprometer aspectos como o espaçamento máximo entre conectores estabelecido por normas. Nesse caso, o número de conectores que aparece em resposta à condição de espaçamento máximo pode resultar em uma situação em que $\eta$ situa-se muito próximo de 1,0 e, conseqüentemente, opta-se por conexão completa objetivando uma melhor eficiência quanto à resistência à flexão da viga.

No caso de pontes, mesmo que desejável adotar-se conexão parcial com vistas a uma maior economia quando da execução, como as ações dinâmicas (veículos) são em geral elevadas, o fenômeno da fadiga deve ser considerado, resultando em um número elevador de conectores e, conseqüentemente, a adoção de conexão completa.

\subsection{2 - GRAU DE INTERAÇ̃̃O}

Grau de interação total consiste na não consideração de deslocamento relativo entre a viga de aço e a laje de concreto, enquanto que interação parcial implica na ocorrência de deslocamento relativo, ocasionando uma descontinuidade no diagrama de deformações, conforme ilustra a figura 2.3.

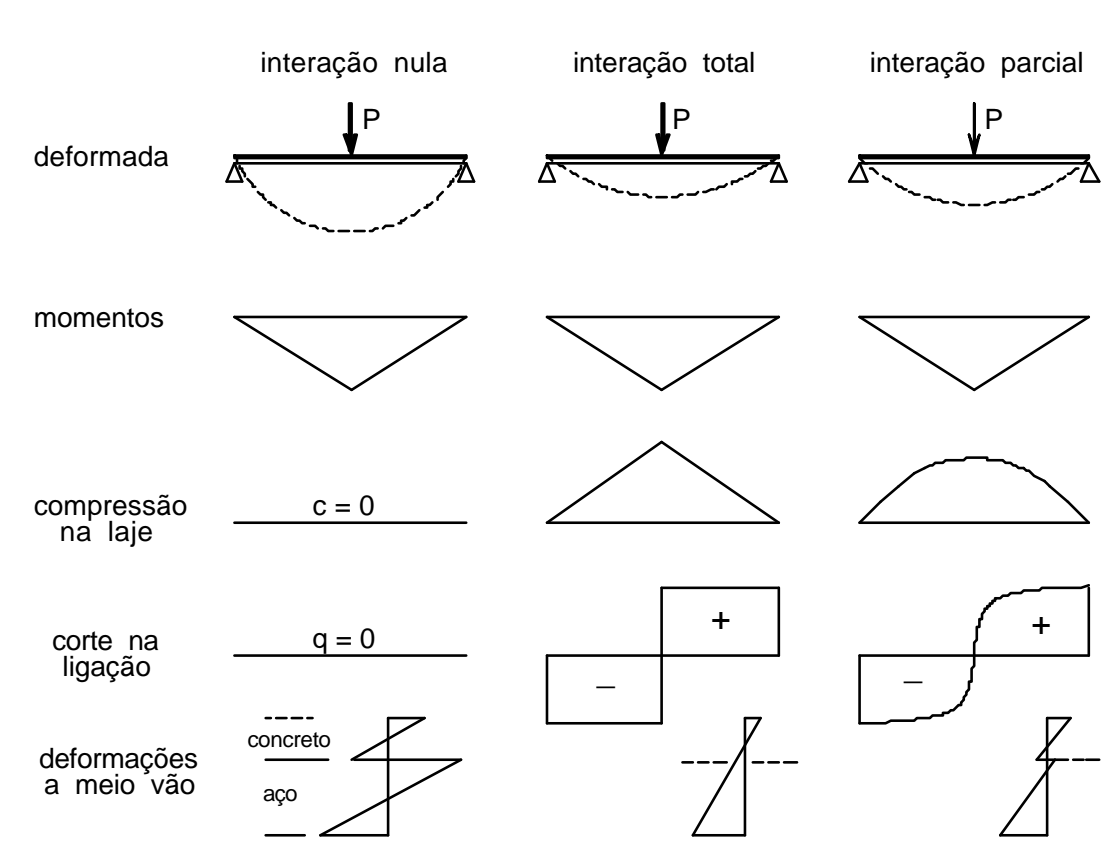

FIGURA 2.3: Interação entre o aço e o concreto no comportamento de viga mista, 
Segundo MALITE (1990), algum deslocamento relativo aço-concreto sempre acontece na prática, e mesmo assim o termo interação total continua sendo utilizado nas normas, pois se entende que pelo fato de o deslocamento ser muito pequeno, esse pode ser desprezado nos cálculos.

Nos estudos realizados por OEHLERS et al. (1997), para vigas mistas utilizadas em edifícios, onde a resultante axial do elemento de concreto $\left(\mathrm{P}_{\mathrm{c}}\right)$ geralmente é maior que a do elemento de aço $\left(\mathrm{P}_{\mathrm{s}}\right)$, com linha neutra plástica na laje, o efeito da interação parcial na conexão de cisalhamento completa foi levado em consideração, demonstrando ter pouco efeito na capacidade à flexão da viga. Por outro lado, ainda com base nos estudos de OEHLERS et al. (1997), a interação parcial pode reduzir a capacidade à flexão de vigas mistas quando a resistência axial do elemento de aço for muito maior que a do elemento de concreto, fato bastante comum em vigas de pontes.

\section{2 - TIPOS DE CONECTORES DE CISALHAMENTO}

Os conectores de cisalhamento são cla ssificados em flexíveis e rígidos, sendo que ambos os tipos são definidos por meio da relação entre força no conector e o deslocamento relativo aço-concreto, que surge em resposta ao fluxo de cisalhamento longitudinal gerado pela transferência de força entre laje de concreto e perfil de aço, conforme figura 2.4. O comportamento flexível, por exemplo, pode ser identificado pela ductilidade da relação entre força e deslocamento.

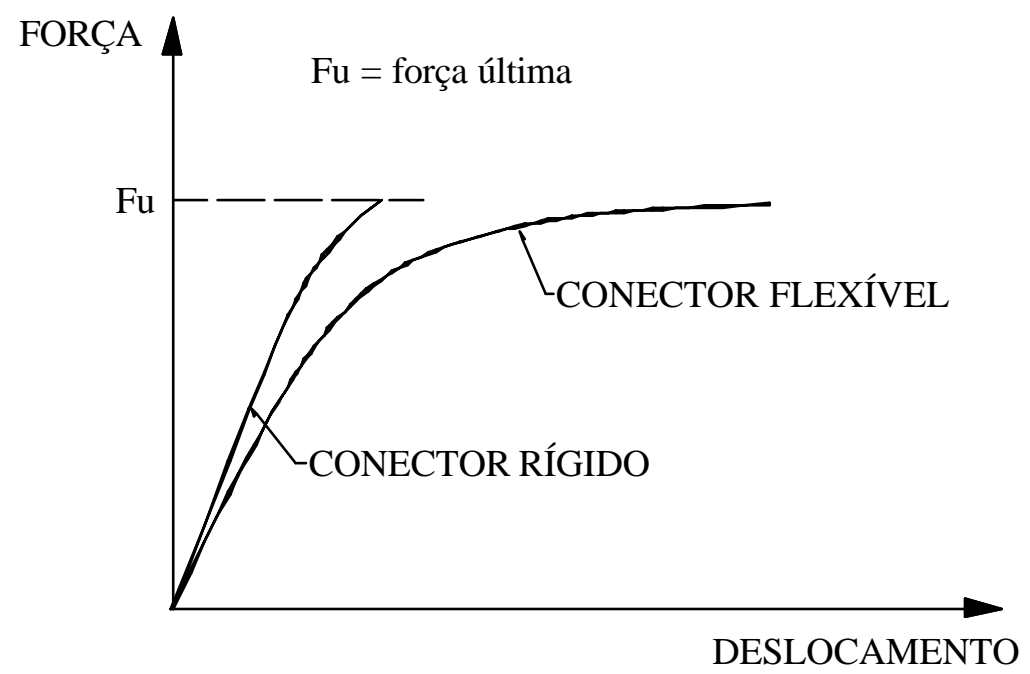

FIGURA 2.4: Relação força-deslocamento para conectores de cisalhamento, ALVA (2000) 
O comportamento dúctil caracteriza-se pela redistribuição do fluxo de cisalhamento longitudinal, de modo que, sob carregamento crescente, o conector continua a se deformar, sem romper, mesmo quando próximo de atingir sua resistência máxima, permitindo que os conectores vizinhos atinjam também a sua resistência máxima. Nesse caso, pode-se admitir espaçamentos iguais entre conectores, objetivando otimizar a execução da viga mista. Conseqüentemente, o colapso de uma viga mista devido à ruptura da ligação aço-concreto será também do tipo dúctil. A figura 2.5 ilustra os tipos de conectores usuais, de comportamento flexível $(a, b, c)$ e comportamento rígido (d, e).

a) Pino com cabeça (STUD)
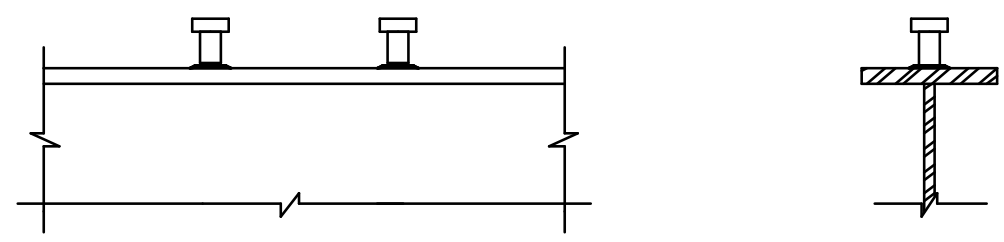

b) Perfil "U"
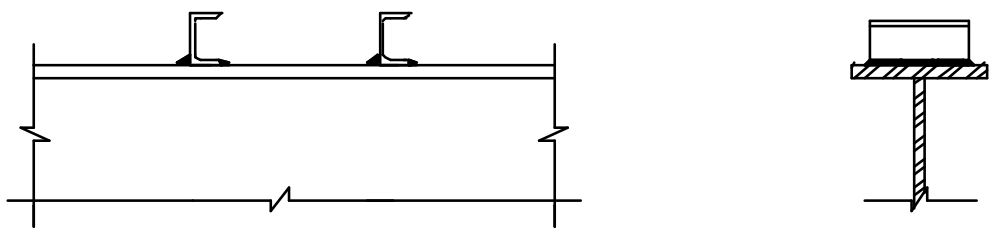

c) Barra com alça
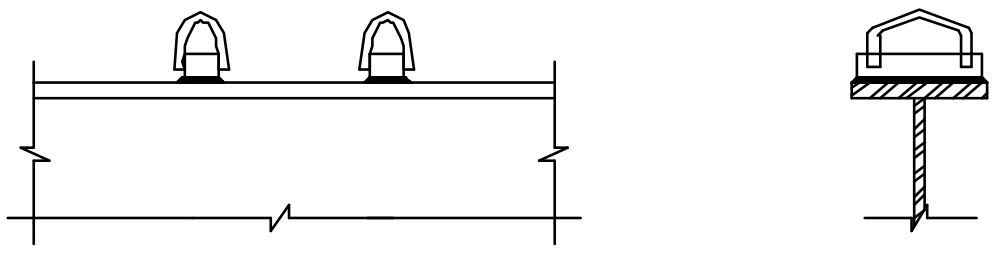

d) Espiral
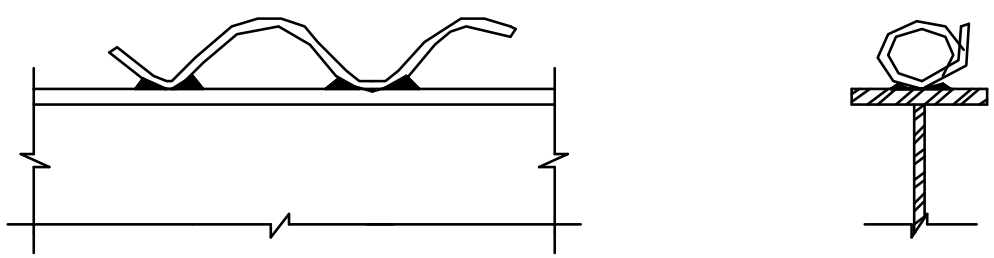

e) Pino com gancho
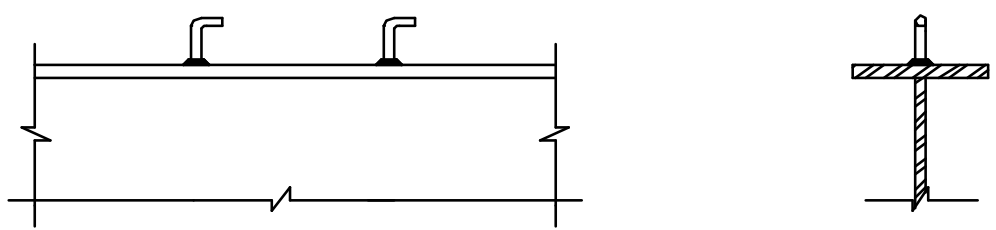

FIGURA 2.5: Tipos usuais de conectores de cisalhamento, MALITE (1990) 
Os tipos de lajes de concreto mais utilizadas são as maciças, bem como as lajes com forma de aço incorporada (lajes mistas), as quais são constituídas de uma fôrma de aço apoiada em vigas metálicas, sobre a qual é moldada uma capa de concreto (figura 2.6). Para esse tipo de laje, o conector mais utilizado é o tipo pino com cabeça (stud), onde o aço utilizado na fabricação dos pinos é o ASTM A108 graus 1010 a 1020, produzido com resistência última mínima de $415 \mathrm{MPa}$ e limite de escoamento não inferior a $345 \mathrm{MPa}$.

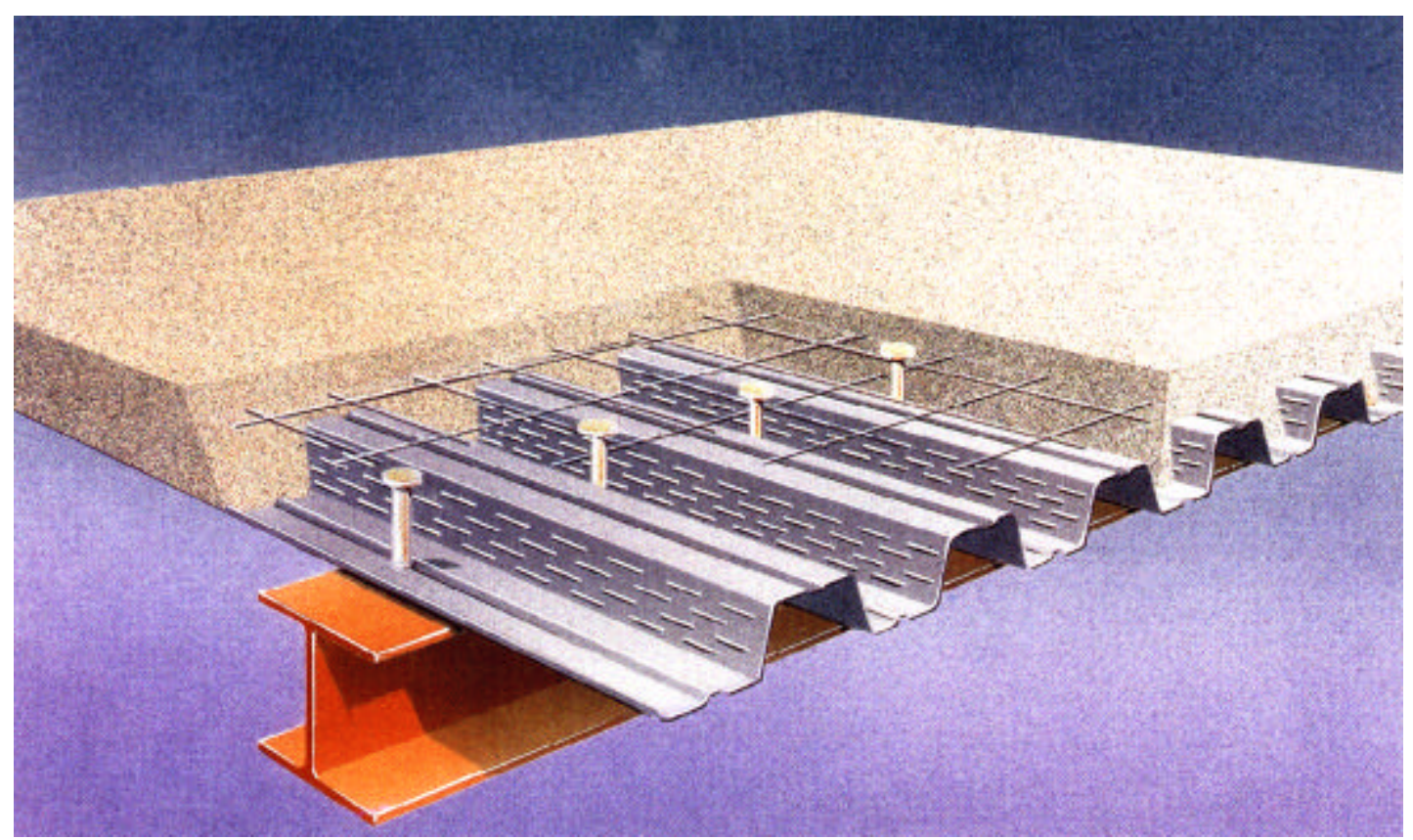

FIGURA 2.6: Detalhe da laje com forma de aço incorporada (laje mista), catálogo da CODEME Engenharia

Segundo o EUROPEAN CONVENTION FOR CONSTRUCTIONAL STEELWORK (ECCS/1993), o conector tipo pino com cabeça (stud), deve seguir as seguintes dimensões ilustradas na figura 2.7 .

Para todos os tipos de pino com cabeça (stud), a altura (h) deve ser maior que três vezes o diâmetro (d), sendo que o comportamento dúctil ocorre para diâmetro entre $16 \mathrm{e}$ $22 \mathrm{~mm}$, e altura não inferior a quatro vezes o seu diâmetro $(\mathrm{h} \geq 4 \mathrm{~d})$. $\mathrm{O}$ limite da espessura $\mathrm{t}_{\mathrm{f}}$ da mesa do perfil, conforme apresenta a figura 2.7, deve ser respeitado somente quando o eixo do conector não estiver coincidente com o correspondente eixo da alma da viga.

Os principais fatores que influenciam na determinação do diâmetro dos pinos com cabeça (stud) são o processo de soldagem e a espessura $\left(t_{f}\right)$ da mesa do perfil (figura 2.7). 


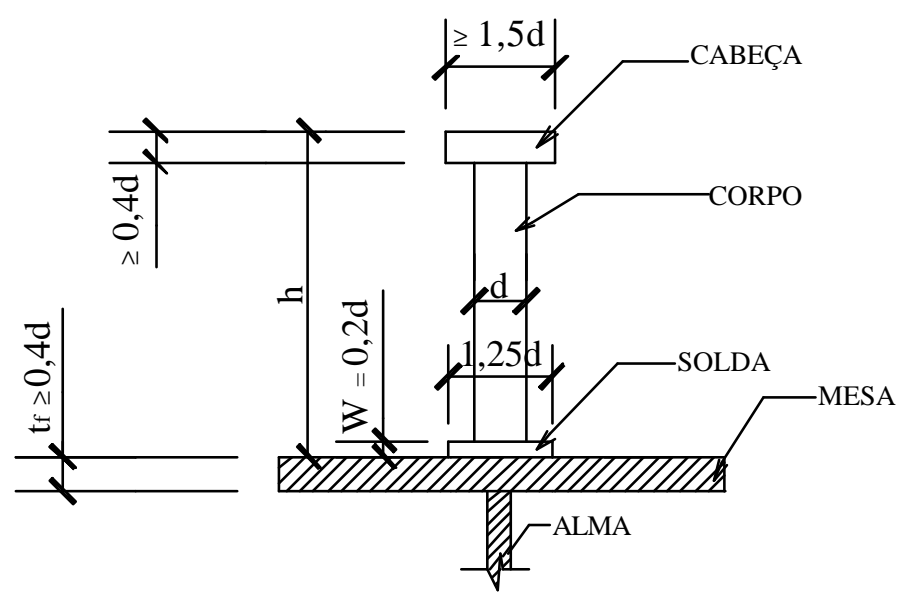

FIGURA 2.7: Dimensões mínimas do conector tipo pino com cabeça (stud)

Com relação ao processo de soldagem utiliza-se o pino com cabeça (stud) e cerâmica, conforme ilustra a figura 2.8a, extraída de QUEIROZ (2001). O pino e a cerâmica são introduzidos em uma pistola automática, ilustrada na figura $2.8 \mathrm{~b}$, ligada a um equipamento específico de soldagem que requer uma fonte de força de aproximadamente 3000 amperes para formar o arco elétrico. A cerâmica tem a finalidade de conter o material fundido e servir de proteção para o arco elétrico.

Segundo QUEIROZ (2001), o processo é iniciado ao se encostar a base do pino ao materiatbase (mesa superior do perfil), como ilustra a figura $2.8 \mathrm{c}$, quando então aperta-se o gatilho da pistola, abrindo-se o arco elétrico, conforme figura $2.8 \mathrm{~d}$. O arco tem uma duração de tempo suficiente para que ocorra a fusão entre o pino e material-base, quando então a pistola, automaticamente, empurra o pino na direção da poça de fusão e, ao mesmo tempo corta-se a corrente elétrica.

Quando ocorrer a solidificação do material fundido, o processo estará completo (figura 2.9), quando então a pistola será retirada do pino, quebrando assim a cerâmica. Este processo se torna mais difícil, e conseqüentemente menos econômico, quando o diâmetro do conector (d) excede $20 \mathrm{~mm}$.

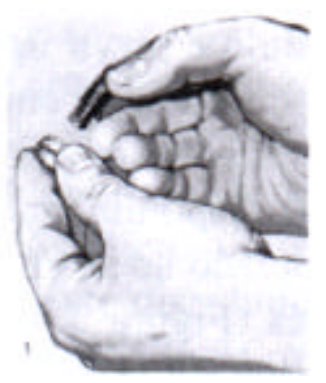

(a)

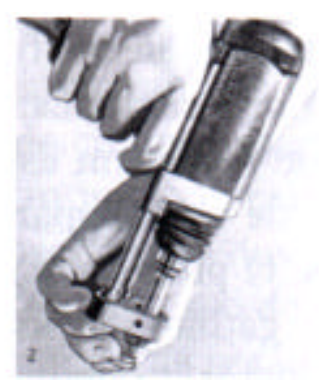

(b)

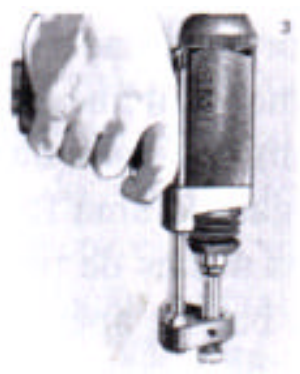

(c)

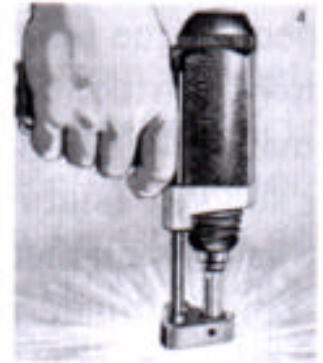

(d)

FIGURA 2.8: Processo de soldagem do conector pino com cabeça (stud), QUEIROZ(2001) 


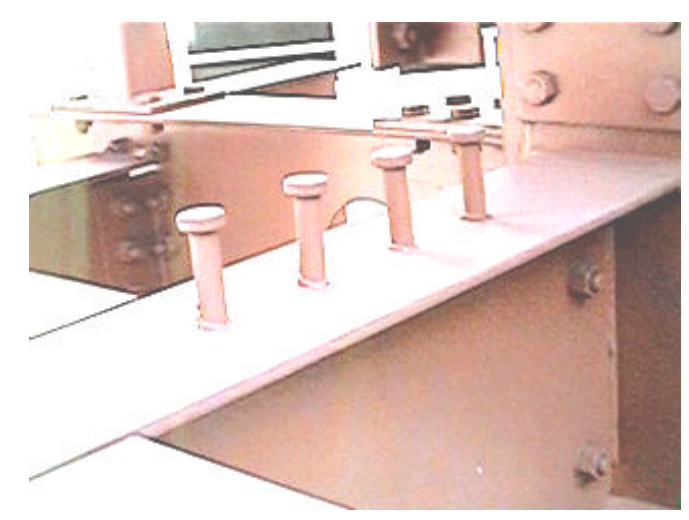

FIGURA 2.9: Resultado final da soldagem do conector tipo pino com cabeça (stud)

A figura 2.10 ilustra a soldagem do conector pino com cabeça (stud) "in loco".

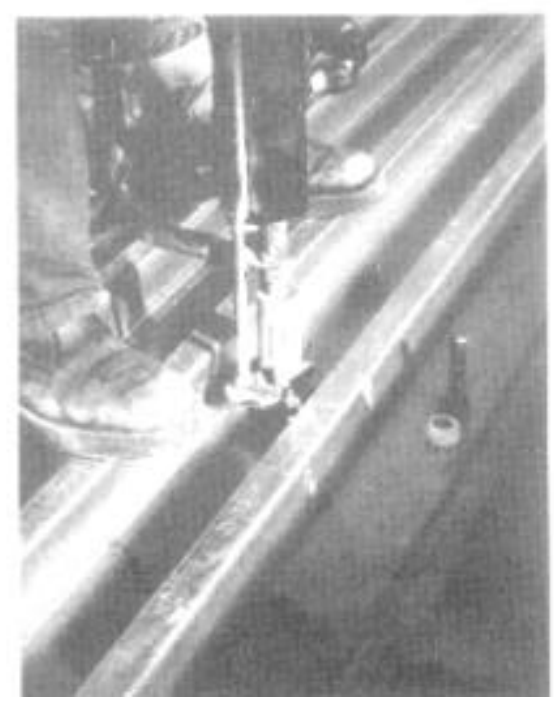

FIGURA 2.10: Soldagem do conector pino com cabeça (stud) “in loco”, QUEIROZ(2001)

Devido ao rápido método de execução e a equivalência na resistência em todas as direções normais ao eixo do conector, o pino com cabeça (stud) é um dos conectores flexíveis mais utilizados na maioria dos países.

No Brasil, além do conector tipo pino com cabeça (stud), utiliza-se o conector tipo perfil " $U$ ", ilustrado na figura 2.11. O conector perfil "U" deve ser soldado com uma das mesas assentada sobre a viga de aço, e com o plano da alma perpendicular ao eixo longitudinal da viga de aço. 


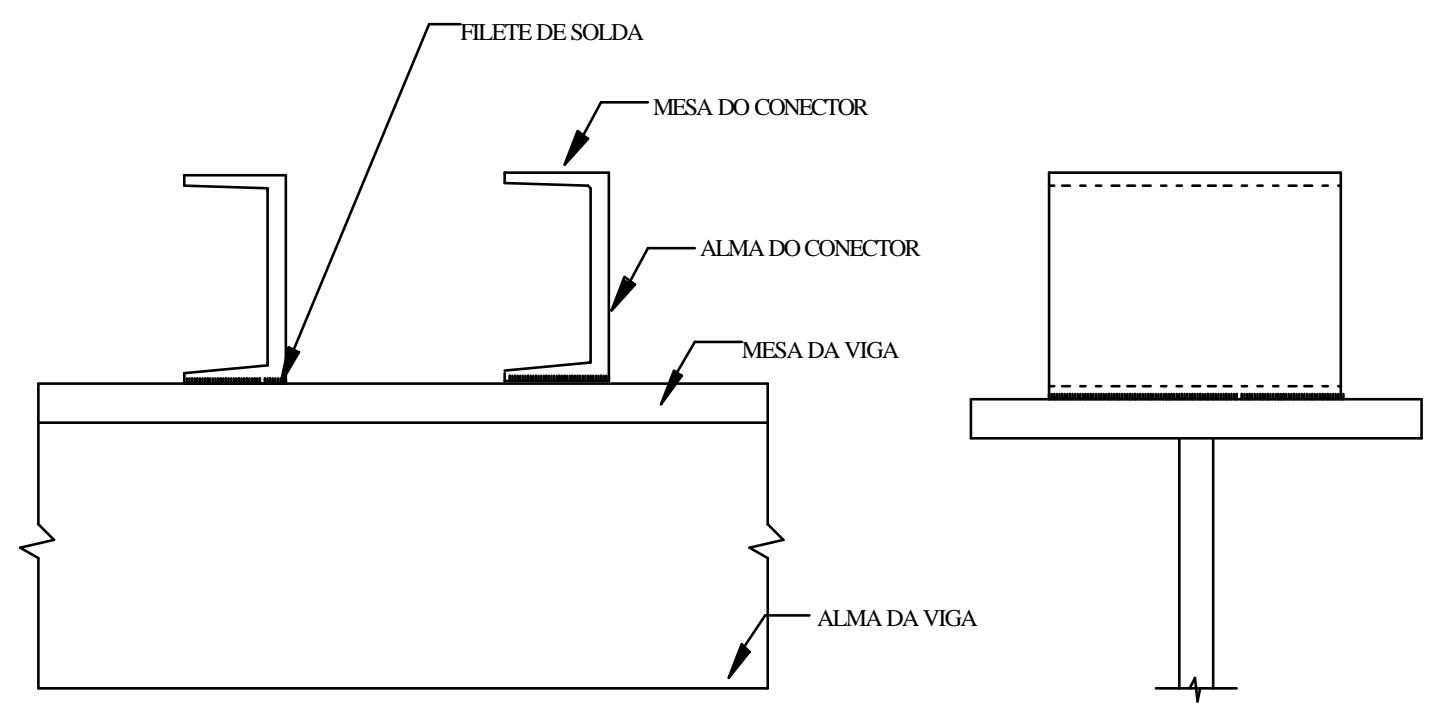

FIGURA 2.11: Conector tipo perfil " $U$ "

Outro tipo de conector que vem sendo utilizado nos países desenvolvidos é o Hilti HVB, preso ao perfil metálico por meio de fixadores a pólvora, conforme ilustra as figuras 2.12 e 2.13, extraída de QUEIROZ (2001). De acordo com QUEIROZ (2001), este tipo de ligação possui a vantagem de não necessitar de fonte energia na obra para sua colocação.
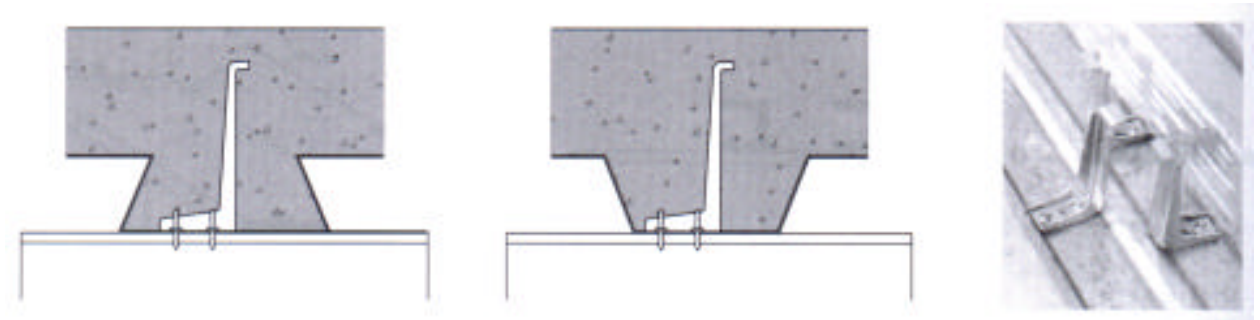

FIGURA 2.12: Conector da Hilti HVB, QUEIROZ (2001)

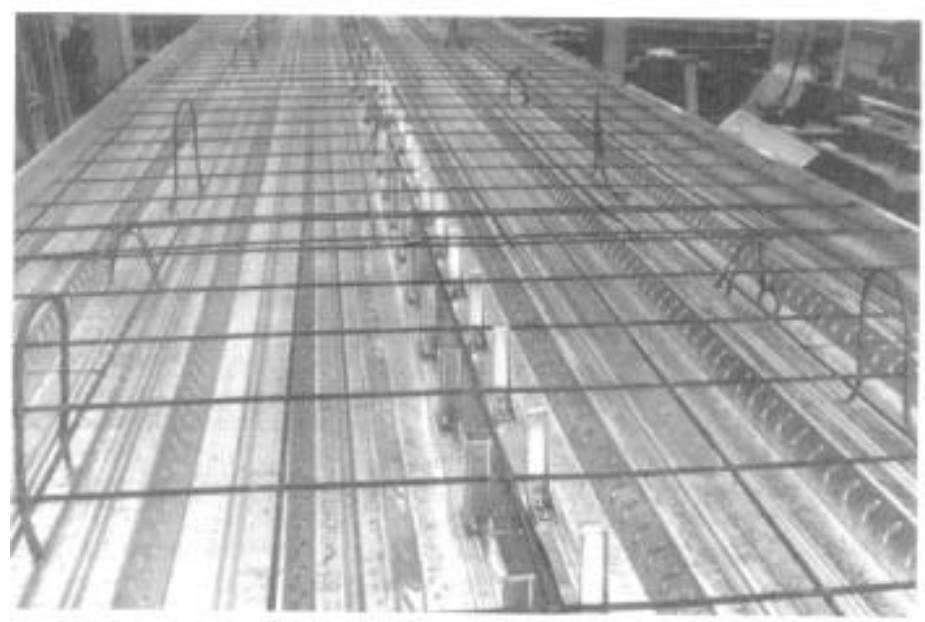

FIGURA 2.13: Conector da Hilti HVB em fôrmas de aço, QUEIROZ (2001) 


\section{3 - ASPECTOS DA RUPTURA DO CONECTOR TIPO PINO COM CABEÇA (STUD)}

A figura 2.14, extraída de OEHLERS \& PARK (1992), ilustra o mecanismo que ocorre no conector pino com cabeça (stud) quando esse transfere forças de cisalhamento longitudinal da laje de concreto para a viga de aço. Segundo OEHLERS \& PARK (1992), o pino do conector é submetido à força de cisalhamento $\left(\mathrm{F}_{\mathrm{sh}}\right)$, distante da mesa do perfil de uma dimensão z. A excentricidade de $\mathrm{F}_{\mathrm{sh}}$ gera um momento $\left(\mathrm{M}_{\mathrm{sh}}\right)$, produto da força pela correspondente excentricidade.

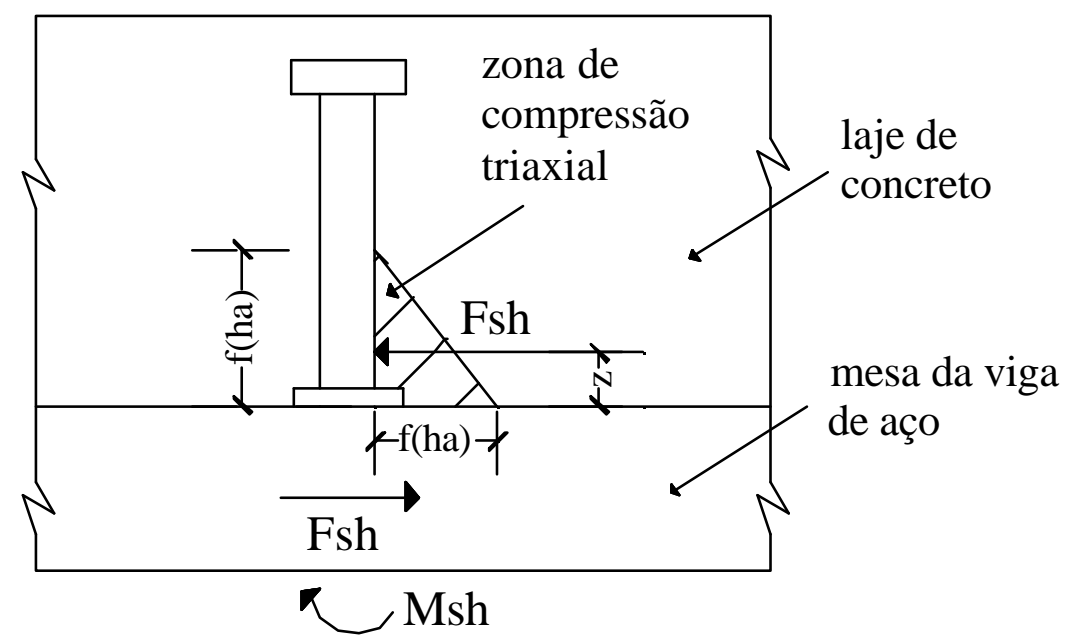

FIGURA 2.14: Transferência de forças de cisalhamento longitudinal do tipo pino com cabeça (stud)

Portanto, o conector está sujeito às tensões de cisalhamento e normal. A dimensão z é função da rigidez relativa do elemento concreto e do conector. Quando a rigidez do elemento concreto $\left(E_{c}\right)$ for muito maior que a rigidez do conector $\left(E_{a}\right)$, a excentricidade $\mathrm{z}$ tenderá a zero, caso contrário, se $\left(\mathrm{E}_{\mathrm{c}}\right)$ for muito menor que $\left(\mathrm{E}_{\mathrm{a}}\right)$, então $\mathrm{z}$ tenderá à metade da altura do pino com cabeça (stud).

A zona de concreto imediatamente em frente ao pino com cabeça (stud), denominada de zona de compressão triaxial, está submetida a altas tensões de compressão, sendo também função da altura efetiva do conector $\left(h_{a}\right)$. Para o conector tipo pino com cabeça, a altura efetiva $\left(h_{a}\right)$ é 1,8 vez o seu diâmetro.

Com base na figura 2.14, a qual esquematiza a transferência das forças de cisalhamento longitudinal da laje para a viga, são descritos a seguir dois mecanismos que podem levar o conector tipo pino com cabeça (stud) à ruptura: 
a) Como um possível mecanismo de ruptura, quando o elemento concreto for menos rígido quando comparado ao elemento do conector, o concreto começa a fissurar tornando-se menos rígido antes que o material do conector plastifique, proporcionado assim o aumento da excentricidade z. Conseqüentemente, as tensões normais no pino do conector aumentarão mais rapidamente que as tensões de cisalhamento, conduzindo o conector à ruptura.

b) Por outro lado, se o elemento conector for menos rígido que o elemento concreto, $\mathrm{z}$ diminui, reduzindo assim o momento $\left(\mathrm{M}_{\mathrm{sh}}\right)$ no conector. Além disso, a zona de compressão triaxial reduzirá, já que diminuirá a altura efetiva do conector, ocasionando assim a ruptura do concreto na zona de compressão triaxial, e conseqüentemente o aumento de $z$, já que a rigidez do elemento concreto $\left(\mathrm{E}_{\mathrm{c}}\right)$ diminui. A partir daí, retorna-se ao mecanismo de ruptura descrito no item a.

Portando, OEHLERS \& PARK (1992) concluem que a resistência do conector tipo pino com cabeça (stud), na conexão de cisalhamento, depende da resistência e rigidez do elemento conector e do concreto na zona de compressão triaxial.

\section{4 - FORÇA DE CISALHAMENTO LONGITUDINAL NOS CONECTORES}

Como já descritos nos itens anteriores, a transferência de forças de cisalhamento longitudinal da laje de concreto para a viga de aço é garantida pelos conectores de cisalhamento. A norma européia EUROCODE 4 (1994): "Proyecto de Estructuras Mixtas de Hormigón y Acero" propõe expressões para a determinação da força de cisalhamento longitudinal de cálculo atuante nos conectores, para algumas situações, mediante a consideração de comportamento elasto-plástico para o cálculo da resistência da viga mista.

\section{1) Conexão completa em conectores flexíveis e rígidos:}

a) A força de cisalhamento longitudinal de cálculo $\left(\mathrm{V}_{1}\right)$ que deve ser resistida pelos conectores na posição entre as seções de momento fletor máximo positivo e o momento nulo, é expressa na forma:

$\mathrm{V}_{1}=\mathrm{F}_{\mathrm{cf}}$ 
onde $\mathrm{F}_{\mathrm{cf}}$ é o menor dos seguintes valores:

$\mathrm{F}_{\mathrm{cf}}=\frac{\mathrm{A}_{\mathrm{a}} \mathrm{f}_{\mathrm{y}}}{\gamma_{\mathrm{a}}}$

$\mathrm{F}_{\mathrm{cf}}=\frac{0,85 \mathrm{~A}_{\mathrm{c}} \mathrm{f}_{\mathrm{ck}}}{\gamma_{\mathrm{c}}}+\frac{\mathrm{A}_{\mathrm{se}} \mathrm{f}_{\mathrm{sk}}}{\gamma_{\mathrm{s}}}$

onde

$\mathrm{A}_{\mathrm{a}}$ é a área da seção transversal da viga de aço;

$\mathrm{A}_{\mathrm{c}}$ é a área da largura efetiva do concreto;

$\mathrm{A}_{\mathrm{se}}$ é a área de qualquer armadura longitudinal na compressão que é incluída no cálculo da resistência à flexão.

$\gamma_{\mathrm{a}}, \gamma_{\mathrm{c}}, \gamma_{\mathrm{s}}$ são os coeficientes de segurança do aço da viga, do concreto e da armadura, tomados como 1,$1 ; 1,5$ e 1,15 , respectivamente.

b) No caso de conectores na posição entre as seções de momento fletor máximo positivo e apoio intermediário, a força deverá ser:

$\mathrm{V}_{1}=\mathrm{F}_{\mathrm{cf}}+\frac{\mathrm{A}_{\mathrm{s}} \mathrm{f}_{\mathrm{sk}}}{\gamma_{\mathrm{s}}}+\frac{\mathrm{A}_{\mathrm{ap}} \mathrm{f}_{\mathrm{yp}}}{\gamma_{\mathrm{ap}}}$

onde

$\mathrm{A}_{\mathrm{s}}$ é a área eficiente da armadura longitudinal da laje;

$\mathrm{A}_{\mathrm{ap}}$ é a área eficiente de qualquer forma de aço nervurada, em caso de laje com forma de aço incorporada.

\section{2) Conexão parcial em conectores flexíveis:}

a) A força de cisalhamento longitudinal para conectores na posição entre seções de momento fletor máximo e momento nulo deverá ser tomado como:

$\mathrm{V}_{1}=\mathrm{F}_{\mathrm{c}}$

onde $\mathrm{F}_{\mathrm{c}}$ é a força de compressão na laje de concreto necessária para resistir o momento fletor positivo de cálculo $\left(\mathrm{M}_{\mathrm{sd}}\right)$. 
$F_{c}=\frac{M_{s d}-M_{a p l, R d}}{M_{p l, R d}-M_{a p l, R d}}$

onde

$\mathrm{M}_{\mathrm{apl}, \mathrm{Rd}}$ é o momento resistente de cálculo positivo à flexão da seção metálica;

$\mathrm{M}_{\mathrm{pl}, \mathrm{Rd}}$ é o momento resistente de cálculo positivo à flexão da seção mista com conexão completa.

b) No caso de conectores na posição entre as seções de momento fletor máximo positivo e o apoio intermediário, a força deverá ser:

$\mathrm{V}_{1}=\mathrm{F}_{\mathrm{c}}+\frac{\mathrm{A}_{\mathrm{s}} \mathrm{f}_{\mathrm{sk}}}{\gamma_{\mathrm{s}}}+\frac{\mathrm{A}_{\mathrm{ap}} \mathrm{f}_{\mathrm{yp}}}{\gamma_{\mathrm{ap}}}$

\section{5 - ASPECTOS DA FISSURAÇÃO NA LAJE DE CONCRETO}

A ruptura do sistema misto, no caso de conexão parcial, geralmente ocorre quando o material do conector atinge a ruptura devido à redução gradual da resistência e rigidez do material do concreto na zona de compressão triaxial, localizada imediatamente em frente ao conector, como já ilustrado na figura 2.14, e denominada zona de influência. A redução da restrição triaxial desta zona é consequiência da fissuração que ocorre no concreto quando o conector aplica uma força concentrada P na laje. OEHLERS (1989) apresenta três modos de fissuração na laje, ilustrados na figura 2.15 e descritos como:

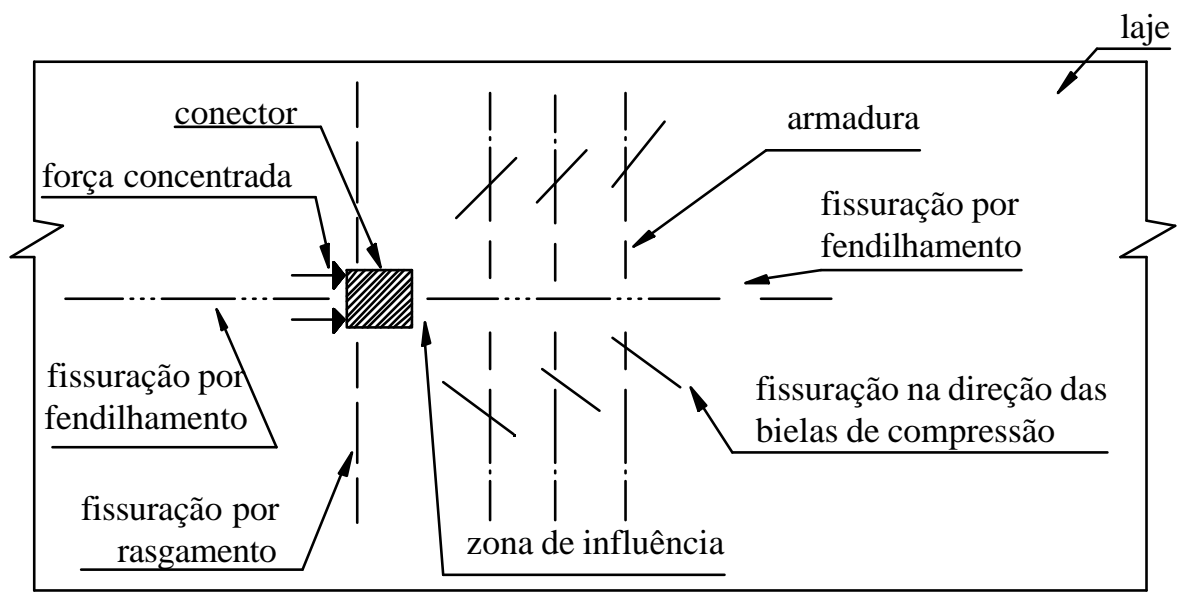

FIGURA 2.15: Tipos de fissuração na laje devida à força concentrada 
a)fissuração devido ao rasgamento, propagando-se nas laterais do conector e que depende da força de compressão no plano da laje.

b)fissuração que se propaga na direção das bielas de compressão do concreto.

c)fissuração por fendilhamento em frente ao conector. A propagação dessas fendas induz o fendilhamento atrás do conector, diminuindo a restrição triaxial na zona de influência.

A fissura por fendillhamento, segundo OEHLERS (1989), é a mais nociva ao concreto, tendo como conseqüência a ruptura do conector. É importante salientar, como mencionado em OEHLERS (1989), que a armadura transversal não evita o fendilhamento do concreto, mas limita a propagação das fissuras. Nesse caso, a resistência ao cisalhamento do conector está diretamente ligada à resistência e à rigidez do material do conector e da laje de concreto, tendo a armadura transversal que compõem a laje, um papel importante apenas no seu confinamento.

Desta forma, para limitar fissurações na laje de concreto na região onde se encontram as linhas de conectores de cisalhamento, são colocadas armaduras transversais adicionais àquelas normalmente utilizadas na laje de concreto armado. Esta armadura deverá ser uniformemente distribuída ao longo do vão da viga e posicionada na face inferior da laje, como ilustra a figura 2.16 .

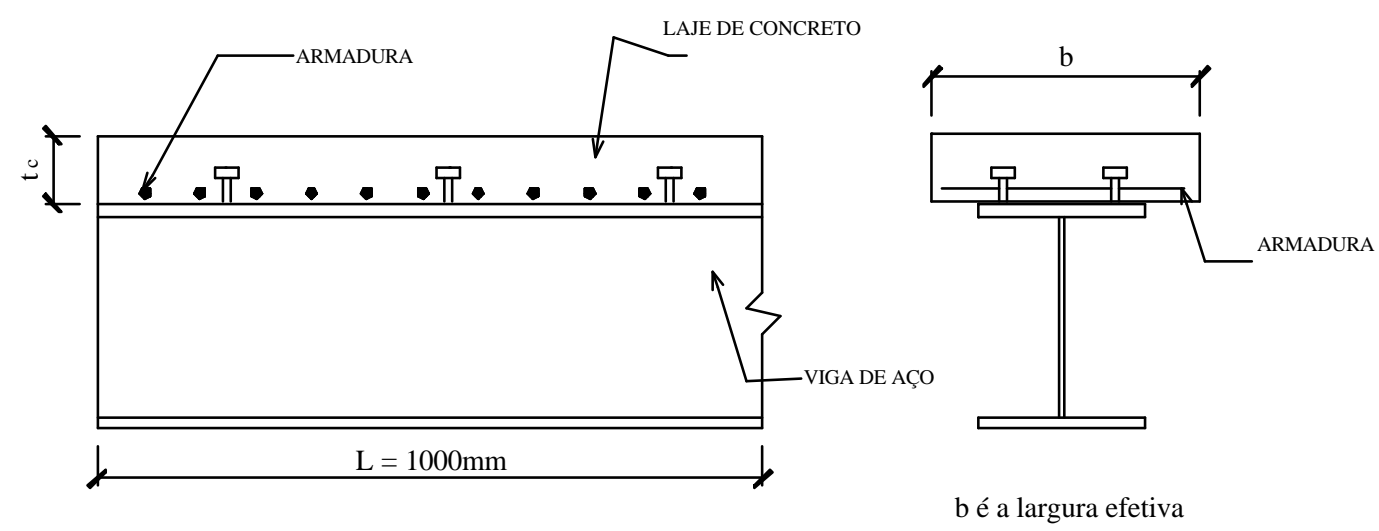

FIGURA 2.16: Disposição das armaduras transversais (adicionais) na laje de concreto

O EUROCODE 4 (1994) apresenta a expressão 2.9 que permite determinar a resistência ao esforço cisalhante na superfície considerada da laje $\left(v_{\mathrm{rd}}\right)$, originada do modelo de treliça de Morsch, ou seja, análogo ao cálculo de estribos em estruturas de concreto armado. 
A expressão 2.9 pode ser aplicada para lajes maciça e com forma de aço incorporada, e considera a resistência do concreto ao cisalhamento e as forças de tração na armadura e na forma de aço incorporada, caso esta esteja disposta com nervuras perpendicular à viga.

$v_{r d}=0,625 A_{c v} \eta \frac{f_{c t k}}{\gamma_{c}}+A_{e} \frac{f_{s k}}{\gamma_{s}}+v_{p d} \leq 0,2 A_{c v} \eta \frac{f_{c k}}{\gamma_{c}}+\frac{v_{p d}}{\sqrt{3}}$

onde

$\mathrm{A}_{\mathrm{cv}}$ é a área média de cisalhamento do concreto por unidade de comprimento da viga;

$\eta=1$ para concreto com densidade normal e $\eta=0,3+0,7(\rho / 24)$ para concreto de baixa densidade, sendo $\rho$ em $\mathrm{kN} / \mathrm{m}^{3}$;

$\mathrm{f}_{\text {ctk }}$ é a resistência característica do concreto a tração em MPa;

$\mathrm{A}_{\mathrm{e}}$ é a área da armadura transversal por unidade de comprimento da viga que passa pela superfície de ruptura considerada (figura 2.17), sendo incluída qualquer armadura de flexão da laje;
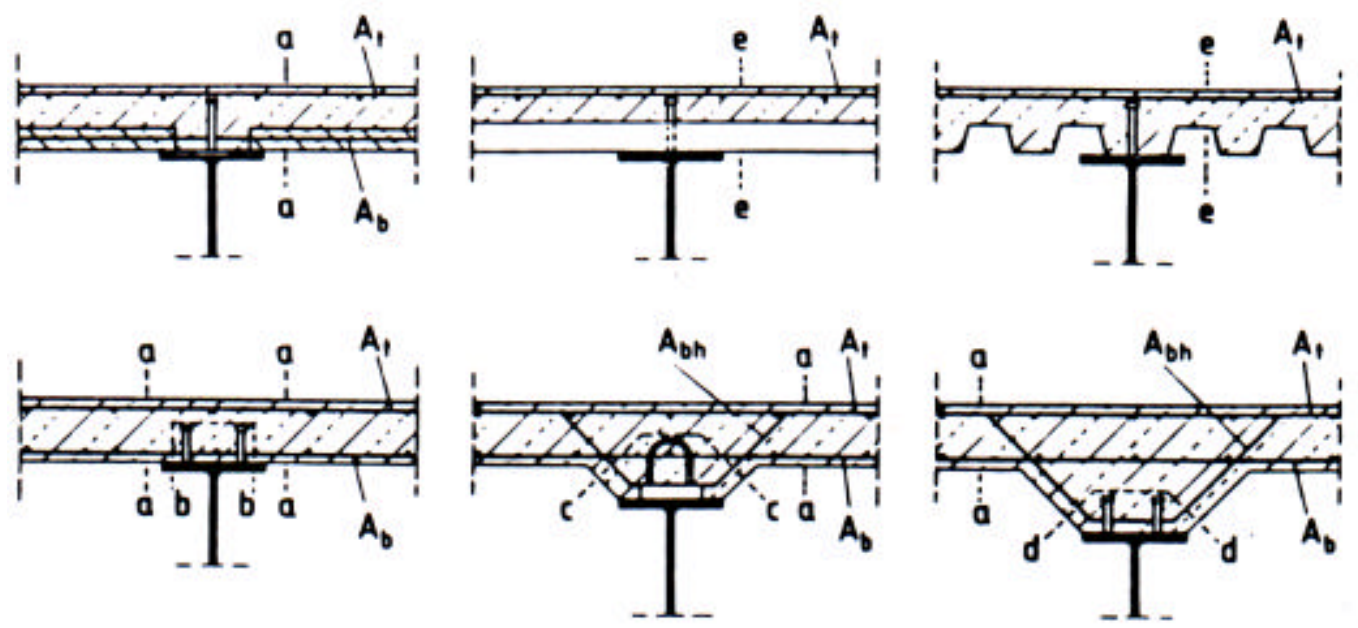

\begin{tabular}{|c|c|}
\hline Tipo & $A_{e}$ \\
\hline$a-a$ & $\left(A_{b}+A_{t}\right)$ \\
$b-b$ & $2 A_{b}$ \\
$c-c$ & $2\left(A_{b}+A_{b h}\right)$ \\
$d-d$ & $A_{b h}$ \\
e-e & $A_{t}$ \\
\hline
\end{tabular}

FIGURA 2.17: Superfícies típicas de falha ao cisalhamento, EUROCODE 4 (1994) 
$\mathrm{f}_{\mathrm{sk}}$ é a tensão de escoamento da armadura;

$\nu_{\mathrm{pd}}$ é a contribuição da forma de aço, sendo que:

- para formas de aço contínuas, $v_{p d}=\frac{A_{p} f_{y p}}{\gamma_{a p}}$

- para formas de aço não contínuas, porém devidamente ancorada na mesa da viga por meio de conectores de cisalhamento, $v_{p d}=\frac{K_{\varphi} d t f_{y p}}{s \gamma_{a p}} \leq \frac{A_{p} f_{y p}}{\gamma_{a p}}$ onde $\mathrm{K}_{\varphi}=1+\frac{\mathrm{a}}{\mathrm{d}} \leq 4,0 ;$

d é o diâmetro do conector; a é a distância do centro do conector à borda da forma, sendo necessário respeitar a relação de $(a<2 d)$;

t é a espessura da forma;

s é o espaçamento longitudinal dos conectores;

$A_{p}$ é área da seção transversal da forma por unidade de comprimento da viga; $\mathrm{f}_{\mathrm{yp}}$ é a tensão de escoamento do aço da forma.

Os coeficientes de segurança $\gamma_{c}, \gamma_{s}$ e $\gamma_{\text {ap }}$ são respectivamente 1,5;1,15 e 1,1.

A resistência de cálculo ao esforço de cisalhamento na superfície considerada da laje $\left(v_{\mathrm{rd}}\right)$, deve ser comparada à força de cisalhamento longitudinal atuante nos conectores, já mencionada no item 2.4 , objetivando verificar se a armadura é suficiente para limitar possíveis fissurações na laje.

Algumas normas estabelecem uma área de armadura transversal mínima, de acordo com a figura 2.16, por unidade de comprimento da viga, que deve ser verificada após o cálculo pela expressão 2.9 .

\section{1) Norma canadense CAN/CSA - S16.1 - 94: Limit States Design of Steel Structures}

Apresentam-se duas situações:

- para laje de concreto maciça: a área da armadura transversal por metro não deverá ser inferior a 0,002 da área de concreto a ser armada. 
- para laje com forma de aço incorporada: em situações onde a nervura é paralela ao vão da viga, a área da armadura transversal por metro não deverá ser inferior a 0,002 da área de concreto da laje situada em cima das nervuras. Por outro lado, no caso de nervuras perpendiculares ao vão da viga a área por metro não deve ser inferior a 0,001 da área de concreto da laje situada em cima das nervuras.

\section{2) Norma brasileira NBR 8800 (1986)}

- para ambos os tipos de lajes, a área da armadura transversal por metro não deverá ser inferior a 0,005 da área da seção de concreto.

\section{3) EUROCODE 4 (1994)}

- para laje de concreto maciça: a área da armadura transversal mínima por metro não deverá ser menor que 0,002 da área de concreto.

- para laje com forma de aço incorporada: em situações onde a nervura está paralela ao vão da viga, a área da armadura transversal por metro não deverá ser menor que 0,002 da área de concreto da laje situada a cima das nervuras. Por outro lado, no caso de nervuras perpendiculares ao vão da viga a área por metro não deve ser inferior a 0,002 da área de concreto medida na direção longitudinal. 


\section{ENSAIO TIPO “PUSH-OUT"}

No cálculo de vigas mistas a relação entre força de cisalhamento no conector e deslocamento relativo entre a viga de aço e a laje de concreto consiste em um dos aspectos de grande interesse para o dimensionamento. Esta relação é mais representativa quando obtida por meio de ensaios experimentais, porém, diversas normas como o EUROCODE $4 \mathrm{e}$ a BRITISH STANDARDS INSTITUTION (BS 5400) utilizam ensaios em modelos experimentais isolados, denominado de "Push-out", para determinação dessa relação. A figura 3.1.ilustra o modelo para o ensaio Push-out proposto pelo EUROCODE 4.
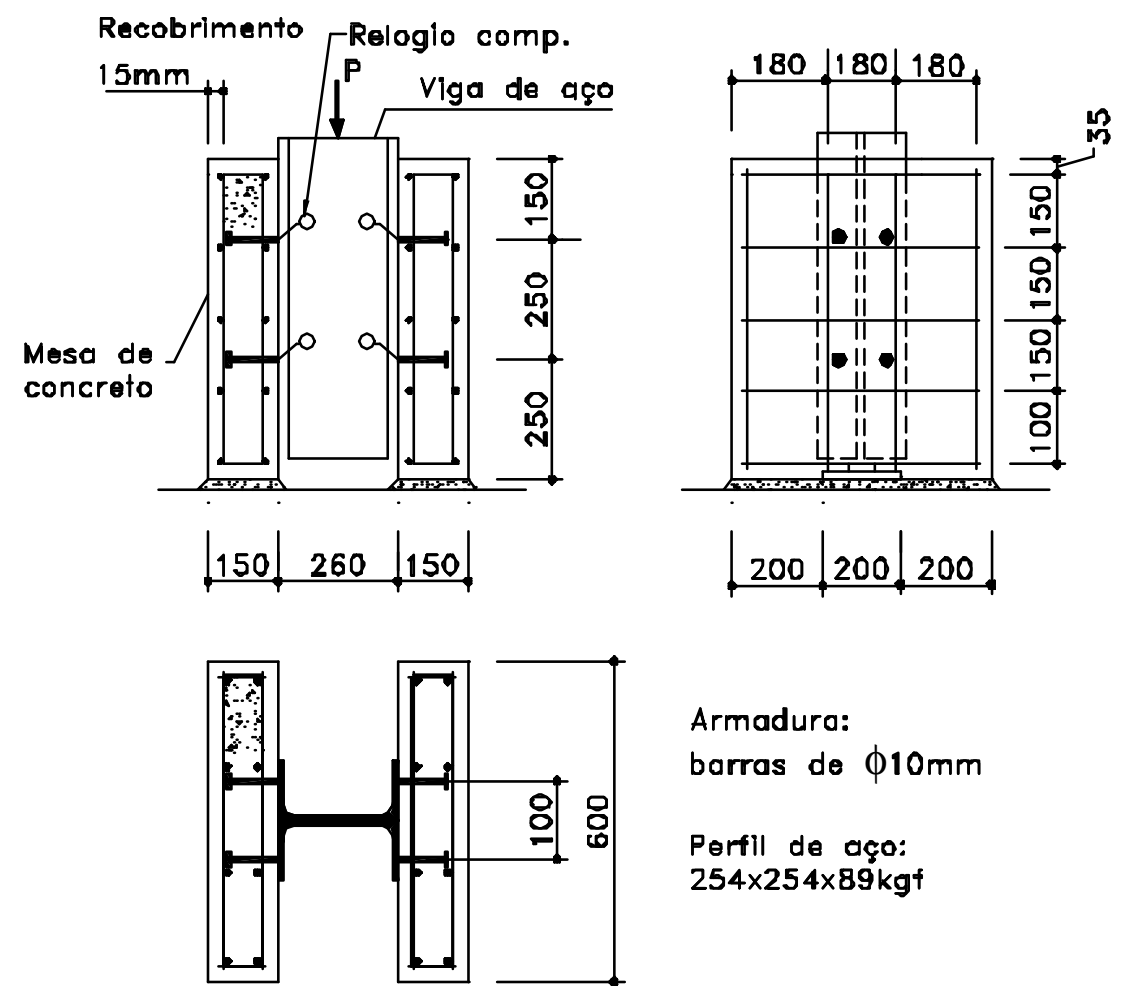

Armadura:

barras de $\phi 10 \mathrm{~mm}$

Perfil de aço:

$254 \times 254 \times 89 \mathrm{kgf}$

FIGURA 3.1: Modelo do ensaio tipo "Push-out" proposto pelo EUROCODE 4 
Vale ressaltar que, segundo o EUROCODE 4, existem modelos para o ensaio de cisalhamento (Push-out) dos tipos normalizado e específico. Se os conectores utilizados na viga mista estão imersos em laje de concreto maciça ou em laje com formas de aço incorporadas, ambas com espessuras uniformes, podem ser utilizados os ensaios de cisalhamento normalizados, caso contrário, utilizam-se os ensaios de cisalhamento específicos. O modelo ilustrado na figura 1 corresponde ao ensaio de cisalhamento normalizado.

No modelo de ensaio, deve-se eliminar a aderência entre a mesa da viga de aço e a laje de concreto utilizando, por exemplo, a graxa. O deslocamento relativo entre o perfil metálico e as duas lajes de concreto é medido por meio de relógios comparadores, conforme figura 3.1, o que possibilita obter o deslocamento médio em correspondência com a força no conector.

\section{1 - PROCEDIMENTOS PARA A REALIZAÇÃo DO ENSAIO E ANÁliSE DOS RESULTADOS OBTIDOS}

Segundo o EUROCODE 4, para a realização do ensaio tipo "Push-out" devem ser respeitados os seguintes procedimentos:

- Inicialmente, aplica-se a força no modelo em de força que variam entre 5\% e $40 \%$ da força de ruptura esperada. A parti daí, os intervalos até alcançar $40 \%$ da força de ruptura esperada. Posteriormente, aplicam-se 25 ciclos incrementos de força seguintes devem ser aplicados de modo a não provocar ruptura antes de um período de 15 minutos.

- O deslocamento longitudinal entre laje de concreto e viga de aço é monitorado em todo o processo da aplicação da força, desde o início do carregamento até ser atingida a força máxima. Na seqüência, o deslocamento permanece sendo monitorado até que o carregamento decresça em $20 \%$ do valor de força máxima. Deve-se também monitorar próximo de cada grupo de conectores a separação transversal entre mesa e laje.

Para análise dos resultados dos ensaios de três modelos nominalmente idênticos, cujas relações entre o resultado individual de cada modelo com os resultados médios não excedam a 10\%, a resistência de cálculo para cada modelo ensaiado pode ser determinada como segue na expressão.

$\mathrm{P}_{\mathrm{rd}}=\left(\mathrm{f}_{\mathrm{u}} / \mathrm{f}_{\mathrm{ut}}\right)\left(\mathrm{P}_{\mathrm{rk}} / ?_{\mathrm{v}}\right) \leq \mathrm{P}_{\mathrm{rk}} / ?_{\mathrm{v}}$ 
onde

$\mathrm{f}_{\mathrm{u}}$ é a resistência última mínima especificada para o material do conector;

$\mathrm{f}_{\mathrm{ut}}$ é a resistência última do conector obtida no ensaio experimental;

$?_{v}$ é o coeficiente de segurança para o estado limite último, igual à 1,25 ;

$\mathrm{P}_{\mathrm{rk}}$ é a força de ruptura mínima dos três ensaios de modelos idênticos (dividida pelo número de conectores) reduzida em $10 \%$.

O deslocamento de interesse de um modelo deve ser tomado como o valor de deslocamento máximo $\left(\delta_{\mathrm{u}}\right)$, medido em $\left(\mathrm{P}_{\mathrm{rk}}\right)$, como ilustrado na figura 3.2. A capacidade de deslocamento característica $\left(\delta_{\mathrm{uk}}\right)$ é o menor dos valores de $\delta_{\mathrm{u}}$ obtidos nos ensaios, e reduzido em $10 \%$.

$$
\mathrm{P}(\mathrm{kN})
$$

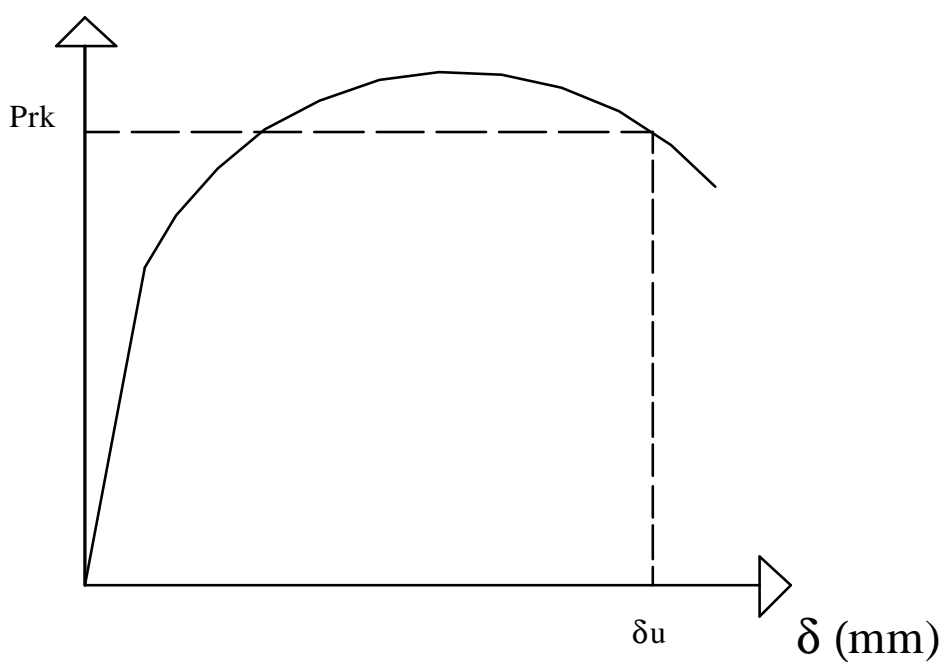

FIGURA 3.2: Determinação da capacidade de deslocamento $\delta_{u}$, em correspondência $P_{r k}$

\section{2 - CONSIDERAÇÕES PARA O ENSAIO TIPO "PUSH-OUT"}

JOHNSON (1994) apresenta alguns fatores que influenciam nos resultados de um ensaio tipo "Push-out". São os seguintes:

a) Número de conectores no modelo de ensaio;

b) Tamanho, arranjo, e resistência da armadura da laje na vizinhança dos conectores;

c) Tensões longitudinais médias na laje de concreto em torno dos conectores;

d) Espessura do concreto junto aos conectores; 
e) Aderência na interface mesa da viga de aço e laje de concreto;

f) Vinculação lateral na base das lajes, pois deslocamentos laterais podem provocar forças de arrancamento (efeito alavanca);

g) Resistência à compressão do concreto;

h) Adensamento do concreto junto à base de cada conector.

Segundo JOHNSON (1994), a resistência do concreto pode influenciar tanto no modo de ruptura como no valor da força de ruptura do modelo. Por exemplo, para conectores do tipo pino com cabeça (stud), têm-se diferentes modos de ruptura em função do diâmetro do conector. Para conectores com diâmetro acima de $16 \mathrm{~mm}$ ocorre ruptura no concreto circundante ao conector, enquanto que para diâmetros menores ocorre o cisalhamento do conector (shearing off). A figura 3.3 esquematiza os modos de ruptura no ensaio tipo "Push-out", os quais podem ocorrer separados ou de forma combinada.

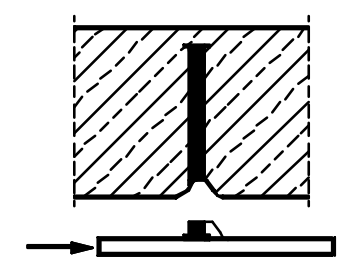

Ruptura por

cisalhamento do

conector junto à

solda

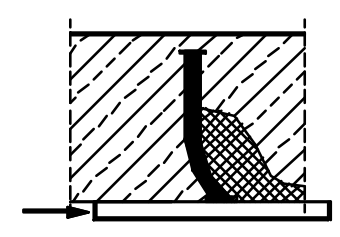

Esmagamento do

concreto circundante ao

conector

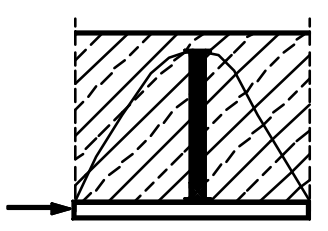

Arrancamento do concreto (forma de cone)

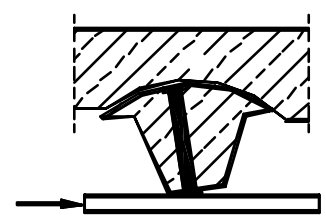

Ruptura por cisalhamento da nervura de concreto

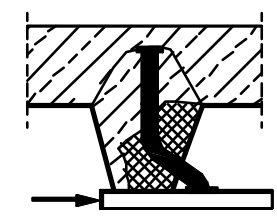

Fissuração do concreto da nervura, devido à formação de rótulas plásticas (deformações excessivas do conector)

FIGURA 3.3: Modos de ruptura do ensaio tipo "Push-out" (segundo o EUROCODE 4) 
De acordo com MALITE (1993), os ensaios tipo "Push-out" mostram que as tensões de contato no corpo do conector variam ao longo de sua altura, sendo que, a máxima tensão de contato ocorre junto à base do conector (local em que o conector está solidarizado à mesa do perfil metálico), devido ao confinamento exercido pela armadura e pela mesa do perfil, conforme ilustra a figura 3.4.
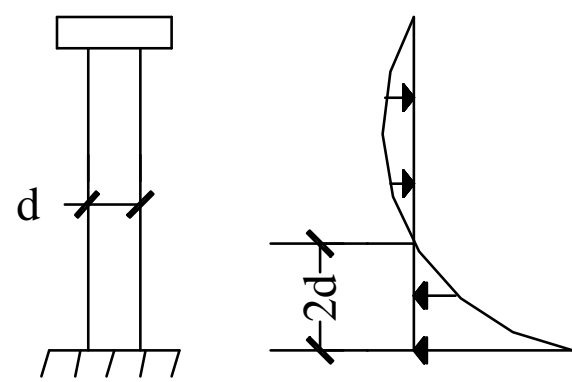

FIGURA 3.4: Tensões de contato no conector tipo pino com cabeça

MALITE (1993) ainda menciona que apesar de as normas atuais especificarem o ensaio tipo "Push-out" para obtenção da relação força-deslocamento no conector, ocorrem algumas diferenças nos resultados desse ensaio em relação àqueles obtidos de ensaio em vigas mistas.

Em vigas biapoiadas, onde a laje é totalmente comprimida, a rigidez da conexão de cisalhamento em regime elástico pode ser até duas vezes maior que o valor obtido nos ensaios tipo "Push-out", porém a resistência última é aproximadamente igual. No entanto, vale ressaltar que a tendência de os resultados no ensaio "Push-out" é a de ficar a favor da segurança, pois a taxa de armadura especificada para a laje (no ensaio) é, em geral, menor que aquela utilizada nas vigas.

MALITE (1993) menciona também que nas regiões de momento fletor negativo, onde a laje de concreto se encontra tracionada, a conexão de cisalhamento é menos rígida, bem como a resistência última ligeiramente reduzida. Nestas regiões recomenda-se considerar apenas $80 \%$ da resistência última dos conectores obtida em ensaios do tipo "Pushout".

Existem outras três situações em que a resistência do conector, obtida no ensaio tipo "Push-out", pode se encontrar ele vadas para projetos:

a) Fadiga: as normas específicas de pontes apresentam valores reduzidos da resistência dos conectores, com base em ensaios isolados ("Push-out") ou em vigas mistas.

b) Conectores próximos à extremidade: a resistência última do conector é reduzida quando os conectores encontram-se muito próximos à extremidade da laje de concreto. Por isso, as 
normas apresentam restrições com relação aos detalhes construtivos de conectores em extremidade de laje.

c) Concretos de baixa densidade: a resistência última de conectores em concretos de baixa densidade é menor que nos concretos de densidade normal com mesma resistência à compressão. Ensaios realizados em concretos de baixa densidade mostraram que a resistência do conector é aproximadamente $15 \%$ menor que ros concretos de densidade normal.

\section{3 - ENSAIOS TIPO "PUSH-OUT" PARA CONECTORES FORMADOS A FRIO}

Em MALITE (1993) são apresentados resultados experimentais de ensaios tipo "Push-out" realizados no Laboratório do Departamento de Engenharia de Estruturas da EESC/USP, para conectores de cisalhamento dos tipos cantoneira e perfil " $U$ " formados a frio. Os modelos de ensaios foram semelhantes àqueles apresentado pela norma inglesa BS 5400, conforme esquematizado na figura 3.5.

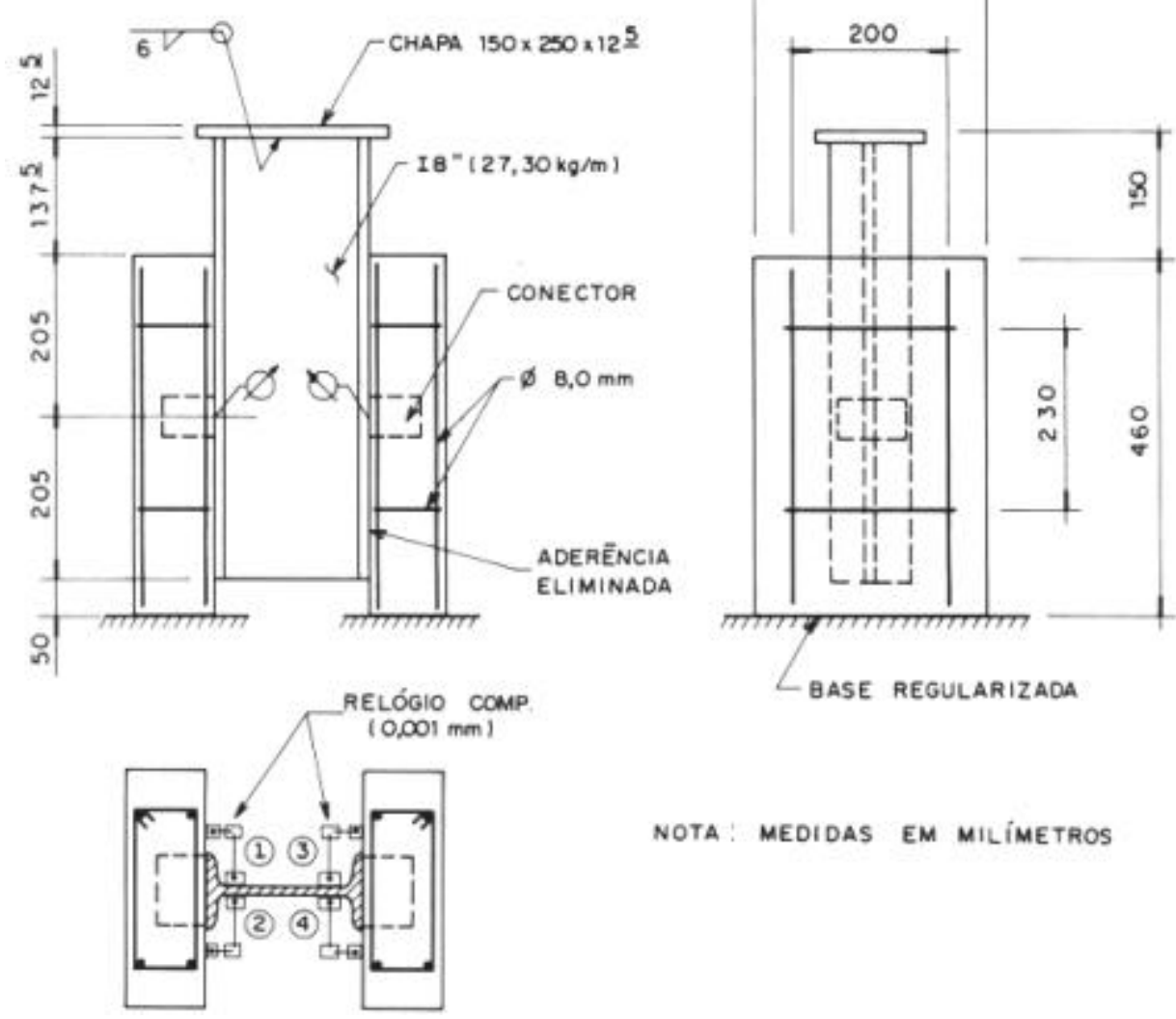

FIGURA 3.5: Esquema geral dos modelos ensaiados por MALITE (1993) 
Os conectores utilizados foram dos tipos cantoneira simples, cantoneira enrijecida e perfil " $U$ ", e em duas espessuras de chapa (2,66 mm e 4,76 mm). Para cada tipo de configuração, foram ensaiados três modelos idênticos para laje de concreto aos 28 dias de idade, sendo que o deslocamento relativo entre a laje de concreto e o perfil metálico foi medido por meio de quatro relógios comparadores, com sensibilidade de leitura de 0,001 $\mathrm{mm}$, posicionados juntos aos conectores. A figura 3.6 esquematiza os conectores e suas correspondentes posições nos modelos ensaiados por MALITE (1993).

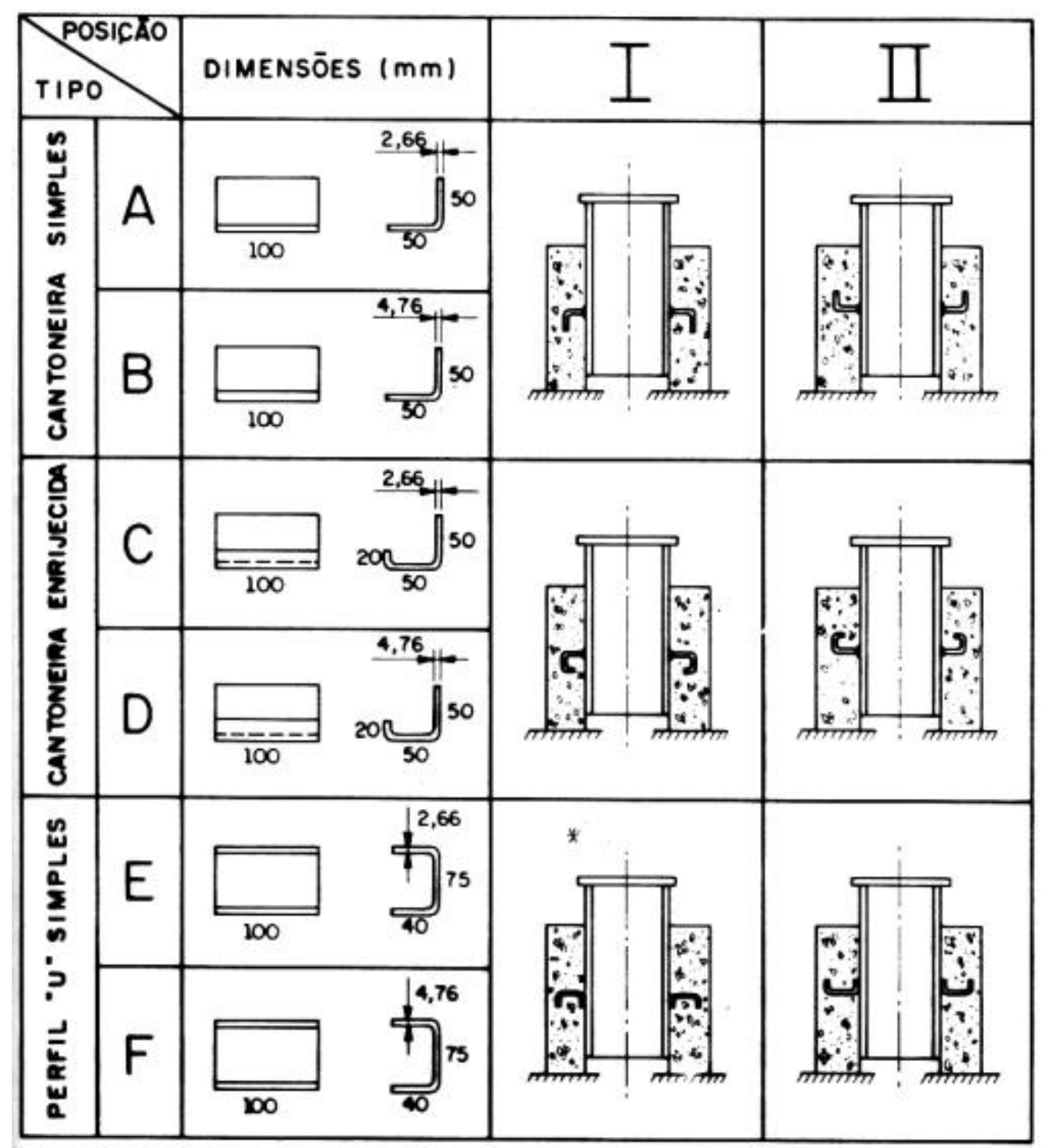

FIGURA 3.6: Tipos e posições dos conectores nos modelos de ensaio

Os ensaios foram conduzidos até que os modelos atingissem a ruptura efetiva. Para efeito de acomodação do modelo, aplicou-se inicialmente $40 \mathrm{kN}$, em duas etapas, seguido de um descarregamento total. Após acomodação do modelo, aplicou-se 
etapas de carregamento de $20 \mathrm{kN}$, com um intervalo de 1,5 minuto entre as leituras dos deslocamentos de duas etapas consecutivas. Não houve leituras dos deslocamentos próximos à ruptura dos modelos, em função da movimentação considerável das cantoneiras de apoio dos relógios comparadores.

As formas de ruptura apresentadas nos modelos foram a ruptura do aço do conector junto à solda e ruptura do concreto. Os dois tipos de modos de falhas ficaram bem divididos em todos os tipos de conectores: o primeiro modo caracterizou-se para conectores com espessura de 2,66 mm, enquanto que o segundo modo para os conectores com espessura de $4,76 \mathrm{~mm}$.

Para os conectores do tipo cantoneira simples, em ambos os tipos de ruptura, houve uma permanência da forma geométrica inicial da cantoneira, ocorrendo apenas uma rotação do conector junto à solda da ligação com a viga de aço. Este mesmo comportamento foi apresentado para os conectores do tipo cantoneira enrijecida, demonstrando que o enrijecedor praticamente não altera a relação força-deslocamento e a força de colapso. A figura 3.7 ilustra a rotação do conector na ligação.

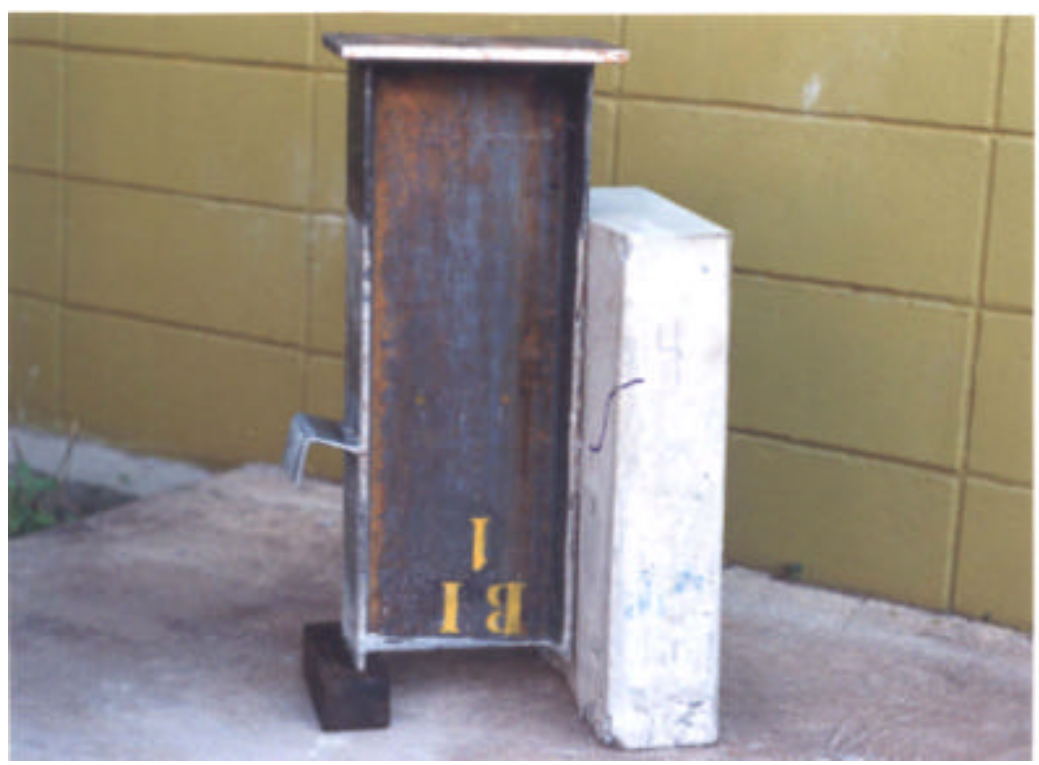

FIGURA 3.7: Rotação do conector junto á ligação com o perfil, modelo ensaiado por MALITE (1993)

Segundo MALITE (1993), os conectores do tipo perfil "U" não apresentaram grandes diferenças no comportamento força-deslocamento em relação aos conectores do tipo cantoneira, apesar da maior altura. Diante disso, concluiu-se que a variável que mais influência na resistência da ligação é a espessura da chapa.

A Tabela 3.1 apresenta as forças no colapso médias dos conectores para as duas posições ensaiadas, referentes à figura 3.6. 
TABELA 3.1: Forças de colapso $\left(P_{u}\right)$ médias dos conectores para os modelos analisados

\begin{tabular}{|c|c|c|}
\hline TIPO DE CONECTOR & POSIÇÃO & FORCA DE COLAPSO $\left(\boldsymbol{P}_{u}\right)(\boldsymbol{k N})$ \\
\hline \multirow{2}{*}{ A } & I & 135,0 \\
\cline { 2 - 3 } & II & 118,8 \\
\hline \multirow{2}{*}{ B } & I & 185,8 \\
\cline { 2 - 3 } & II & 170,0 \\
\hline \multirow{2}{*}{ C } & I & 128,3 \\
\cline { 2 - 3 } & II & 108,3 \\
\hline \multirow{2}{*}{ D } & I & 168,3 \\
\cline { 2 - 3 } & II & 171,7 \\
\hline \multirow{2}{*}{ E } & I & 124,7 \\
\cline { 2 - 3 } & II & 121,7 \\
\hline \multirow{2}{*}{ F } & I & 203,3 \\
\cline { 2 - 3 } & II & 168,3 \\
\hline \multirow{2}{*}{} & & \\
\hline
\end{tabular}

É importante destacar, com relação à tabela 3.1, que não houve grandes diferenças em relação à força de colapso do conector quanto às posições I e II. Porém o comportamento da relação força-deslocamento para os conectores na posição I apresentou-se mais dúctil quando comparada à relação obtida com referência à posição II, como ilustrado na figura 3.8, correspondente ao modelo com conector perfil " $U$ " de 2,66 mm.

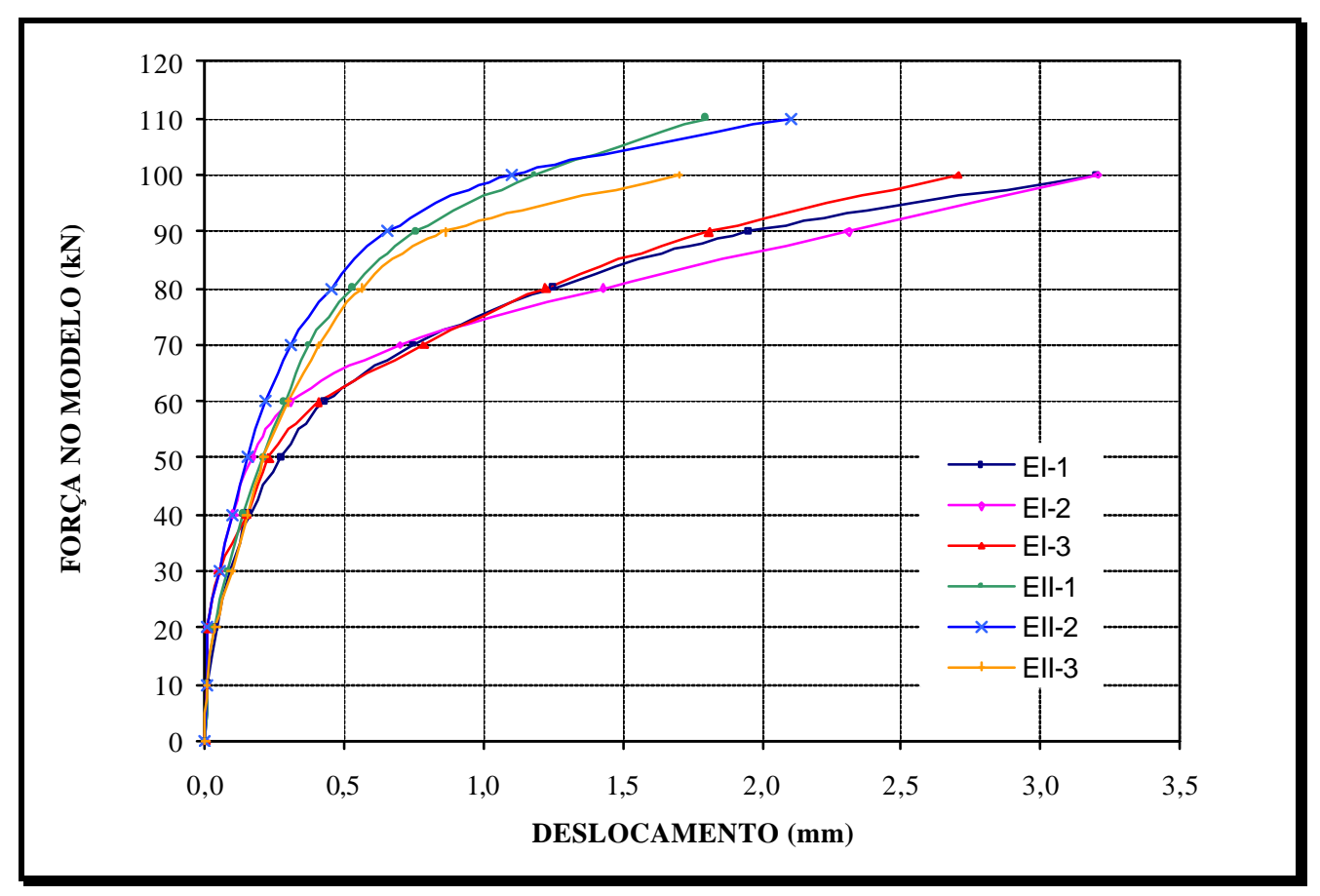

FIGURA 3.8: Relação força $x$ deslocamento para os modelos com conector perfil " $U$ " de 2,66 mm nas duas posições (EI e EII) 


\section{4 - DETERMINAÇÃO DA RESISTÊNCIA AO CISALHAMENTO DOS CONECTORES EM VIGAS MISTAS AÇO-CONCRETO}

Um dos primeiros estudos experimentais, baseado em 48 ensaios tipo "Pushout" com laje de concreto maciça, para determinação da resistência ao cisalhamento do conector tipo pino com cabeça (stud) de diâmetros de 16 e 19mm, foi realizado por OLLGAARD et al. (1971) apud OEHLERS \& PARK (1992). Como resultado, foi proposta a expressão 3.2, que determina a resistência última do conector tipo pino com cabeça (stud), em concretos de densidades normal e baixa, função apenas da resistência à compressão e módulo de elasticidade do concreto.

$\mathrm{Q}_{\mathrm{u}}=0,5 \mathrm{~A}_{\mathrm{s}}\left(\mathrm{f}_{\mathrm{ck}} \mathrm{E}_{\mathrm{c}}\right)^{0,5}$

onde

$\mathrm{Q}_{\mathrm{u}}$ é a resistência última do conector $(\mathrm{N})$;

$\mathrm{A}_{\mathrm{s}}$ é a área do corpo do conector tipo pino com cabeça (stud) em $\mathrm{mm}^{2}$;

$\mathrm{f}_{\mathrm{ck}}$ é a resistência característica à compressão do concreto (MPa);

$\mathrm{E}_{\mathrm{c}}$ é o módulo de elasticidade do concreto (MPa).

No entanto, pesquisas realizadas na Austrália por HAWKINS (1973), demonstraram ganho na resistência do pino com cabeça (stud) quando a resistência do material do conector $\left(f_{u}\right)$ é aumentada. Nesse sentido, OEHLERS \& JOHNSON (1987) apud OEHLERS \& PARK (1992) propuseram modificações na expressão 3.2, na qual passa a ser também levada em consideração a interação entre as resistências e rigidezes do concreto e aço do conector. Nesse caso, reescreveu-se a expressão 3.2 na forma.

$$
\begin{aligned}
& \mathrm{Q}_{\mathrm{u}}=\mathrm{Kf}_{\mathrm{u}} \mathrm{A}_{\mathrm{s}}\left[\frac{\mathrm{E}_{\mathrm{c}}}{\mathrm{E}_{\mathrm{a}}}\right]^{0,40}\left[\frac{\mathrm{f}_{\mathrm{ck}}}{\mathrm{f}_{\mathrm{u}}}\right]^{0,35} \\
& \mathrm{~K}=4,3-1, \ln _{\mathrm{r}}{ }^{-0,5}
\end{aligned}
$$

onde

$\mathrm{Q}_{\mathrm{u}}$ é a resistência última do conector $(\mathrm{N})$;

$\mathrm{f}_{\mathrm{u}}$ é a resistência última do aço do conector $(\mathrm{MPa})$;

$\mathrm{A}_{\mathrm{s}}$ é a área do corpo do conector tipo pino com cabeça (stud) em $\mathrm{mm}^{2}$; 
$\mathrm{f}_{\mathrm{ck}}$ é a resistência característica à compressão do concreto (MPa);

$\mathrm{E}_{\mathrm{c}}$ é o módulo de elasticidade do concreto (MPa);

$\mathrm{E}_{\mathrm{a}}$ é o módulo de elasticidade do aço do conector (MPa).

$\mathrm{n}_{\mathrm{r}}$ é o número de conectores que podem ser assumidos com a possibilidade de romperem em grupo (deslocamentos similares);

Apesar da expressão 3.3 ser aplicável diretamente para determinação da resistência última do conector em viga mista, pode-se determinar a resistência última dos conectores no ensaio tipo "Push-out", utilizando K com valor igual a 5,3.

A expressão 3.3 possibilita considerar a diferença entre a resistência última obtida no ensaio "Push-out" em relação àquela observada no ensaio de viga mista, as quais ocorrem pela suas diferentes restrições e também pelo fato de os pinos com cabeça (stud) serem dúcteis suficientes para romperem em grupo.

As resistências ao cisalhamento dos conectores tipos pino com cabeça (stud), perfil "U" e "L" em lajes maciças, baseadas em ensaios experimentais, também são propostas pelas principais normas, como apresentado a seguir.

1) CONECTOR TIPO PINO COM CABEÇA (STUD)

- Norma brasileira (NBR - 8800/1986): Projeto e Execução de Estruturas de Aço de Edifícios e a (AISC-LRFD/1994): "Load and Resistance Factor Design"

$\mathrm{q}_{\mathrm{n}}=0,5 \mathrm{~A}_{\mathrm{sc}} \sqrt{\mathrm{f}_{\mathrm{ck}} \mathrm{E}_{\mathrm{c}}} \leq \mathrm{A}_{\mathrm{sc}} \mathrm{f}_{\mathrm{u}}$

$\mathrm{E}_{\mathrm{c}}=42 \gamma_{\mathrm{c}}{ }^{1,5} \sqrt{\mathrm{f}_{\mathrm{ck}}}$

onde

$\mathrm{q}_{\mathrm{n}}$ é a resistência nominal do conector $(\mathrm{N})$;

$\mathrm{A}_{\mathrm{sc}}$ é a área da seção transversal do conector $\left(\mathrm{mm}^{2}\right)$;

$\mathrm{f}_{\mathrm{ck}}$ é o resistência característica à compressão do concreto (MPa);

$\gamma_{c}$ é o peso específico do concreto em $\mathrm{kN} / \mathrm{m}^{3}$;

$\mathrm{f}_{\mathrm{u}}$ é a resistência última do aço do conector (MPa);

$\mathrm{E}_{\mathrm{c}}$ é o módulo de elasticidade do concreto (MPa). 
De acordo com $N B R-8800$, a expressão (3.5) aplica-se a concretos com $\mathrm{f}_{\mathrm{ck}}$ menor ou igual a $28 \mathrm{MPa}$.

- Norma canadense CAN/CSA-S16.1 (1994): "Limits States Design of Steel Structures"

$\mathrm{q}_{\mathrm{rd}}=0,5 \phi_{\mathrm{sc}} \mathrm{A}_{\mathrm{sc}} \sqrt{\mathrm{f}_{\mathrm{ck}} \mathrm{E}_{\mathrm{c}}} \leq \mathrm{A}_{\mathrm{sc}} \phi_{\mathrm{sc}} \mathrm{f}_{\mathrm{u}}$

onde

$\mathrm{q}_{\mathrm{rd}}$ é a resistência de cálculo do conector $(\mathrm{N})$;

$\phi_{\text {sc }}$ é o coeficiente de resistência, igual à 0,8 ;

$\mathrm{A}_{\mathrm{sc}}$ é a área da seção transversal do conector $\left(\mathrm{mm}^{2}\right)$;

$\mathrm{f}_{\mathrm{ck}}$ é o resistência característica à compressão do concreto (MPa);

$\mathrm{E}_{\mathrm{c}}$ é o módulo de elasticidade do concreto (MPa);

$\mathrm{f}_{\mathrm{u}}$ é a resistência última do aço do conector $(\mathrm{MPa})$.

- Norma européia EUROCODE 4: "Proyecto de Estructuras Mixtas de Hormigón y Acero (1994)"

A resistência de cálculo é, nesse caso, tomada como o menor valor entre aqueles obtidos por meio das seguintes expressões:

$$
\begin{aligned}
\mathrm{q}_{\mathrm{rd}} & =\frac{0,8 \mathrm{f}_{\mathrm{u}}\left(\frac{\pi \mathrm{d}^{2}}{4}\right)}{\gamma_{\mathrm{v}}} \\
\mathrm{q}_{\mathrm{rd}}= & \frac{0,29 \alpha \mathrm{d}^{2} \sqrt{\mathrm{f}_{\mathrm{ck}} \mathrm{E}_{\mathrm{c}}}}{\gamma_{\mathrm{v}}}
\end{aligned}
$$

onde

$\mathrm{q}_{\mathrm{rd}}$ é a resistência de cálculo do conector $(\mathrm{N})$;

$\mathrm{f}_{\mathrm{u}}$ é a resistência última do aço do conector ( $\left.\mathrm{MPa}\right)$;

d é o diâmetro do conector ( $\mathrm{mm})$;

$\mathrm{f}_{\mathrm{ck}}$ é a resistência característica à compressão do concreto (MPa);

$\mathrm{E}_{\mathrm{c}}$ é o módulo de elasticidade do concreto (MPa); 
$\mathrm{a}=0,2\left(\frac{\mathrm{h}_{\mathrm{cs}}}{\mathrm{d}}+1\right)$ para $3 \leq \frac{\mathrm{h}_{\mathrm{cs}}}{\mathrm{d}} \leq 4 ; \mathrm{a}=1,0$ para $\frac{\mathrm{h}_{\mathrm{cs}}}{\mathrm{d}}>4$;

$\gamma_{\mathrm{v}}$ é o coeficiente de segurança para o estado limite último, igual à 1,25;

$\mathrm{h}_{\mathrm{cs}}$ é a altura do conector (mm).

As expressões 3.8 e 3.9 não podem ser usadas para conectores tipo pino com cabeça (stud), com diâmetro maior que $22 \mathrm{~mm}$.

\section{- Norma britânica BS 5950 (1990): "Structural use steelwork in building"}

A capacidade nominal do conector $\left(q_{n}\right)$ é apresentada na tabela 3.2, em função do diâmetro e altura do conector, bem como em função da resistência característica à compressão do concreto $\left(\mathrm{f}_{\mathrm{ck}}\right)$.

TABELA 3.2: Capacidade nominal dos conectores tipo pino com cabeça em lajes maciças

\begin{tabular}{|c|c|c|c|c|c|}
\hline \multicolumn{2}{|c|}{ Dimensões do conector } & \multicolumn{4}{|c|}{ Capacidade nominal do conector $(\mathrm{kN})$} \\
\hline \multirow{2}{*}{$\begin{array}{c}\text { Diâmetro } \\
(\mathrm{mm})\end{array}$} & \multirow{2}{*}{$\begin{array}{l}\text { Altura } \\
(\mathrm{mm})\end{array}$} & \multicolumn{4}{|c|}{ Resistência característica à compressão do concreto $(\mathrm{MPa})$} \\
\hline & & 25 & 30 & 35 & 40 \\
\hline 25 & 100 & 146 & 154 & 161 & 168 \\
\hline 22 & 100 & 119 & 126 & 132 & 139 \\
\hline 19 & 100 & 95 & 100 & $\overline{104}$ & 109 \\
\hline 19 & 75 & 82 & 87 & 91 & 96 \\
\hline 16 & 75 & 70 & 74 & 78 & 82 \\
\hline 13 & 65 & 44 & 47 & 49 & 52 \\
\hline \multicolumn{6}{|c|}{$\begin{array}{l}\text { Nota 1: Para concretos com } \mathrm{f}_{\mathrm{ck}}>40 \mathrm{MPa} \text {, utilizar os valores para } \mathrm{f}_{\mathrm{ck}}=40 \mathrm{MPa} \\
\text { Nota 2: Para conectores com alturas maiores que } 100 \mathrm{~mm} \text {, utilizar o valor correspondente à maior } \\
\text { altura tabelada. }\end{array}$} \\
\hline
\end{tabular}

Vale ressaltar que todas as normas citadas no item em questão apresentam expressões para determinação de um coeficiente de redução $\left(\mathrm{C}_{\mathrm{red}}\right)$ que, ao multiplicar o valor da resistência de cálculo do conector tipo pino com cabeça para lajes maciças, permite determinar o valor da resistência de cálculo do mesmo conector para lajes com forma de aço incorporada. As expressões que determinam os referidos coeficientes de redução, para cada norma, encontram-se descritas no anexo I do presente trabalho. 


\section{2) CONECTOR TIPO PERFIL "U” LAMINADO}

- $\quad$ AISC-LFRD (1994)

$\mathrm{q}_{\mathrm{n}}=0,0003\left(\mathrm{t}_{\mathrm{f}}+0,5 \mathrm{t}_{\mathrm{w}}\right) \mathrm{L}_{\mathrm{c}} \sqrt{\mathrm{f}_{\mathrm{ck}} \mathrm{E}_{\mathrm{c}}}$

onde

$\mathrm{q}_{\mathrm{n}}$ é a capacidade nominal do conector $(\mathrm{kN})$;

$\mathrm{t}_{\mathrm{w}}$ é a espessura da alma do conector ( $\left.\mathrm{mm}\right)$;

$\mathrm{t}_{\mathrm{f}}$ é a espessura da mesa do conector (mm);

$\mathrm{L}_{\mathrm{c}}$ é o comprimento do perfil "U" laminado (mm);

$\mathrm{E}_{\mathrm{c}}$ é o módulo de elasticidade do concreto $(\mathrm{MPa}), \mathrm{E}_{\mathrm{c}}=42 \gamma_{\mathrm{c}}^{1,5} \sqrt{\mathrm{f}_{\mathrm{ck}}}$;

$\mathrm{f}_{\mathrm{ck}}$ é a resistência característica à compressão do concreto (MPa).

- Norma britânica BS 5400 (1979) "Code of pratice for design of composite bridges"

A norma britânica na apresenta valores para determinação da capacidade nominal $\left(\mathrm{q}_{\mathrm{n}}\right)$ do conector tipo perfil " $\mathrm{U}$ " laminado, conforme tabela 3.3.

TABELA 3.3: Capacidade nominal dos conectores tipo perfil " $U$ " laminado

\begin{tabular}{|c|c|c|c|c|c|}
\hline \multirow{3}{*}{ Tipo de perfil "U" (mm) } & \multirow{3}{*}{$\begin{array}{l}\text { Material } \\
\text { do } \\
\text { conector }\end{array}$} & \multicolumn{4}{|c|}{ Resistência do conector $(k N)$} \\
\hline & & \multicolumn{4}{|c|}{$\begin{array}{c}\text { Resistência característica à compressão do } \\
\text { concreto }-f_{c k}(\mathrm{MPa})\end{array}$} \\
\hline & & 20 & 30 & 40 & 50 \\
\hline $127 \times 64 \times 14,90 \mathrm{Kg} \times 150$ & \multirow{3}{*}{$\begin{array}{c}\text { Grau } 43 \mathrm{da} \\
\text { BS } 4360 \\
(1972)\end{array}$} & 351 & 397 & $\overline{419}$ & 442 \\
\hline $102 \times 51 \times 10,42 \mathrm{Kg} \times 150$ & & 293 & 337 & 364 & 390 \\
\hline $76 \times 38 \times 6,70 \mathrm{Kg} \times 150$ & & 239 & 283 & 305 & 326 \\
\hline
\end{tabular}

- NBR 8800 (1986)

$\mathrm{q}_{\mathrm{n}}=0,0365\left(\mathrm{t}_{\mathrm{f}}+0,5 \mathrm{t}_{\mathrm{w}}\right) \mathrm{L}_{\mathrm{c}} \sqrt{\mathrm{f}_{\mathrm{ck}}}$ 
onde

$\mathrm{q}_{\mathrm{n}}$ é a capacidade nominal do conector $(\mathrm{kN})$;

$\mathrm{t}_{\mathrm{w}}$ é a espessura da alma do conector (mm);

$\mathrm{t}_{\mathrm{f}}$ é a espessura da mesa do conector ( $\left.\mathrm{mm}\right)$;

$\mathrm{L}_{\mathrm{c}}$ é o comprimento do perfil " $\mathrm{U}$ " laminado (mm);

$\mathrm{f}_{\mathrm{ck}}$ é a resistência característica à compressão do concreto (MPa).

A NBR 8800 limita a utilização da expressão 3.11 para concretos com peso específico superior a $22 \mathrm{kN} / \mathrm{m}^{3}$ e com $\mathrm{f}_{\mathrm{ck}}$ entre 20 e $28 \mathrm{MPa}$.

\section{3) CONECTOR TIPO PERFIL “U”E PERFIL "L” FORMADO A FRIO}

- MALITE et al. (1998):

$\mathrm{q}_{\mathrm{n}}=0,00045 \mathrm{tL} \sqrt{\mathrm{f}_{\mathrm{ck}} \mathrm{E}_{\mathrm{c}}}$

onde

$\mathrm{q}_{\mathrm{n}}$ é a capacidade nominal do conector $(\mathrm{kN})$;

t é a espessura da chapa do conector (mm);

L é o comprimento do conector ( $\mathrm{mm}$ );

$\mathrm{f}_{\mathrm{ck}}$ é a resistência característica à compressão do concreto (MPa);

$\mathrm{E}_{\mathrm{c}}$ é o módulo de elasticidade do concreto $(\mathrm{MPa}), \mathrm{E}_{\mathrm{c}}=42 \gamma_{\mathrm{c}}^{1,5} \sqrt{\mathrm{f}_{\mathrm{ck}}}$;

$\gamma_{c}$ é o peso específico do concreto em $\mathrm{kN} / \mathrm{m}^{3}$.

A expressão 3.12 é derivada da expressão 3.10 para perfil laminado, uma vez que as espessuras da mesa e da alma são iguais em perfis formados a frio. Na ausência de resultados experimentais para os conectores tipo perfil " $U$ " e tipo perfil "L", ambos formados a frio, pode-se utilizar a expressão 3.12, já que sua aplicação foi verificada por meio dos resultados de ensaios "Push-out" descritos no item 2.3.

\section{5 - LOCAÇÃO E ESPAÇAMENTO DOS CONECTORES SEGUNDO} ALGUMAS NORMAS 
DAVIS (1967) apud HOUSAIN (1988), demonstrou por meio de ensaios "Push-out" que a locação e o espaçamento entre conectores tinham bastante influência na resistência ao cisalhamento. Por exemplo, a diminuição do espaçamento entre conectores resultava numa diminuição da resistência à ruptura, devido à superposição de sucessivas zonas de compressão triaxial.

Nesse sentido, as normas apresentam recomendações para vigas mistas quanto à locação e espaçamento dos conectores, para que as expressões dispostas no item 3.4 apresentem resultados representativos e aplicáveis à prática de projetos.

\section{- NBR 8800 (1986)}

a) Os conectores de cisalhamento, colocados de cada lado da seção de momento fletor máximo, podem ser uniformemente espaçados entre esta seção e as seções adjacentes de momento nulo, exceto nas regiões de momento fletor positivo situadas entre uma seção com força concentrada e uma seção adjacente de momento nulo (ambas situadas do mesmo lado, relativamente à seção de momento máximo). Nesse último caso, o número de conectores necessários não pode ser inferior a n'.

$n^{\prime}=n\left(\frac{M_{d}^{\prime}-\phi_{b} M_{a}}{M_{d}-\phi_{b} M_{a}}\right)$

onde

n é o número de conectores de cisalhamento colocados de cada lado da seção de momento fletor máximo e a seção de momento nulo adjacente;

$\mathrm{M}_{\mathrm{d}}$ é o momento fletor de cálculo no ponto de força concentrada (inferior ao momento máximo);

$\phi_{\mathrm{b}} \mathrm{M}_{\mathrm{a}}$ é a resistência de cálculo ao momento fletor da viga de aço isolada, baseada no estado limite FLA (flambagem local da alma);

$\mathrm{M}_{\mathrm{d}}$ é o momento fletor máximo de cálculo.

A expressão 3.13 objetiva distribuir os conectores de cisalhamento entre as seções de momentos máximo e nulo, de modo que o trecho entre o ponto de aplicação da força concentrada e o ponto de momento nulo contenha uma parcela de "n" proporcional a intensidade do momento provocado pela força concentrada. 
Vale ressaltar que essa verificação faz-se desnecessária caso se tenha $\phi_{\mathrm{b}} \mathrm{M}_{\mathrm{a}}$ maior ou igual à $\mathrm{M}_{\mathrm{d}}^{\prime}$.

b) O espaçamento máximo entre linhas de centro de conectores (figura 3.9) deve ser igual a oito vezes a espessura total da laje, não sendo superior a $800 \mathrm{~mm}$ no caso de lajes com forma de aço incorporadas, com nervuras perpendiculares à viga.

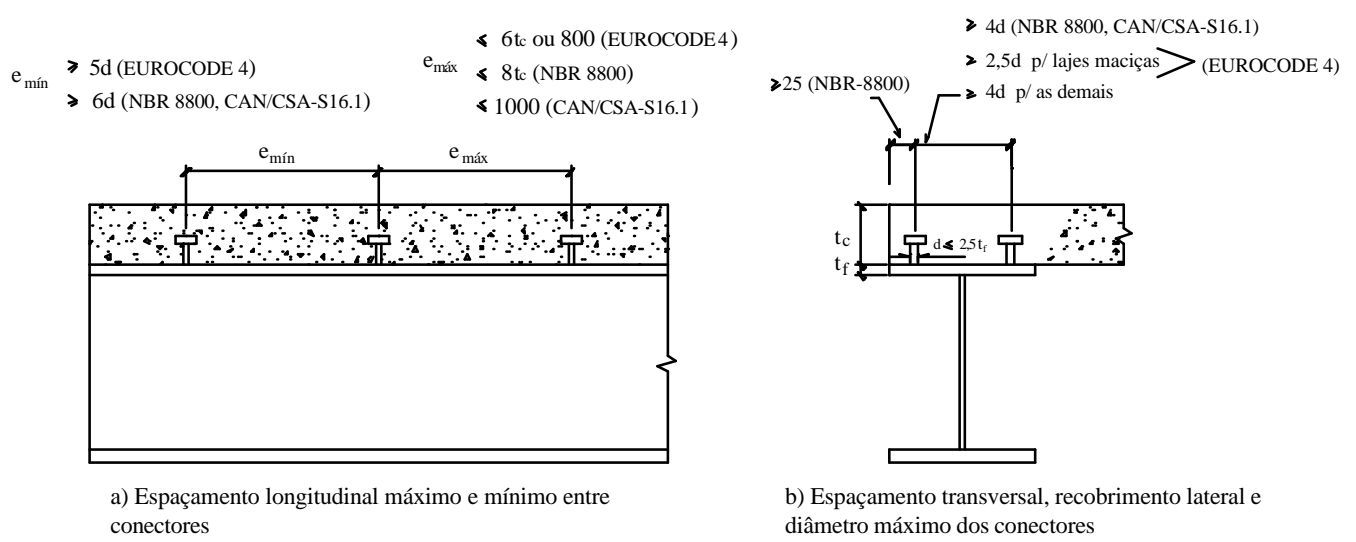

FIGURA 3.9: Comparação das recomendações das normas quanto à locação e espaçamento dos conectores

c) Os espaçamentos mínimos entre linhas de centro de conectores tipo pino com cabeça (stud) devem ser iguais a seis diâmetros ao longo do vão da viga e quatro diâmetros na direção transversal do mesmo vão.

d) Os conectores tipo pino com cabeça (stud) não podem ter diâmetros maiores que 2,5 vezes a espessura da mesa a qual são soldados, a menos que sejam colocados na posição coincidente com a alma da viga.

e) O recobrimento lateral de concreto para qualquer tipo de conector deve ser no mínimo igual a $25 \mathrm{~mm}$, excetuando-se o caso de conectores colocados em nervuras de fôrma de aço.

\section{- EUROCODE 4 (1994)}

a) O recobrimento mínimo sobre o conector deve ser maior ou igual que $20 \mathrm{~mm}$ ou o especificado pelo EUROCODE 2 (1991): "Design of concrete structures", para armaduras com diâmetro menor que $5 \mathrm{~mm}$. 
b) Quando a alma está comprimida e pertence a uma classe 3 ou 4 (mais esbelta), toma-se como hipótese que ela esteja na classe 1 ou 2 (menos esbelta) devido a ação dos conectores. Para isto, o espaçamento entre centros de conectores na direção da compressão não deve ser maior que:

$22 t \sqrt{\frac{235}{f_{y}}}$

quando a laje está em contato com a mesa da viga de aço em toda a direção longitudinal (por exemplo as lajes maciças).

$$
15 t \sqrt{\frac{235}{f_{y}}}
$$

quando a laje não está em contato com a mesa da viga de aço em toda a direção longitudinal (por exemplo as lajes com suas nervuras dispostas na direção transversal a viga).

Além disso, a distância mínima entre a borda da alma comprimida e a linha mais próxima de conectores não deve ser maior que:

$9 t \sqrt{\frac{235}{f_{y}}}$

onde

t é a espessura da alma;

$f_{y}$ é a tensão de escoamento do aço.

c) O espaçamento máximo entre linhas de centro de conectores deve ser igual a seis vezes a espessura total da laje, não sendo superior à $800 \mathrm{~mm}$.

d) Os conectores tipo pino com cabeça (stud) não podem ter diâmetros maiores que 2,5 vezes a espessura da mesa à qual forem soldados, a menos que sejam colocados na posição correspondente à alma da viga. 
e) O espaçamento mínimo entre linhas de centro deve ser igual a cinco diâmetros ao longo do vão; na direção transversal igual 2,5 vezes o diâmetro do pino no caso de lajes maciças e quatro vezes o diâmetro do pino nos demais casos.

\section{- CAN/CSA-S16. 1 (1994)}

a) O espaçamento longitudinal de conectores tipo pino com cabeça (stud) para ambos os tipos de lajes (maciças e com forma de aço incorporado com nervuras paralelas à viga), não deve ser inferior a seis vezes o diâmetro do pino do conector e não superior a 1000mm.

b) O espaçamento transversal para conectores do tipo pino com cabeça (stud) não deve ser menor que quatro vezes o diâmetro do pino.

c) O item (a) da NBR-8800 (1986) também é válido para a norma canadense. 


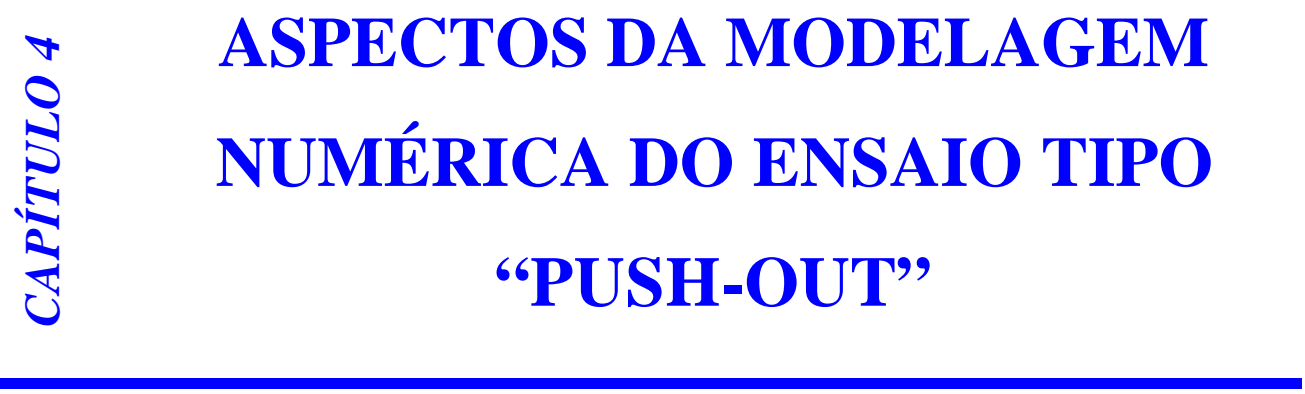

\section{1 - CONSIDERAÇÕES INICIAIS}

A complexidade da análise multiaxial, nos campos das tensões e das deformações, pode dificultar na maioria das vezes a elaboração de formulações analíticas referentes ao ensaio "Push-out", provável razão pela qual quase sempre têm sido propostas expressões empíricas que representam o comportamento dos conectores de cisalhamento. Com a evolução dos micro-computadores e dos códigos de cálculo, a análise multiaxial para as estruturas de um modo geral deixa de ser um problema.

Alguns trabalhos, como por exemplo, KALFAS et al.(1997) e OGUEIJIOFOR \& HOUSAIN (1997), propõem modelos numéricos simulando o ensaio tipo "Push-out" para avaliar o comportamento dos conectores de cisalhamento. Esses modelos numéricos, de um modo geral, representam de forma satisfatória a relação entre força aplicada no modelo e deslocamento relativo entre a mesa de aço e a laje de concreto. Porém, a simplificação assumida quando da utilização de elementos bidimensionais e uniaxiais para o perfil metálico e para o conector, respectivamente, podem não avaliar de forma satisfatória alguns parâmetros, como por exemplo, a concentração das tensões e das deformações.

Desta forma, é proposto no presente trabalho um modelo numérico tridimensional baseado no modelo para o ensaio experimental "Push-out", recomendado pelo EUROCODE 4 (figura 3.1, do capítulo 3), cuja simulação numérica é realizada por meio da utilização do código de cálculo ANSYS, versão 5.7, o qual foi elaborado com base no Método dos Elementos Finitos.

Pelo fato de o modelo para o ensaio experimental "Push-out" possuir simetria, tanto com referência à sua geometria, bem como com referência ao modo de 
aplicação da solicitação, adotou-se apenas metade do modelo experimental para construir o modelo numérico, conforme ilustra a figura 4.1.

A escolha pela modelagem de apenas metade do modelo experimental, ao invés de um quarto do mesmo modelo, foi feita com vistas a se ter inicialmente maior simplificação das condições de contorno que garantem uma resposta compatível com o comportamento global do modelo, bem como com vistas a uma análise mais significativa da região do conector.

Para simular modelos experimentais com o eixo do conector coincidente com o correspondente eixo da alma do perfil, utilizando apenas um quarto do modelo global, haveria a necessidade de dividir o conector pela metade, fato que poderia eventualmente dificultar a análise na região do conector, bem como provocar eventuais complicações quando do processamento, como conseqüência do seccionamento dos elementos de contato, os quais serão devidamente descritos a seguir no item 4.2.1.4.

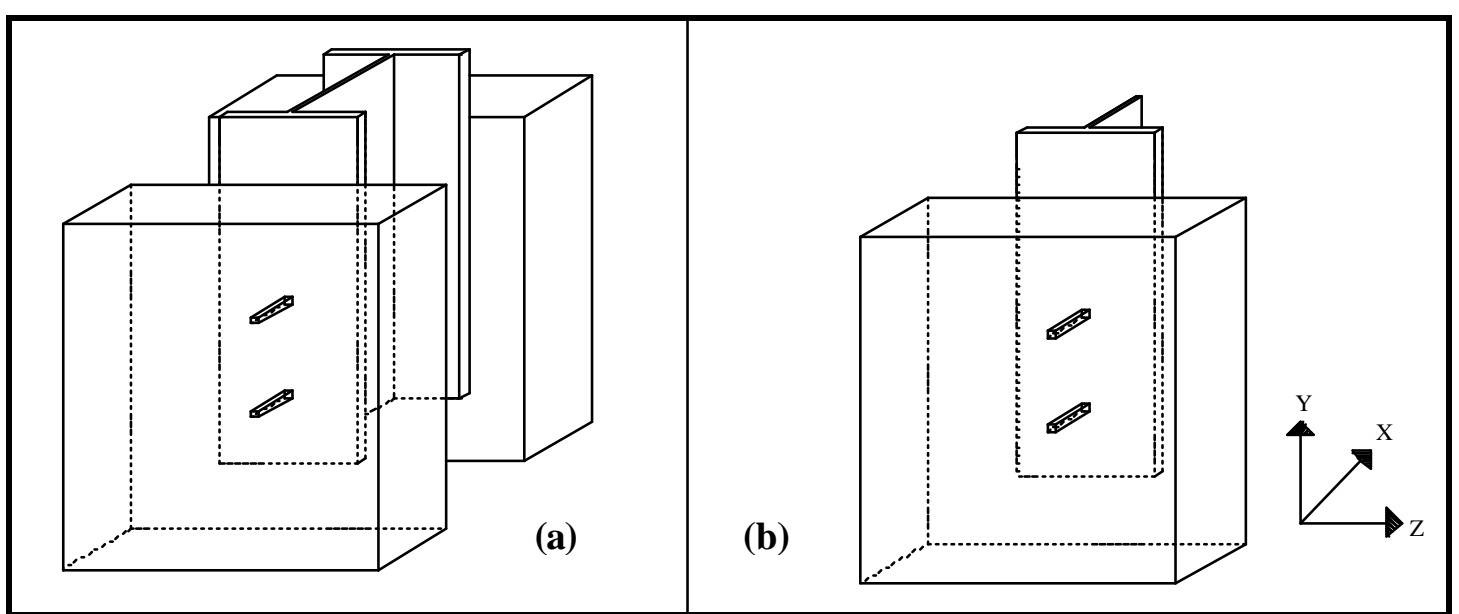

FIGURA 4.1: a) modelo típico para o ensaio experimental "Push-out".

b) modelo utilizado para a simulação numérica.

\section{2 - MÉTODO ADOTADO PARA OS MODELOS NUMÉRICOS PROPOSTOS}

A elaboração dos modelos numéricos consiste basicamente de algumas etapas, as quais serão enumeradas a seguir. É importante ressaltar que cada etapa depende do sucesso da etapa anterior.

I. Definição das dimensões geométricas do modelo;

II. Escolha dos tipos de elementos finitos a serem adotados; 
III. Definição das propriedades físicas dos materiais;

IV. Definição da malha de elementos finitos a ser adotada;

V. Discretização da geometria do modelo;

VI. Definição das condições de contorno e de solicitação;

VII. Escolha dos parâmetros para efetuar o processamento, como por exemplo, número de incrementos, número máximo de iterações e critério de convergência;

VIII. Processamento.

\subsection{1-ELEMENTOS FINITOS ADOTADOS PARA OS MODELOS PROPOSTOS}

Os modelos numéricos propostos foram elaborados a partir de quatro tipos de elementos finitos disponibilizados na biblioteca interna do código de cálculo ANSYS, os quais são apresentados a seguir. É importante observar que todos os elementos adotados têm apenas três graus de liberdade, referentes às translações segundo as coordenadas $\mathrm{x}, \mathrm{y} \mathrm{e} \mathrm{z}$, indicadas nas figuras a seguir, uma vez que não há o interesse imediato na quantificação da rotação dos elementos.

\subsubsection{1-ELEMENTO SOLID 65}

O elemento concreto armado tridimensional SOLID 65 é utilizado para a discretização da laje de concreto. Este elemento é constituído por oito nós (figura 4.2), em que cada nó possui três graus de liberdade, no caso, translações em x, y e z.

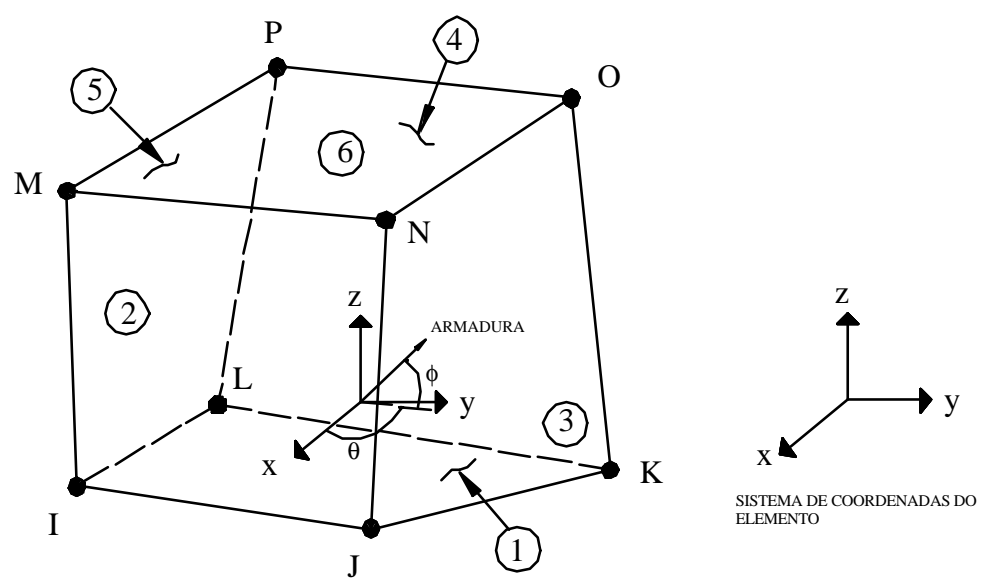

FIGURA 4.2: Elemento finito tipo SOLID 65 
O SOLID 65 permite simular fissuração na tração (nas três direções ortogonais) e esmagamento na compressão, bem como um comportamento com nãolinearidade física, o que permite avaliar, caso seja de interesse do usuário, deformações plásticas.

Possibilita também a inclusão das barras de armadura na forma de taxas, denominada armadura dispersa, as quais são resistentes apenas esforços de tração e de compressão. Essas barras de armadura são dispostas no elemento em concordância com o sistema de coordenadas ilustrado na figura 4.2, ou seja, rotacionadas de um ângulo $\phi$ em relação ao plano xy, bem como de um ângulo $\theta$ em relação ao eixo x do elemento.

No entanto, caso seja de interesse, o elemento SOLID 65 permite ainda a introdução de as mesmas barras de armadura na forma discreta, procedimento esse adotado para os modelos numéricos do presente trabalho e que será apresentada no item 4.2.3.

\subsubsection{2 - ELEMENTO SOLID 45}

Utiliza-se o elemento sólido estrutural tridimensional SOLID 45 (figura 4.3) objetivando simular o comportamento do perfil metálico e dos conectores de cisalhamento. Análogo ao mencionado para o SOLID 65, o SOLID 45 também possui oito nós, sendo cada nó com três graus de liberdade, referentes às translações segundo x, y e z. O SOLID 45 também permite considerar a plasticidade, bem como a ortotropia do material.
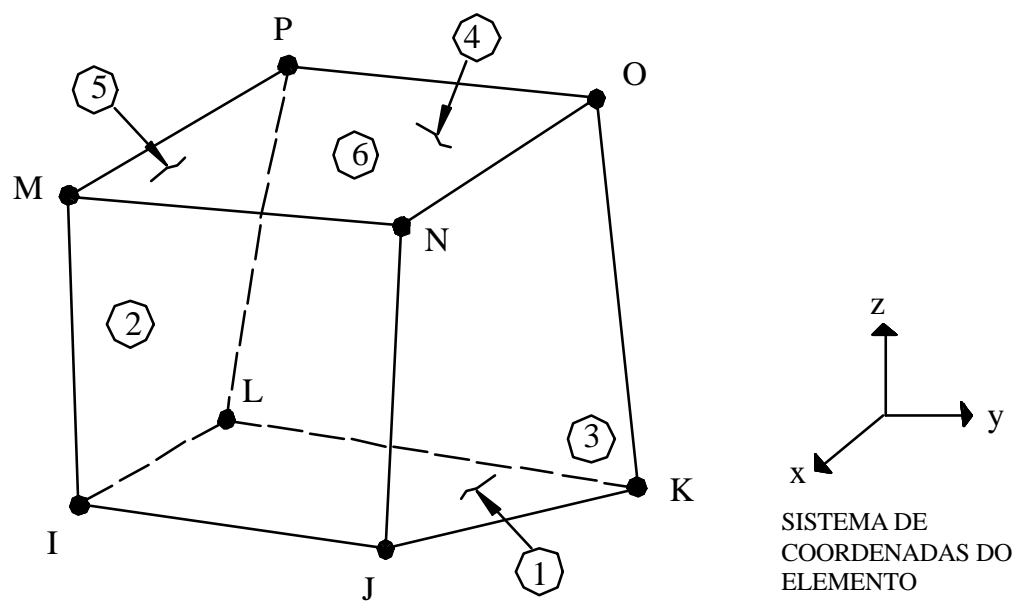

FIGURA 4.3: Elemento finito tipo SOLID 45 


\subsubsection{3 - ELEMENTO LINK 8}

As barras de armaduras dispostas na laje de concreto são discretizadas com o elemento barra tridimensional LINK 8, o qual é constituído por dois nós (I e J), um em cada extremidade, em que cada nó possui três graus de liberdade, referentes às translações segundo x, y e z. Como ilustrado na figura 4.4, o eixo x do elemento é orientado ao longo do comprimento do elemento em questão.

Vale ressaltar que o elemento em questão não permite a consideração de esforços de flexão. No entanto, o mesmo elemento disponibiliza ao usuário a possibilidade de se admitir a ocorrência de deformação plástica.

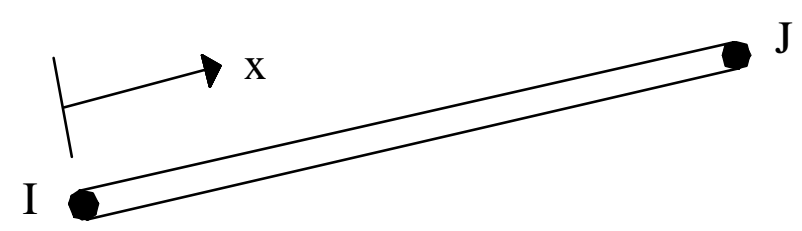

FIGURA 4.4: Elemento finito tipo LINK 8

\subsubsection{4 - TARGE 170 E CONTAC 173}

São definidos pelo ANSYS como elemento de contato, os quais possuem três graus de liberdade em cada nó, com translações segundo x, y e z. Ambos trabalham associados para dar origem a uma nova ferramenta numérica denominada par de contato.

Ambos os elementos representam o modelo de contato definido pelo ANSYS como superfície-superfície, bem como possuem propriedades físicas idênticas e são utilizados para o caso tridimensional.

O elemento TARGE 170 é definido para a superfície alvo e o elemento CONTAC 173 para a superfície de contato, conforme instruções impostas pelo ANSYS. Essas duas superfícies precisam ser estabelecidas pelo usuário, em que a superfície alvo será aquela mais rígida e a superfície de contato a mais deformável.

Para o caso particular do modelo numérico proposto, os elementos de contato são utilizados apenas na interface conector-laje. As faces do elemento de concreto na interface laje e conector de cisalhamento foram considerados como superfície alvo, enquanto que as faces do elemento do conector foram consideradas como superfície de contato. Essas duas superfícies são caracterizadas como deformáveldeformável. 
Para se estabelecer uma rigidez entre as duas superfícies (alvo e contato) é necessário informar ao ANSYS um fator de rigidez normal de contato $(\mathrm{FKN})$. Este fator controla a intensidade de penetração e de afastamento entre as duas superfícies, razão pela qual tem grande influência na convergência durante o processamento do modelo. O FKN pode variar dependendo do tamanho do elemento finito, ou seja, modelos mais refinados podem ter FKN diferente de modelos menos refinados.

\subsection{2 - CRITÉRIOS GERAIS ADOTADOS NOS MODELOS NUMÉRICOS}

Como mencionado anteriormente foi modelada apenas metade do modelo experimental tipo "Push-out" (figura 4.1), devido às simetrias de geometria e solicitação, tendo como aspecto de grande importância os benefícios decorrentes da minimização do esforço computacional, no caso, o tempo de processamento dos modelos.

Os dois tipos de conectores simulados numericamente são os tipos pino com cabeça (stud) e o perfil "U" formado a frio. Para ambos os conectores, os procedimentos adotados para a modelagem são os mesmos. A tabela 4.1 apresenta os modelos numéricos com seus respectivos tipos de conectores. Vale ressaltar que os tipos de posições apresentados na tabela 4.1 têm correspondência com aqueles apresentados na figura 3.6, do capítulo 3.

TABELA 4.1: Detalhe das características dos modelos numéricos

\begin{tabular}{|c|c|c|c|}
\hline MODELO & $\begin{array}{c}\text { TIPO DE } \\
\text { CONECTOR }\end{array}$ & $\begin{array}{c}\text { DIAMETRO } \\
\text { DO } \\
\text { CONECTOR }\end{array}$ & $\begin{array}{c}\text { ALTURA DO } \\
\text { CONECTOR }\end{array}$ \\
\hline PHS-1 & Stud & $13 \mathrm{~mm}$ & $75 \mathrm{~mm}$ \\
\hline PHS-2 & Stud & $19 \mathrm{~mm}$ & $75 \mathrm{~mm}$ \\
\hline MODELO & $\begin{array}{c}\text { TIPODE } \\
\text { CONECTOR }\end{array}$ & $\begin{array}{c}\text { ESPESSURA } \\
\text { DO } \\
\text { CONECTOR }\end{array}$ & TIPO DE POSIÇAO \\
\hline PHU-EI & Perfil "U" & $2,66 \mathrm{~mm}$ & I \\
\hline PHU-EII & Perfil "U" & $2,66 \mathrm{~mm}$ & II \\
\hline PHU-FI & Perfil "U" & $4,76 \mathrm{~mm}$ & II \\
\hline PHU-FII & Perfil "U" & $4,76 \mathrm{~mm}$ & \\
\hline
\end{tabular}




\subsubsection{1 - DEFINIÇÃO DA MALHA DE ELEMENTOS FINITOS}

Os modelos elaborados com vistas à análise numérica são constituídos por componentes que definem a laje de concreto, a armadura, os conectores de cisalhamento e o perfil metálico. Como foram elaborados seis modelos diferentes, serão apresentadas nos itens que seguem as malhas dos componentes citados, porém, apenas de alguns modelos. Além disso, será mostrada a malha dos elementos de contato para os conectores tipos pino com cabeça (stud) e perfil "U" formado a frio.

- LAJE DE CONCRETO

A malha, de elementos finitos, referente à laje de concreto para o modelo PHU-EI é apresentada na figura 4.5.

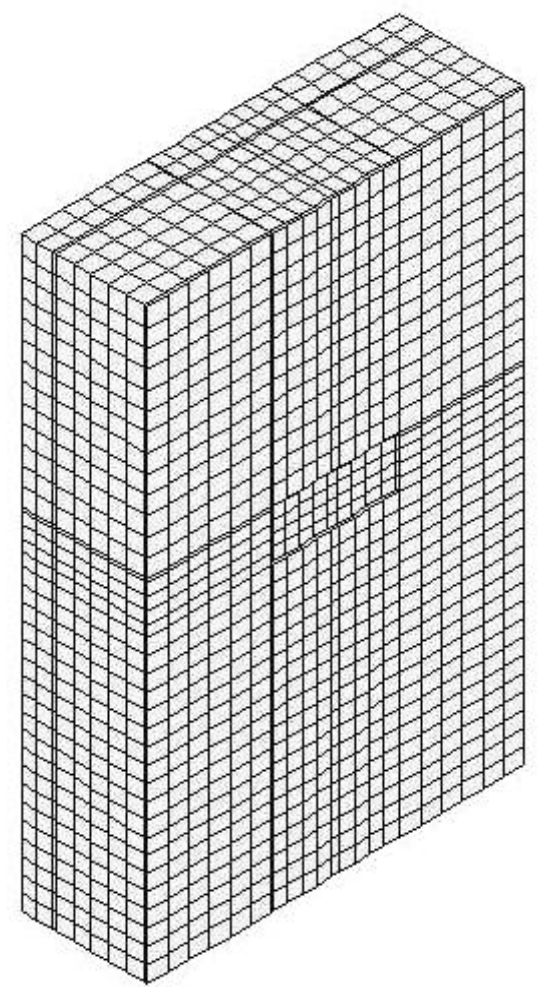

FIGURA 4.5: Malha de elementos finitos para a laje de concreto referente ao modelo PHU-EI

Nessa mesma figura, pode-se notar que a discretização da laje de concreto na região circundante aos conectores de cisalhamento passou por um processo de refinamento 
maior que as demais, por ser essa uma região com grande concentração de tensões, e conseqüentemente, com grande influência no comportamento do conector, bem como do modelo.

Os nós pertencentes à laje de concreto e à mesa do perfil metálico foram acoplados apenas na direção X, conforme ilustra a figura 4.6, objetivando minimizar a rotação da laje em torno do eixo $\mathrm{Z}$.
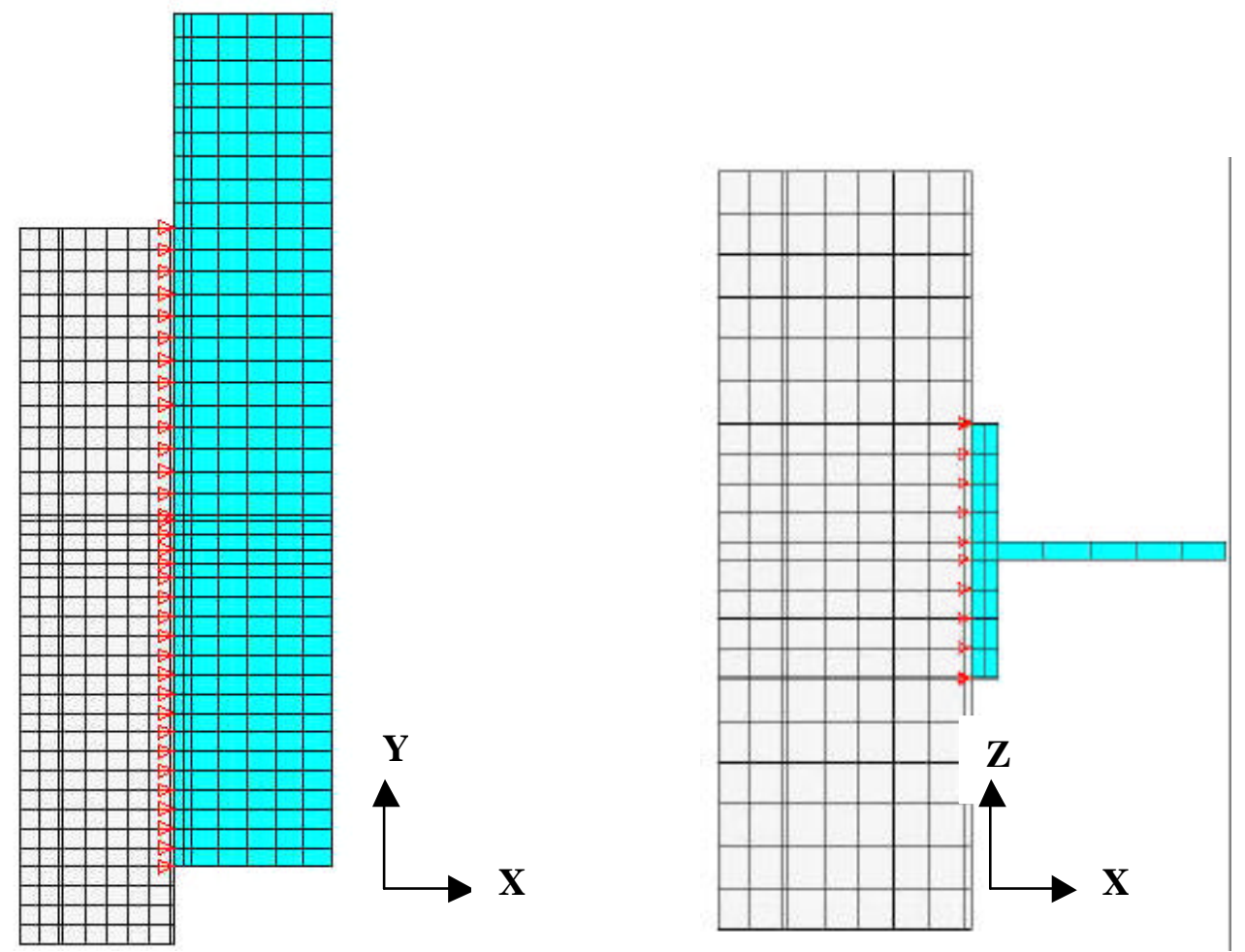

FIGURA 4.6: Detalhe dos acoplamentos dos nós entre a laje de concreto e o perfil metálico modelo PHU-EI

\section{- PERFIL METÁLICO E CONECTORES}

As discretizações das malhas de elementos finitos referentes aos conectores de cisalhamento e perfil metálico estão ilustradas nas figuras 4.7 e 4.8 .

Vale ressaltar que os nós na interseção entre conectores de cisalhamento e a mesa do perfil metálico pertencem aos dois componentes, já que o conector é soldado à mesa do perfil metálico, garantindo assim que os nós entre os elementos dos conectores e da mesa tenham deslocamentos iguais em todas as direções. 

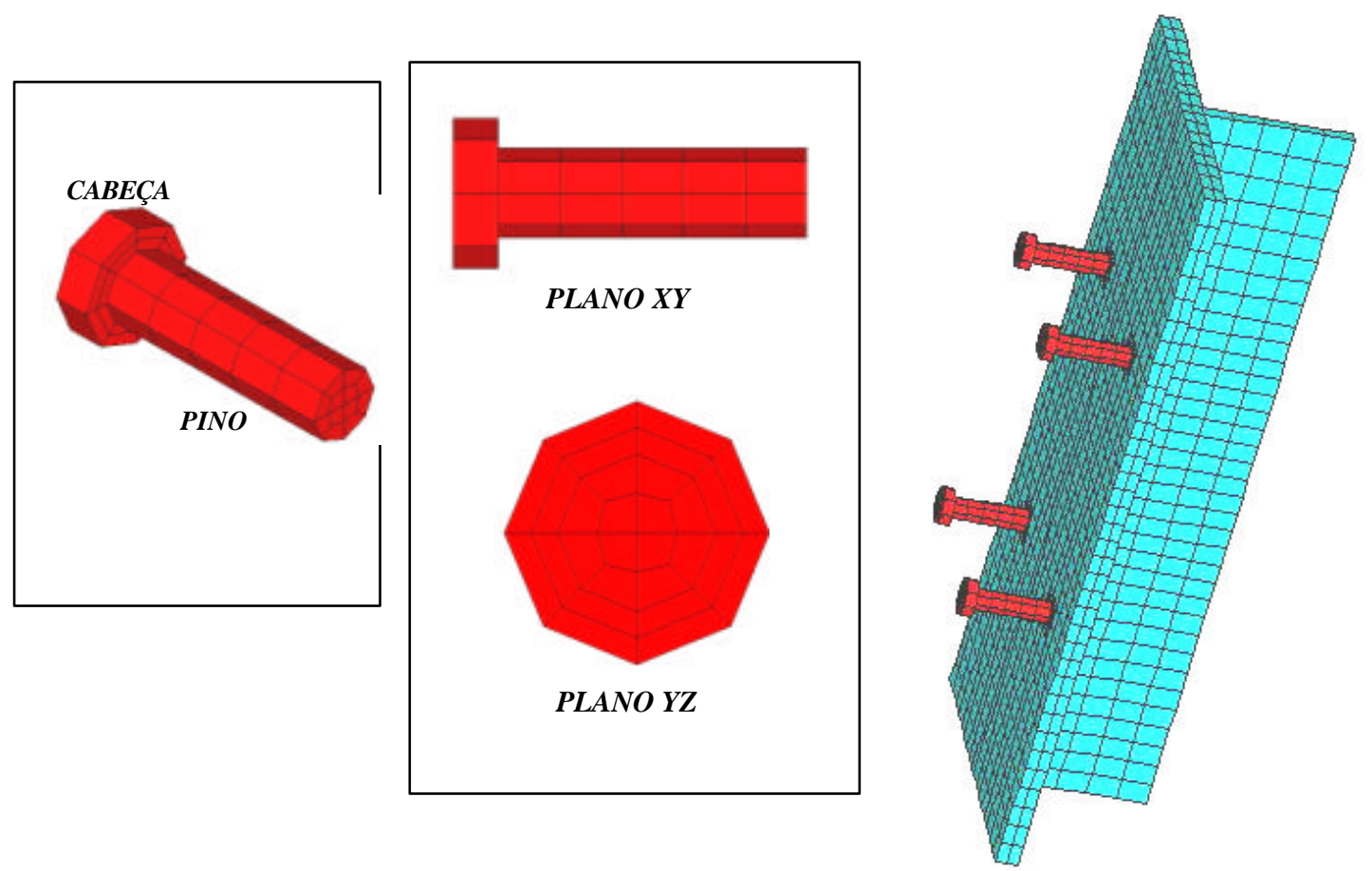

FIGURA 4.7: Malha referente ao perfil metálico e conector tipo pino com cabeça (stud) modelo PHS-2
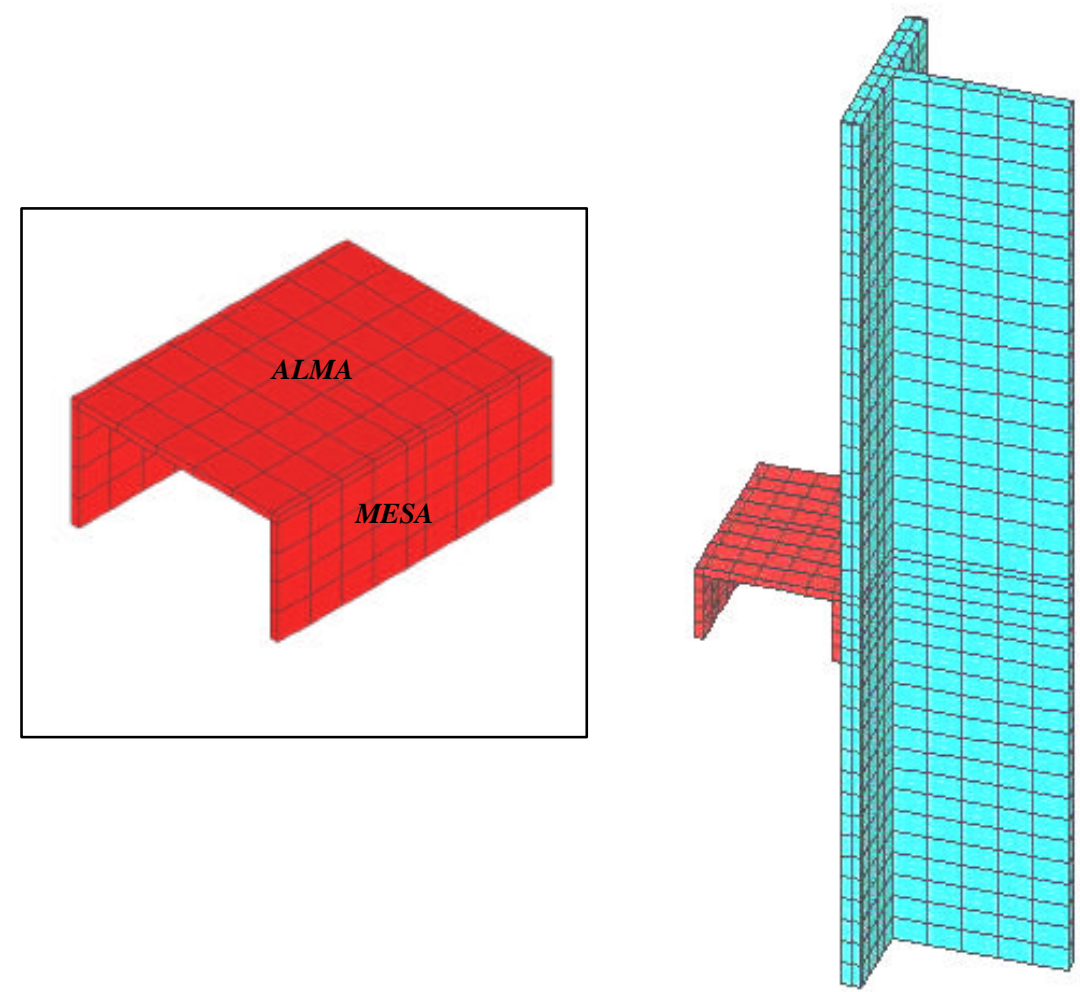

FIGURA 4.8: Malha referente ao perfil metálico e conector tipo perfil " $U$ " modelo PHU-FI 
- ARMADURA NA LAJE DE CONCRETO

A armadura foi discretizada de tal maneira que os nós que constituem seus elementos são os mesmos que constituem a malha da laje de concreto, nas posições coincidentes, reproduzindo assim a ligação necessária para a transferência de esforços do concreto para a armadura. A armadura é ilustrada na figura 4.9.

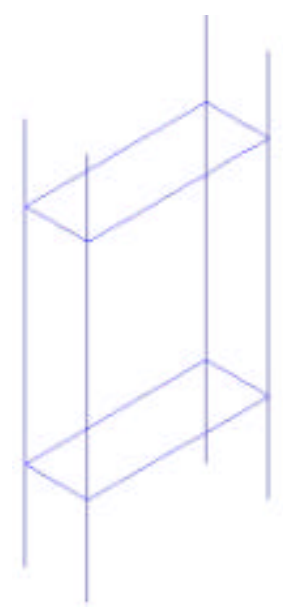

FIGURA 4.9: Detalhe da armadura na laje de concreto referente ao modelo PHU-FI

- ELEMENTOS DE CONTATO

Os elementos de contato foram introduzidos nos modelos nas interfaces entre os elementos dos conectores de cisalhamento e dos elementos da laje de concreto, como já mencionado no item 4.2.4, e são ilustrados nas figuras 4.10 e 4.11

Estes elementos permitem possíveis descolamentos entre o conector e a laje de concreto, fato que não ocorreria caso estes nós na interface pertencessem diretamente aos elementos do conector e da laje.

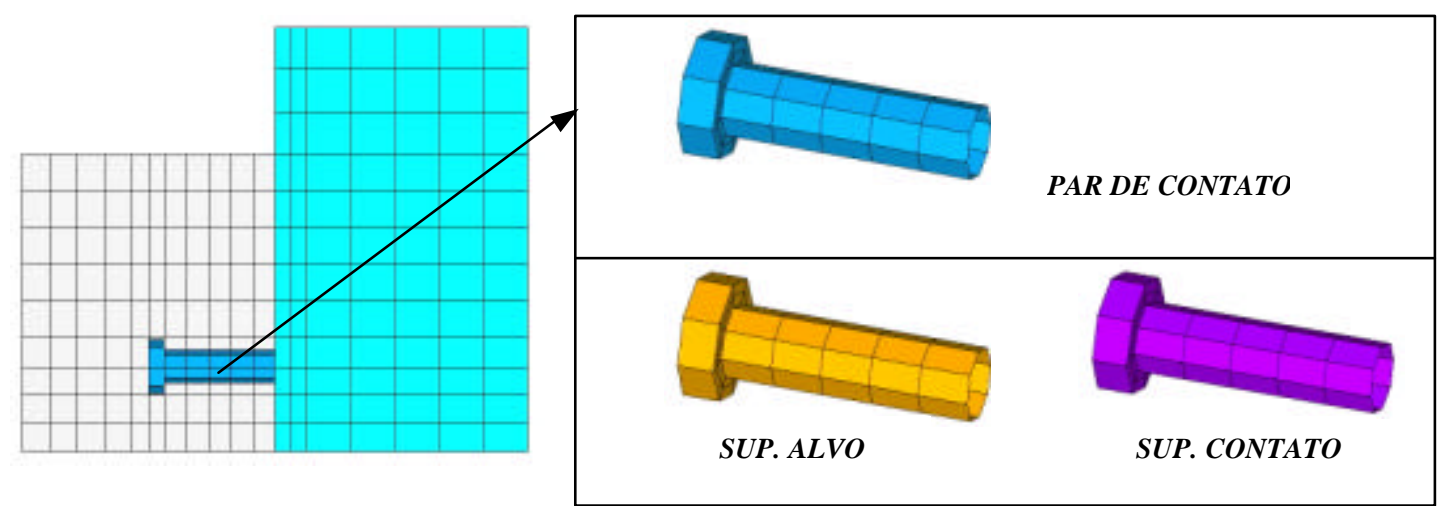

FIGURA 4.10: Detalhe dos elementos de contato para os conectores pino com cabeça (stud), modelo PHS-2 


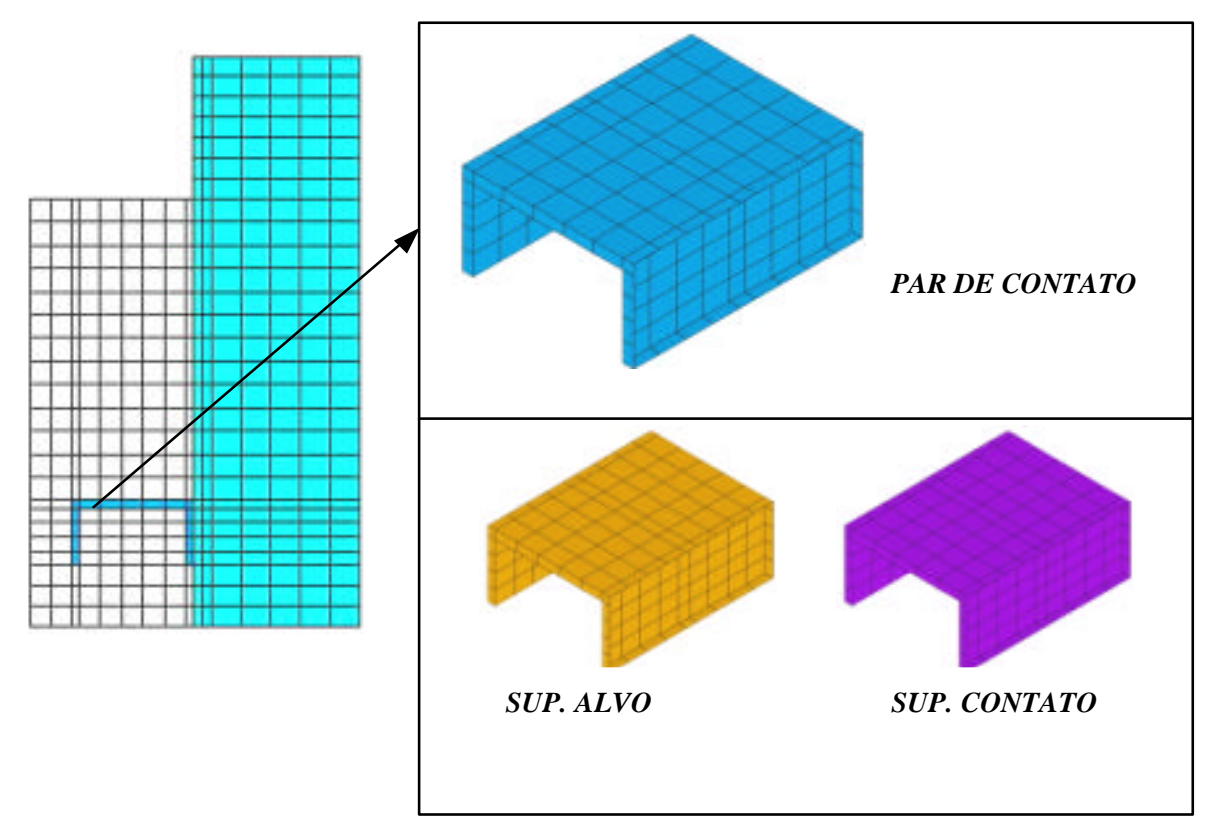

FIGURA 4.11: Detalhe dos elementos de contato para os conectores perfil " $U$ ", modelo PHU-FI

\subsubsection{2 - CONDIÇÕES DE CONTORNO ADOTADAS NO MODELO}

De acordo com a figura 4.12, a face inferior da laje de concreto é restringida nas três direções, no plano XY e também na direção normal a este plano, em concordância com o sistema global (figura 4.1), objetivando garantir a estabilidade do modelo, quando da aplicação das solicitações no perfil metálico.

Como o modelo numérico leva em conta apenas a metade do modelo experimental "Push-out", restringiu-se segundo a direção X o deslocamento da alma do perfil, em toda sua extensão (na vertical), objetivando garantir para o modelo ilustrado na figura 4.12, concordância com as condições de vinculação do modelo experimental.

\subsubsection{3 - CONSIDERAÇÕES NA APLICAÇÃO DA SOLICITAÇÃO}

Conforme ilustra a figura 4.13, aplica-se uma solicitação na face superior do perfil metálico, na forma de pressão, coerente com aquela identificada no ensaio experimental. A intensidade da pressão é definida por meio da relação entre a força de ruptura estimada e a área da seção transversal do perfil metálico. 

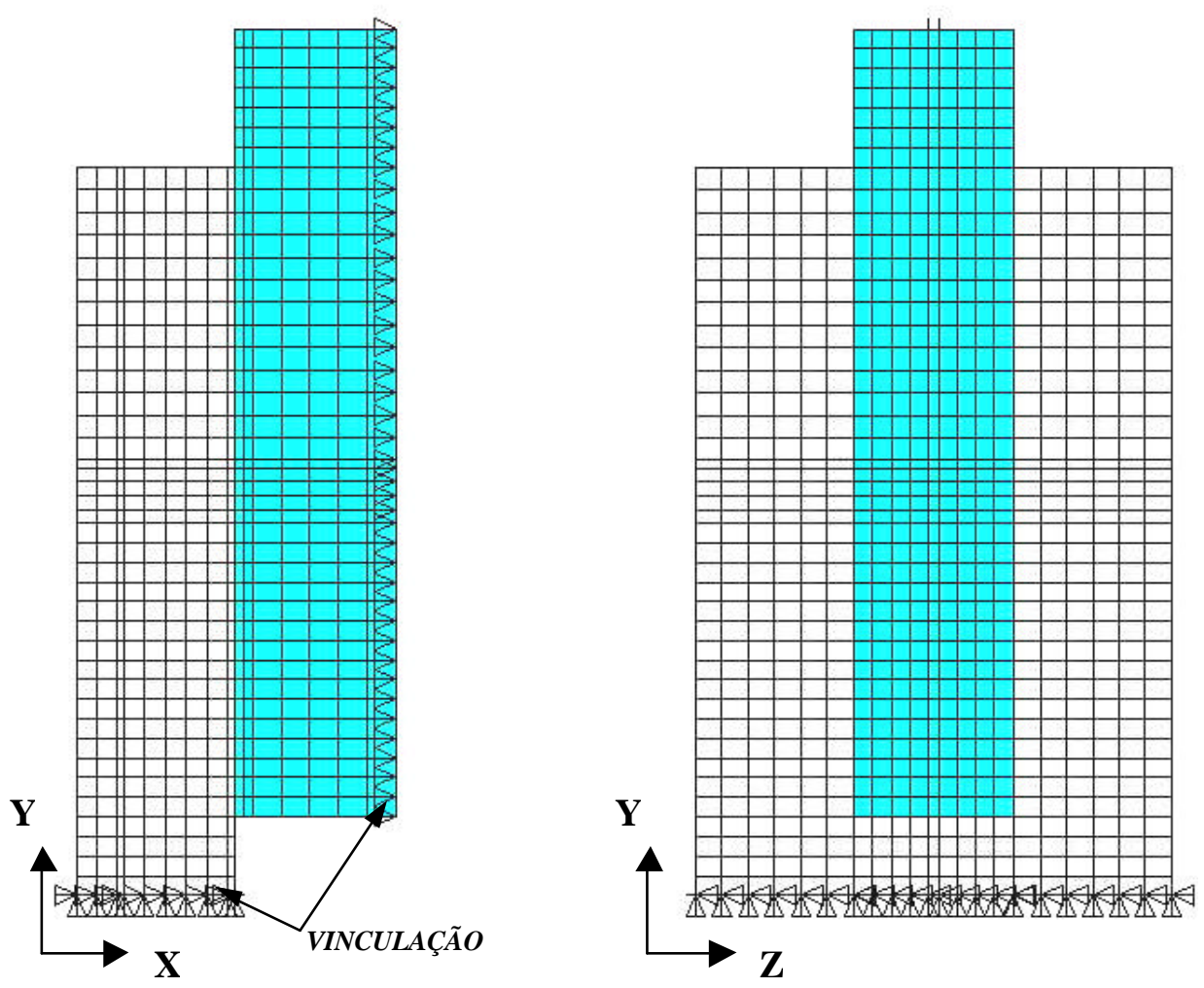

FIGURA 4.12: Condições de contorno, modelo PHU-FI

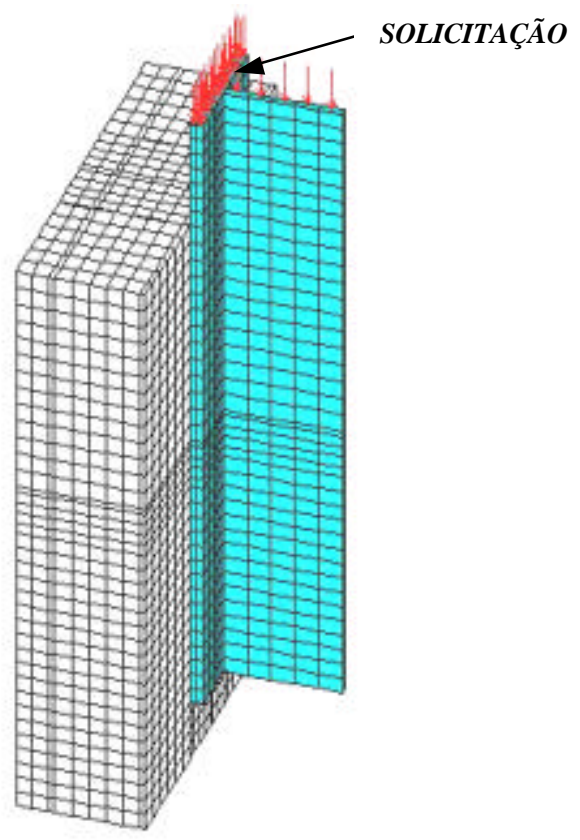

FIGURA 4.13: Aplicação da solicitação, modelo PHU-FI 


\subsection{3 - MODELOS COM NÃO-LINEARIDADE FÍSICA ADOTADOS PARA OS MATERIAIS AÇO E CONCRETO}

O código de cálculo ANSYS possibilita, por meio de alguns elementos finitos, a consideração da não-linearidade física dos materiais, com base em alguns critérios de resistência. Nos modelos numéricos estudados, para o aço do conector e do perfil metálico adota-se o comportamento elasto-plástico multilinear com encruamento isótropo. Já para o aço da armadura, considera-se o comportamento elasto-plástico perfeito.

Para o concreto, adotam-se o modelo concreto e o modelo elástico não-linear. Nos modelos com conector tipo pino com cabeça (stud) adota-se o modelo concreto praticamente em toda laje, exceto nos elementos finitos sujeitos às vinculações de base do modelo (figura 4.12), em que se utiliza o modelo elástico não-linear, já que nesses elementos o modelo concreto não apresenta bom comportamento, quando do processamento numérico.

Por outro lado, para os modelos com conector tipo perfil " $U$ " formado a frio utiliza-se o modelo concreto nas regiões da laje próximas aos conectores, constituídas por faixas, e submetidas a tensões de compressão e de tração, consideradas elevadas quando comparadas às correspondentes resistências.

Em contrapartida, nas regiões da laje onde as tensões não são elevadas adotase o modelo elástico não-linear, desde que as tensões de tração, quando verificadas, resultem próximas da resistência à tração do concreto $\left(\mathrm{f}_{\mathrm{t}}\right)$. Essa verificação deve-se ao fato de $o$ modelo elástico não-linear adotar para esforços de tração o mesmo comportamento $(\sigma \times \varepsilon)$ adotado para esforços de compressão e, portanto, inconsistente com o comportamento real do concreto verificado experimentalmente. As regiões da laje em que foram adotados modelos de não-linearidade serão destacadas no capítulo 5, para cada modelo numérico.

\subsubsection{1 - COMPORTAMENTO ELASTO-PLÁSTICO PERFEITO ADOTADO PARA O AÇO DA ARMADURA}

O comportamento elasto-plástico perfeito adotado para a armadura é associado ao critério de Von Mises, com base na comparação entre a tensão equivalente de Mises $\left(\sigma_{\mathrm{e}}\right)$ e uma tensão de plastificação, no caso, a tensão de escoamento do aço $\left(\mathrm{f}_{\mathrm{y}}\right)$. Quando a tensão equivalente $\left(\sigma_{\mathrm{e}}\right)$ for menor que a tensão de escoamento $\left(\mathrm{f}_{\mathrm{y}}\right)$, o comportamento do material terá correspondência com o trecho elástico-linear da relação tensão-deformação (figura 4.14). No caso da tensão equivalente ser maior ou igual a tensão 
de escoamento, o material desenvolverá deformações plásticas. O comportamento plástico adotado está representado pela relação tensão-deformação ilustrada na figura 4.14.

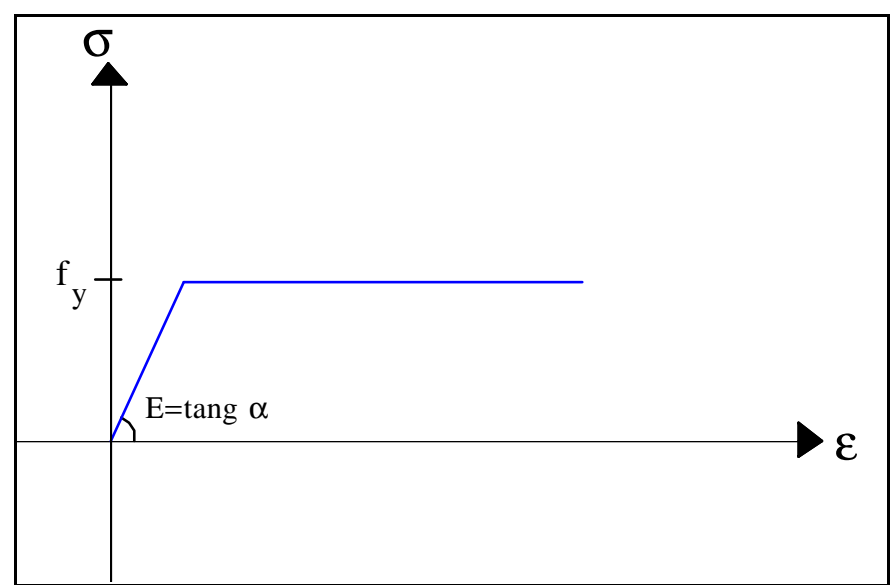

FIGURA 4.14: Representação gráfica do comportamento elasto-plástico perfeito

Para definição da relação tensão-deformação no ANSYS, o usuário deve informar como dados de entrada a tensão de escoamento $\left(\mathrm{f}_{\mathrm{y}}\right)$, bem como o módulo plástico do material $\left(\mathrm{E}_{\mathrm{p}}\right)$ após ser atingido $\mathrm{f}_{\mathrm{y}}$. Como se trata de um comportamento elasto-plástico perfeito, ao atingir a tensão de escoamento, o material não permitirá mais o acréscimo de tensão, devendo-se, nesse caso, considerar o módulo plástico $\left(\mathrm{E}_{\mathrm{p}}\right)$ nulo.

\subsubsection{2 - COMPORTAMENTO ELASTO-PLÁSTICO MULTILINEAR COM ENCRUAMENTO ISÓTROPO PARA O AÇO DO CONECTOR E DO PERFIL}

O comportamento adotado para os conectores e o perfil também é associado ao critério de Von Mises, para a qual adotam-se quatro retas que objetivam simular o comportamento do aço.

Ao contrário do comportamento elásto-plástico perfeito, quando a tensão $\left(\sigma_{\mathrm{e}}\right)$ atinge $0,7 f_{y}$, o aço desenvolve deformações plásticas e permite o acréscimo de tensões até a tensão $\sigma_{\mathrm{d}}$, a qual corresponde a resistência última do aço $\left(\mathrm{f}_{\mathrm{u}}\right)$.

Vale lembrar, apenas em caráter complementar, que no encruamento isótropo, sempre que violado o limite elástico atual do material, ocorrerá uma expansão do domínio elástico sem mudança na origem do sistema $\sigma \times \varepsilon$, dando origem a novos valores para os limites elásticos. 
No ANSYS, para definição da relação entre tensão e deformação referente ao comportamento em questão, é necessário informar pontos definidos por pares de tensão e deformação, como ilustra a figura 4.15.

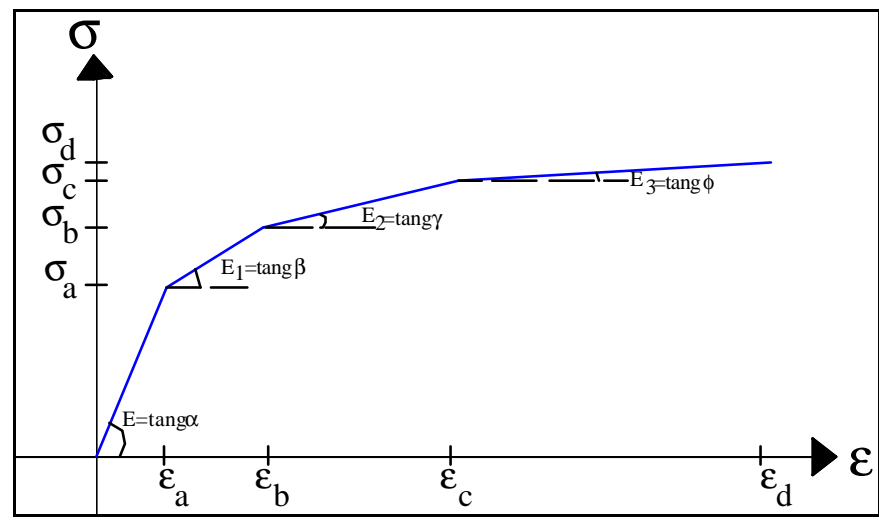

\begin{tabular}{|c|c|c|}
\hline PONTOS & $\sigma$ & $\varepsilon$ \\
\hline$a$ & $0,7 \mathrm{f}_{\mathrm{y}}$ & $0,7 \mathrm{f}_{\mathrm{y}} / \mathrm{E}$ \\
\hline $\mathrm{b}$ & $\mathrm{f}_{\mathrm{y}}$ & $\varepsilon_{\mathrm{a}}+\frac{\mathrm{f}_{\mathrm{y}}-0,7 \mathrm{f}_{\mathrm{y}}}{\mathrm{E}_{1}}$ \\
\hline $\mathrm{c}$ & $\mathrm{f}_{\mathrm{u}}$ & $\varepsilon_{\mathrm{b}}+\frac{\mathrm{f}_{\mathrm{u}}-\mathrm{f}_{\mathrm{y}}}{\mathrm{E}_{2}}$ \\
\hline $\mathrm{d}$ & $\mathrm{f}_{\mathrm{u}}$ & 1 \\
\hline
\end{tabular}

FIGURA 4.15: Comportamento elasto-plástico multilinear com encruamento isótropo

\subsubsection{3 -COMPORTAMENTO NÃO-LINEAR DO MODELO CONCRETO}

Para a discretização da laje de concreto utiliza-se o modelo concreto, disponibilizado pelo ANSYS, o qual representa o comportamento de materiais frágeis. Este modelo é disponibilizado somente quando se adota o elemento o SOLID 65, o qual é capaz de simular o esmagamento na compressão e a fissuração na tração. O modelo concreto tem como base o critério de ruptura para o estado de tensão multiaxial de tensões, proposto por "Willam-Warnke", expresso na forma:

$$
\frac{\mathrm{F}}{\mathrm{f}_{\mathrm{c}}}-\mathrm{S} \geq 0
$$

sendo

$\mathrm{F}$ uma função do estado de tensões principais $\left(\sigma_{\mathrm{xp}}, \sigma_{\mathrm{yp}}\right.$ e $\left.\sigma_{\mathrm{zp}}\right)$;

$\mathrm{S}$ é a superfície de ruptura expresso em termos das tensões principais e dos parâmetros $\mathrm{f}_{\mathrm{t}}, \mathrm{f}_{\mathrm{c}}, \mathrm{f}_{\mathrm{cb}}, \mathrm{f}_{1}$ e $\mathrm{f}_{2}$, descritos na tabela 4.2 ;

$\mathrm{f}_{\mathrm{c}}$ é a resistência uniaxial à compressão do concreto.

Caso a expressão 4.1 não seja satisfeita, o material terá comportamento elástico-linear. Por outro lado, se a expressão 4.1 for satisfeita, o material vai fissurar se 
qualquer tensão principal for de tração, ou esmagar se qualquer tensão principal for de compressão.

TABELA 4.2: Parâmetros do Modelo Concreto, de acordo com o manual do ANSYS

\begin{tabular}{|c|}
\hline DESCRIÇÃO DOS PARÂMETROS \\
\hline Coeficiente de transferência de cisalhamento para fissura aberta \\
\hline Coeficiente de transferência de cisalhamento para fissura fechada \\
\hline Resistência uniaxial à tração do material $\left(\mathrm{f}_{\mathrm{t}}\right)$ \\
\hline Resistência uniaxial à compressão do material $\left(\mathrm{f}_{\mathrm{c}}\right)$ \\
\hline Resistência biaxial à compressão do material $\left(\mathrm{f}_{\mathrm{cb}}\right)$ \\
\hline Estado de tensão hidrostática ambiente $\left(\sigma_{\mathrm{h}}{ }^{\mathrm{a}}\right)$ \\
\hline Resistência ultima a compressão para o estado biaxial de compressão superposta ao estado \\
de tensão hidrostático ambiente $\left(\mathrm{f}_{1}\right)$ \\
\hline Resistência ultima a compressão para o estado uniaxial de compressão superposta ao estado \\
de tensão hidrostático ambiente $\left(\mathrm{f}_{2}\right)$ \\
\hline Coeficiente para o amolecimento do material fissurado na tração
\end{tabular}

Adotou-se para os modelos numéricos propostos um $\sigma_{\mathrm{h}}{ }^{\mathrm{a}}$ igual a $10^{-10}$, objetivando calibrar os meridianos de tração e compressão, pertencentes à superfície de ruptura do critério em questão, para a obtenção de uma convergência satisfatória quando dos processamentos modelos numéricos.

Vale ressaltar que para valores maiores que $10^{-10}$ não foi possível a obtenção de convergência. Além disso, pela falta de ensaios experimentais específicos para o concreto, todos os parâmetros $\mathrm{f}_{\mathrm{cb}}, \mathrm{f}_{1}$ e $\mathrm{f}_{2}$ foram tomados como padrão, em concordância com expressões sugeridas pelo manual do ANSYS.

Detalhes com relação ao critério de ruptura de "Willam-Warnke" associado ao modelo concreto, em especial, com relação aos parâmetros envolvidos nas expressões que definem a superfície de ruptura, estão apresentados no apêndice I. 


\subsubsection{4 - MODELO DE COMPORTAMENTO ELÁSTICO NÃO-LINEAR}

O modelo de comportamento não-linear, também adotado para discretização da laje de concreto, permite a consideração de uma relação clássica não-linear entre tensão e deformação. Para os modelos numéricos propostos foi adotada a relação entre tensão e deformação na compressão, referente ao comportamento do concreto, ilustrada na figura 4.16, e de acordo com a prescrição do CEB-FIP (1991).

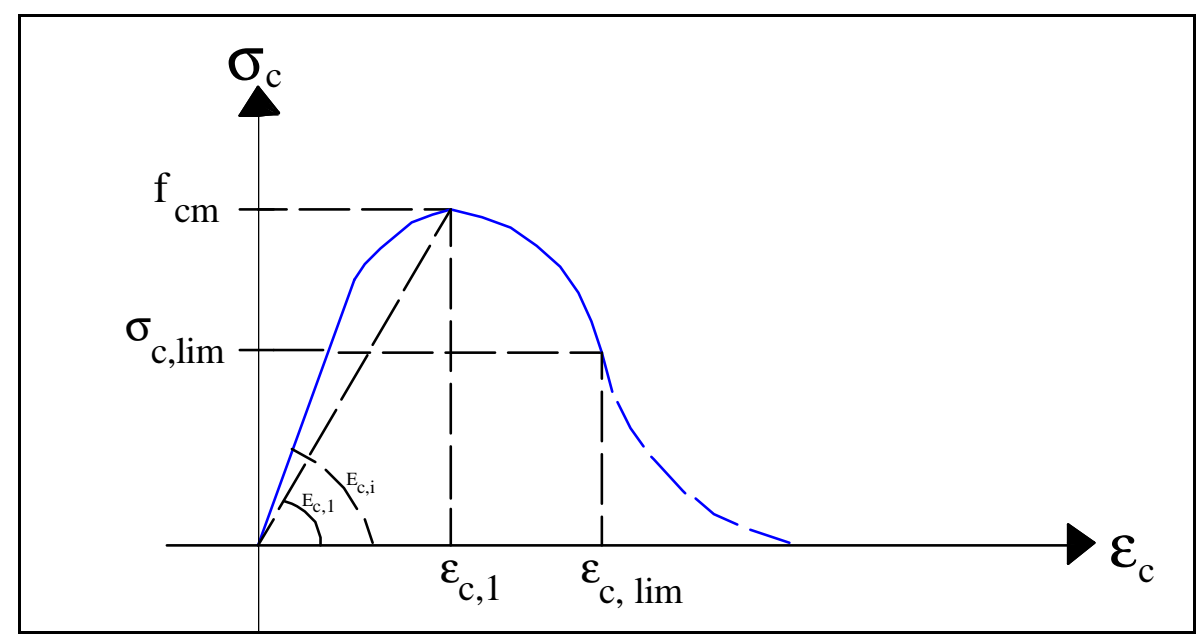

FIGURA 4.16: Relação tensão x deformação do concreto, CEB-FIP (1991)

Para a obtenção da parte do diagrama $\sigma_{\mathrm{c}} \times \varepsilon_{\mathrm{c}}$ que ocorre antes $\varepsilon_{\mathrm{c}, \mathrm{lim}}$, ou seja, $\left|\varepsilon_{\mathrm{c}}\right|<\left|\varepsilon_{\mathrm{c}, \text { lim }}\right|$, utiliza-se a expressão 4.2, expressa na forma:

$$
\sigma_{\mathrm{c}}=-\mathrm{f}_{\mathrm{cm}} \frac{\frac{\mathrm{E}_{\mathrm{ci}}}{\mathrm{E}_{\mathrm{c} 1}} \frac{\varepsilon_{\mathrm{c}}}{\varepsilon_{\mathrm{c} 1}}-\left(\frac{\varepsilon_{\mathrm{c}}}{\varepsilon_{\mathrm{c} 1}}\right)^{2}}{1+\left(\frac{\mathrm{E}_{\mathrm{ci}}}{\mathrm{E}_{\mathrm{c} 1}}-2\right) \frac{\varepsilon_{\mathrm{c}}}{\varepsilon_{\mathrm{cl}}}}
$$

onde

$\sigma_{\mathrm{c}}$ é a tensão de compressão (MPa);

$\varepsilon_{\mathrm{c}}$ é a deformação na compressão;

$\mathrm{E}_{\mathrm{ci}}$ é o módulo de elasticidade tangente (MPa), tomado como $2,15 \times 10^{4}\left(\mathrm{f}_{\mathrm{cm}} / 10\right)^{1 / 3}$;

$\mathrm{E}_{\mathrm{c} 1}$ é o módulo de elasticidade secante (MPa), tomado como $\mathrm{f}_{\mathrm{cm}} / 0,0022$;

$\varepsilon_{\mathrm{c} 1}=-0,0022$. 
Para todos os tipos de concreto nos modelos numéricos foi adotado que $\mathrm{f}_{\mathrm{cm}} \mathrm{e}$ igual ao $\mathrm{f}_{\mathrm{ck}}$, ou seja, a resistência característica à compressão do concreto.

Já para a obtenção da parte do diagrama $\sigma_{\mathrm{c}} \times \varepsilon_{\mathrm{c}}$ que ocorre durante e após $\varepsilon_{\mathrm{c}, \text { lim }}$, ou seja , $\left|\varepsilon_{\mathrm{c}}\right| \geq\left|\varepsilon_{\mathrm{c}, \mathrm{lim}}\right|$, aplicam-se as expressões 4.3 e 4.4. Esta parte só é válida para $\left|\sigma_{\mathrm{c}}\right| / \mathrm{f}_{\mathrm{cm}} \geq 0,5$.

$$
\begin{aligned}
& \sigma_{\mathrm{c}}=-\mathrm{f}_{\mathrm{cm}}\left[\left(\frac{1}{\varepsilon_{\mathrm{c}, \mathrm{lim}} / \varepsilon_{\mathrm{c} 1}} \xi-\frac{2}{\left(\varepsilon_{\mathrm{c}, \mathrm{lim}} / \varepsilon_{\mathrm{c} 1}\right)^{2}}\right)\left(\frac{\varepsilon_{\mathrm{c}}}{\varepsilon_{\mathrm{c} 1}}\right)^{2}+\left(\frac{4}{\varepsilon_{\mathrm{c}, \mathrm{lim}} / \varepsilon_{\mathrm{c} 1}}-\xi\right) \frac{\varepsilon_{\mathrm{c}}}{\varepsilon_{\mathrm{c} 1}}\right]^{-1} \\
& \xi=\frac{4\left[\left(\frac{\varepsilon_{\mathrm{c}, \mathrm{lim}}}{\varepsilon_{\mathrm{c} 1}}\right)^{2}\left(\frac{\mathrm{E}_{\mathrm{ci}}}{\mathrm{E}_{\mathrm{c} 1}}-2\right)+2 \frac{\varepsilon_{\mathrm{c}, \mathrm{lim}}}{\varepsilon_{\mathrm{c} 1}}-\frac{\mathrm{E}_{\mathrm{ci}}}{\mathrm{E}_{\mathrm{c} 1}}\right]}{\left[\frac{\varepsilon_{\mathrm{c}, \mathrm{lim}}}{\varepsilon_{\mathrm{c} 1}}\left(\frac{\mathrm{E}_{\mathrm{ci}}}{\mathrm{E}_{\mathrm{c} 1}}-2\right)+1\right]}
\end{aligned}
$$

Para determinar quando utilizar a expressão 4.2 ou 4.3, é necessário determinar o $\varepsilon_{c, \text { lim. }}$ O CEB-FIP (1991) estabelece que a deformação $\varepsilon_{c, \text { lim }}$ ocorrerá em $\sigma_{c, \lim }=-0,5 f_{c m}$, quando então determina-se $\varepsilon_{\mathrm{c}, \lim }$ por meio da expressão 4.5 .

$$
\varepsilon_{\mathrm{c}, \lim }=\varepsilon_{\mathrm{c} 1}\left\{\frac{1}{2}\left(\frac{1}{2} \frac{\mathrm{E}_{\mathrm{ci}}}{\mathrm{E}_{\mathrm{cl}}}+1\right)+\left[\frac{1}{4}\left(\frac{1}{2} \frac{\mathrm{E}_{\mathrm{ci}}}{\mathrm{E}_{\mathrm{cl}}}+1\right)^{2}-\frac{1}{2}\right]^{1 / 2}\right\}
$$




\section{ANÁLISE E DISCUSSÃO DOS RESULTADOS NUMÉRICOS}

São apresentados neste capítulo resultados obtidos de seis modelos numéricos. A elaboração dos modelos numéricos, desde as dimensões geométricas até as características dos materiais, partiu de modelos experimentais para o ensaio tipo "Push-out".

Para os modelos numéricos com conector tipo perfil "U" formado a frio foram utilizadas informações e dados referentes aos modelos experimentais de MALITE (1993), já descritos no item 3.3 do capítulo 3 do presente trabalho. Já para os modelos com conector tipo pino com cabeça (stud) foram considerados informações e dados de modelos experimentais de outros pesquisadores, os quais serão devidamente mencionados a seguir.

Os modelos numéricos foram calibrados com os experimentais por meio de confronto entre as relações força e deslocamento do conector, uma vez que essa relação consiste no resultado comumente obtido e disponibilizado quando da realização do ensaio experimental tipo "Push-out".

A partir da calibração do modelo numérico com os resultados experimentais, verificada por meio da relação força-deslocamento, foram analisados outros parâmetros de interesse como a concentração de tensões e deformações, ressaltando-se que a análise desses parâmetros deu-se somente com vistas a uma interpretação puramente numérica, uma vez que não se têm resultados experimentais disponíveis para um confronto direto.

A força total estimada foi aplicada em pequenos incrementos, que variam de 100 a 250, adotando como critérios de convergência a variação dos deslocamentos com tolerância para convergência de 0,001 , bem como uma tolerância de $1 \mathrm{~mm}$ para penetração entre as superfícies alvo e de contato.

$\mathrm{O}$ processo incrementaliterativo tem correspondência com o método de Newton-Raphson para a solução do sistema de equações de equilíbrio 
Vale ressaltar que os modelos numéricos foram processados em um microcomputador Pentium III, com 2 processadores de 1 GB cada e 2 GB de RAM, sendo o tempo total para processamento de cada modelo resultou em, aproximadamente, quatro dias.

\section{1 - MODELOS NUMÉRICOS COM CONECTOR TIPO PINO COM CABEÇA (STUD)}

Foram elaborados e analisados modelos numéricos com conectores tipo pino com cabeça (stud), com diâmetros de 13 e 19 mm, sendo estes modelos diferentes entre si apenas quanto à geometria, características dos materiais e quantidade de conectores soldados ao perfil metálico. Estas variações nos modelos são de interesse para uma análise ampla do comportamento do conector tipo pino com cabeça (stud) sobre diferentes condições.

\subsection{1 - MODELO NUMÉRICO PHS-1}

O modelo apresentado a seguir, denominado PHS-1, foi elaborado com base nos dados dos ensaios experimentais realizados por KALFAS et al (1997). Nestes ensaios foram analisados nove modelos idênticos que consistem basicamente de dois pinos com cabeça (stud), em cada laje, com $13 \mathrm{~mm}$ de diâmetro e $75 \mathrm{~mm}$ de altura, espaçados entre si $250 \mathrm{~mm}$. Na figura 5.1 tem-se uma visão geral do modelo PHS-1, enquanto que as dimensões do modelo são ilustradas na figura 5.2.
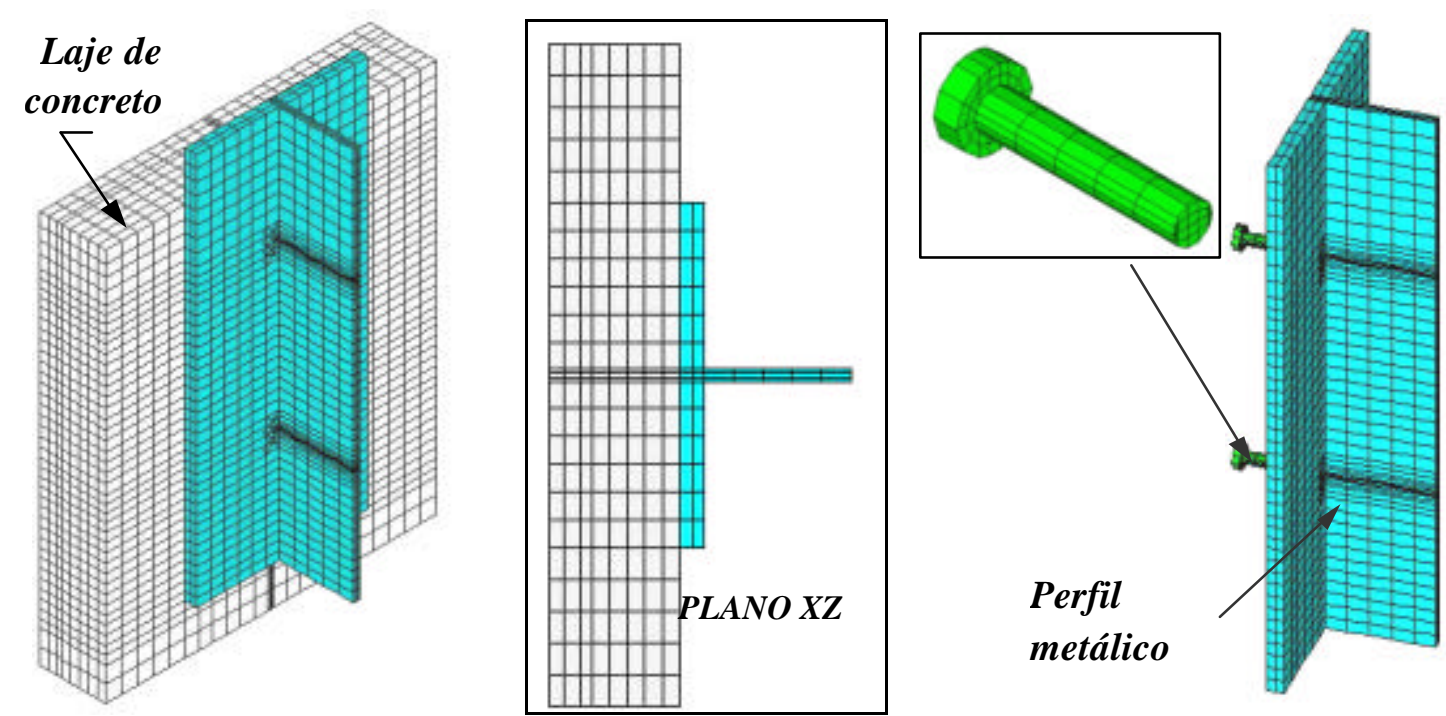

FIGURA 5.1: Visão geral do modelo $P H S-1$ 


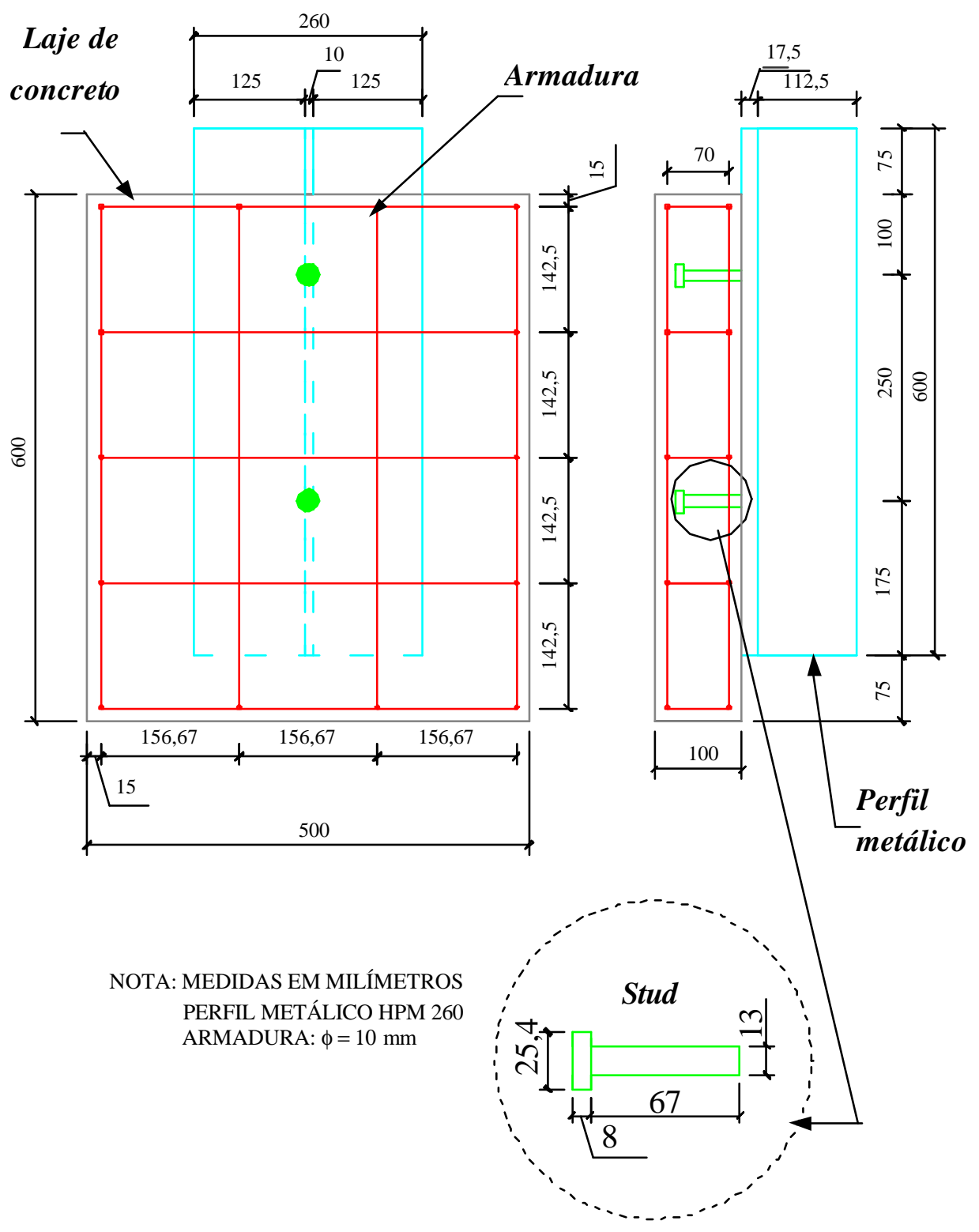

FIGURA 5.2: Dimensões do modelo PHS-1

\subsubsection{1 - CARACTERÍSTICAS ADOTADAS PARA OS MATERIAIS}

As propriedades dos materiais adotadas no modelo numérico PHS-1 foram as mesmas do observadas no modelo experimental. As tabelas 5.1 e 5.2 apresentam as características dos aços de acordo com os modelos de não-linearidade apresentado no item 4.2.3 do capítulo 4 do presente trabalho. Vale ressaltar ainda que os parâmetros $\sigma_{\mathrm{b}} \mathrm{e}$ $\sigma_{c}=\sigma_{d}$, têm correspondência direta com $\mathrm{f}_{\mathrm{y}}$ e $\mathrm{f}_{\mathrm{u}}$, respectivamente 
TABELA 5.1: Propriedades do aço do conector pino com cabeça (stud) e do perfil metálico (referente à figura 4.14, capítulo 4), modelo PHS-1

\begin{tabular}{|c|c|c|c|c|c|c|c|c|}
\hline MATERIAL & $\begin{array}{c}\sigma_{\mathrm{a}} \\
\left(\mathbf{k N} / \mathbf{c m}^{2}\right)\end{array}$ & $\begin{array}{c}\sigma_{\mathbf{b}} \\
\left(\mathbf{k N} / \mathbf{c m}^{2}\right)\end{array}$ & $\begin{array}{c}\sigma_{\mathbf{c}} \\
\left(\mathbf{k N} / \mathbf{c m}^{2}\right)\end{array}$ & $\begin{array}{c}\sigma_{\mathbf{d}} \\
\left(\mathbf{k N} / \mathbf{c m}^{2}\right)\end{array}$ & $\begin{array}{c}\mathbf{E} \\
\left(\mathbf{k N} / \mathbf{c m}^{2}\right)\end{array}$ & $\begin{array}{c}\mathbf{E}_{1} \\
\left(\mathbf{k N} / \mathbf{c m}^{2}\right)\end{array}$ & $\begin{array}{c}\mathbf{E}_{2} \\
\left(\mathbf{k N} / \mathbf{c m}^{2}\right)\end{array}$ & $\begin{array}{c}\mathbf{E}_{3} \\
\left(\mathbf{k N} / \mathbf{c m}^{2}\right)\end{array}$ \\
\hline $\begin{array}{c}\text { AÇO DO } \\
\text { CONECTOR }\end{array}$ & 28,0 & 40,0 & 49,6 & 49,6 & 20000 & 200 & 20 & 0 \\
\hline $\begin{array}{c}\text { AÇO DO } \\
\text { PERFIL }\end{array}$ & 17,5 & 25,0 & 40,0 & 40,0 & 20500 & 205 & 20,5 & 0 \\
\hline
\end{tabular}

TABELA 5.2: Propriedades do aço da armadura (referente à figura 4.13), modelo PHS-1

\begin{tabular}{|c|c|c|}
\hline MATERIAL & $\mathbf{f}_{\mathbf{y}}\left(\mathbf{k N} / \mathbf{c m}^{2}\right)$ & $\mathbf{E}\left(\mathbf{k N} / \mathbf{c m}^{2}\right)$ \\
\hline AÇO DA ARMADURA & 50,0 & 21000 \\
\hline
\end{tabular}

O coeficiente de Poisson (v) adotado para o aço foi de 0,3 . Para o concreto da laje, conforme apresentado no item 4.2.3 (capítulo 4), adotam-se dois modelos de nãolinearidade. A tabela 5.3 apresenta os parâmetros para o modelo concreto, enquanto que o gráfico 5.1 ilustra a relação tensão-deformação utilizada para o modelo elástico não-linear.

TABELA 5.3: Valores dos parâmetros para o modelo concreto, modelo PHS-1

\begin{tabular}{|c|c|}
\hline DESCRIÇÃO DOS PARÂMETROS & VALOR \\
\hline Módulo de elasticidade $\left(\mathrm{E}_{\mathrm{c}}\right)-\left(\mathrm{kN} / \mathrm{cm}^{2}\right)$ & 2782 \\
\hline Coeficiente de transferência de cisalhamento para fissura aberta & 0,7 \\
\hline Coeficiente de transferência de cisalhamento para fissura fechada & 1,0 \\
\hline Resistência uniaxial à tração do material $\left(\mathrm{f}_{\mathrm{t}}\right)-\left(\mathrm{kN} / \mathrm{cm}^{2}\right)$ & 0,199 \\
\hline Resistência uniaxial à compressão do material $\left(\mathrm{f}_{\mathrm{c}}\right)-\left(\mathrm{kN} / \mathrm{cm}^{2}\right)$ & 1,712 \\
\hline Resistência biaxial à compressão do material $\left(\mathrm{f}_{\mathrm{cb}}\right)-\left(\mathrm{kN} / \mathrm{cm}^{2}\right)$ & 2,054 \\
\hline Estado de tensão hidrostática ambiente $\left(\sigma_{\mathrm{h}}{ }^{\mathrm{a}}\right)-\left(\mathrm{kN} / \mathrm{cm}^{2}\right)$ & $10^{-10}$ \\
\hline $\begin{array}{l}\text { Resistência ultima a compressão para o estado biaxial de compressão } \\
\text { superposta ao estado de tensão hidrostático ambiente }\left(\mathrm{f}_{1}\right)-\left(\mathrm{kN} / \mathrm{cm}^{2}\right)\end{array}$ & 2,482 \\
\hline $\begin{array}{l}\text { Resistência ultima a compressão para o estado uniaxial de compressão } \\
\text { superposta ao estado de tensão hidrostático ambiente }\left(\mathrm{f}_{2}\right)-\left(\mathrm{kN} / \mathrm{cm}^{2}\right)\end{array}$ & 2,953 \\
\hline Coeficiente para o amolecimento do mate & 1,0 \\
\hline
\end{tabular}




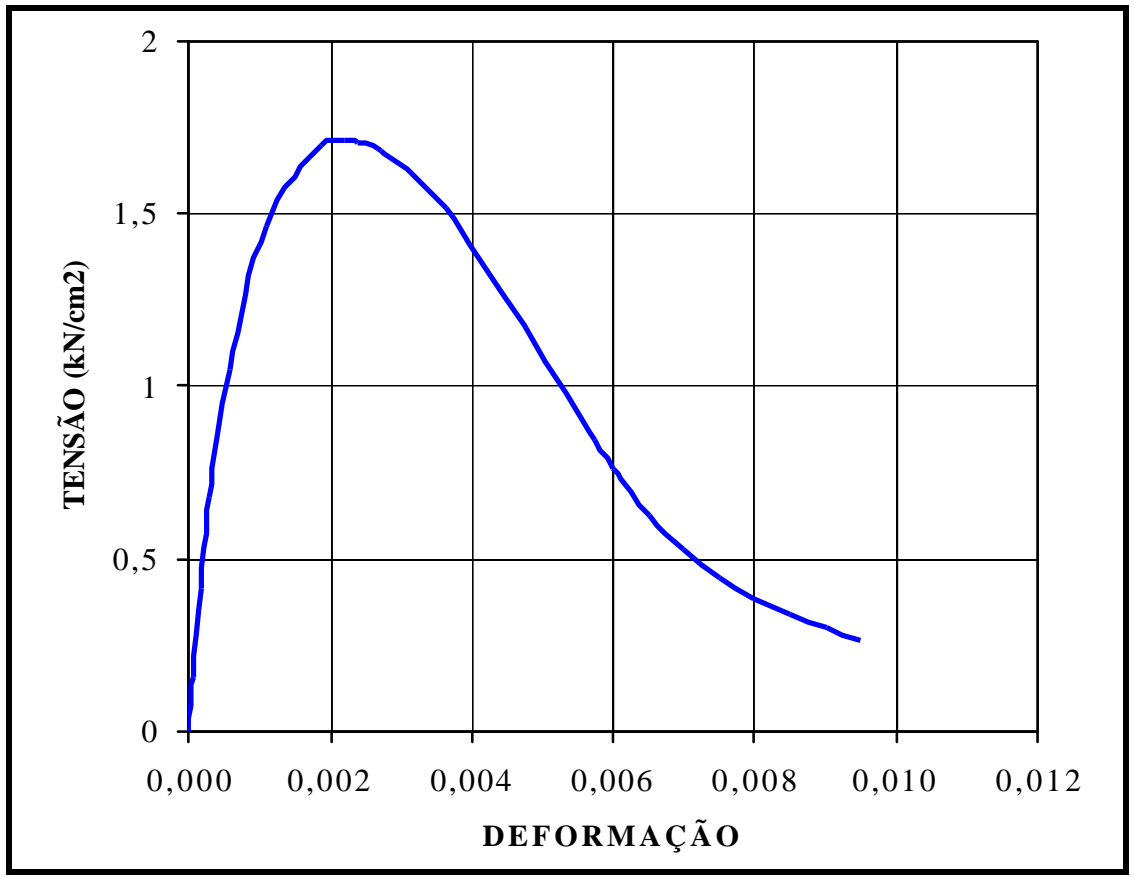

GRÁFICO 5.1: Relação tensão x deformação para compressão do concreto, modelo PHS-1

A figura 5.3 ilustra as regiões da laje de concreto, para as quais foram utilizados os modelos com não-linearidades, no caso, o modelo concreto e o modelo elástico não-linear.

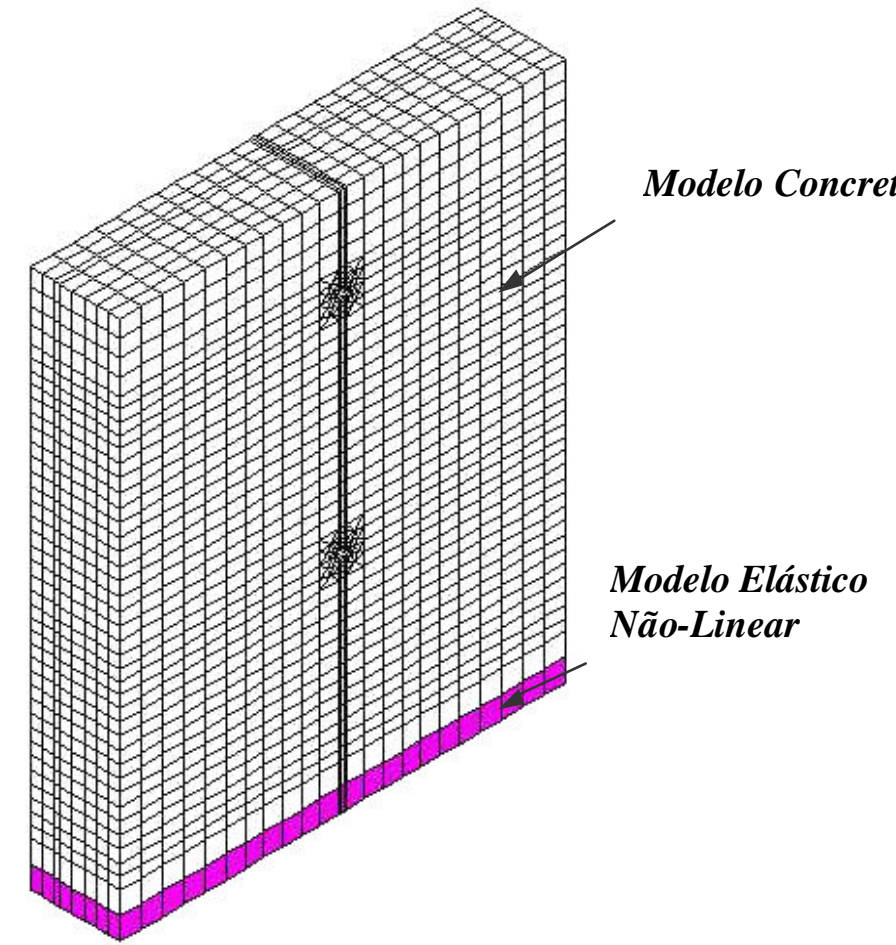

FIGURA 5.3: Detalhe da aplicação dos modelos de não-linearidade no concreto, modelo PHS-1 


\subsubsection{2 - CONFRONTO DA RELAÇÃO ENTRE FORÇA E DESLOCAMENTO} PARA O MODELO NUMÉRICO PHS-1

O gráfico 5.2 ilustra a comparação do resultado numérico do modelo PHS-1, por meio da relação entre força e deslocamento do conector, confrontado com três resultados entre os mais representativos dos nove ensaios experimentais realizados por KALFAS et al. (1997). A força total aplicado no modelo foi dividida igualmente entre os dois conectores. O valor adotado para a rigidez normal de contato (FKN) foi 500 .

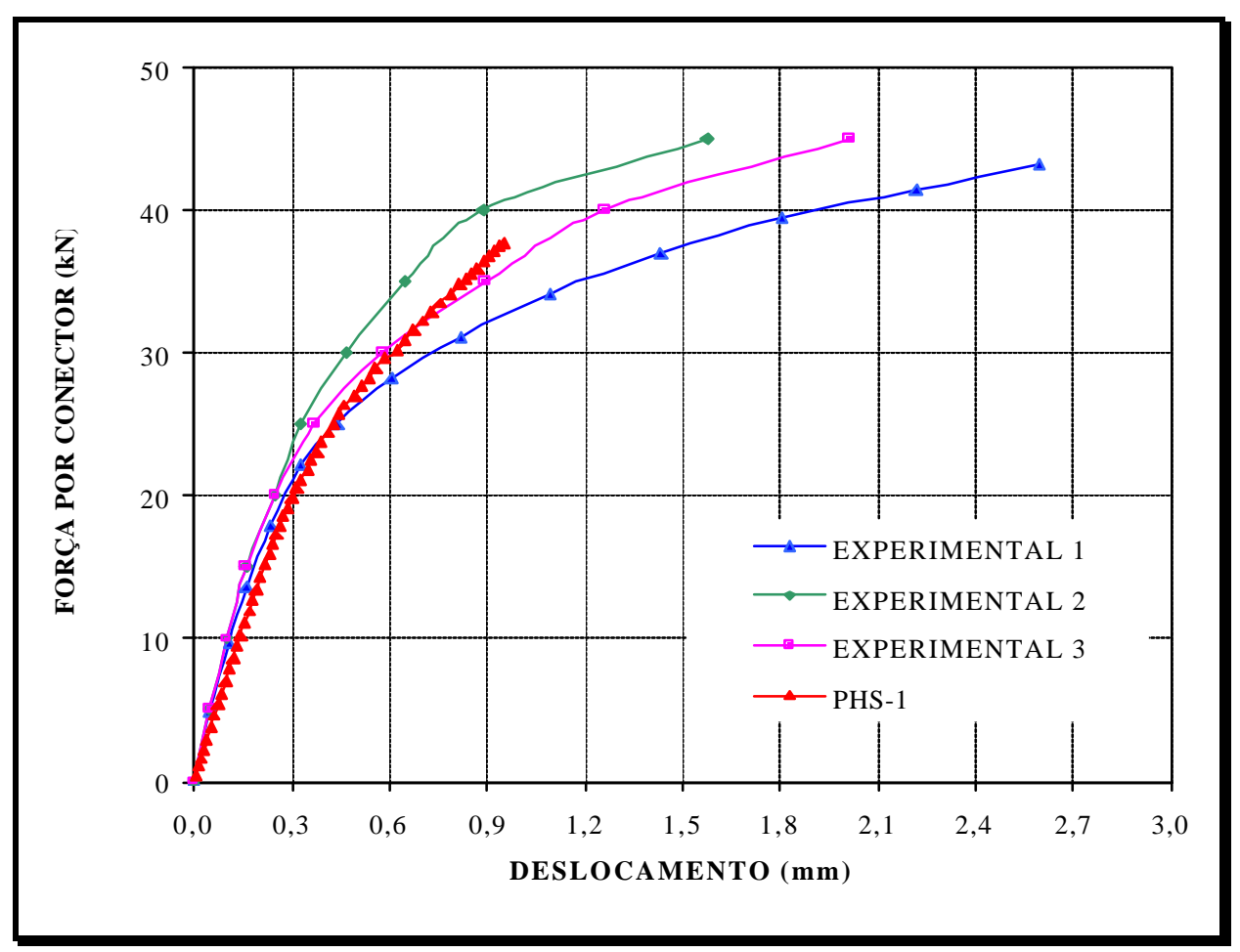

GRÁFICO 5.2: Relação força $x$ deslocamento, modelo PHS-1

Por uma análise com referência ao gráfico 5.2, é possível identificar uma concordância bastante satisfatória do resultado do modelo PHS-1 quando comparado com os resultados experimentais, até o valor de força igual a $37,75 \mathrm{kN}$, a partir do qual não mais apresentou convergência, em correspondência a uma tolerância de 0,001 com referência às diferenças entre deslocamentos sucessivos. 


\subsubsection{3 - ANÁLISE DA RESPOSTA NUMÉRICA DE COMPONENTES QUE} CONSTITUEM O MODELO PHS-1

Apresenta-se a seguir alguns resultados numéricos do modelo PHS-1, os quais tem por objetivo interpretar numericamente o comportamento dos componentes que o constituem. A figura 5.4 ilustra a tensão axial na armadura quando o modelo é submetido a força última de $75,5 \mathrm{kN}$. Adicionalmente, no gráfico 5.3 é apresento o histórico de deformação na região da armadura próxima aos conectores, posições 1, 2 e 3 indicadas na figura 5.4.

FORÇA DE 75,5 $k N$

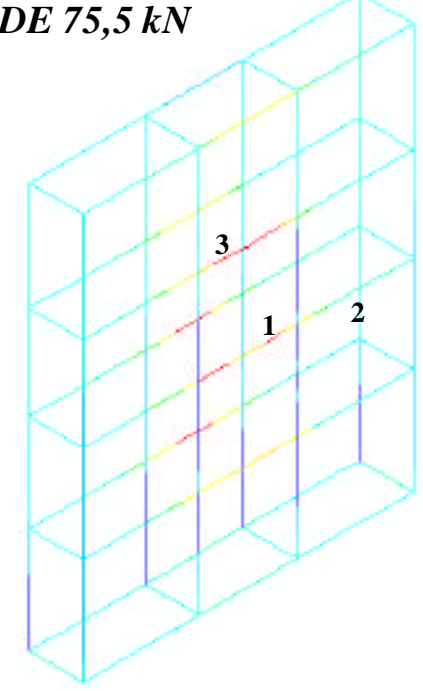

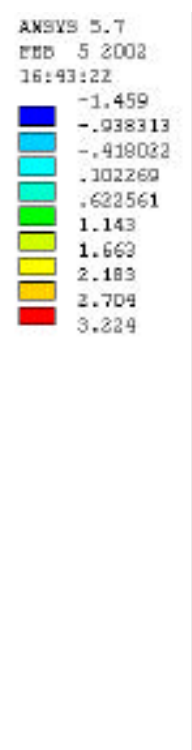

FIGURA 5.4: Tensão axial $\left(\mathrm{kN} / \mathrm{cm}^{2}\right)$ na armadura da laje de concerto para o modelo PHS-1

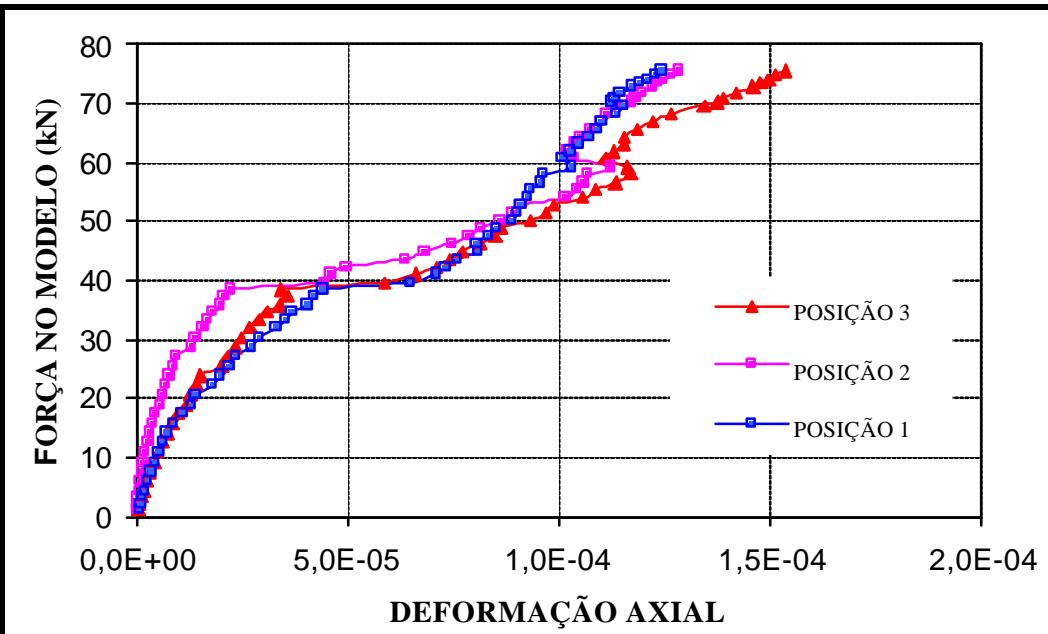

GRÁFICO 5.3: Relação força x deformação axial na região mais solicitada da armadura, modelo PHS-1 
No gráfico 5.3, nota-se que os valores de deformações na armadura, para uma força de aproximadamente $60 \mathrm{kN}$, apresentam perturbações, provavelmente, em função da redistribuição de esforços do concreto para armadura, uma vez que as deformações na armadura para a força de $60 \mathrm{kN}$ corresponde a tensões baixas. O gráfico 5.4 apresenta a relação entre força e tensão de mises no concreto, na mesma região da armadura, posições 1 e 3 (indicada na figura 5.4), em que é possível observar, também para uma força de $60 \mathrm{kN}$, uma perturbação similar àquela identificada no gráfico 5.3

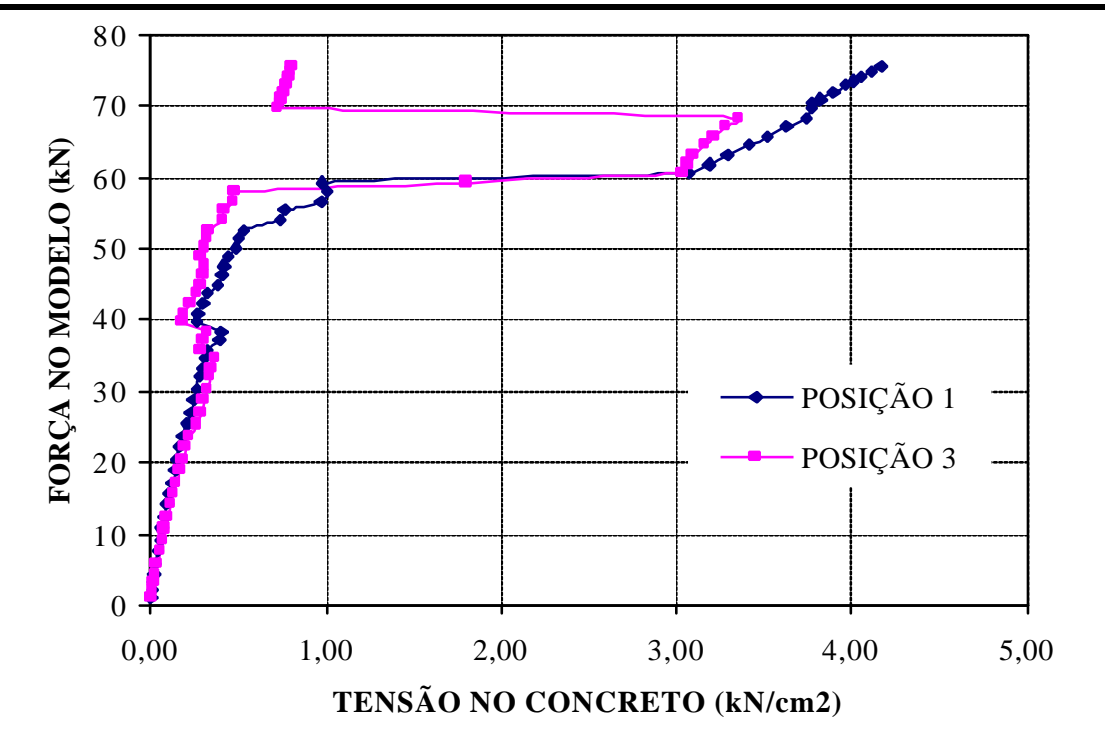

GRÁFICO 5.4: Relação força $x$ tensão no concreto na região da armadura, modelo PHS-1

É importante destacar que as tensões nas armaduras resultaram baixas comprovando, como já comentado em capítulos anteriores, a sua função de apenas confinar o concreto. As tensões de Mises no concreto na região da laje imediatamente abaixo do conector resultaram elevadíssimas em alguns elementos (figura 5.6), provavelmente devido à significativa pressão de contato entre conector e concreto, como ilustrado na figura 5.5.

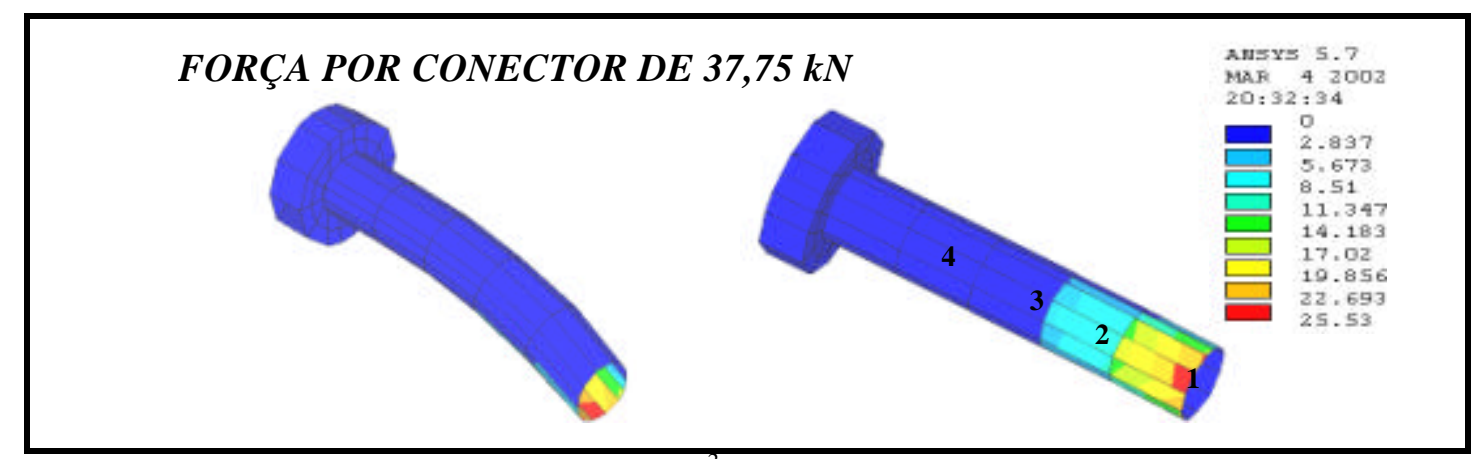

FIGURA 5.5: Pressão de contato $\left(\mathrm{kN} / \mathrm{cm}^{2}\right)$ entre o conector e o concreto, modelo PHS-1 
O comportamento da pressão de contato ao longo da solicitação é apresentada no gráfico 5.5, com referência as posições ilustrada na figura 5.5.

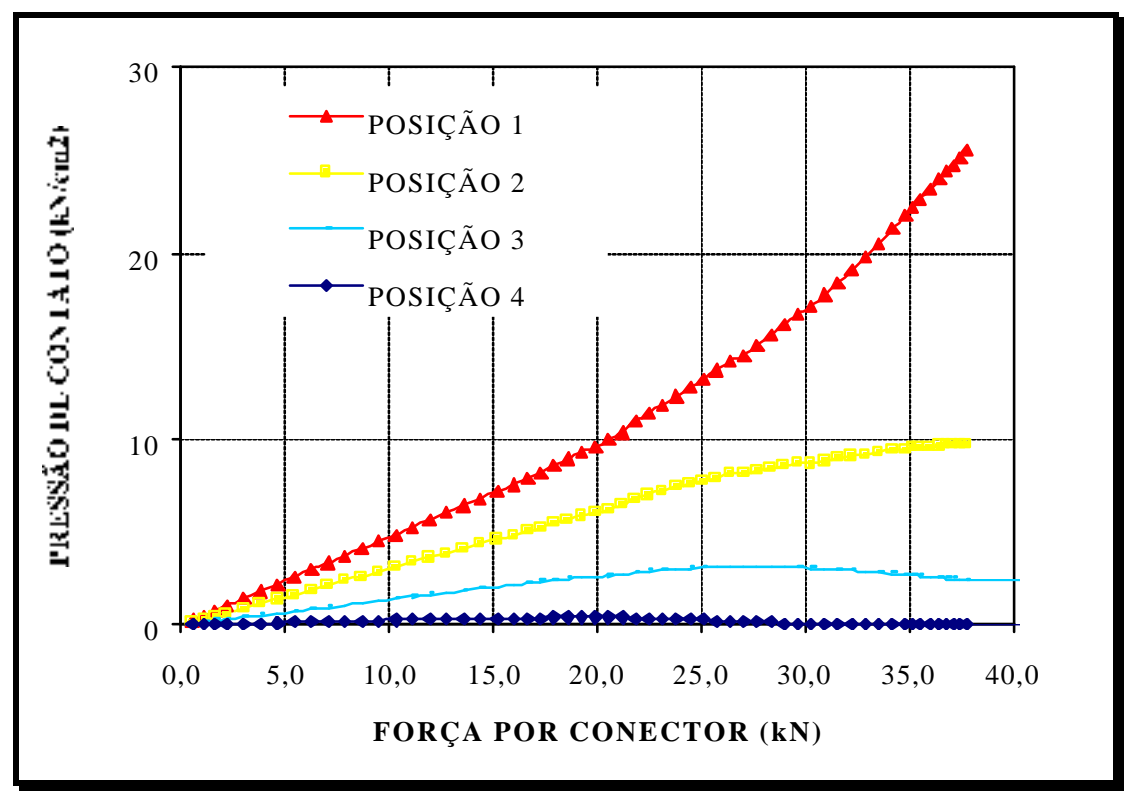

GRÁFICO 5.5: Relação pressão de contato x força por conector, modelo PHS-1

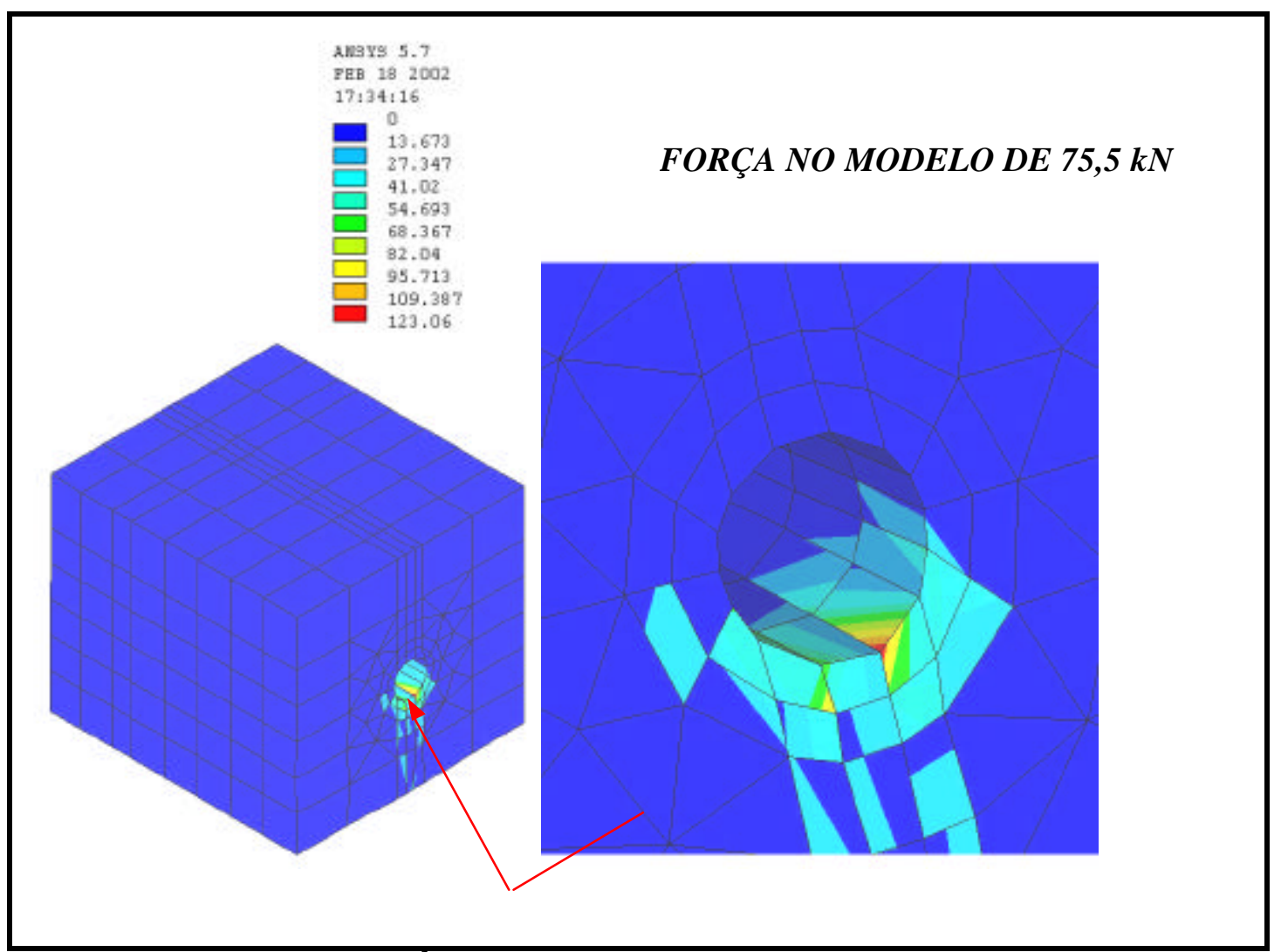

FIGURA 5.6: Tensão $\left(\mathrm{kN} / \mathrm{cm}^{2}\right)$ na laje de concreto, região circundante ao conector, modelo PHS-1 
A figura 5.7 ilustra as tensões de Mises em apenas um conector, uma vez que o comportamento dos dois conectores é igual. As posições no conector (figura 5.7) indicadas pelos números 1, 2, 3 e 4 representam regiões para as quais serão plotadas relações entre tensão de Mises e força no conector (gráfico 5.6).

Percebe-se por meio do gráfico 5.6 a redistribuição de tensões que ocorre ao longo do comprimento do conector. Vale destacar que em nenhuma região do conector foi atingido o valor da tensão de escoamento $\left(f_{\mathrm{y}}\right)$.

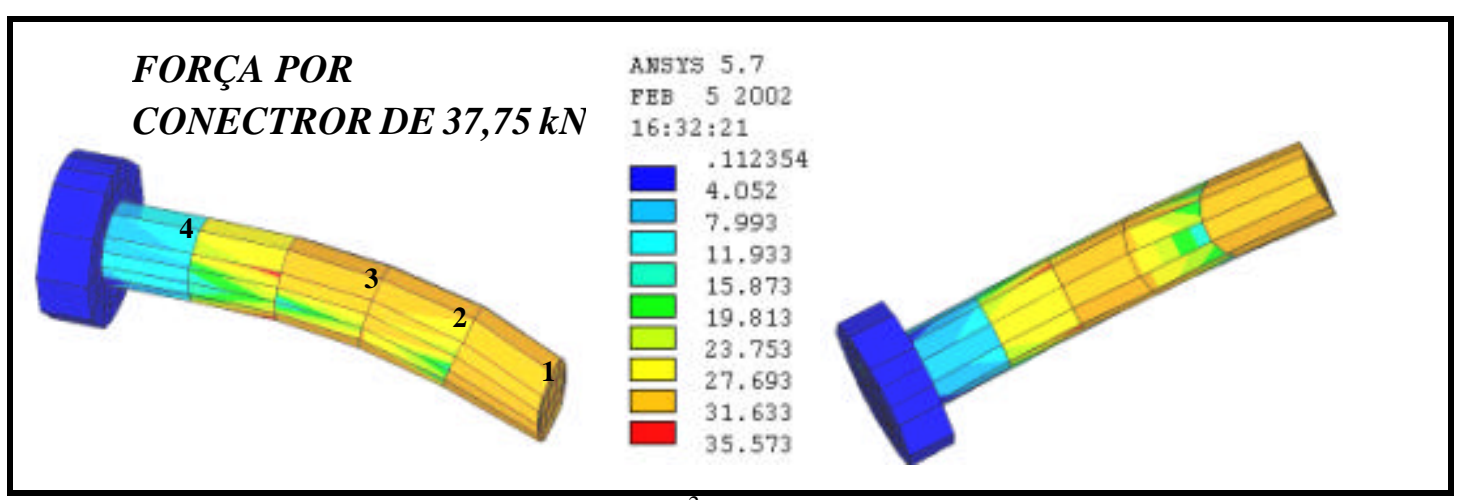

FIGURA 5.7: Estado de tensão $\left(\mathrm{kN} / \mathrm{cm}^{2}\right)$ no pino com cabeça ( $\left.\mathrm{stud}\right)$, modelo PHS-1

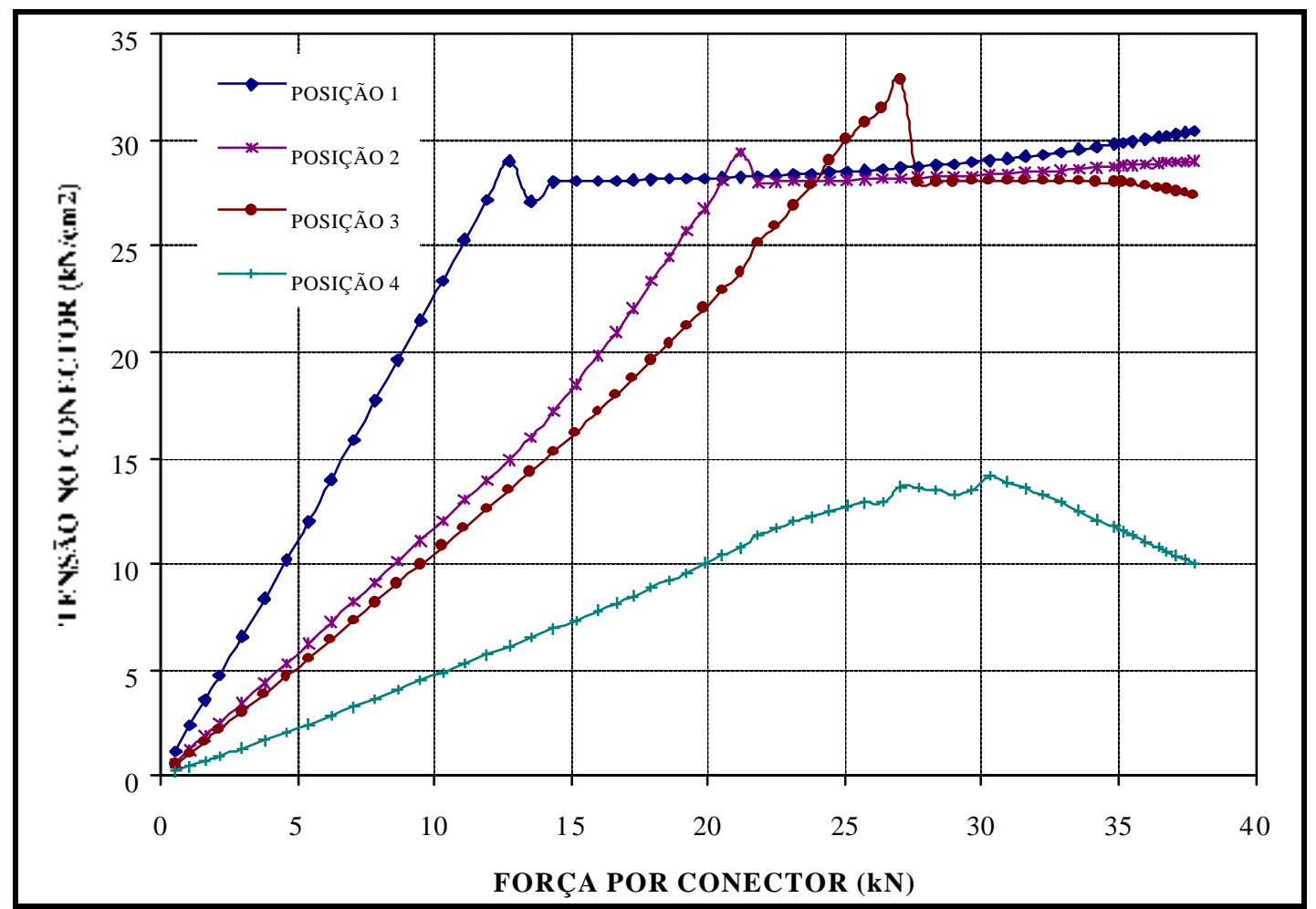

GRÁFICO 5.6: Relação tensão $x$ f orça no conector, modelo PHS-1 
Para o mesmo modelo, é apresentada na figura 5.8 a evolução das fissuras na laje de concreto, em correspondência às etapas de forças no modelo de 10, 30, 40 50, 60 e $75,5 \mathrm{kN}$. As fissuras na laje são provocadas pela fissuração do concreto na tração e pelo esmagamento do concreto na compressão.

Por uma análise com relação às etapas ilustradas na figura 5.8, as fissuras nos primeiros incrementos de força iniciam-se na região circundante ao conector e, com o aumento da força, se expandem pela laje de concreto.
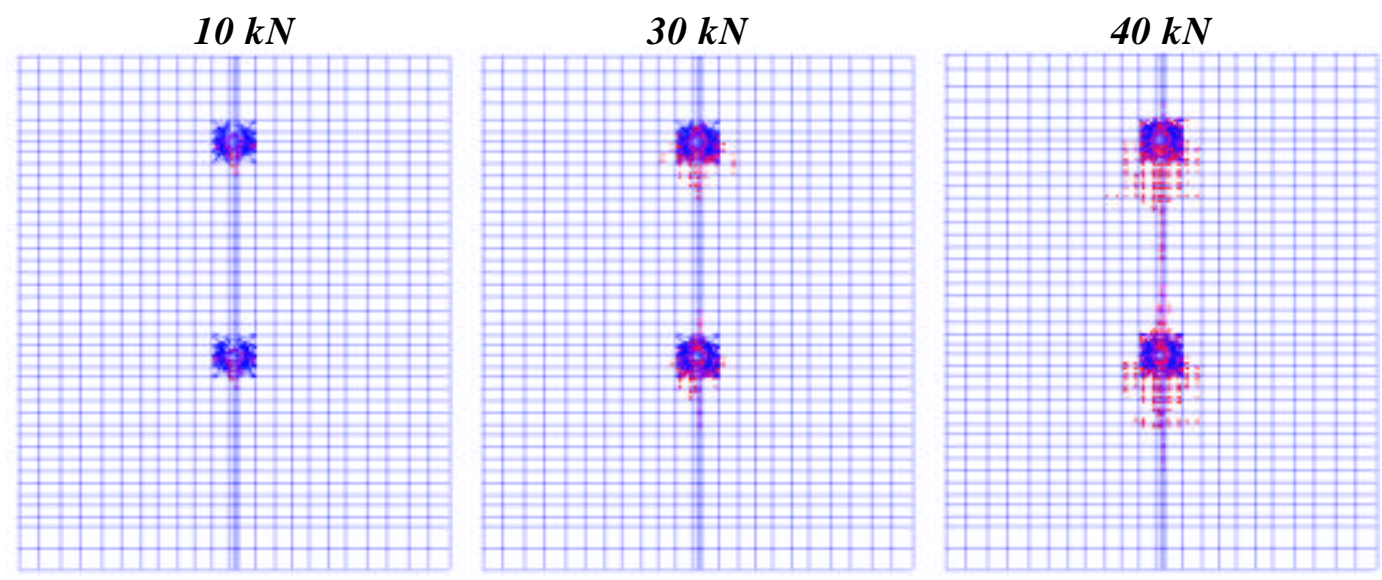

$50 k N$

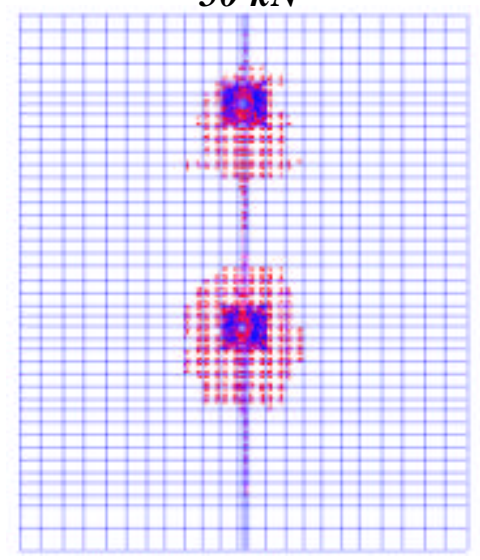

$60 k N$

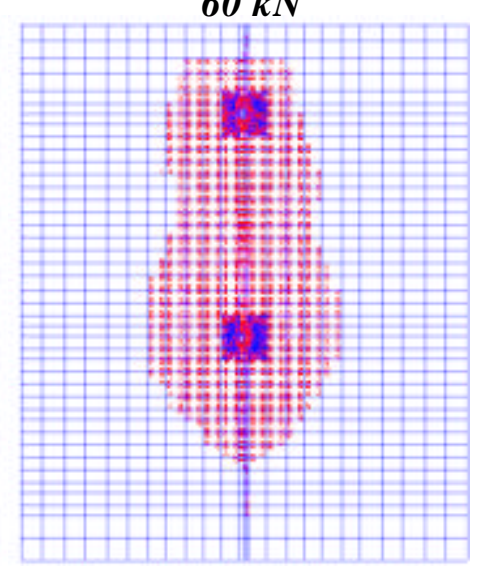

$75,5 \mathrm{kN}$

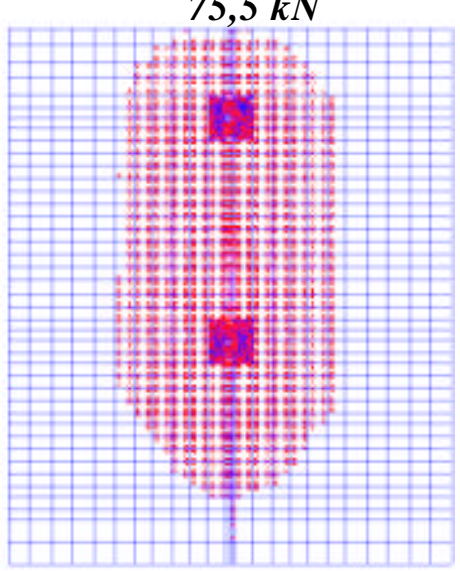

FIGURA 5.8: Progressão das fissuras na laje de concreto, modelo PHS-1

\subsection{2 - MODELO NUMÉRICO PHS-2}

O modelo numérico PHS-2, foi elaborado com base nos dados dos ensaios experimentais realizados por AN \& CEDERWALL (1996), em que foram analisados conectores de $19 \mathrm{~mm}$, embutidos em concreto de resistência normal e de alta resistência. Vale ressaltar, nesse caso, que na elaboração de o modelo numérico PHS-2 foi considerado 
apenas o concreto de resistência normal. As figuras 5.9 e 5.10 ilustram o modelo experimental adotado por AN \& CEDERWALL (1996) e o modelo PHS-2, respectivamente.
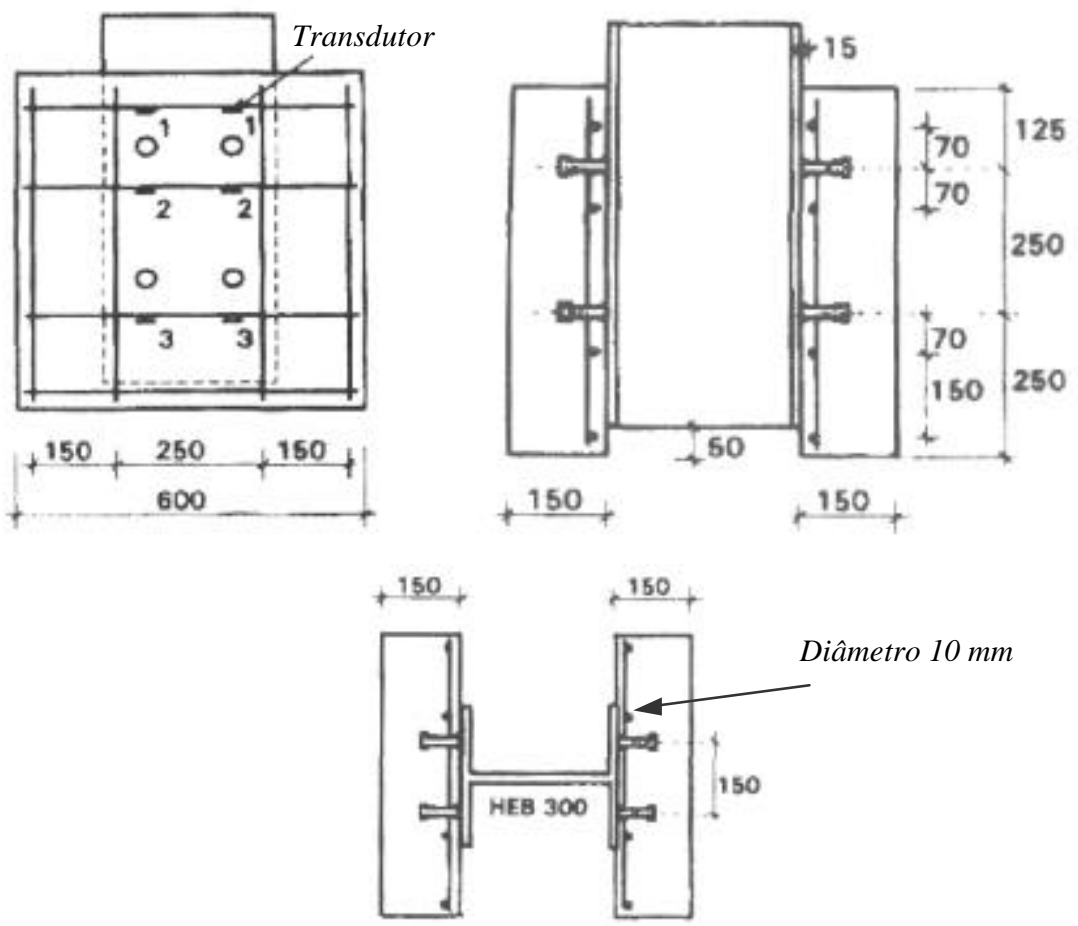

FIGURA 5.9: Apresentação do modelo experimental utilizado por AN \& CEDERWALL (1996)
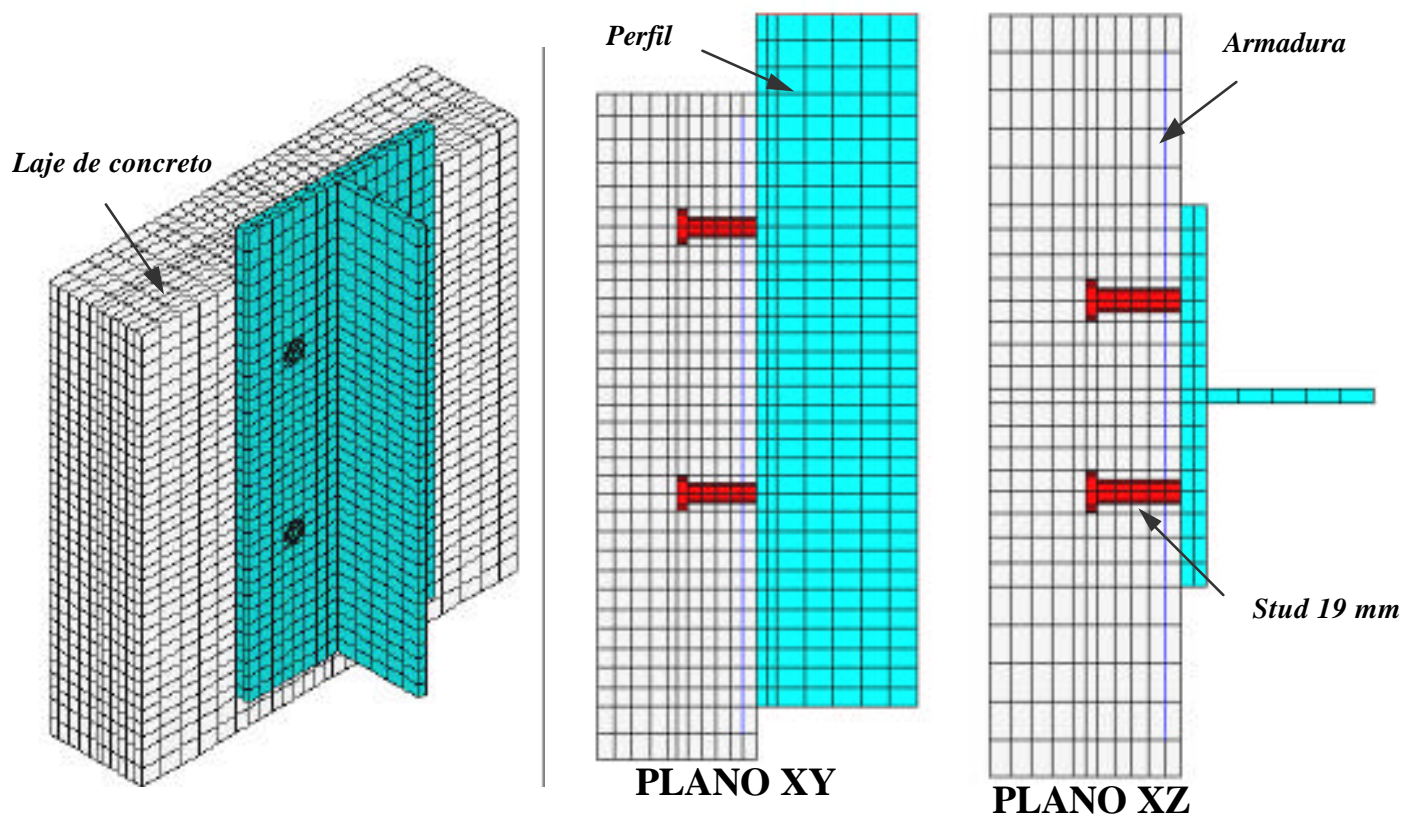

FIGURA 5.10: Visão geral do modelo numérico PHS-2 
Maiores detalhes com referência ao modelo PHS-2 encontram-se disponíveis na figura 4.7 do capítulo 4 .

\subsubsection{1 - CARACTERÍSTICAS DOS MATERIAIS, MODELO PHS-2}

As propriedades dos materiais adotadas para o modelo PHS-2 foram as mesmas do modelo experimental. É importante ressaltar que o módulo de elasticidade do concreto $\left(\mathrm{E}_{\mathrm{c}}\right)$ foi calculado por AN \& CEDERWALL (1996) por meio da expressão do ACI (1993).

As tabelas 5.4 e 5.5 apresentam as características dos aços, de acordo com os modelos de não-linearidade apresentado no item 4.2.3 do capítulo 4 do presente trabalho.

TABELA 5.4: Propriedades do aço do conector pino com cabeça (stud) e do perfil metálico (referente à figura 4.14, capítulo 4), modelo PHS-2

\begin{tabular}{|c|c|c|c|c|c|c|c|c|}
\hline MATERIAL & $\begin{array}{c}\sigma_{\mathrm{a}} \\
\left(\mathbf{k N} / \mathbf{c m}^{2}\right)\end{array}$ & $\begin{array}{c}\sigma_{\mathbf{b}} \\
\left(\mathbf{k N} / \mathbf{c m}^{2}\right)\end{array}$ & $\begin{array}{c}\sigma_{\mathbf{c}} \\
\left(\mathbf{k N} / \mathbf{c m}^{2}\right)\end{array}$ & $\begin{array}{c}\sigma_{\mathbf{d}} \\
\left(\mathbf{k N} / \mathbf{c m}^{2}\right)\end{array}$ & $\begin{array}{c}\mathbf{E} \\
\left(\mathbf{k N} / \mathbf{c m}^{2}\right)\end{array}$ & $\begin{array}{c}\mathbf{E}_{1} \\
\left(\mathbf{k N} / \mathbf{c m}^{2}\right)\end{array}$ & $\begin{array}{c}\mathbf{E}_{2} \\
\left(\mathbf{k N} / \mathbf{c m}^{2}\right)\end{array}$ & $\begin{array}{c}\mathbf{E}_{3} \\
\left(\mathbf{k N} / \mathbf{c m}^{2}\right)\end{array}$ \\
\hline $\begin{array}{c}\text { AÇO DO } \\
\text { CONECTOR }\end{array}$ & 29,26 & 41,80 & 51,90 & 51,90 & 20700 & 207 & 20,70 & 0 \\
\hline $\begin{array}{c}\text { AÇO DO } \\
\text { PERFIL }\end{array}$ & 17,5 & 25,0 & 40,0 & 40,0 & 20500 & 205 & 20,5 & 0 \\
\hline
\end{tabular}

TABELA 5.5: Propriedades do aço da armadura (referente à figura 4.13), modelo PHS-2

\begin{tabular}{|c|c|c|}
\hline MATERIAL & $\mathbf{f}_{\mathbf{y}}\left(\mathbf{k N} / \mathbf{c m}^{2}\right)$ & $\mathbf{E}\left(\mathbf{k N} / \mathbf{c m}^{2}\right)$ \\
\hline AÇO DA ARMADURA & 50,9 & 21000 \\
\hline
\end{tabular}

Análogo ao modelo PHS-1, para o concreto da laje, conforme apresentado no item 4.2.3 (capítulo 4), adotam-se dois modelos de não-linearidade. A tabela 5.6 apresenta os parâmetros para o modelo concreto, enquanto que o gráfico 5.7 ilustra a relação tensãodeformação utilizada para o modelo elástico não-linear.

As regiões da laje de concreto, para as quais foram utilizados os modelos com não-linearidades, no caso, o modelo concreto e o modelo elástico não-linear são as mesmas do modelo PHS-1, ou seja, modelo concreto em toda a laje exceto nos elementos finitos da laje que estão vinculados à base do modelo. 
TABELA 5.6: Valores dos parâmetros para o modelo concreto, modelo PHS-2

\begin{tabular}{|c|c|}
\hline DESCRIÇÃO DOS PARÂMETROS & VALOR \\
\hline Módulo de elasticidade $\left(\mathrm{E}_{\mathrm{c}}\right)-\left(\mathrm{kN} / \mathrm{cm}^{2}\right)$ & 2710 \\
\hline Coeficiente de transferência de cisalhamento para fissura aberta & 0,7 \\
\hline Coeficiente de transferência de cisalhamento para fissura fechada & 1,0 \\
\hline Resistência uniaxial à tração do material $\left(\mathrm{f}_{\mathrm{t}}\right)-\left(\mathrm{kN} / \mathrm{cm}^{2}\right)$ & 0,322 \\
\hline Resistência uniaxial à compressão do material $\left(\mathrm{f}_{\mathrm{c}}\right)-\left(\mathrm{kN} / \mathrm{cm}^{2}\right)$ & 3,077 \\
\hline Resistência biaxial à compressão do material $\left(\mathrm{f}_{\mathrm{cb}}\right)-\left(\mathrm{kN} / \mathrm{cm}^{2}\right)$ & 3,692 \\
\hline Estado de tensão hidrostática ambiente $\left(\sigma_{\mathrm{h}}{ }^{\mathrm{a}}\right)-\left(\mathrm{kN} / \mathrm{cm}^{2}\right)$ & $10^{-10}$ \\
\hline $\begin{array}{l}\text { Resistência ultima a compressão para o estado biaxial de compressão } \\
\text { superposta ao estado de tensão hidrostático ambiente }\left(\mathrm{f}_{1}\right)-\left(\mathrm{kN} / \mathrm{cm}^{2}\right)\end{array}$ & 4,462 \\
\hline $\begin{array}{l}\text { Resistência ultima a compressão para o estado uniaxial de compressão } \\
\text { superposta ao estado de tensão hidrostático ambiente }\left(\mathrm{f}_{2}\right)-\left(\mathrm{kN} / \mathrm{cm}^{2}\right)\end{array}$ & 5,308 \\
\hline Coeficiente para o amolecimento do material fissurado na tração & 1,0 \\
\hline
\end{tabular}

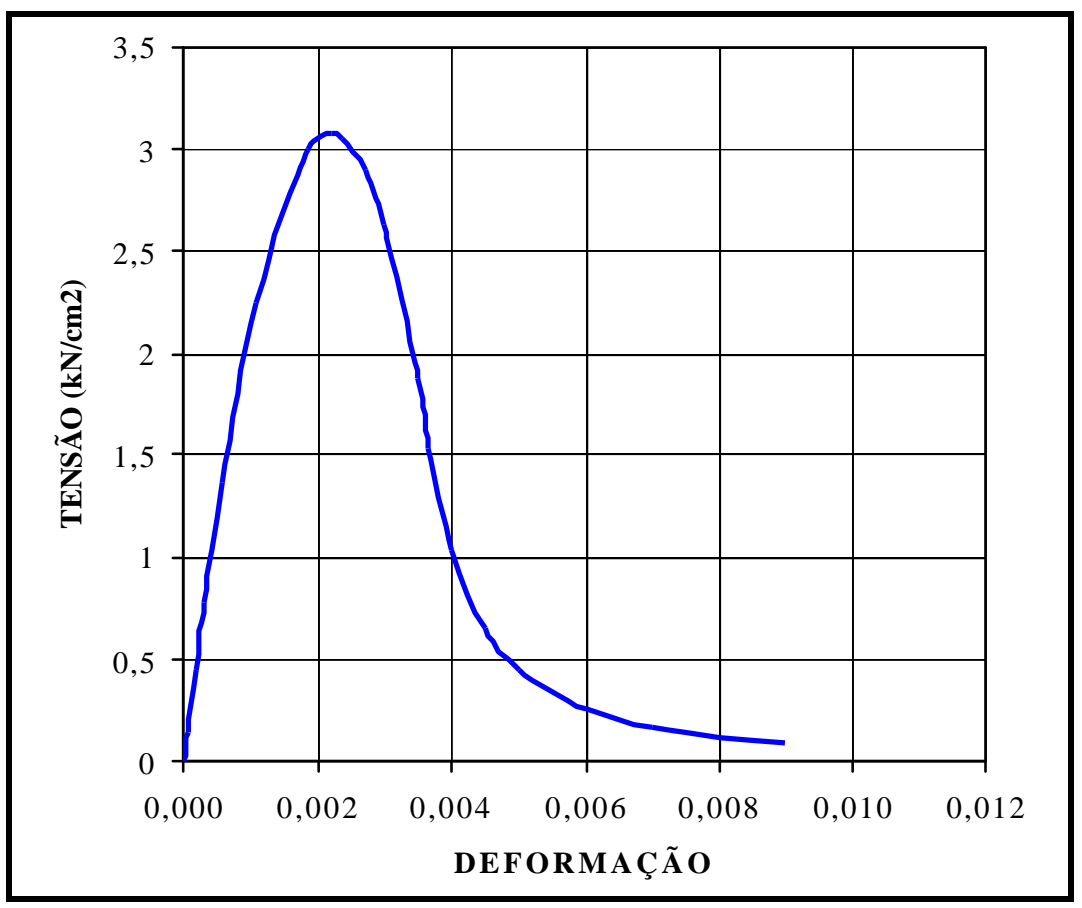

GRÁFICO 5.7: Relação tensão x deformação para compressão do concreto, modelo PHS-2 


\subsubsection{2 - CONFRONTO DA RELAÇÃO ENTRE FORÇA E DESLOCAMENTO} PARA O MODELO NUMÉRICO PHS-2

A calibração do modelo PHS-2 teve como base a relação entre força e deslocamento do conector para o modelo experimental. O gráfico 5.8 apresenta relações força-deslocamento de dois modelos experimentais idênticos, bem como a relação forçadeslocamento obtida no modelo numérico PHS-2. A força aplicada no modelo PHS-2 foi dividida igualmente entre os quatro conectores e plotada em correspondência aos deslocamentos obtidos. O valor adotado para a rigidez normal de contato (FKN) foi 2000.

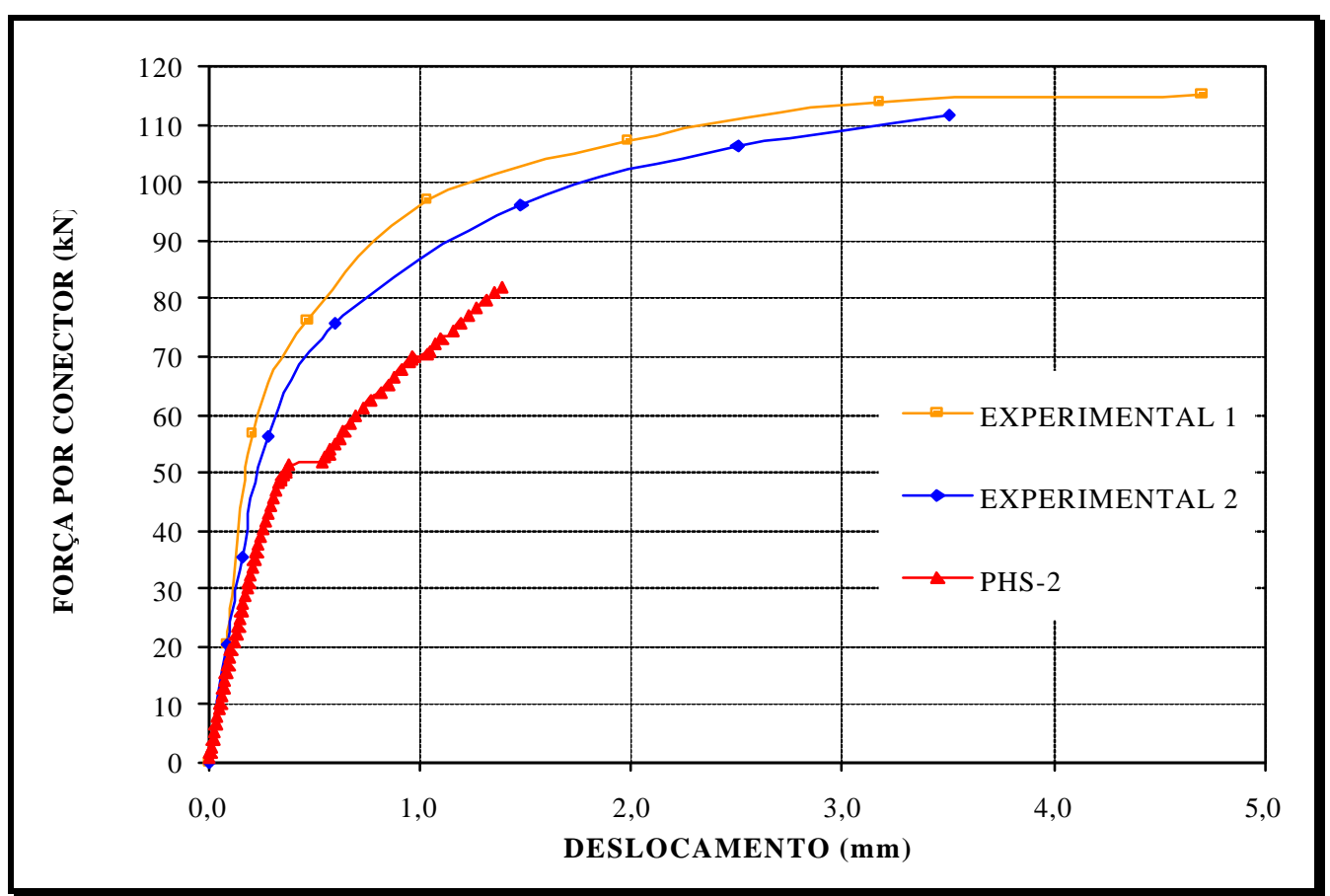

GRÁFICO 5.8: Relação força $x$ deslocamento do conector, modelo PHS-2

O modelo PHS-2 representou de forma satisfatória a rigidez inicial do modelo experimental, porém, para uma força de aproximadamente $25 \mathrm{kN}$, o modelo PHS-2 começou a perder consideravelmente a rigidez, até a força de $82 \mathrm{kN}$, a partir da qual não mais obteve convergência com referência às diferenças entre deslocamentos sucessivos. Também foi observado uma descontinuidade no gráfico 5.8, para uma força de aproximadamente $50 \mathrm{kN}$, devido ao aumento das fissurações na laje de concreto neste nível de força. 
A progressão das fissuras na laje de concreto representados pelas forças por conector de 10, 20, 30 40, 50, 52, 60, 70 e $82 \mathrm{kN}$ é apresentado na figura 5.11. As fissuras na laje são provocadas pela fissuração do concreto na tração e pelo esmagamento do concreto na compressão.

$10 k N$

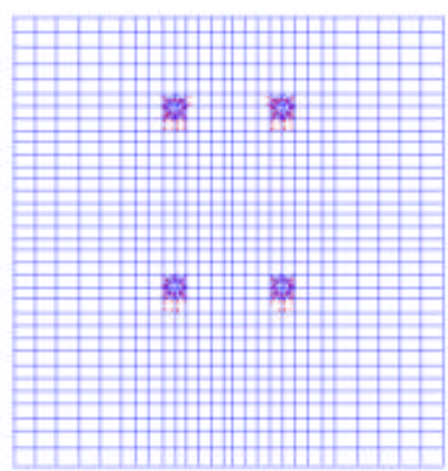

$40 k N$

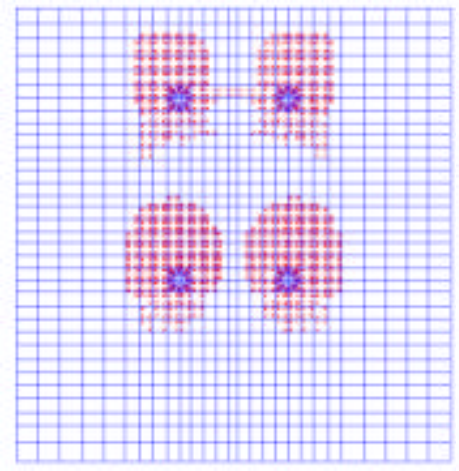

$60 k N$

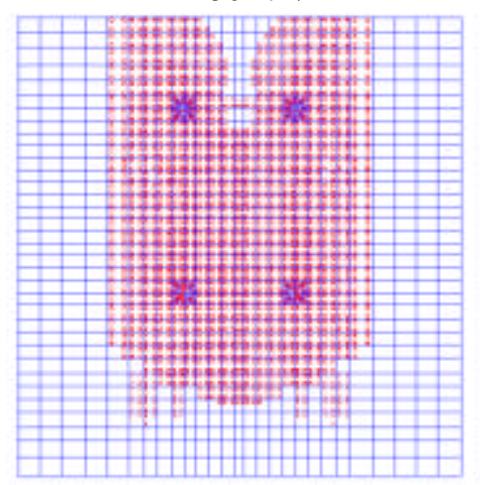

$20 k N$

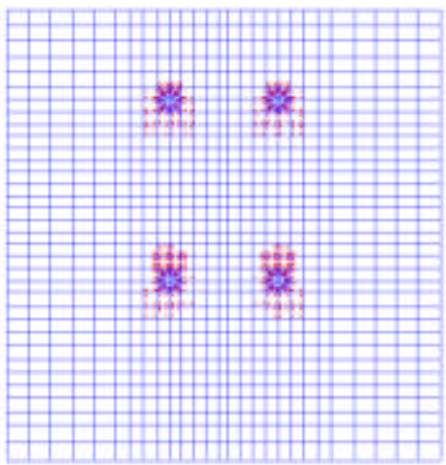

$50 k N$

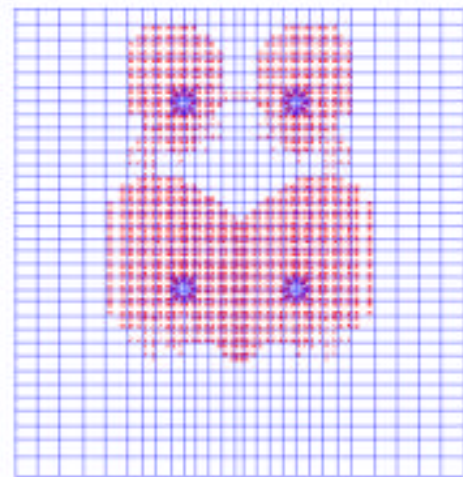

$70 \mathrm{kN}$

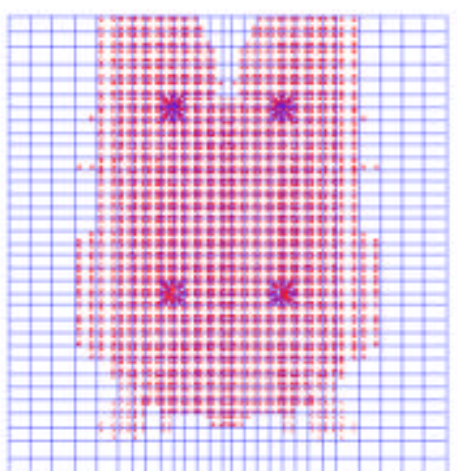

$30 k N$

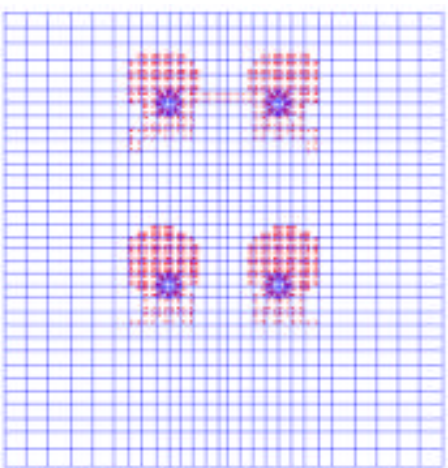

$52 \mathrm{kN}$

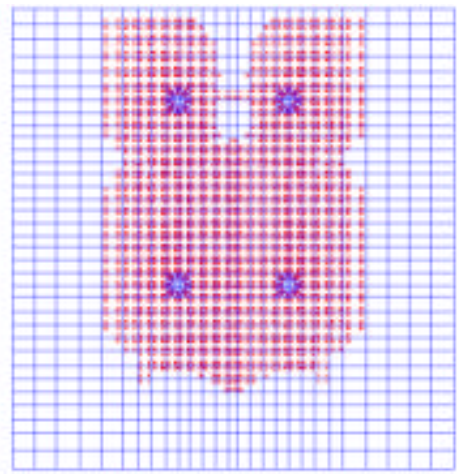

$82 \mathrm{kN}$

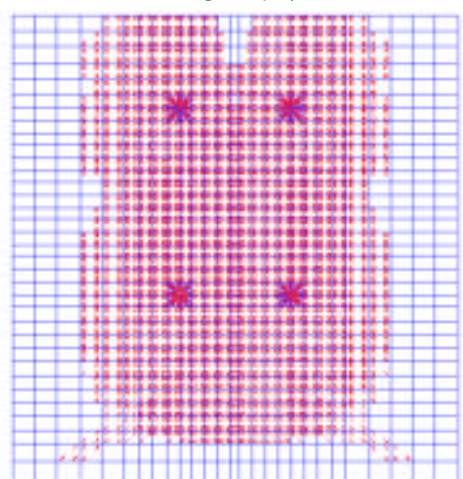

FIGURA 5.11: Progressão das fissuras na laje de concreto, modelo PHS-2

Como mencionado anteriormente, houve um aumento significativo das fissuras na laje entre as forças de 50 e $52 \mathrm{kN}$, o que leva a acreditar ser esse o principal motivo para o escorregamento do modelo PHS-2 na relação força-deslocamento. 
A pressão de contato entre o conector e o concreto para a força por conector de $82 \mathrm{kN}$ é apresentada na figura 5.12 .

O gráfico 5.9 apresenta o comportamento da pressão de contato no decorrer da solicitação, com referência as posições 1,2 e 3.

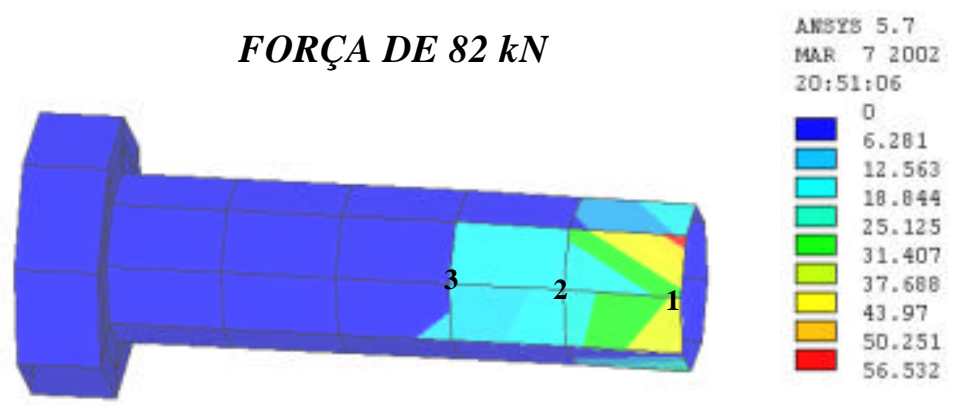

FIGURA 5.12: Pressão de contato $\left(\mathrm{kN} / \mathrm{cm}^{2}\right)$ entre o conector e o concreto, modelo PHS-2

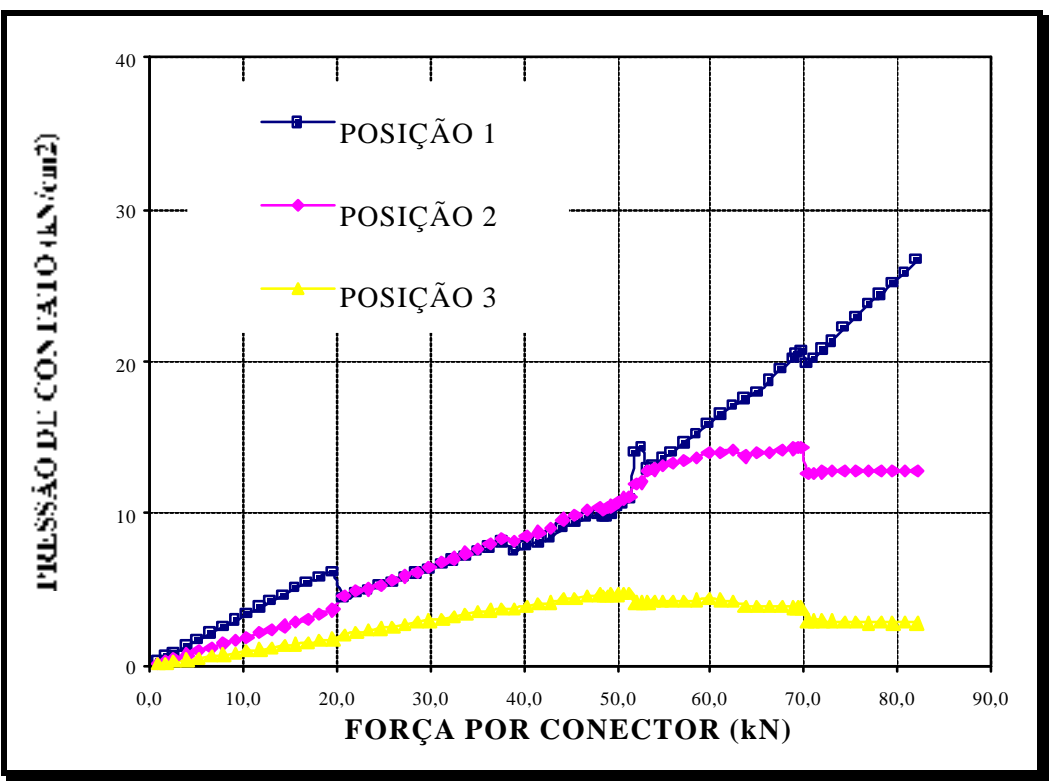

GRÁFICO 5.9: Relação pressão de contato x força por conector, modelo PHS-2

Assim como no modelo PHS-1, as tensões na armadura resultaram muito abaixo da tensão de escoamento do aço da armadura, como ilustrado na figura 5.13 para força no modelo de $328 \mathrm{kN}$. 


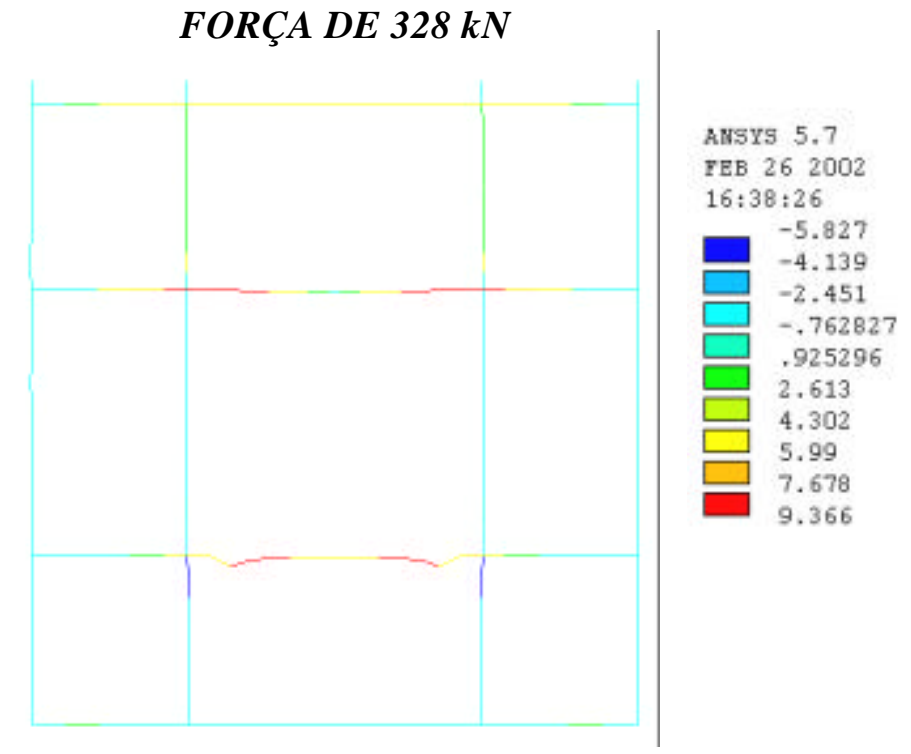

FIGURA 5.13: Tensão axial $\left(\mathrm{kN} / \mathrm{cm}^{2}\right)$ na armadura, modelo $P H S-2$

As tensões de Mises que ocorrem em um dos conectores, uma vez que os quatro apresentam comportamentos bastante semelhantes, é apresentada na figura 5.14 para força por conector de $82 \mathrm{kN}$. As regiões no conector para as quais são plotadas a relação entre tensão e força no conector (gráfico 5.10) são indicadas pelos números 1, 2, 3 e 4 na figura 5.14.

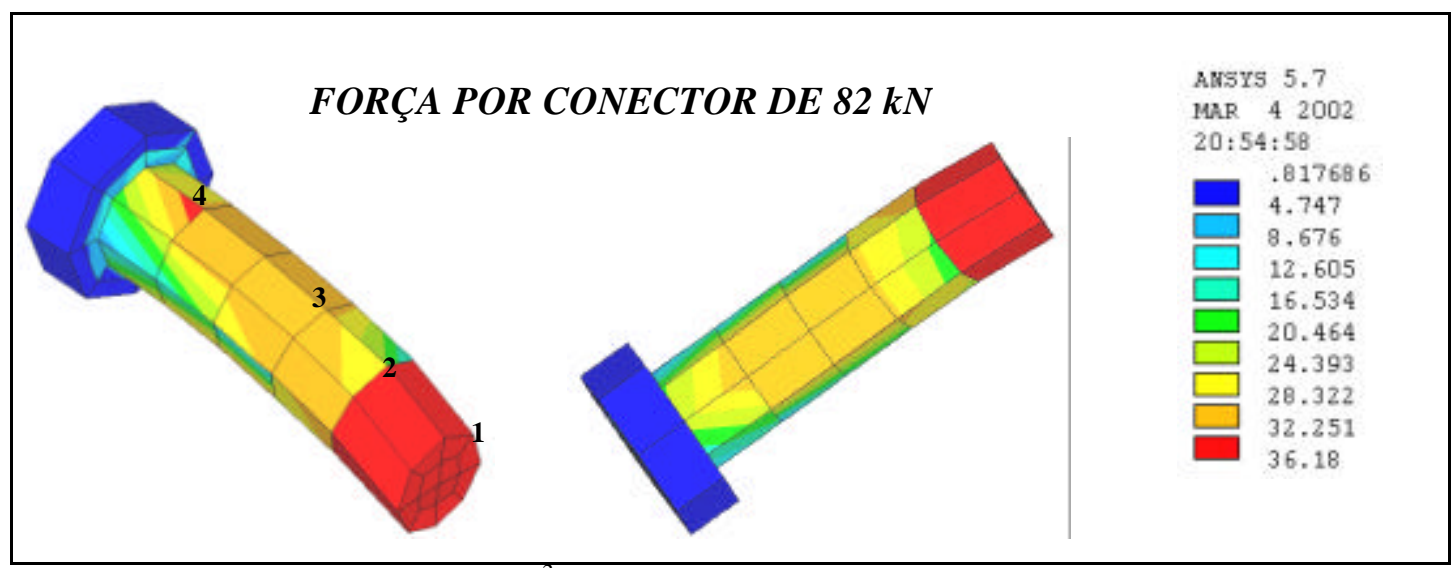

FIGURA 5.14: Tensão $\left(\mathrm{kN} / \mathrm{cm}^{2}\right)$ no conector pino com cabeça (stud), modelo PHS-2 


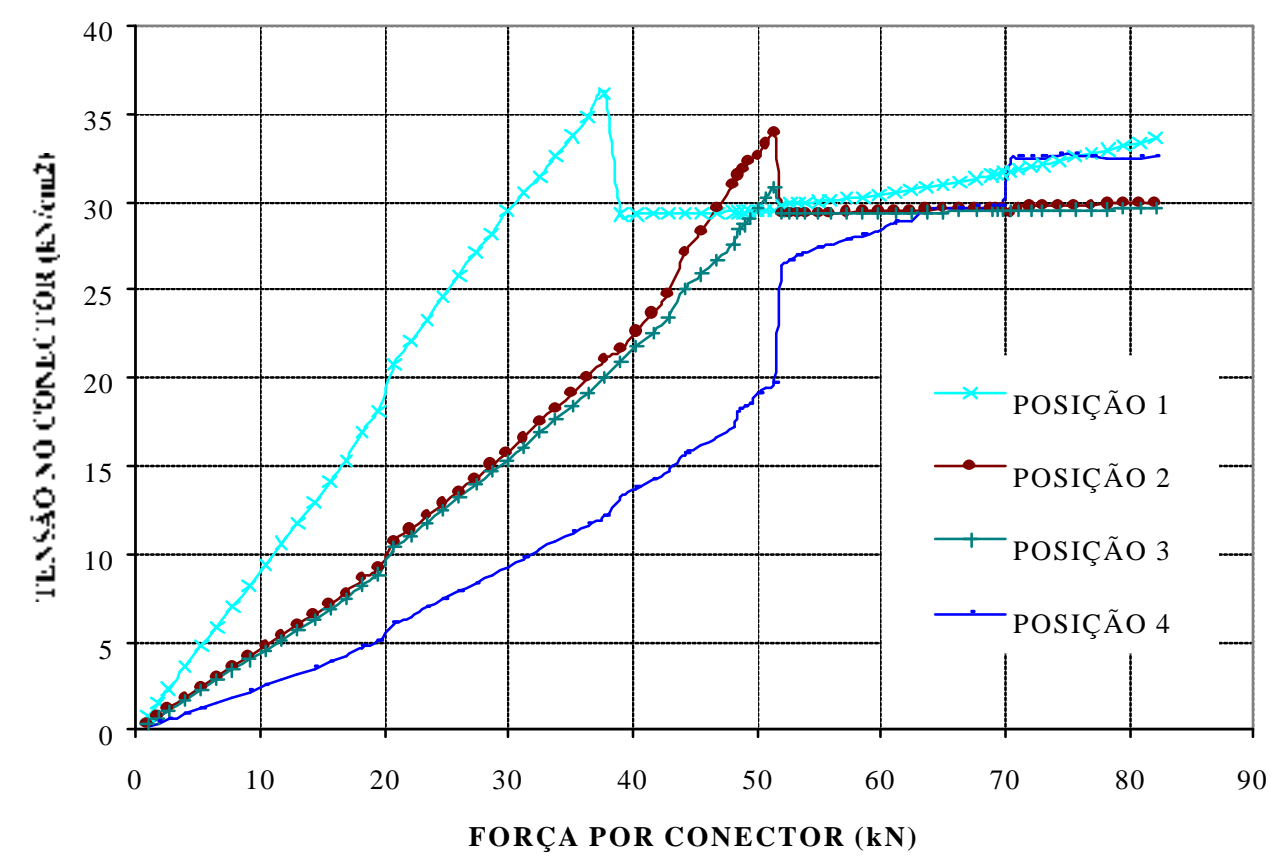

GRÁFICO 5.10: Relação tensão x força no conector, modelo PHS-2

\section{2 - MODELOS NUMÉRICOS COM CONECTORES TIPO PERFIL “U” FORMADOS A FRIO}

Conforme apresentado no item 3.3, MALITE (1993) realizou alguns ensaios tipo "Push-out" no Laboratório do Departamento de Estruturas das EESC/USP, utilizando nos modelos experimentais conectores tipo perfil " $U$ " formado a frio.

Em correspondência aos ensaios realizados por MALITE (1993), foram simulados numericamente quatro modelos experimentais referentes ao conector perfil " $U$ ", com aquelas dimensões já definidas nas figuras 3.5 e 3.6 do capítulo 3 do presente trabalho. Os modelos numéricos foram então denominados de PHU-EI, PHU-EII, PHU-FI e PHU-FII (tabela 4.1, capítulo 4), os quais serão melhores detalhados posteriormente.

As tabelas 5.7 e 5.8 apresentadas a seguir, definem as propriedades para aços do conector e da armadura, de acordo com os modelos de não-linearidade apresentado no item 4.2.3 do capítulo 4 do presente trabalho, e em correspondência com as características dos materiais utilizados nos modelos experimentais, obtidas em laboratório Essas propriedades são aplicadas para todos os modelos numéricos. 
TABELA 5.7: propriedades do aço do conector perfil " $U$ " formado a frio e do perfil metálico (referente à figura 4.14, capítulo 4)

\begin{tabular}{|c|c|c|c|c|c|c|c|c|}
\hline MATERIAL & $\begin{array}{c}\sigma_{\mathrm{a}} \\
\left(\mathrm{kN} / \mathrm{cm}^{2}\right)\end{array}$ & $\begin{array}{c}\sigma_{\mathrm{b}} \\
\left(\mathrm{kN} / \mathrm{cm}^{2}\right)\end{array}$ & $\begin{array}{c}\sigma_{\mathrm{c}} \\
\left(\mathrm{kN} / \mathrm{cm}^{2}\right)\end{array}$ & $\begin{array}{c}\sigma_{\mathrm{d}} \\
\left(\mathrm{kN} / \mathrm{cm}^{2}\right)\end{array}$ & $\begin{array}{c}E \\
\left(\mathrm{kN} / \mathrm{cm}^{2}\right)\end{array}$ & $\begin{array}{c}\mathrm{E}_{1} \\
\left(\mathrm{kN} / \mathrm{cm}^{2}\right)\end{array}$ & $\begin{array}{c}\mathrm{E}_{2} \\
\left(\mathrm{kN} / \mathrm{cm}^{2}\right)\end{array}$ & $\begin{array}{c}\mathrm{E}_{3} \\
\left(\mathrm{kN} / \mathrm{cm}^{2}\right)\end{array}$ \\
\hline $\begin{array}{c}\text { AÇO DO } \\
\text { CONECTOR }\end{array}$ & 17,35 & 24,78 & 35,37 & 35,37 & 19900 & 199 & 19,90 & 0 \\
\hline $\begin{array}{l}\text { AÇO DO } \\
\text { PERFIL }\end{array}$ & 17,40 & 37,73 & 54,26 & 54,26 & 19900 & 199 & 19,90 & 0 \\
\hline
\end{tabular}

TABELA 5.8: propriedades do aço da armadura (referente à figura 4.13, capítulo 4)

\begin{tabular}{|c|c|c|}
\hline MATERIAL & $\mathbf{f}_{\mathbf{y}}\left(\mathbf{k N} / \mathbf{c m}^{2}\right)$ & $\mathbf{E}\left(\mathbf{k N} / \mathbf{c m}^{2}\right)$ \\
\hline AÇO DA ARMADURA & 50,0 & 21000 \\
\hline
\end{tabular}

As tabelas 5.9 e 5.10, por sua vez, apresentam parâmetros para o modelo concreto (disponibilizado pelo ANSYS), associados aos modelos PHU-EI, PHU-EII, PHUFI e PHU-FII. Já o gráfico 5.11 ilustra a relação entre tensão e deformação, utilizada para o modelo elástico não-linear.

Vale ressaltar que se procurou manter um mesmo padrão de refinamento na discretização dos modelos numéricos, objetivando assim uma comparação mais confiável na relação entre a força e o deslocamento do conector, bem como das tensões nos componentes do modelo.

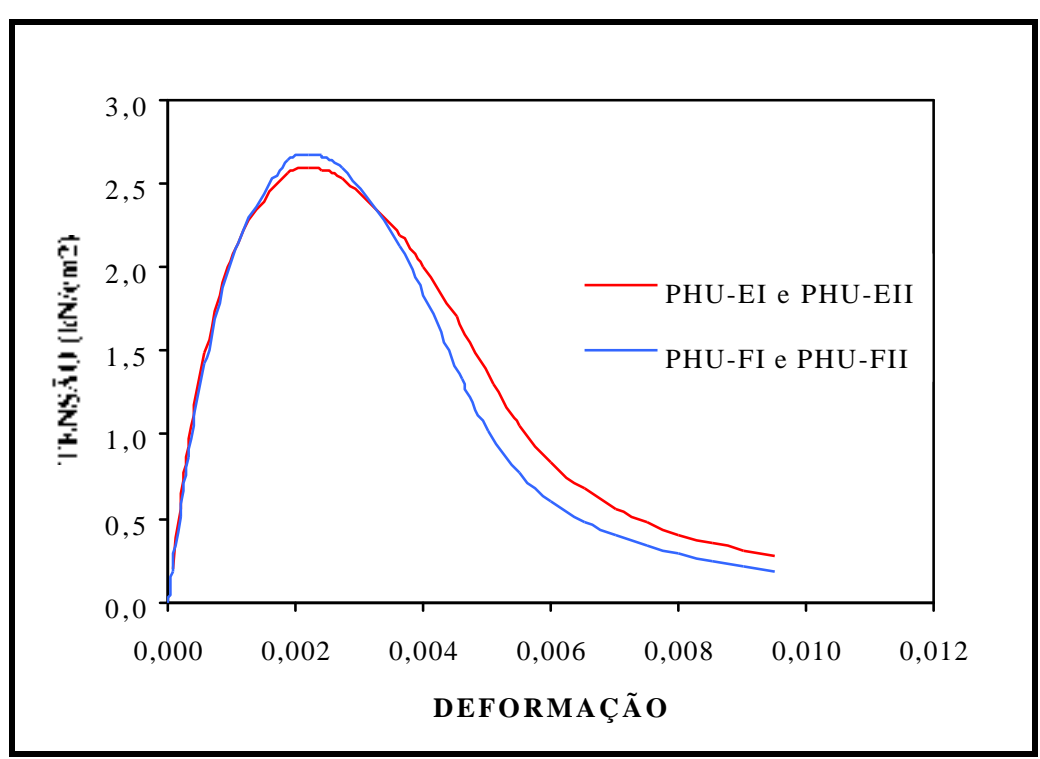

GRÁFICO 5.11: Relação tensão x deformação para o concreto, modelos PHU-EI, PHUEII, PHU-FI e PHU-FII 
TABELA 5.9: Valores dos parâmetros para o modelo concreto, modelos PHU-EI e PHU-

EII

\begin{tabular}{|c|c|}
\hline DESCRIÇÃO DOS PARÂMETROS & $\overline{V A L O R}$ \\
\hline Módulo de elasticidade $(\mathrm{E})-\left(\mathrm{kN} / \mathrm{cm}^{2}\right)$ & 3609 \\
\hline Coeficiente de transferência de cisalhamento para fissura aberta & 0,7 \\
\hline Coeficiente de transferência de cisalhamento para fissura fechada & 1,0 \\
\hline Resistência uniaxial à tração do material $\left(\mathrm{f}_{\mathrm{t}}\right)-\left(\mathrm{kN} / \mathrm{cm}^{2}\right)$ & 0,271 \\
\hline Resistência uniaxial à compressão do material $\left(\mathrm{f}_{\mathrm{c}}\right)-\left(\mathrm{kN} / \mathrm{cm}^{2}\right)$ & 2,59 \\
\hline Resistência biaxial à compressão do material $\left(\mathrm{f}_{\mathrm{cb}}\right)-\left(\mathrm{kN} / \mathrm{cm}^{2}\right)$ & 3,108 \\
\hline Estado de tensão hidrostática ambiente $\left(\sigma_{\mathrm{h}}{ }^{\mathrm{a}}\right)-\left(\mathrm{kN} / \mathrm{cm}^{2}\right)$ & $10^{-10}$ \\
\hline $\begin{array}{l}\text { Resistência ultima a compressão para o estado biaxial de compressão } \\
\text { superposta ao estado de tensão hidrostático ambiente }\left(\mathrm{f}_{1}\right)-\left(\mathrm{kN} / \mathrm{cm}^{2}\right)\end{array}$ & 3,756 \\
\hline $\begin{array}{l}\text { Resistência ultima a compressão para o estado uniaxial de compressão } \\
\text { superposta ao estado de tensão hidrostático ambiente }\left(\mathrm{f}_{2}\right)-\left(\mathrm{kN} / \mathrm{cm}^{2}\right)\end{array}$ & 4,468 \\
\hline Coeficiente para o amolecimento do material fiss & 1,0 \\
\hline
\end{tabular}

TABELA 5.10: Valores dos parâmetros para o modelo concreto, modelos PHU-FIePHU-

FII

\begin{tabular}{|c|c|}
\hline DESCRIÇÃO DOS PARÂMETROS & $\overline{V A L O R}$ \\
\hline Módulo de elasticidade $(\mathrm{E})-\left(\mathrm{kN} / \mathrm{cm}^{2}\right)$ & 3215 \\
\hline Coeficiente de transferência de cisalhamento para fissura aberta & 0,7 \\
\hline Coeficiente de transferência de cisalhamento para fissura fechada & 1,0 \\
\hline Resistência uniaxial à tração do material $\left(\mathrm{f}_{\mathrm{t}}\right)-\left(\mathrm{kN} / \mathrm{cm}^{2}\right)$ & 0,276 \\
\hline Resistência uniaxial à compressão do material $\left(\mathrm{f}_{\mathrm{c}}\right)-\left(\mathrm{kN} / \mathrm{cm}^{2}\right)$ & 2,67 \\
\hline Resistência biaxial à compressão do material $\left(\mathrm{f}_{\mathrm{cb}}\right)-\left(\mathrm{kN} / \mathrm{cm}^{2}\right)$ & 3,204 \\
\hline Estado de tensão hidrostática ambiente $\left(\sigma_{\mathrm{h}}{ }^{\mathrm{a}}\right)-\left(\mathrm{kN} / \mathrm{cm}^{2}\right)$ & $10^{-10}$ \\
\hline $\begin{array}{l}\text { Resistência ultima a compressão para o estado biaxial de compressão } \\
\text { superposta ao estado de tensão hidrostático ambiente }\left(\mathrm{f}_{1}\right)-\left(\mathrm{kN} / \mathrm{cm}^{2}\right)\end{array}$ & 3,872 \\
\hline $\begin{array}{l}\text { Resistência ultima a compressão para o estado uniaxial de compressão } \\
\text { superposta ao estado de tensão hidrostático ambiente }\left(\mathrm{f}_{2}\right)-\left(\mathrm{kN} / \mathrm{cm}^{2}\right)\end{array}$ & 4,606 \\
\hline Coeficiente para o amolecimento do material fissurado na tracão & 1,0 \\
\hline
\end{tabular}




\subsection{1 - ANÁLISE DO MODELO NUMÉRICO PHU-EI}

A figura 5.15 ilustra o modelo PHU-E1, responsável pela simulação numérica do ensaio tipo "Push-out" para conector perfil " $U$ " formado a frio com 2,66 mm de espessura na posição I.

Para calibração do modelo numérico foram confrontados, no gráfico 5.12, os resultados entre a força e o deslocamento do conector, com valores médios dos três modelos experimentais idênticos. $\mathrm{O}$ fator de rigidez de contato $(\mathrm{FKN})$ adotado para os ele mentos de contato foi 500 .

O modelo PHU-E1 apresentou correspondência bastante satisfatória para um nível de solicitação de aproximadamente $60 \mathrm{kN}$, ou seja, na fase elástica-linear. A partir desta força, até $84 \mathrm{kN}$, o modelo PHU-E1 tem maior rígidez quando comparada aos experimentais, a partir da qual não se obteve mais convergência.

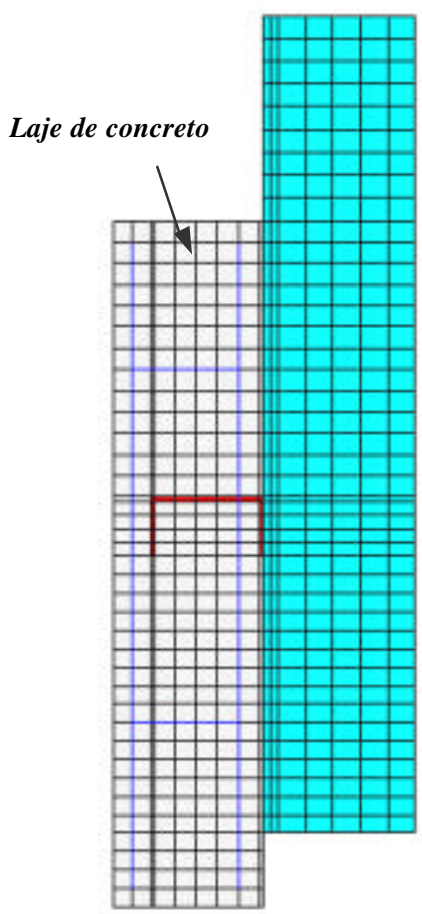

PLANO XY

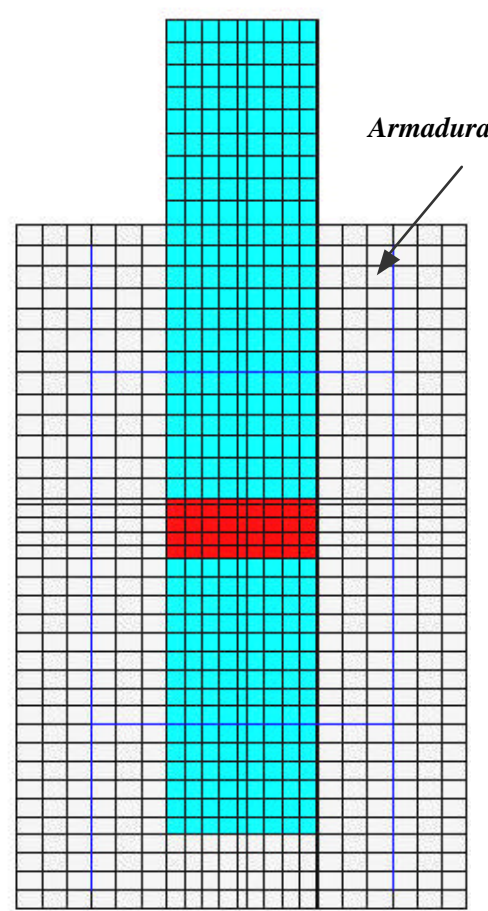

PLANO YZ

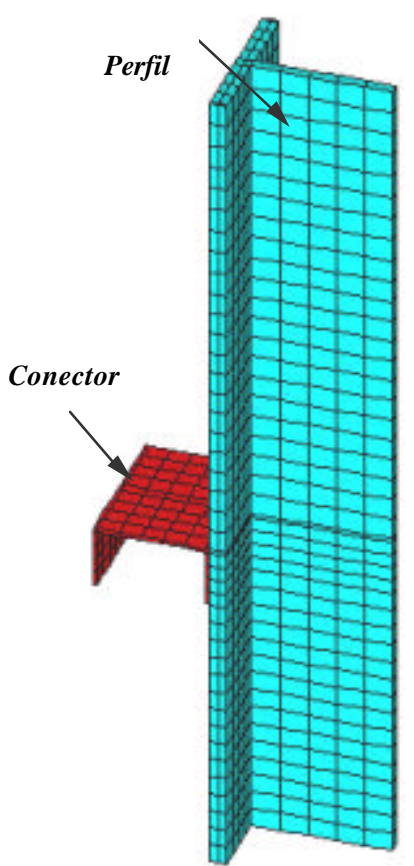

FIGURA 5.15: Visão geral do modelo numérico denominado PHU-EI 


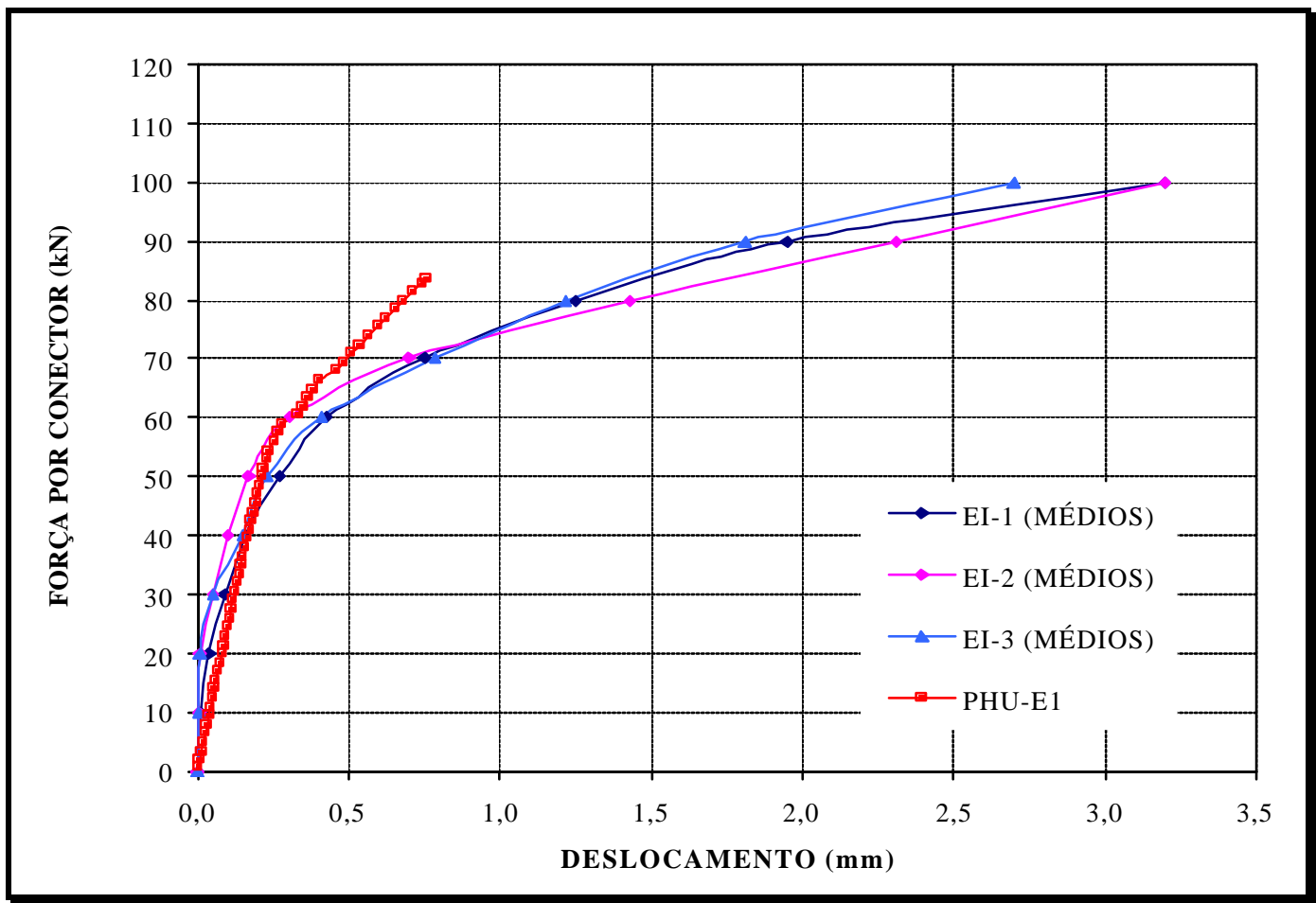

GRÁFICO 5.12: Relação força $x$ deslocamento referente ao modelo PHU-EI

A figura 5.16 ilustra as regiões da laje de concreto em que se adotou os modelos de não-linearidade para o concreto, no caso, modelo concreto e modelo elástico não-linear. As tensões de Mises na laje, para solicitação no modelo igual a 84 kN, são ilustradas na figura 5.17.

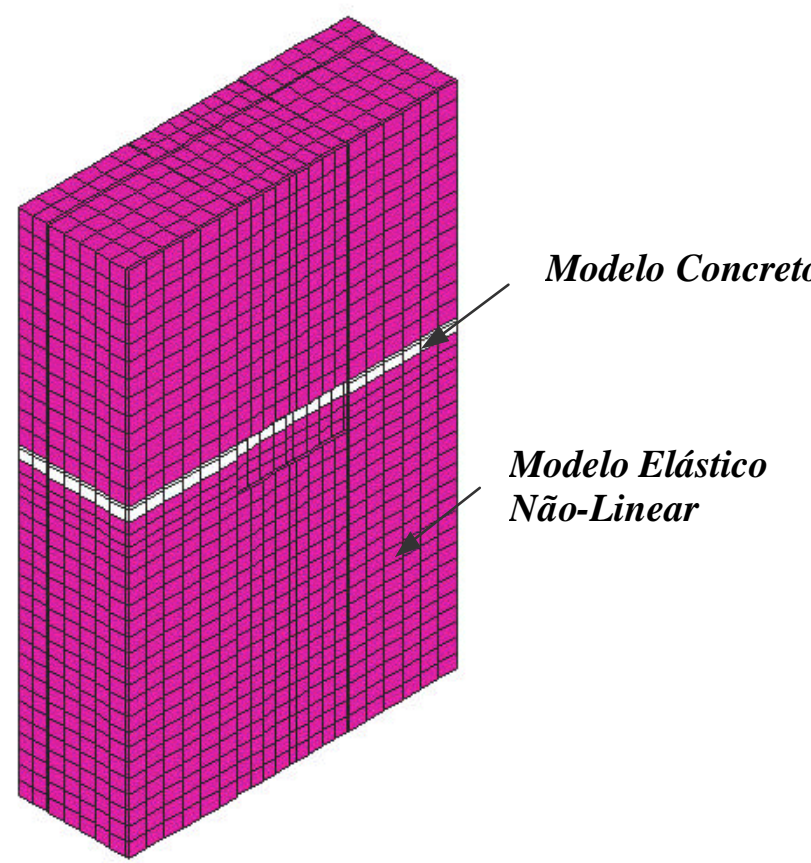

FIGURA 5.16: Modelos de não-linearidade na laje de concreto, modelo PHU-EI 


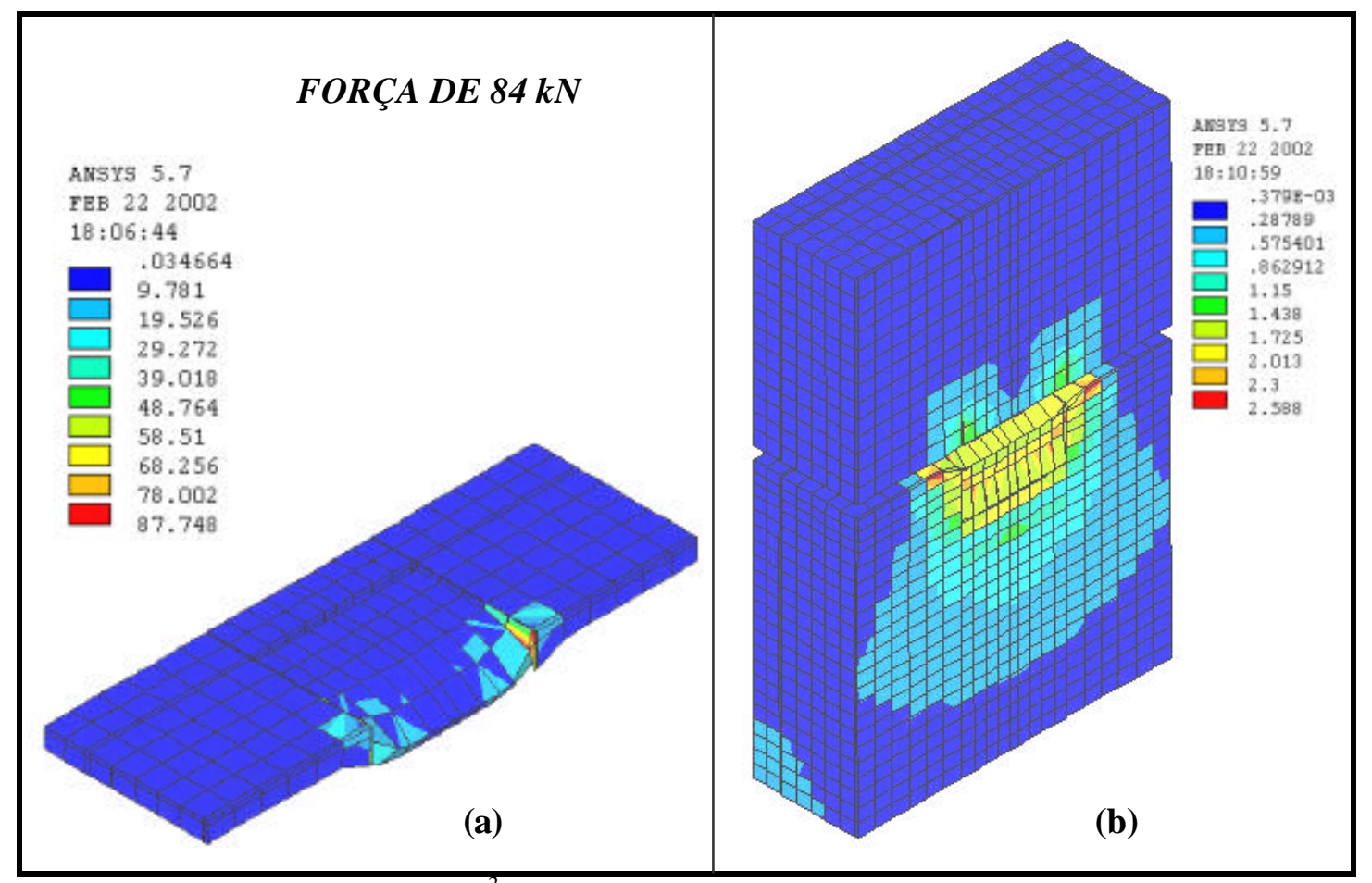

FIGURA 5.17: Tensão $\left(\mathrm{kN} / \mathrm{cm}^{2}\right)$ no concreto, região da laje com o modelo concreto $($ a) $e$ modelo elástico não-linear (b), modelo PHU-EI

As tensões na armadura resultaram baixas em todos os incrementos de força, como ilustra a figura 5.18, inclusive para força última de $84 \mathrm{kN}$. Os números 1, 2, 3, 4 e 5 apresentados na figura 5.18 têm correspondência com as posições na armadura, para as quais serão plotadas, no gráfico 5.13, a relação entre a força no modelo e a tensão na armadura, para todos os incrementos de força.

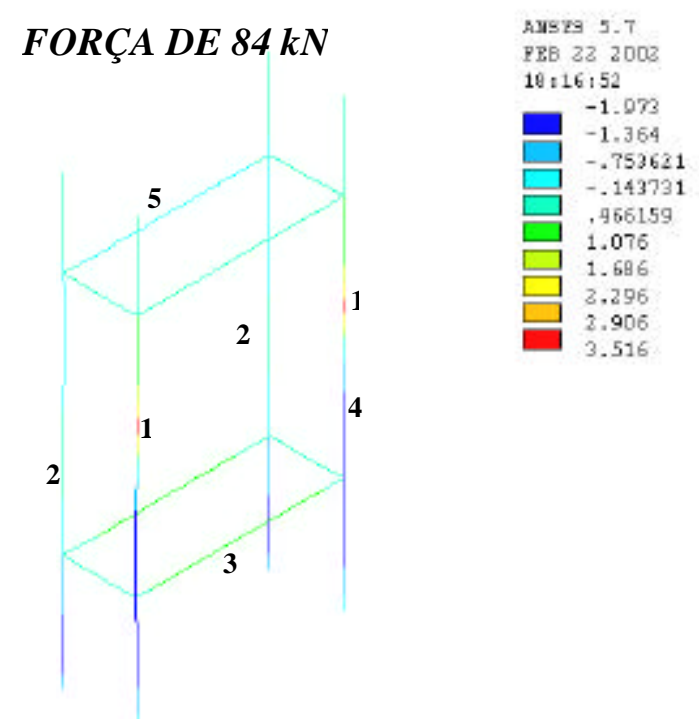

FIGURA 5.18: Tensão axial $\left(\mathrm{kN} / \mathrm{cm}^{2}\right)$ na armadura da laje, modelo PHU-EI 


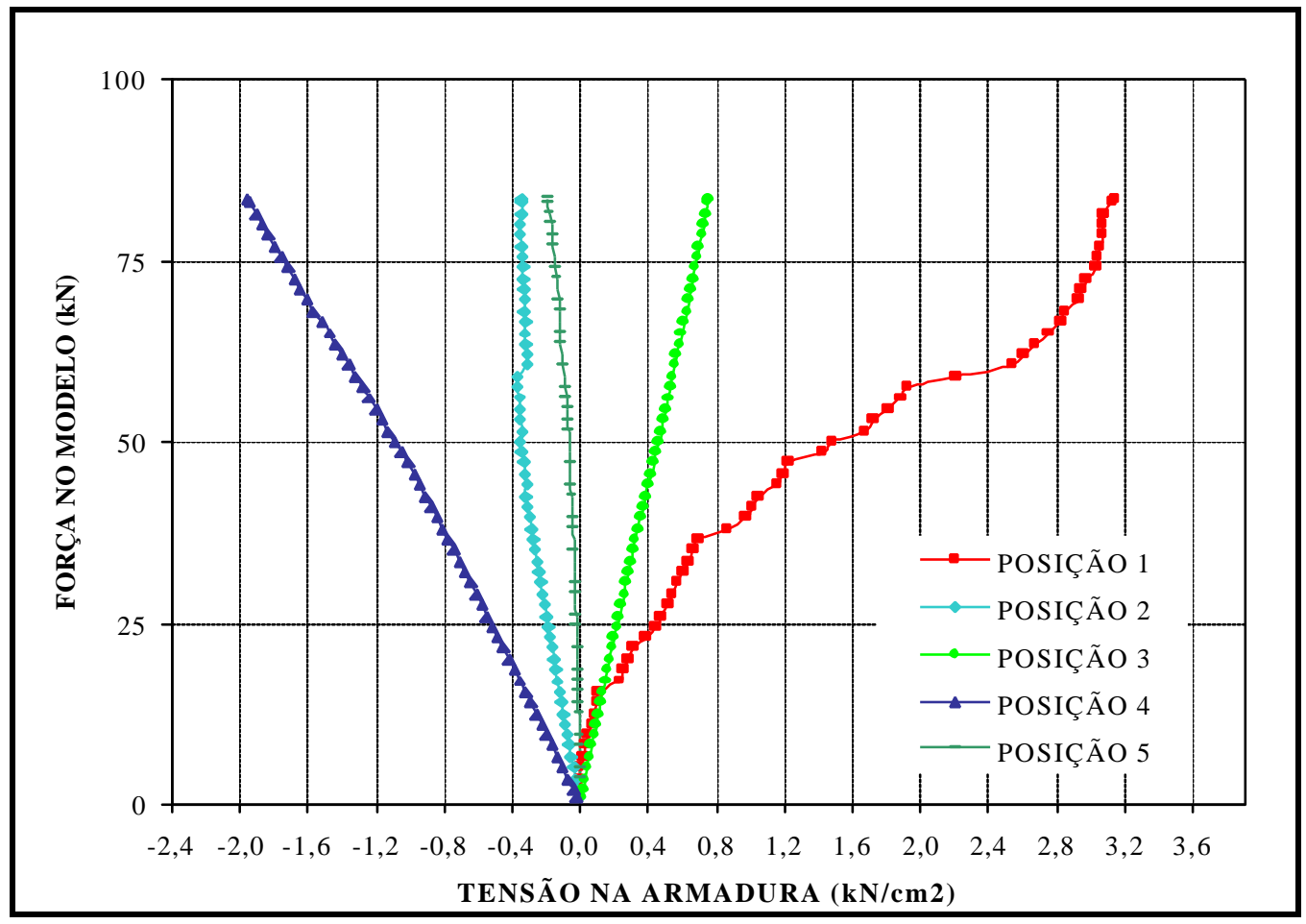

GRÁFICO 5.13: Relação força $x$ tensão na armadura, modelo PHU-EI

Pode-se observar que nestas regiões não ocorrem inversões de esforços, ou seja, as posições 2, 4 e 5 resultam sempre comprimidas, enquanto que as posições 1 e 3 resultam sempre tracionadas. A posição 1 é a região mais solicitada da armadura.

As tensões de Mises no conector são apresentadas na figura 5.19, em que a maior tensão de Mises, foi identificada na região da alma do perfil "U".

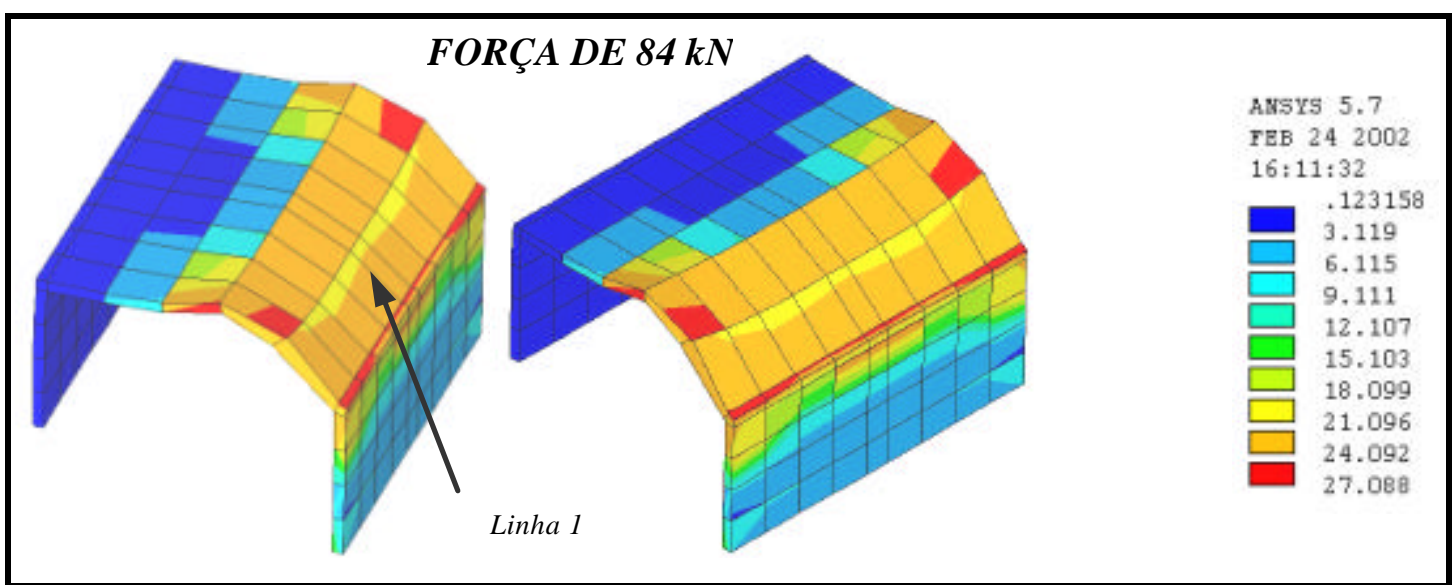

FIGURA 5.19: Tensão $\left(\mathrm{kN} / \mathrm{cm}^{2}\right)$ no conector, modelo PHU-EI 
No gráfico 5.14 apresenta-se o comportamento do conector com relação às tensões de Mises atuantes, em $\mathrm{kN} / \mathrm{cm}^{2}$, o qual os valores foram tomados a partir dos nós indicados na linha 1 (figura 5.19), ou seja, posições 1, 2, 3, 4, 5 e 6 (ao longo da altura do perfil "U”).

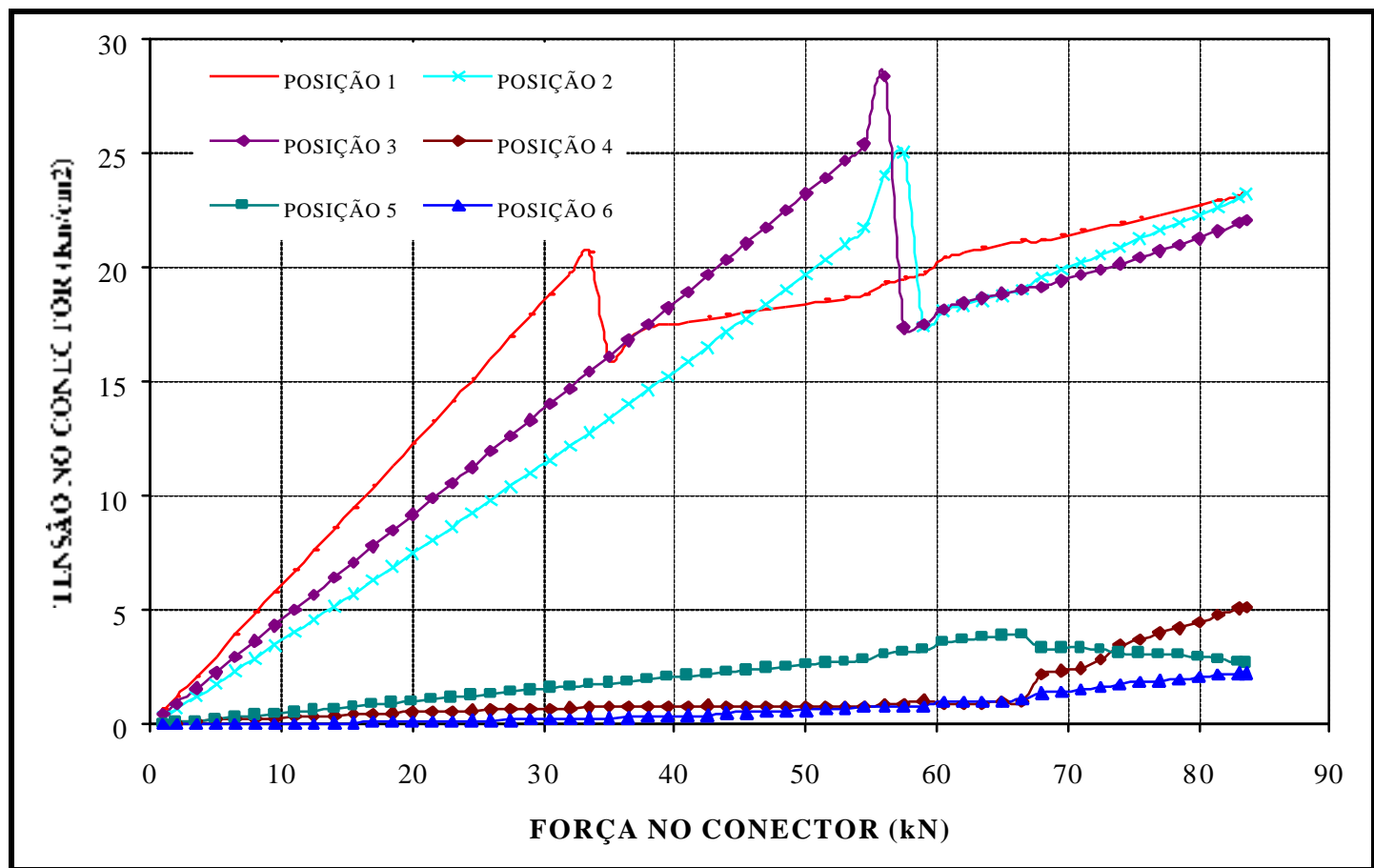

GRÁFICO 5.14: Relação tensão $x$ força no conector, modelo PHU-EI

Por uma análise com referência ao gráfico 5.14, inicialmente para a posição 1 , as tensões aumentam rapidamente até atingir a tensão de proporcionalidade $\left(\sigma_{\mathrm{a}}\right)$ de 17,35 $\mathrm{kN} / \mathrm{cm}^{2}$. A partir desse instante, os elementos localizados nas posições número 2 e 3 começam a ser responsável por uma maior parcela de força, e conseqüentemente, um aumento nas tensões até atingirem a tensão de escoamento $\left(f_{\mathrm{y}}\right)$ igual a $24,78 \mathrm{kN} / \mathrm{cm}^{2}$.

\subsection{2 - ANÁLISE DO MODELO NUMÉRICO PHU-EII}

O modelo numérico PHU-EII com conector na posição II é ilustrado na figura 5.20. Analogamente ao modelo PHU-EI, o gráfico 5.15 apresenta os resultados da relação força e deslocamento do conector do modelo PHU-EII, confrontado com valores 
médios de três modelos experimentais idênticos. Assim como no modelo PHU-EI, o fator de rigidez de contato (FKN) adotado para os elementos de contato foi 500 .

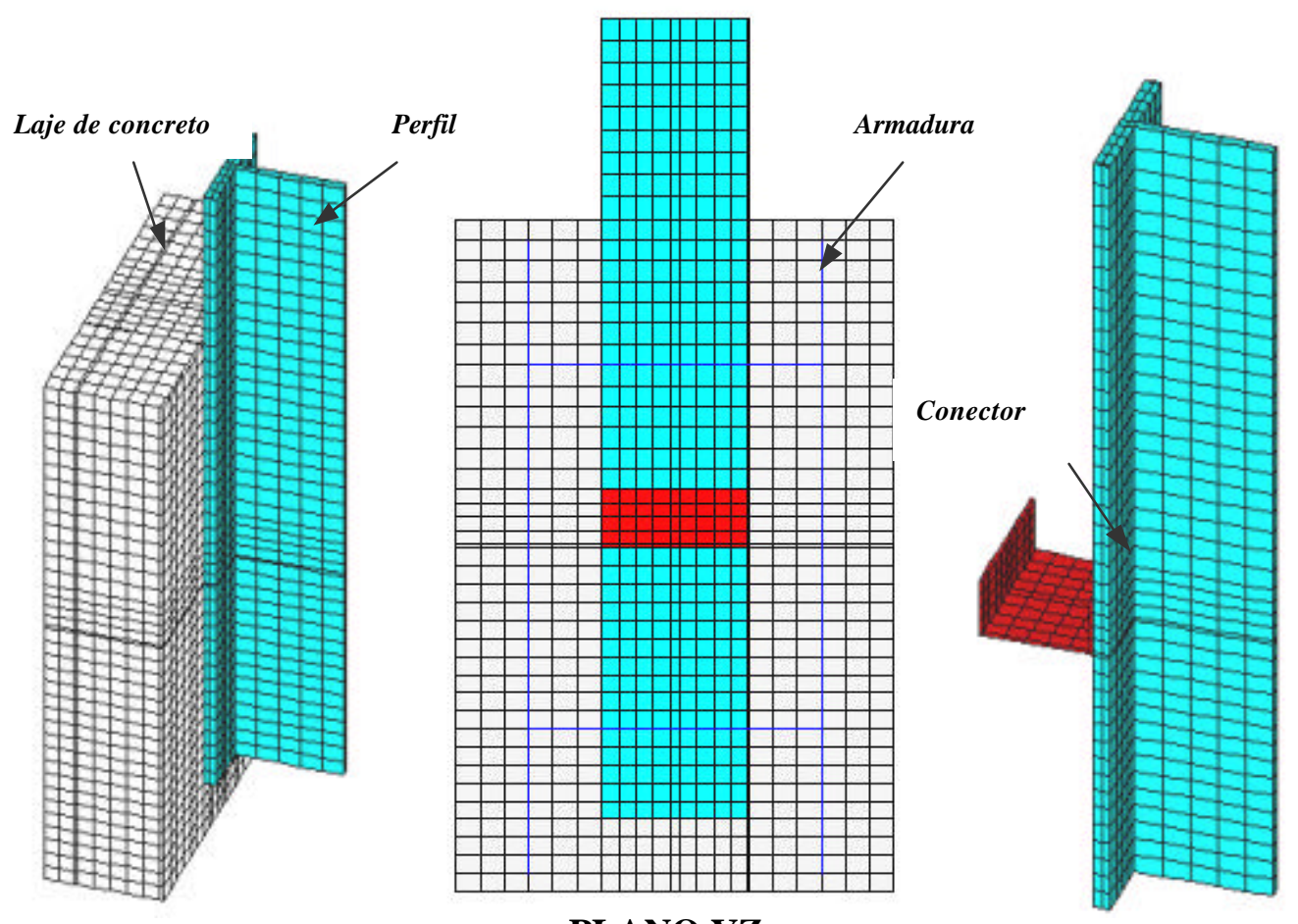

PLANO YZ

FIGURA 5.20: Visão geral do modelo numérico denominado PHU-EII

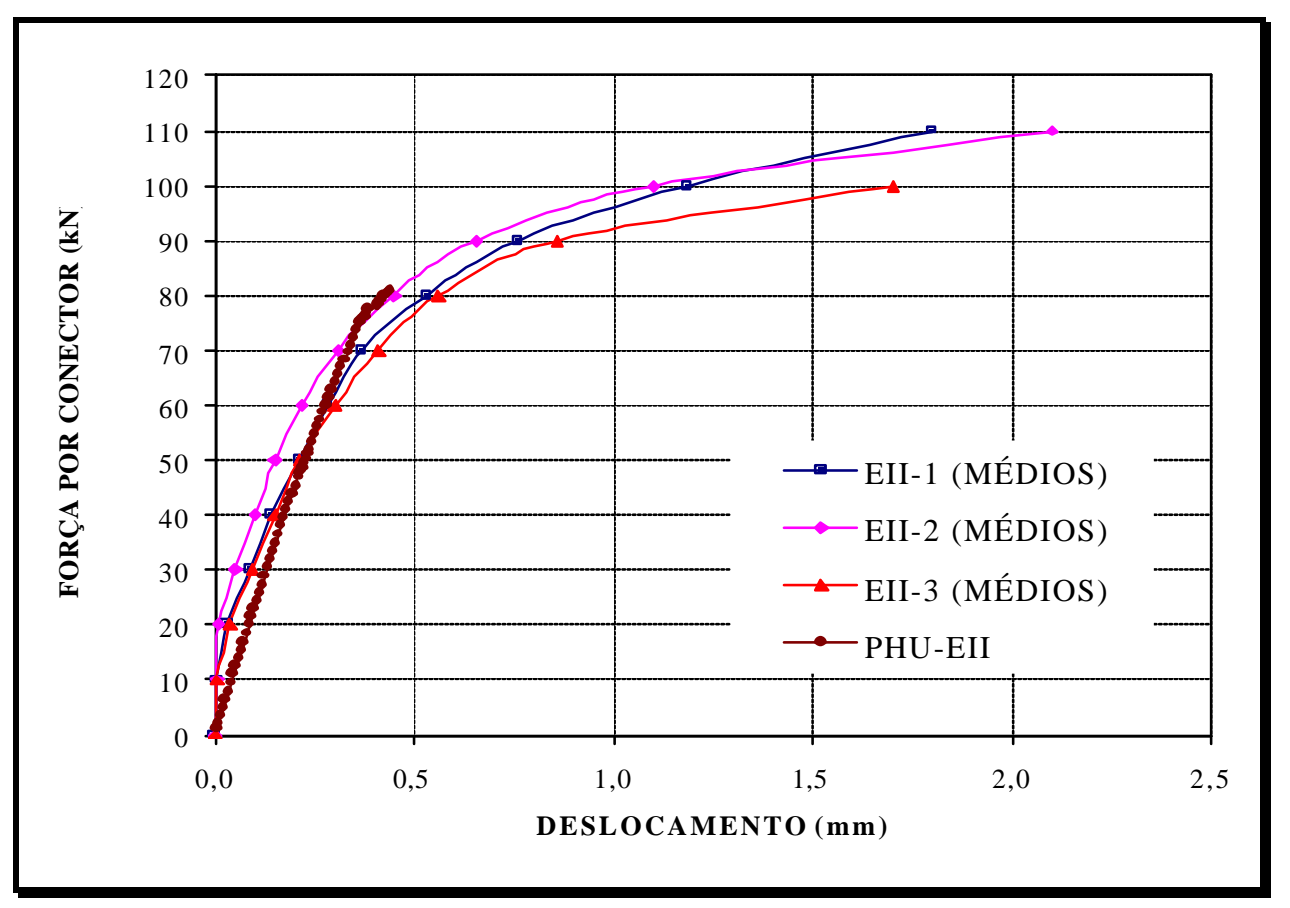

GRÁFICO 5.15: Relação força $x$ deslocamento referente ao modelo PHU-EII 
$\mathrm{O}$ modelo PHU-EII apresentou até a força de $70 \mathrm{kN}$ rigidez um pouco menor quando comparada com os experimentais. A partir desta força, o modelo PHU-EII começou a apresentar uma não-linearidade na relação força-deslocamento, até atingir a força de $81 \mathrm{kN}$, a partir da qual não obteve mais convergência.

A figura 5.21 ilustra as regiões da laje de concreto em que se adotou os modelos de não-linearidade para o concreto, no caso, modelo concreto e modelo elástico não-linear. As tensões de Mises na laje, para força no modelo de $81 \mathrm{kN}$, são ilustradas na figura 5.22 .

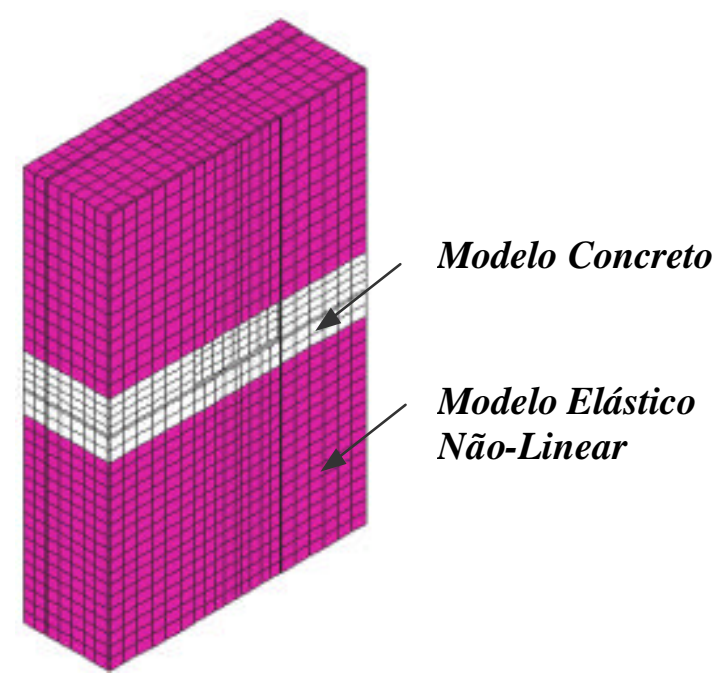

FIGURA 5.21: Modelos de não-linearidade na laje de concreto, modelo PHU-EII

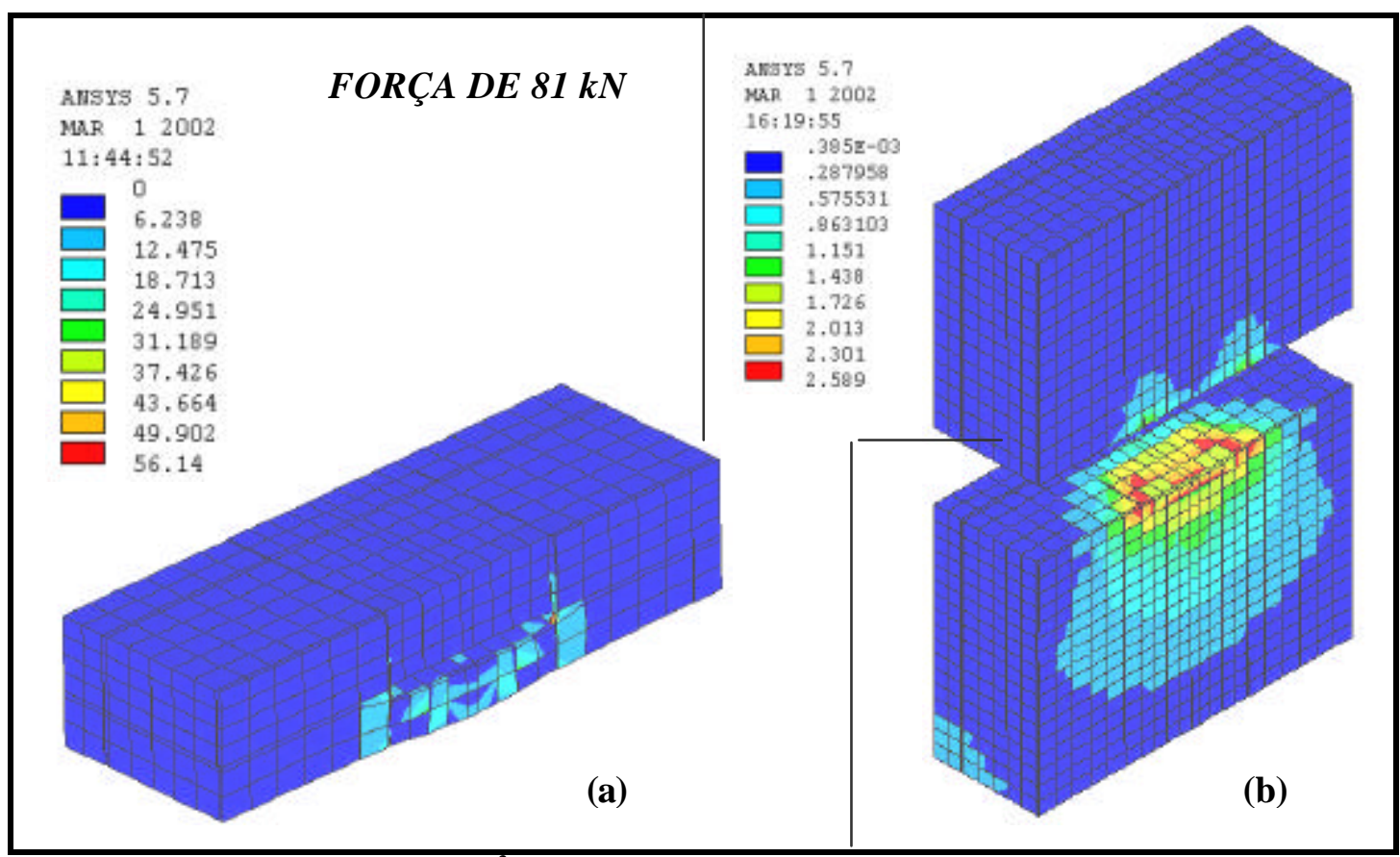

FIGURA 5.22: Tensão $\left(\mathrm{kN} / \mathrm{cm}^{2}\right)$ no concreto, região da laje com o modelo concreto $(a) e$ modelo elástico não-linear (b), modelo PHU-EII 
A figura 5.23 ilustra os valores de tensões na armadura, para uma força de 81 kN aplicada ao modelo, em que observa-se uma mesma distribuição de tensões quando comparada àquelas obtidas com o modelo PHU-EI.

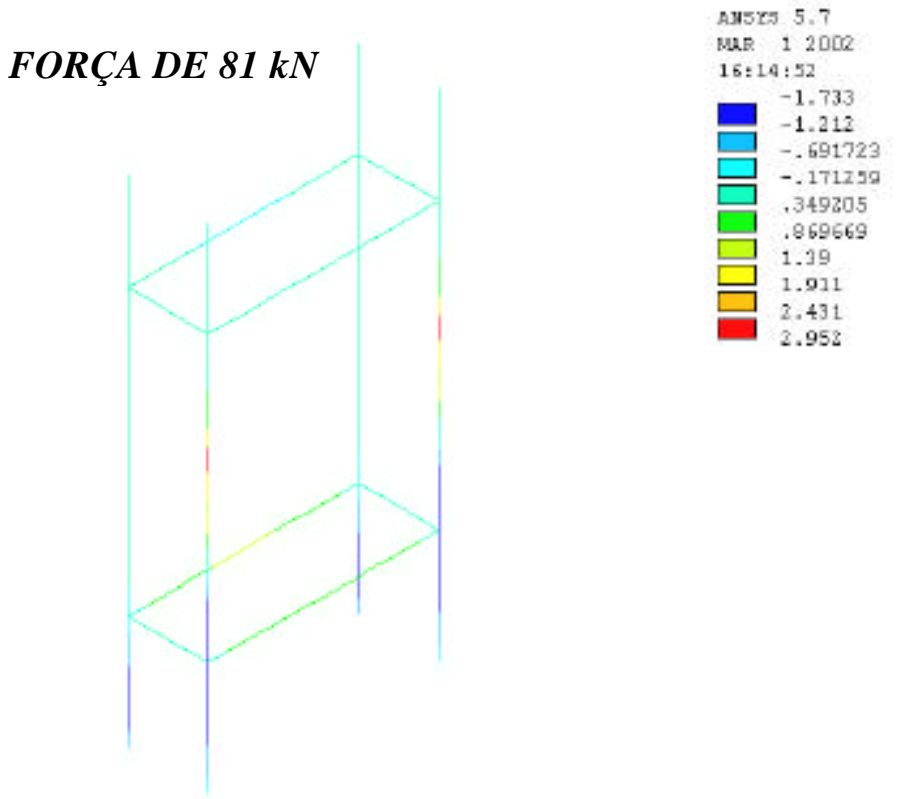

FIGURA 5.23: Tensão axial $\left(\mathrm{kN} / \mathrm{cm}^{2}\right)$ na armadura da laje, modelo PHU-EII

A tensão de Mises no conector sob uma força de $81 \mathrm{kN}$ é apresentada na figura 5.24. Assim como no modelo PHU-EI, a região de maior tensão situa-se na alma do perfil "U". No gráfico 5.16 é apresentada a relação entre tensão de Mises e força no conector, o qual os valores foram tomados a partir dos nós indicados na linha 1 (figura 5.24), ou seja, posições 1, 2, 3, 4, 5 e 6 (ao longo da altura do perfil "U"). O comportamento do conector no modelo PHU-EII mostrou-se semelhante a do modelo PHU-EI.

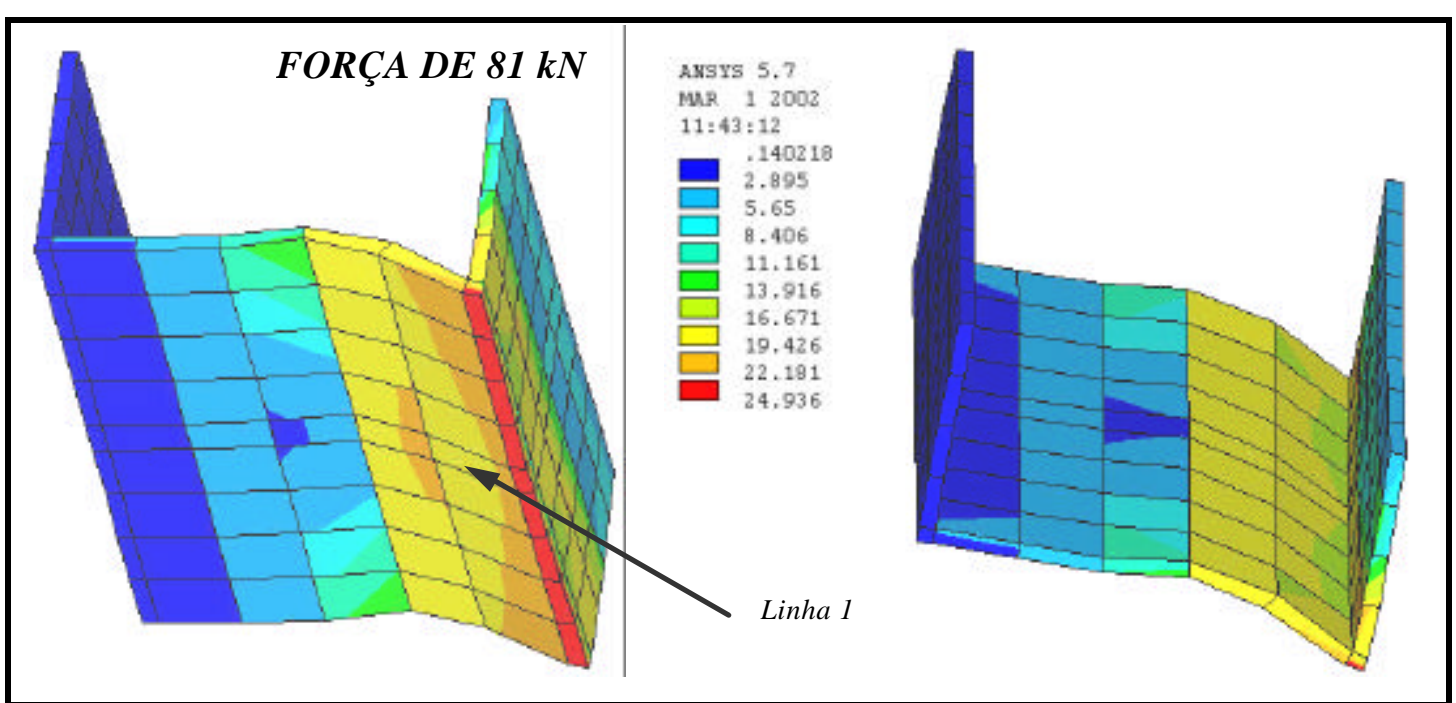

FIGURA 5.24: Tensão $\left(\mathrm{kN} / \mathrm{cm}^{2}\right)$ no conector, modelo PHU-EII 


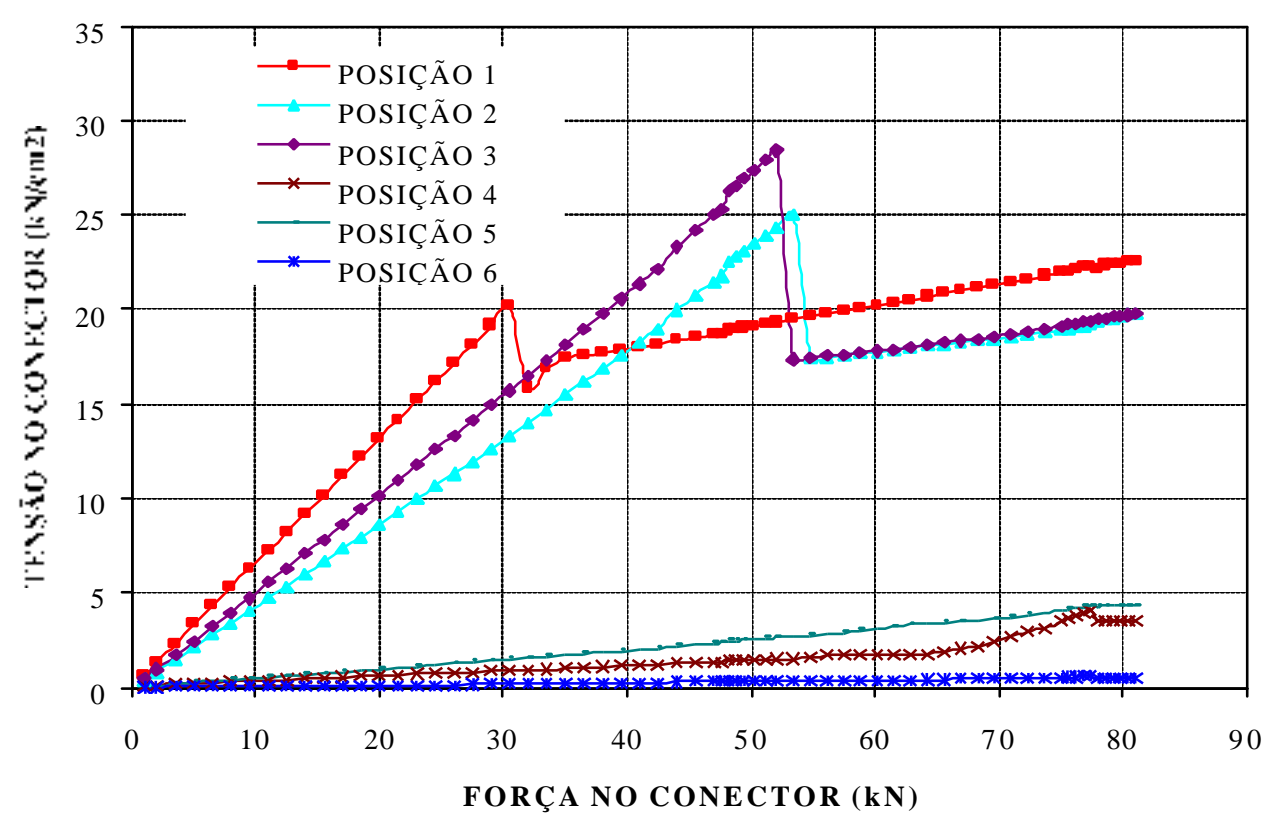

GRÁFICO 5.16: Relação tensão $x$ força no conector, modelo PHU-EII

\subsection{3 - ANÁLISE DO MODELO NUMÉRICO PHU-FI}

Na figura 5.25 é ilustrado o modelo PHU-F1, responsável pela simulação numérica do ensaio tipo "Push-out" para conector perfil " $U$ " formado a frio com 4,76 mm de espessura.
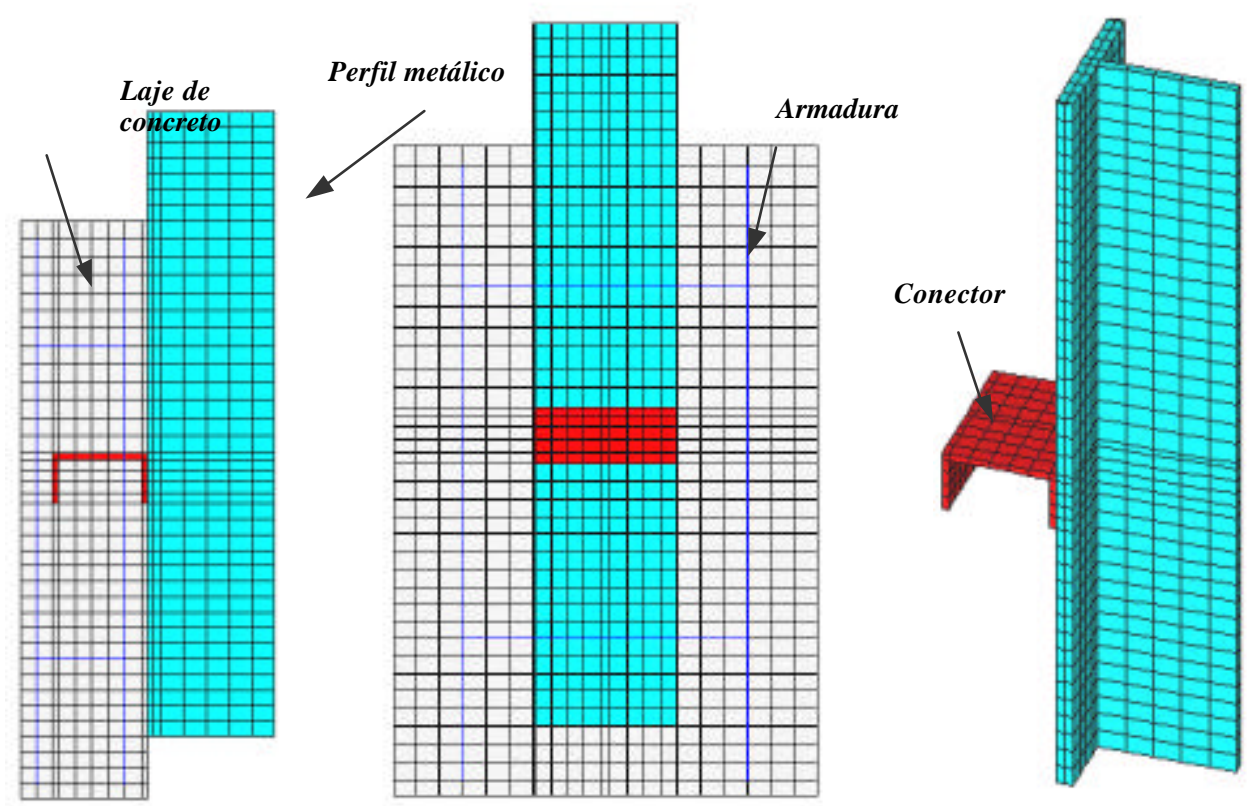

FIGURA 5.25: Visão geral do modelo numérico PHU-FI 
Analogamente ao modelo numérico PHU-E1, para calibração do modelo numérico PHU-F1 foram confrontados, no gráfico 5.17, os resultados entre a força e o deslocamento do conector com valores médios de três modelos experimentais idênticos. $\mathrm{O}$ fator de rigidez (FKN) adotado para os elementos de contato foi 500.

O resultado do modelo apresenta ótima concordância quando comparado com os experimentais, até o valor de força igual a $147 \mathrm{kN}$, a partir da qual não mais apresentou convergência em correspondência a uma tolerância de 0,001 com referência às diferenças entre deslocamentos sucessivos.

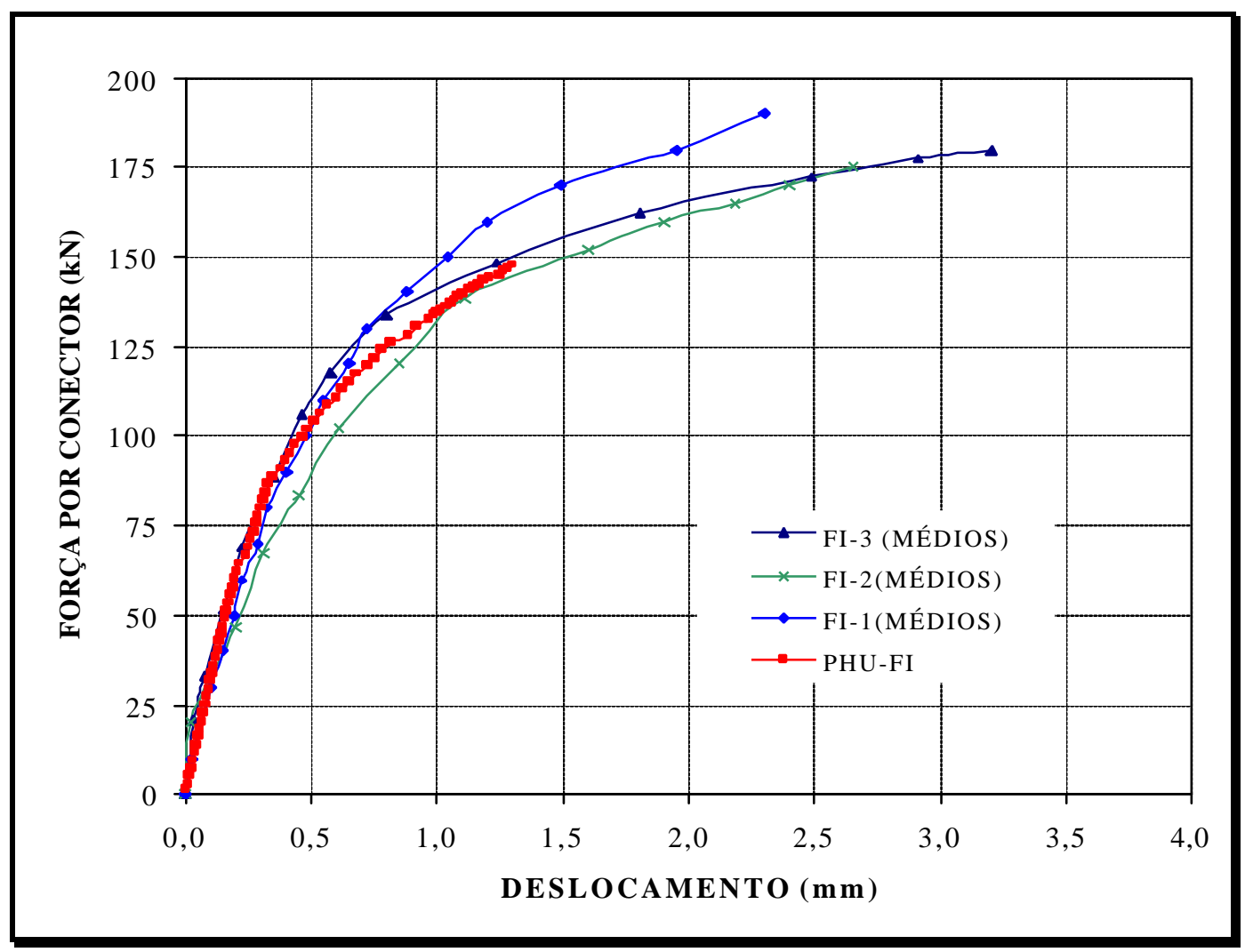

GRÁFICO 5.17: Relação força $x$ deslocamento, modelo PHU-FI

As regiões na laje de concreto em que se utilizam os modelos de nãolinearidade são ilustradas na figura 5.26. A região que utiliza elementos finitos que correspondem ao modelo concreto são aquelas em que são identificadas tensões bastante elevadas, as quais aparecem em resposta à pressão de contato exercida pelo conector, conforme ilustra a figura 5.27, para uma força aplicada ao modelo igual a $147 \mathrm{kN}$. 


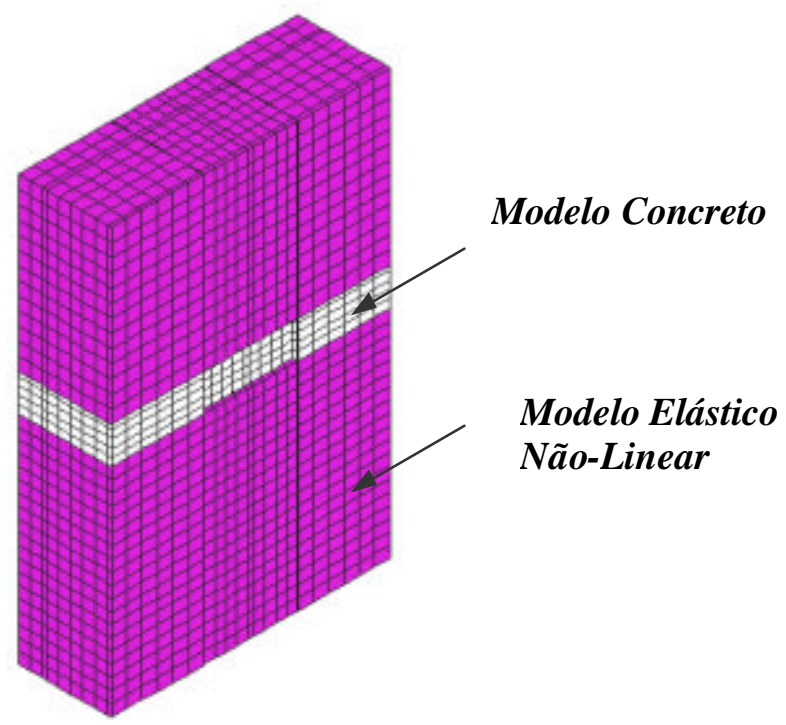

FIGURA 5.26: Modelos de não-linearidade na laje de concreto, modelo PHU-FI

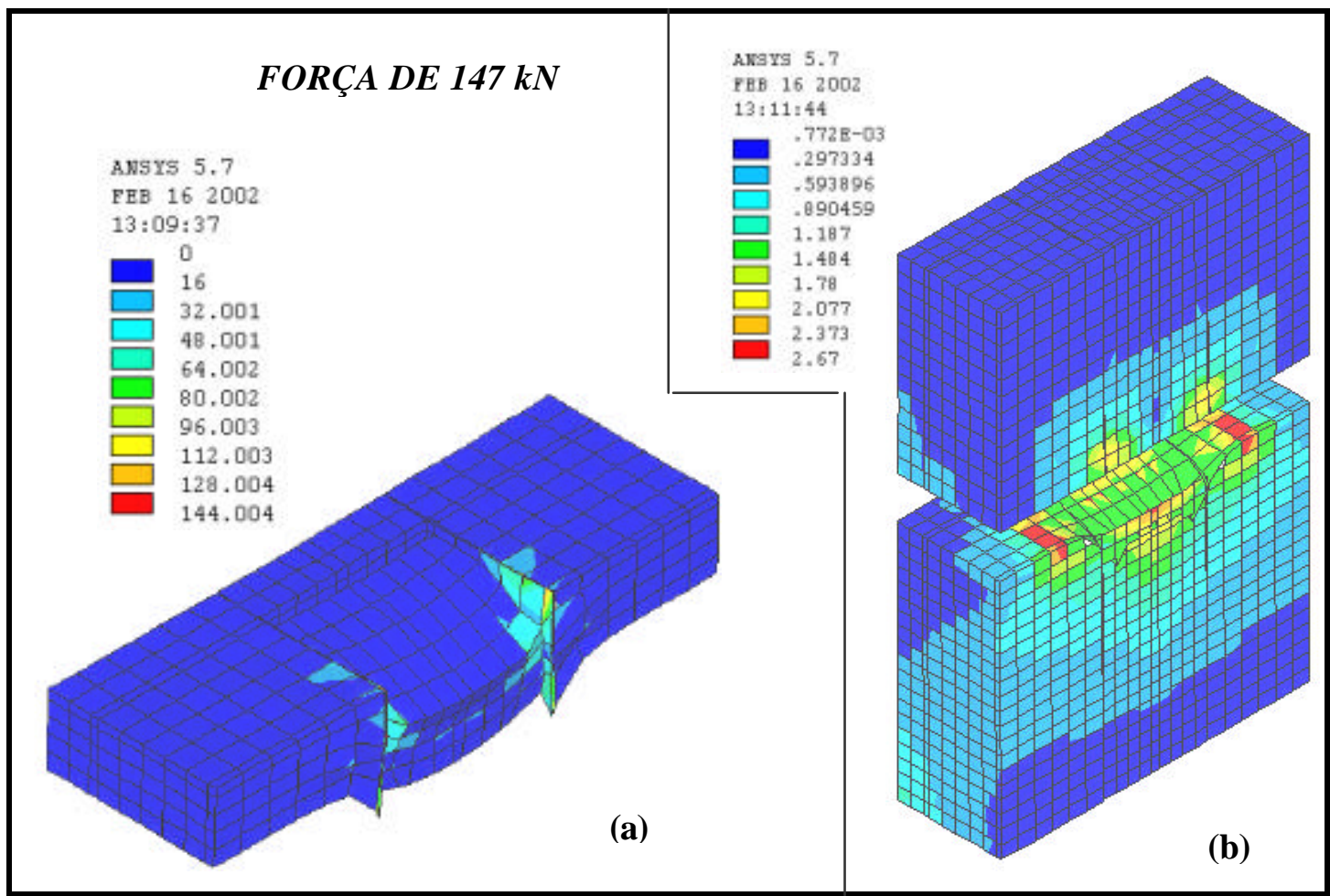

FIGURA 5.27: Tensão de Mises $\left(\mathrm{kN} / \mathrm{cm}^{2}\right)$ no concreto, região da laje com o modelo concreto(a) e modelo elástico não-linear (b), modelo PHU-FI

As tensões na armadura, assim como nos outros modelos, resultaram baixas, mesmo em estágios últimos de solicitação, como ilustradas na figura 5.28. Vale ressaltar que as maiores tensões foram verificadas na região do conector, referentes as posições 1 e 2 . 
O gráfico 5.18 mostra a relação entre a força no modelo e a tensão na armadura, nas posições 1 e 2. Na posição 1, a armadura está comprimida até a força de 9,5 $\mathrm{kN}$, a partir do qual passa a ficar tracionada. Por outro lado, na posição 2, a armadura fica comprimida até a força de $97 \mathrm{kN}$ e, posteriormente, tracionada até a força última.

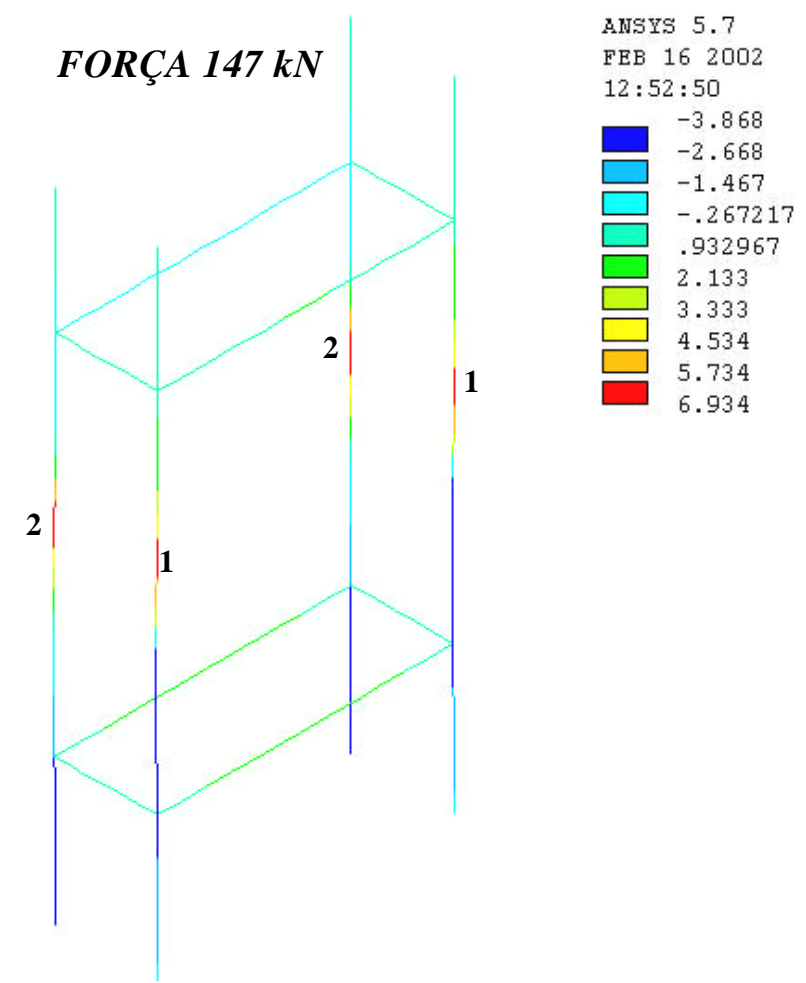

FIGURA 5.28: Tensão axial $\left(\mathrm{kN} / \mathrm{cm}^{2}\right)$ na armadura da laje, modelo PHU-FI

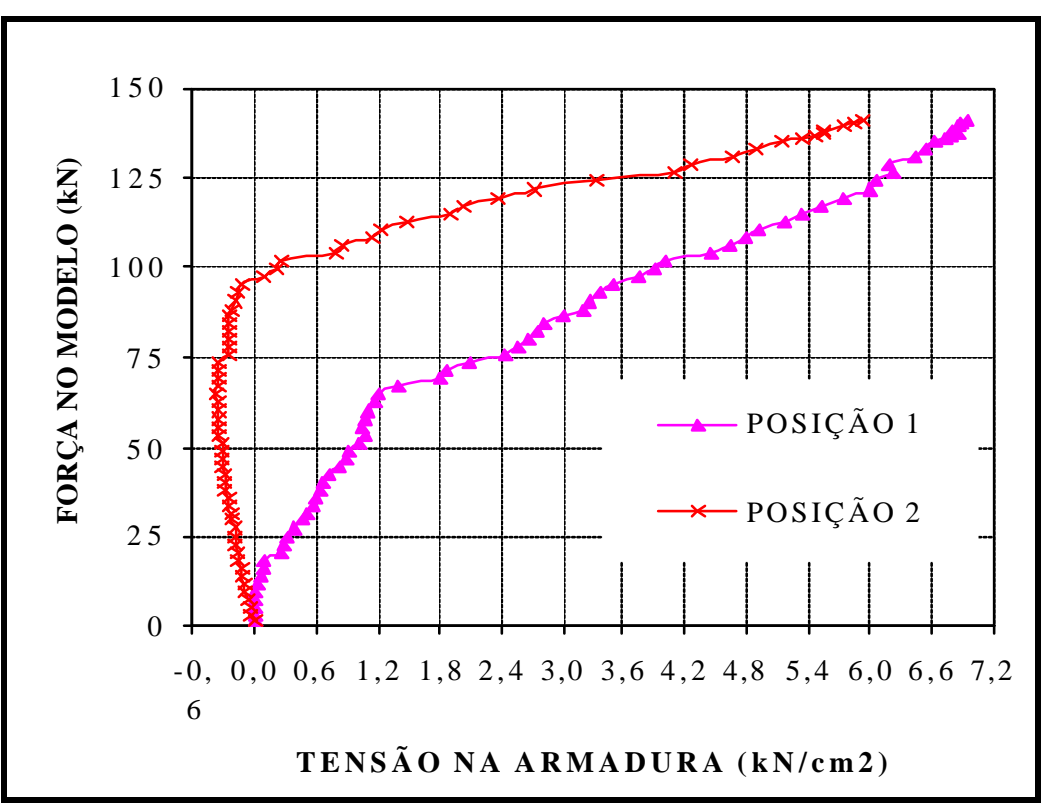

GRÁFICO 5.18: Relação força $x$ tensão na armadura, modelo PHU-FI 
As tensões de Mises no conector também são apresentadas na figura 5.29, em que a maior tensão dá-se na região da alma. Vale ressaltar que na figura 5.29, os três elementos finitos que apresentam cor vermelha têm tensões elevadas, mesmo estando na região da alma mais afastada da mesa do perfil metálico.

Tal fato deve-se à redistribuição das tensões que ocorrem quando o elemento de posição 1 atinge a tensão de proporcionalidade $\left(\sigma_{\mathrm{a}}\right)$ de $24,78 \mathrm{kN} / \mathrm{cm}^{2}$ e logo depois os elementos de posições 2 e 3 , atingem a tensão de escoamento do aço do conector $\left(f_{y}\right)$ de $24,78 \mathrm{kN} / \mathrm{cm}^{2}$, conforme comportamento exemplificado no gráfico 5.19 , por meio da relação entre a tensão e a força no conector, o qual os valores foram tomados a partir dos nós indicados na linha 1 (figura 5.29), ou seja, posições 1, 2, 3, 4, 5 e 6 (ao longo da altura do perfil "U").

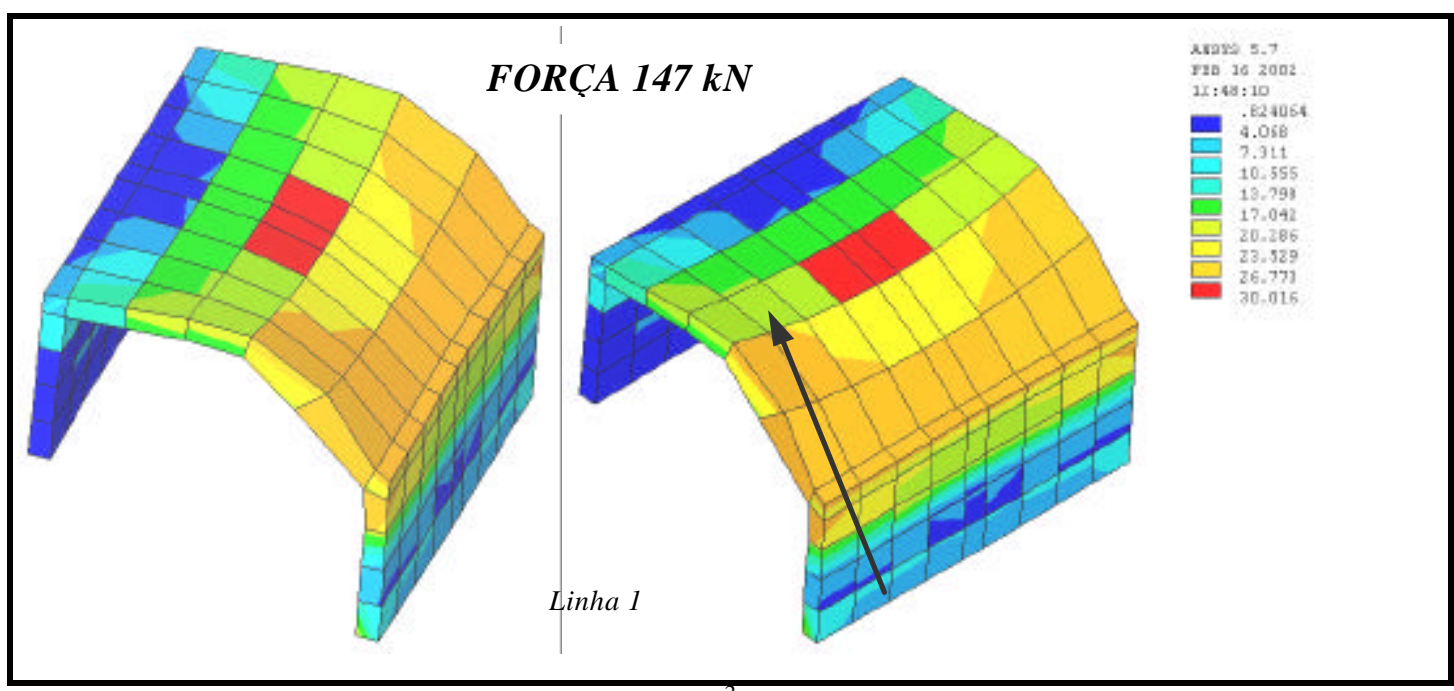

FIGURA 5.29: Tensão $\left(\mathrm{kN} / \mathrm{cm}^{2}\right)$ no conector, modelo $\mathrm{PHU}-\mathrm{FI}$

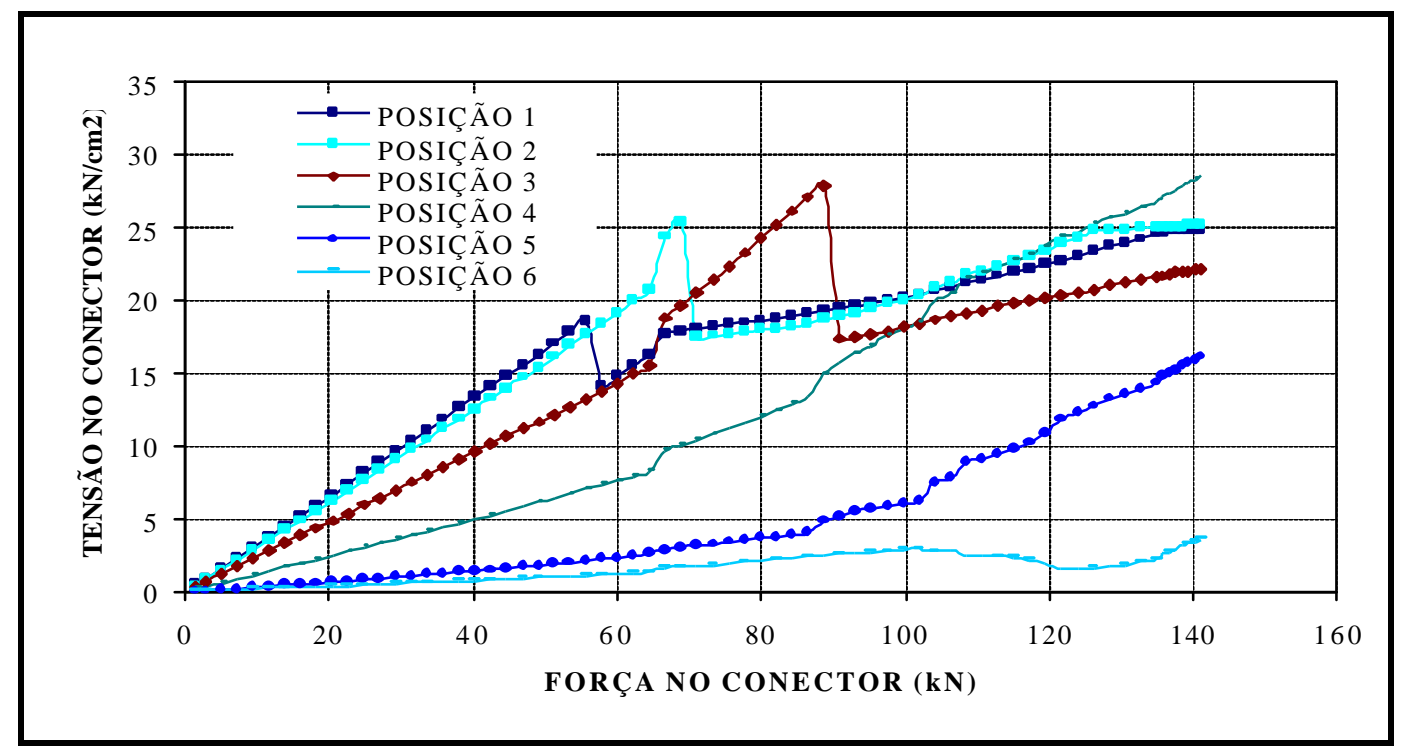

GRÁFICO 5.19: Relação tensão $x$ força no conector, modelo PHU-FI 


\subsection{4 - ANÁLISE DO MODELO NUMÉRICO PHU-FII}

$\mathrm{Na}$ figura 5.30 ilustra-se uma visão global do modelo PHU-FII, cuja discretização foi elaborada com vistas à obtenção do mesmo grau de refinamento aplicado ao modelo PHU-FI. No modelo em questão, PHU-FII, é possível notar que o conector perfil "U” está na posição invertida quando comparada àquela adotada no modelo PHU-FI.

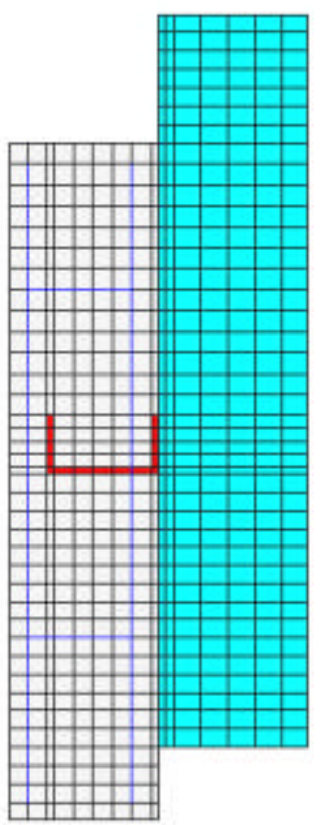

PLANO XY

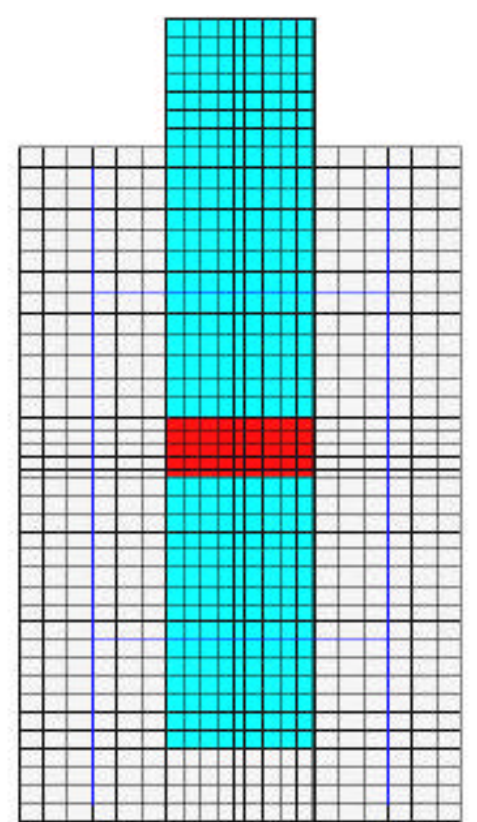

PLANO YZ

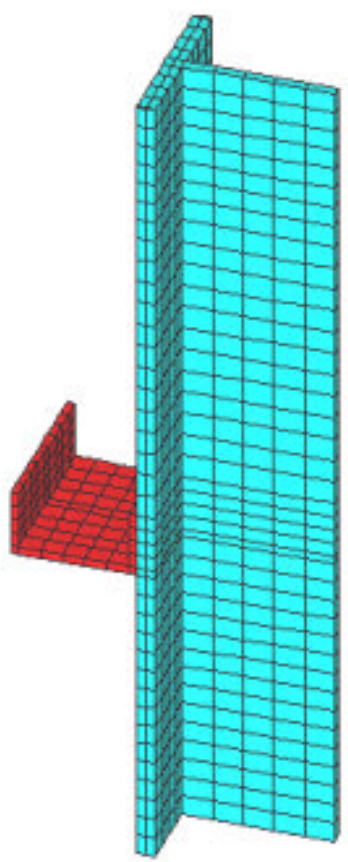

FIGURA 5.30: Visão geral do modelo PHU-FII

No gráfico 5.20 são confrontados os resultados entre força e deslocamento do conector para o modelo numérico PHU-FII, com valores médios dos três modelos experimentais idênticos. Assim como no modelo PHU-FI, o fator de rigidez de contato (FKN) adotado para os elementos de contato do modelo PHU-FII foi 500.

Por meio de uma análise com referência ao gráfico 5.20, nota-se que o modelo PHU-FII, até um nível de solicitação aplicada igual a $139 \mathrm{kN}$, apresentou resultados bastante satisfatórios quando comparados aos resultados experimentais. A partir de então, não mais apresentou convergência para uma tolerância de 0,001 com relação aos incrementos de deslocamentos.

A discretização adotada para a laje de concreto quanto à consideração de não-linearidade do material está ilustrado na figura 5.31, em que foi utilizado o modelo concreto nas regiões críticas do modelo, cujas tensões resultaram bastante elevadas. 


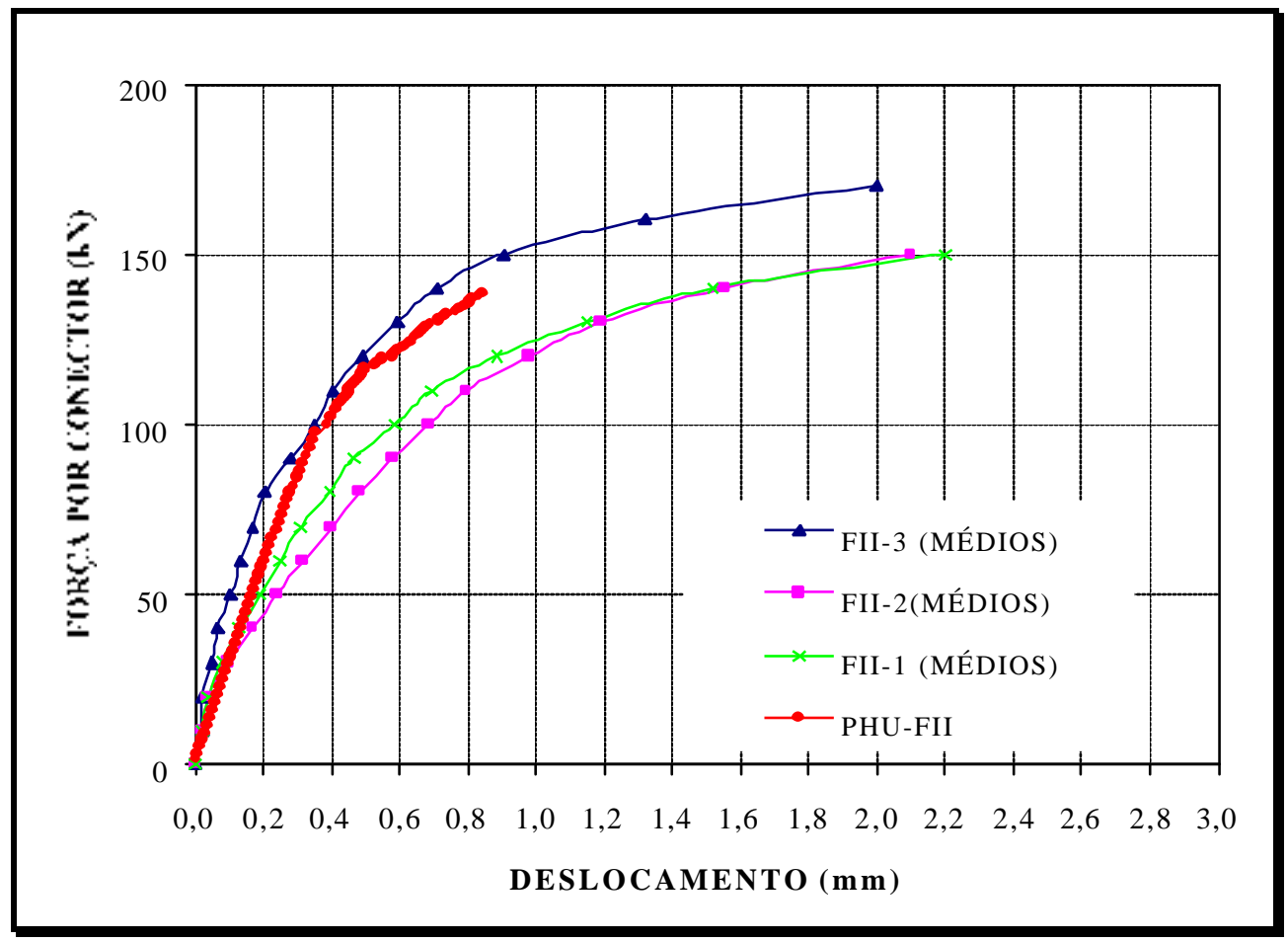

GRÁFICO 5.20: Relação força $x$ deslocamento, modelo PHU-FII

Vale ressaltar que a porção da laje constituída pelo modelo concreto aumentou em relação ao modelo PHU-FI, pois foram observadas tensões elevadas não só nos elementos situados na região do conector, mas também nos elementos abaixo do perfil "U”, provavelmente devido à pressão de contato da alma do perfil "U" em relação ao concreto da laje, fato que pode ser verificado na figura 5.32, para um nível de solicitação no modelo igual a $139 \mathrm{kN}$, para valores de tensões expressos em $\mathrm{kN} / \mathrm{cm}^{2}$.

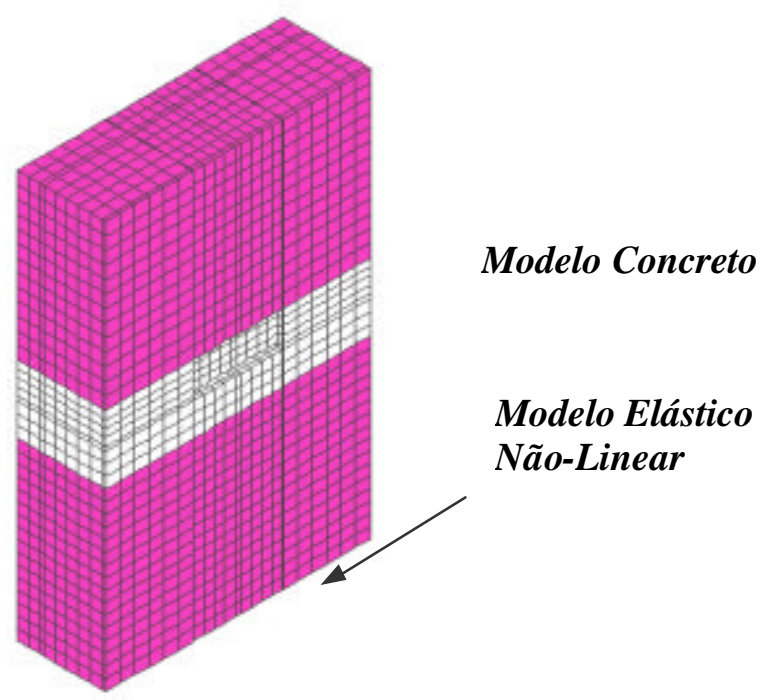

FIGURA 5.31: Modelos de não-linearidade na laje de concreto, modelo PHU-FII 


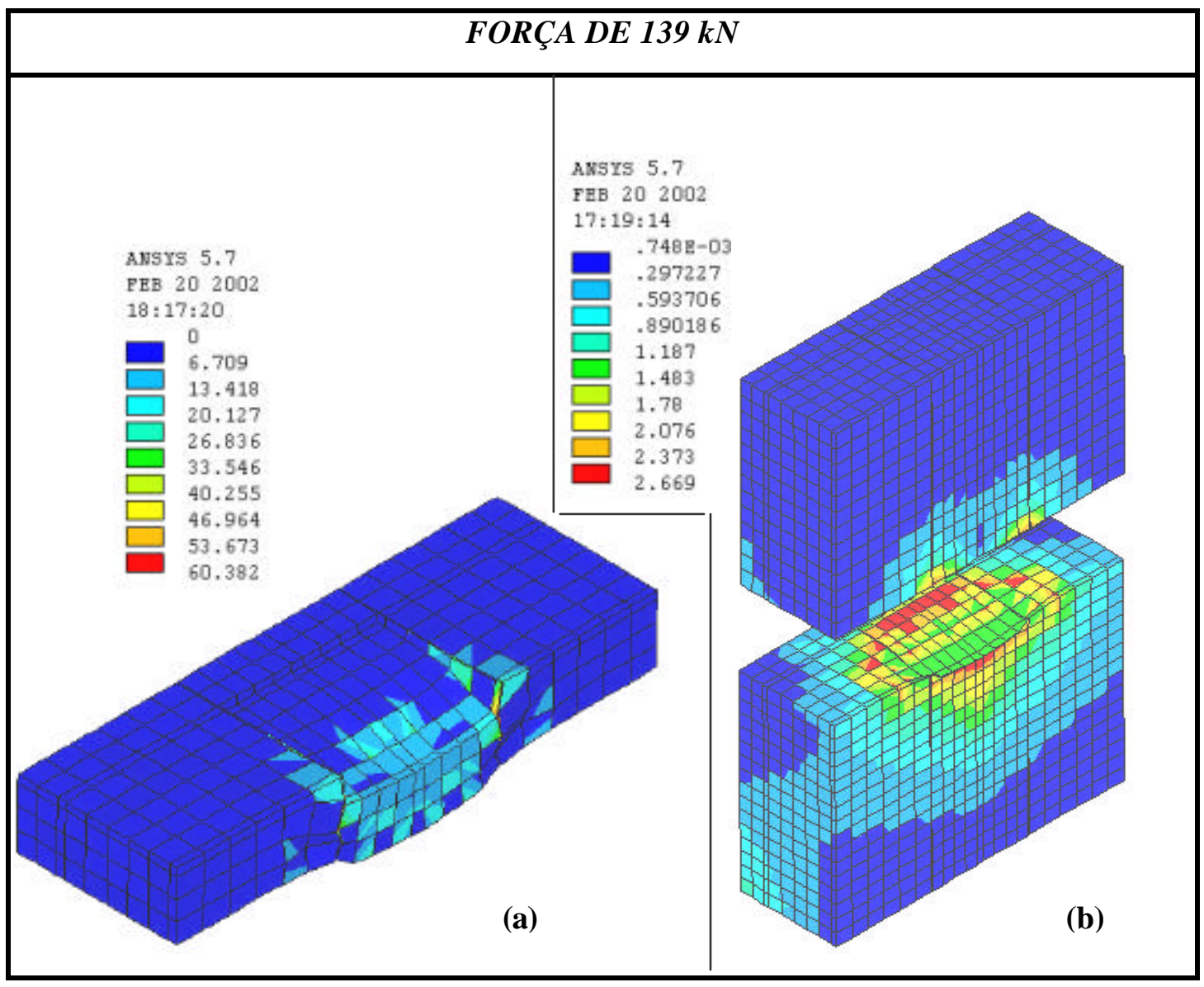

FIGURA 5.32: Tensão $\left(\mathrm{kN} / \mathrm{cm}^{2}\right)$ no concreto, região da laje com o modelo concreto(a)(abaixo da alma do perfil" $U$ ”) e modelo elástico não-linear (b)

Assim como no modelo PHU-FI, as tensões na armadura resultaram baixas, mesmo em estágios últimos de solicitação, conforme ilustradas na figura 5.33. Vale ressaltar que as maiores tensões verificam-se na região do conector, ou seja, posições 1 e 2 .

O gráfico 5.21 mostra a relação entre a força no modelo e tensão na armadura, nas posições 1 e 2 . Vale ressaltar que na posição 1 , a armadura está comprimida apenas no início da solicitação e, a partir da força de $5 \mathrm{kN}$, passa ficar tracionada. Por outro lado, na posição 2 a armadura está comprimida até a força de $99 \mathrm{kN}$, quando então passa a ficar tracionada. O comportamento da armadura no modelo numérico PHU-FII apresentou-se bastante semelhante àquele identificado no modelo numérico PHU-FI. 


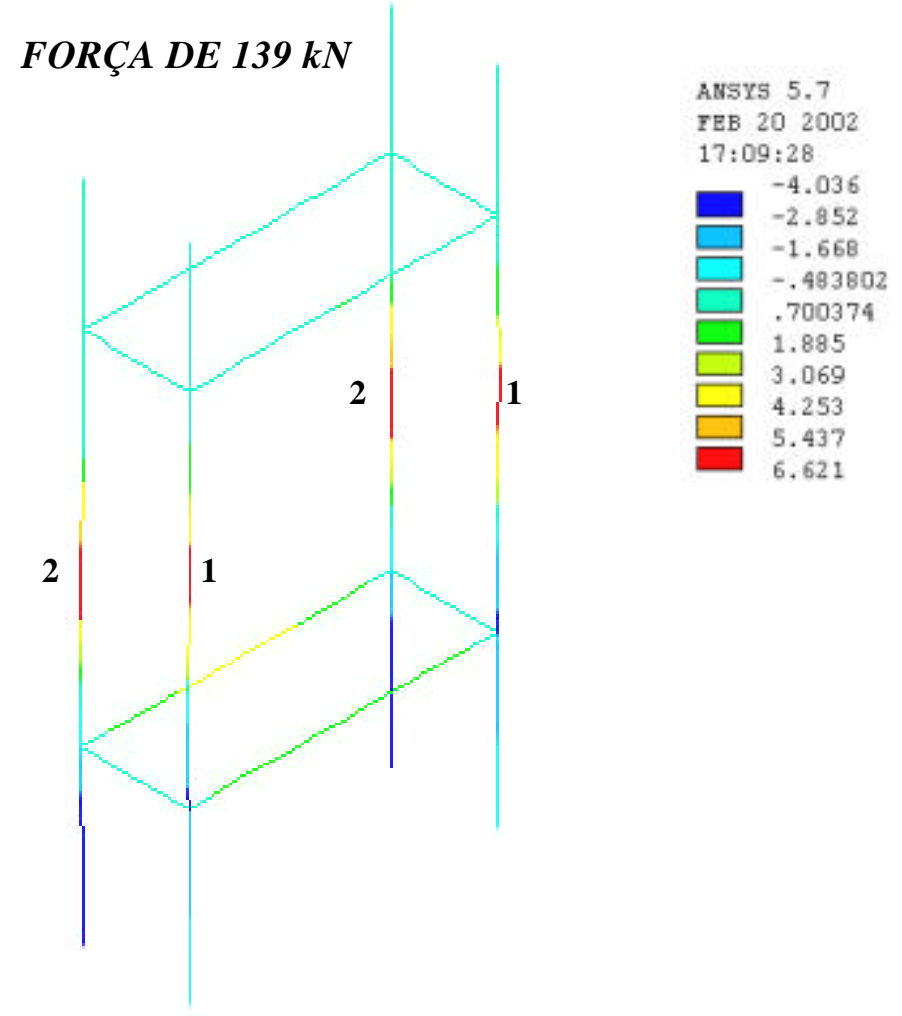

FIGURA 5.33: Tensão axial $\left(\mathrm{kN} / \mathrm{cm}^{2}\right)$ na armadura, modelo PHU-FII

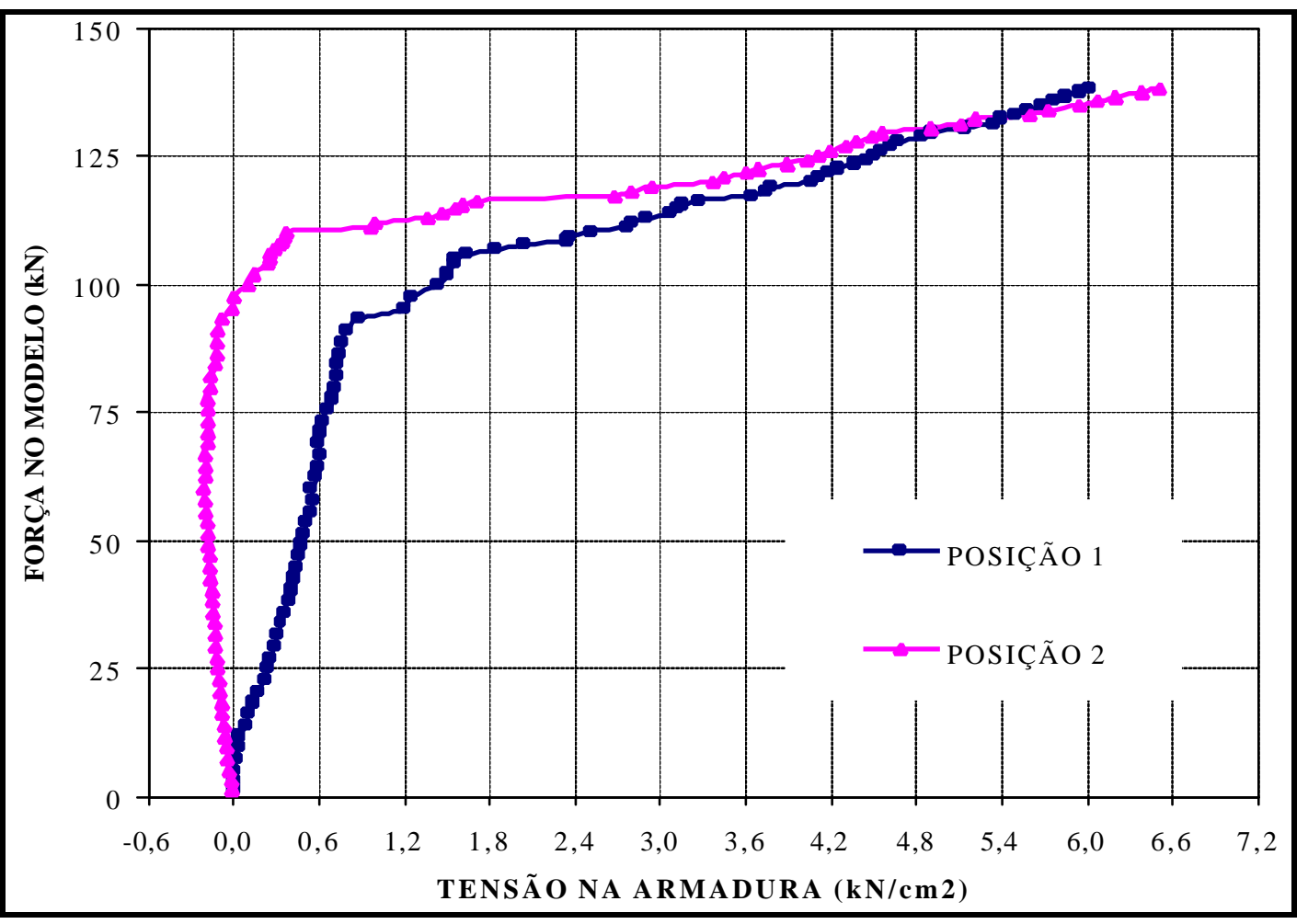

GRÁFICO 5.21: Relação força $x$ tensão na armadura, modelo PHU-FII 
As tensões de Mises no conector são apresentadas na figura 5.34. O processo de redistribuição das tensões que ocorrem no modelo PHU-FII é o mesmo do modelo PHUFI, ou seja, quando o elemento situado na posição 1 (figura 5.34) atingem a tensão de proporcionalidade $\left(\sigma_{\mathrm{a}}\right)$ de $24,78 \mathrm{kN} / \mathrm{cm}^{2}$, bem como logo depois os elementos situados nas posições 2 e 3 (figura 5.34) atingem a tensão de escoamento do aço do conector $\left(\mathrm{f}_{\mathrm{y}}\right.$ ) de 24,78 $\mathrm{kN} / \mathrm{cm}^{2}$, ocorrem distribuições de tensões para outros elementos. Este comportamento é mostrado no gráfico 5.22, por meio da relação entre a tensão e a força no conector, o qual os valores foram tomados a partir dos nós indicados na linha 1 (figura 5.29), ou seja, posições $1,2,3,4,5$ e 6 (ao longo da altura do perfil "U").

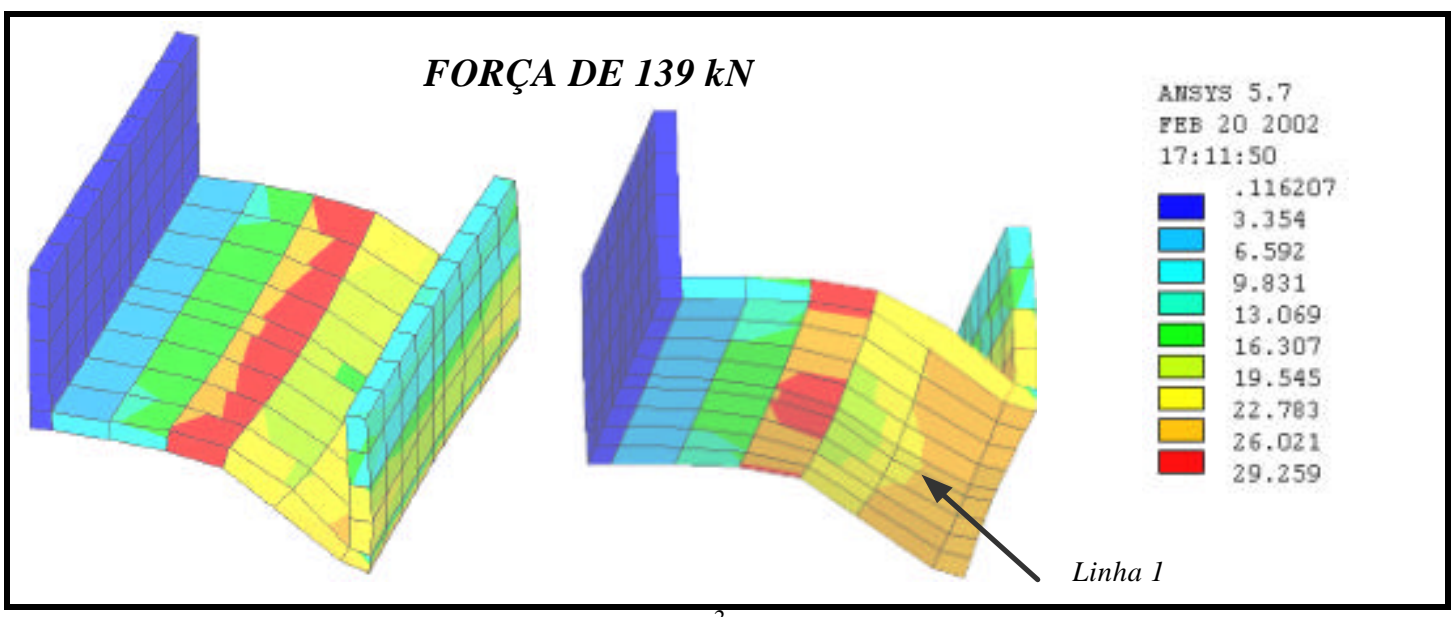

FIGURA 5.34: Tensão $\left(\mathrm{kN} / \mathrm{cm}^{2}\right)$ no conector, modelo PHU-FII

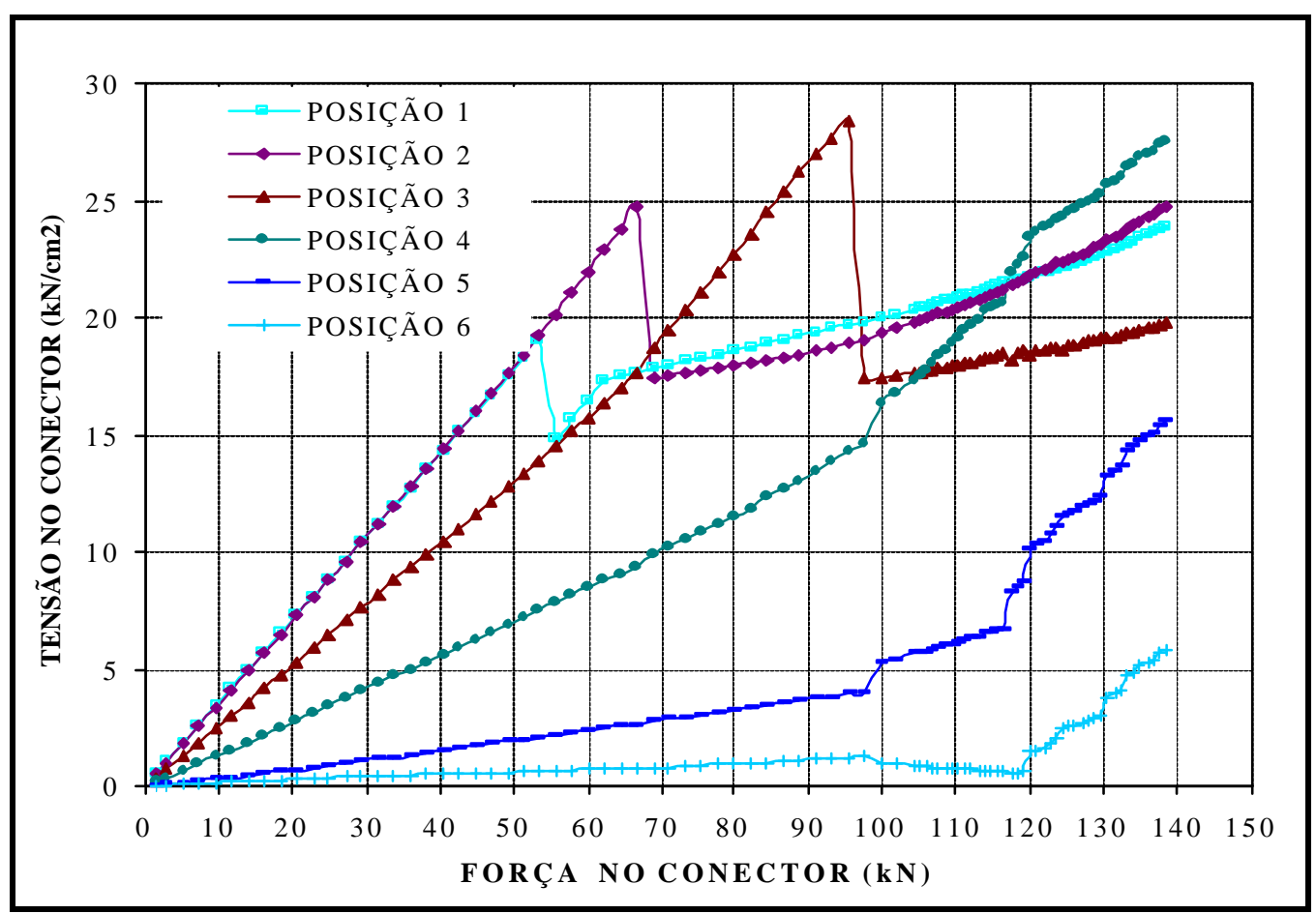

GRÁFICO 5.22: Relação tensão x força no conector, modelo PHU-FII 


\section{3 - CONFRONTO ENTRE RESULTADOS NUMÉRICOS DOS MODELOS COM CONECTOR TIPO PERFIL “U” FORMADO A FRIO}

Serão confrontados nos itens que seguem alguns resultados numéricos entre os modelos PHU-EI, PHU-EII, PHU-FI e PHU-FII, com vistas a uma avaliação da influência da posição do conector, bem como da espessura do conector.

\subsection{1 - INFLUÊNCIA DA POSIÇÃO DO CONECTOR}

Para avaliar a influência da posição dos conectores nos modelos será confrontada a relação força-deslocamento do conector (gráfico 5.23) entre os modelo PHUEI e PHU-EII, assim como entre os modelos PHU-FI e PHU-FII. Os modelos PHU-EI e PHU-FI apresentaram comportamentos mais dúcteis quando comparados àqueles obtidos nos modelos PHU-EII e PHU-FII, respectivamente.

Apesar da diferença na ductilidade do conector, não houve grande diferença com relação à força última no conector entre os modelos de mesma espessura de conector, ou seja, a diferença entre os modelos PHU-EI e PHU-EII foi de aproximadamente 3,5\%, enquanto que entre os modelos PHU-FI e PHU-FII foi de aproximadamente $5 \%$.

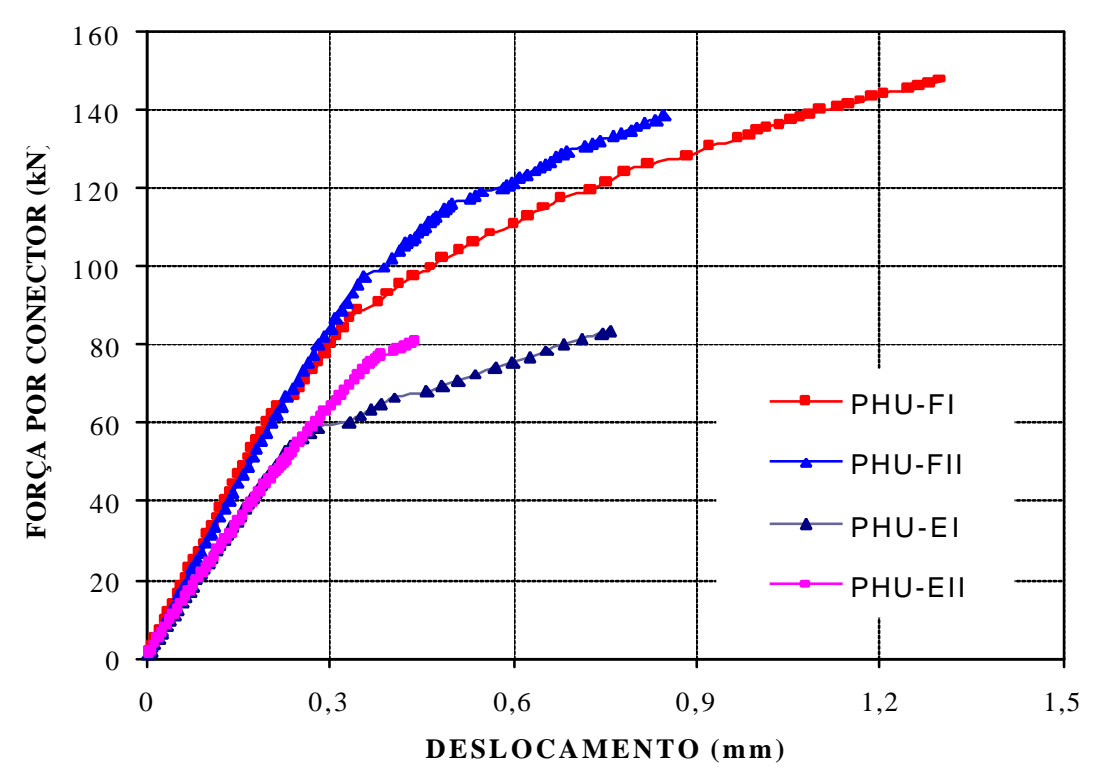

GRÁFICO 5.23: Comparação da força última do conector entre os modelos PHU-EI, 
O gráfico 5.24 apresenta a comparação da tensão de Mises no conector entre os modelos PHU-FI e PHU-FII, em três regiões distintas do conector, em que é possível observar que praticamente não houve diferença nos valores de tensões.

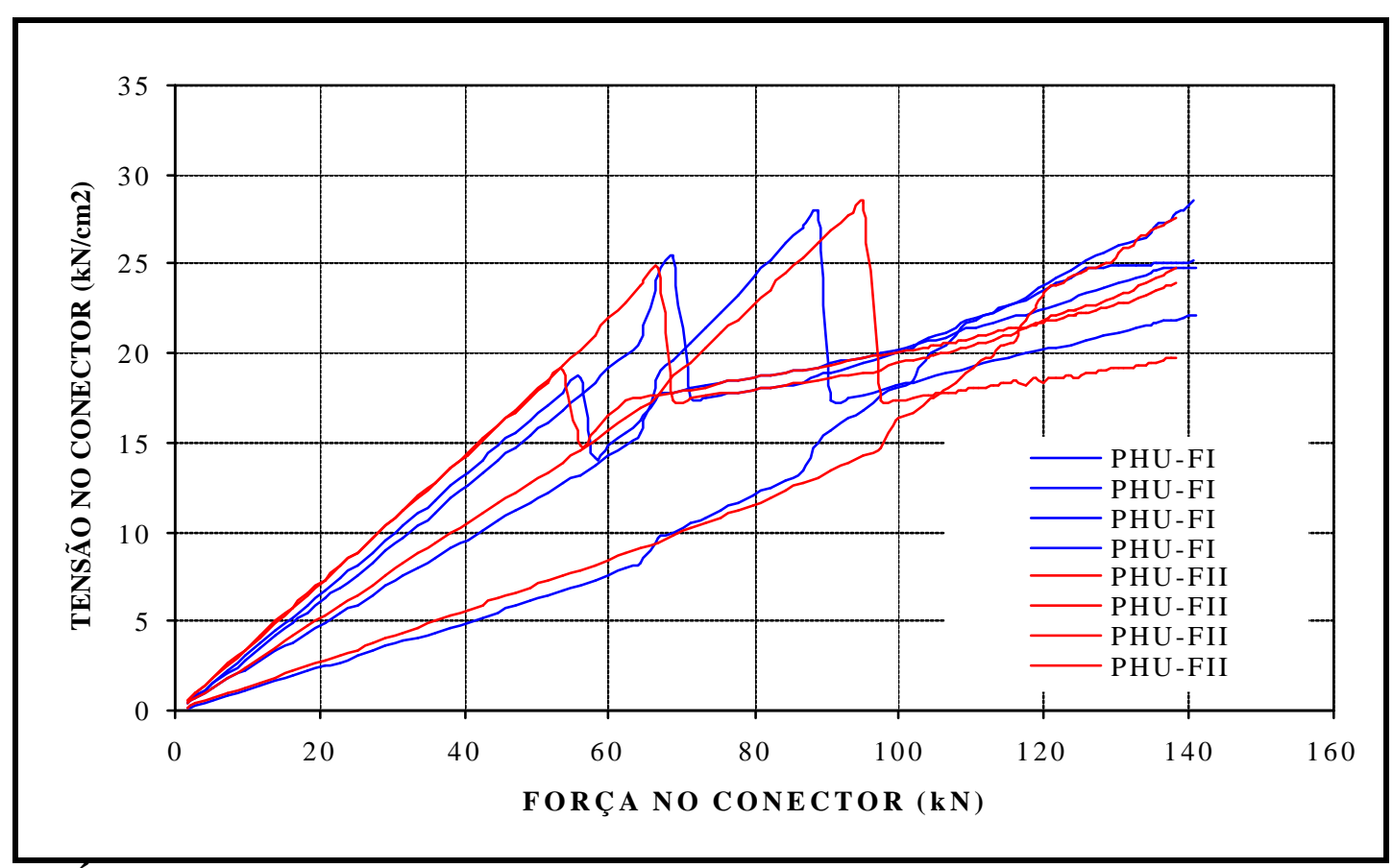

GRÁFICO 5.24: Comparação da tensão no conector entre os modelos PHU-FIe PHU-FII

Ainda, comparando os conectores de os modelos PHU-FI e PHU-FII, nota-se na figura 5.35 que a distribuição das tensões nos conectores são semelhantes, sendo esta juntamente com o comportamento do concreto uma das justificativas para a proximidade da força última entre os dois modelos.

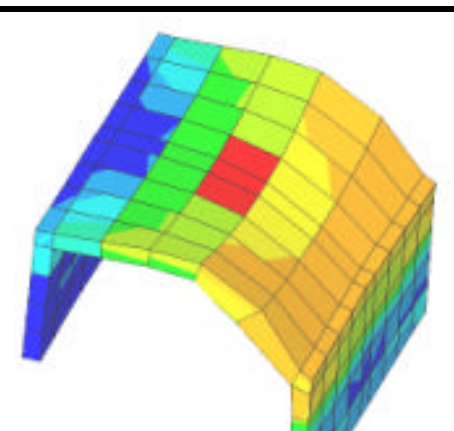

(a)

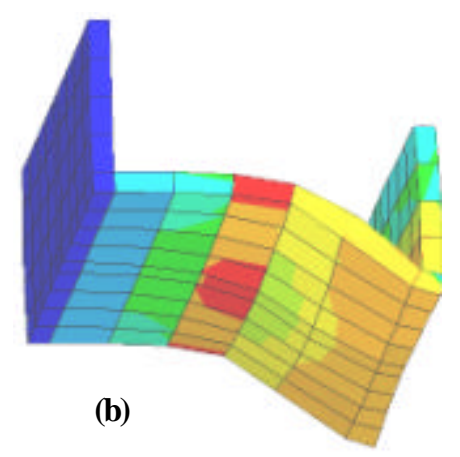

FIGURA 5.35: Comparação da distribuição da tensão no conector entre os modelos (a) PHU-FI e (b) PHU-FII, referente às forças últimas de cada modelo 
A pressão de contato entre o conector e o concreto nos modelos PHU-FI e PHU-FII é apresentada na figura 5.36, referente à força de $139 \mathrm{kN}$. Apesar de ocorrer distribuições semelhantes de pressão de contato, o modelo PHU-FI apresenta uma pressão um pouco maior que a do modelo PHU-FII e, conseqüentemente, uma maior transferência de esforços para o concreto, ocasionado assim uma maior deformação. Acredita-se que este mecanismo pode justificar a maior ductilidade do modeb PHU-FI em relação ao PHU-FII.

O gráfico 5.25 ilustra o comportamento da pressão de contato entre conector e laje de concreto ao longo da solicitação para os modelos PHU-FI e PHU-FII, o qual os valores foram tomados a partir dos nós indicados na linha 1 e linha 2 (figura 5.36).

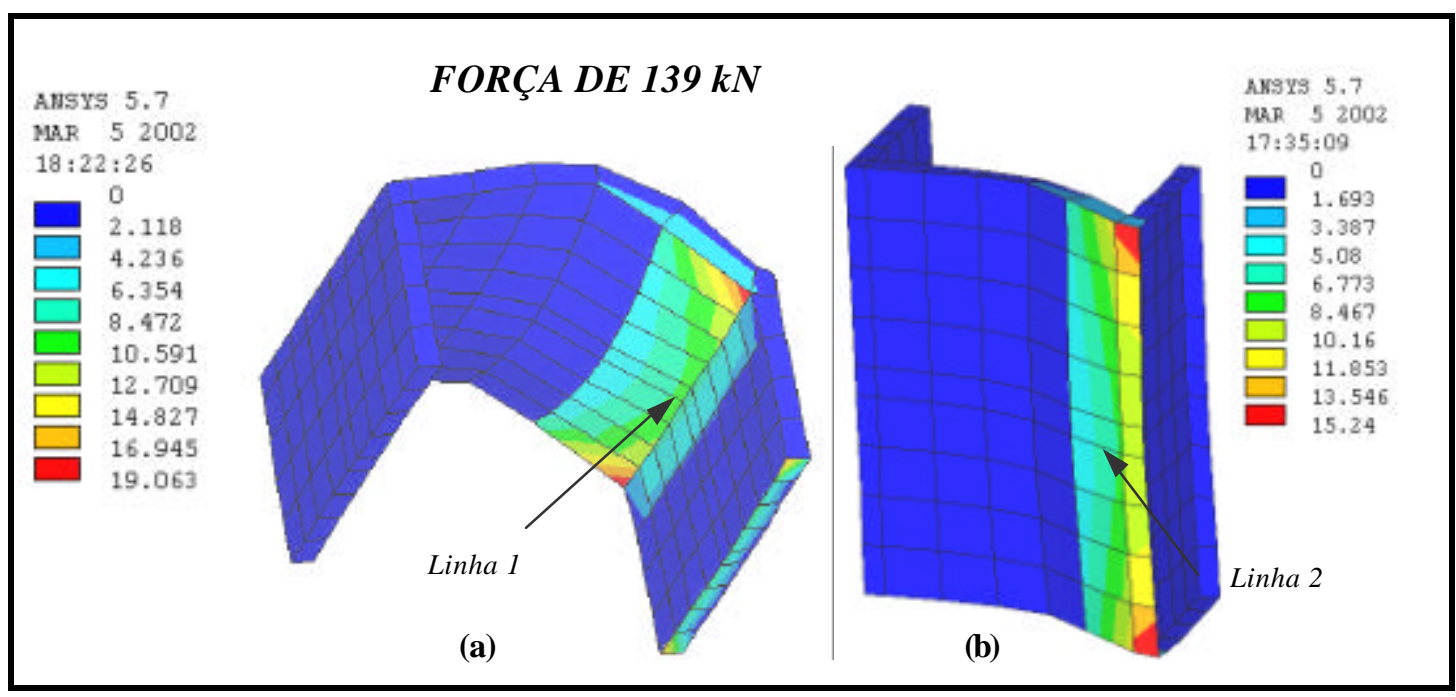

FIGURA 5.36: Comparação da pressão de contato entre os modelos (a) PHU-FI e (b)

PHU-FII, referente à força de $139 \mathrm{kN}$
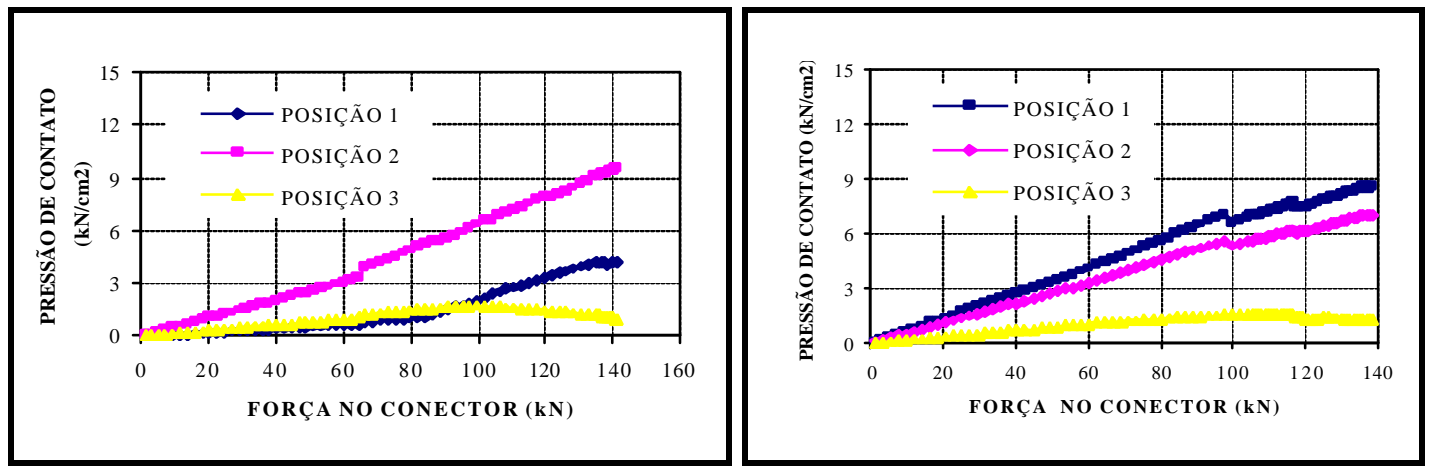

GRÁFICO 5.25: Relação pressão de contato x força, modelos PHU-FI e PHU-FII

A análise realizada anteriormente para o conector de espessura 4,76 mm, não será feita para o conector de espessura 2,66mm, já que existem algumas diferenças entre os 
modelos PHU-EI e PHU-EII, quanto à porção da laje com o modelo concreto e o modelo elástico não-linear.

\subsection{2 - INFLUÊNCIA DA ESPESSURA DO CONECTOR}

Apesar da diferença na espessura do conector entre os modelos PHU-EII e PHU-FII, não foram identificadas grandes diferenças nos valores das tensões de Mises no conector, como apresentado na figura 5.37 para as forças últimas de cada modelo.

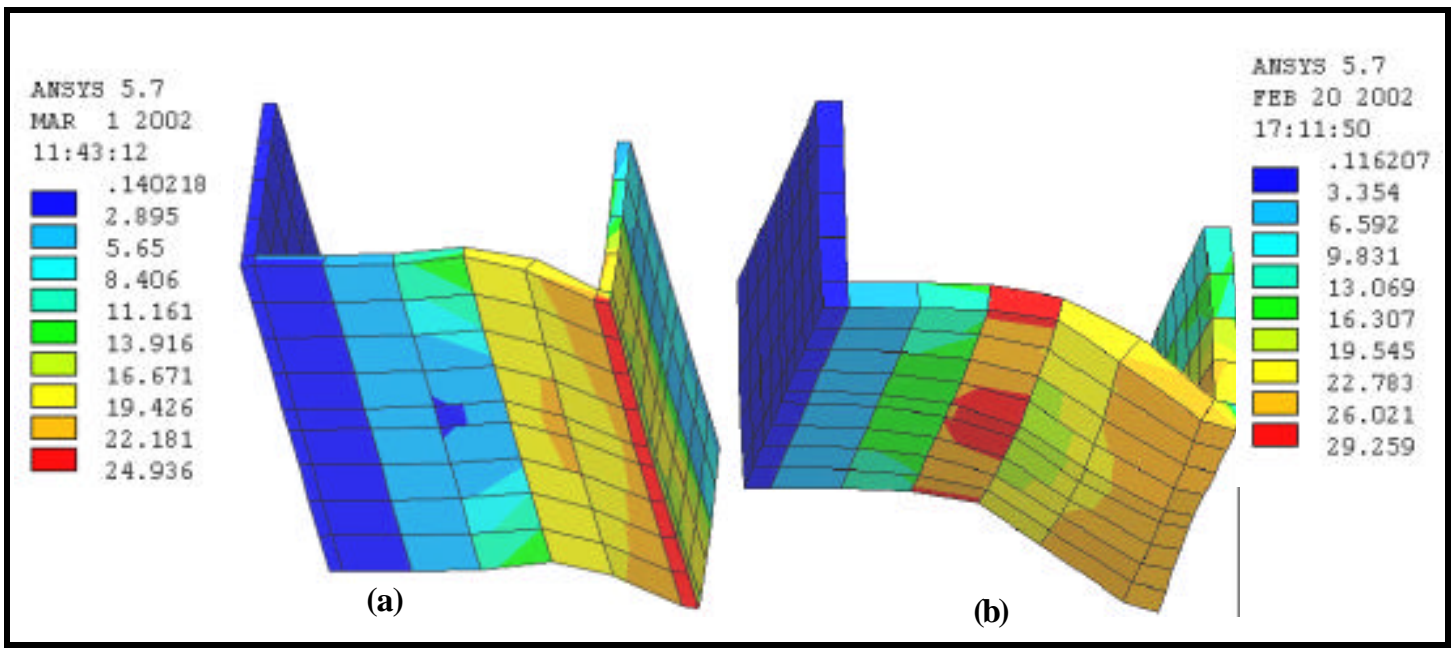

FIGURA 5.37: Comparação da distribuição da tensão no conector entre os modelos (a) PHU-EII e (b) PHU-FII, referente às forças últimas de cada modelo

A figura 5.38 apresenta a pressão de contato para os modelos PHU-EII e PHU-FII, sob uma força de $81 \mathrm{kN}$.

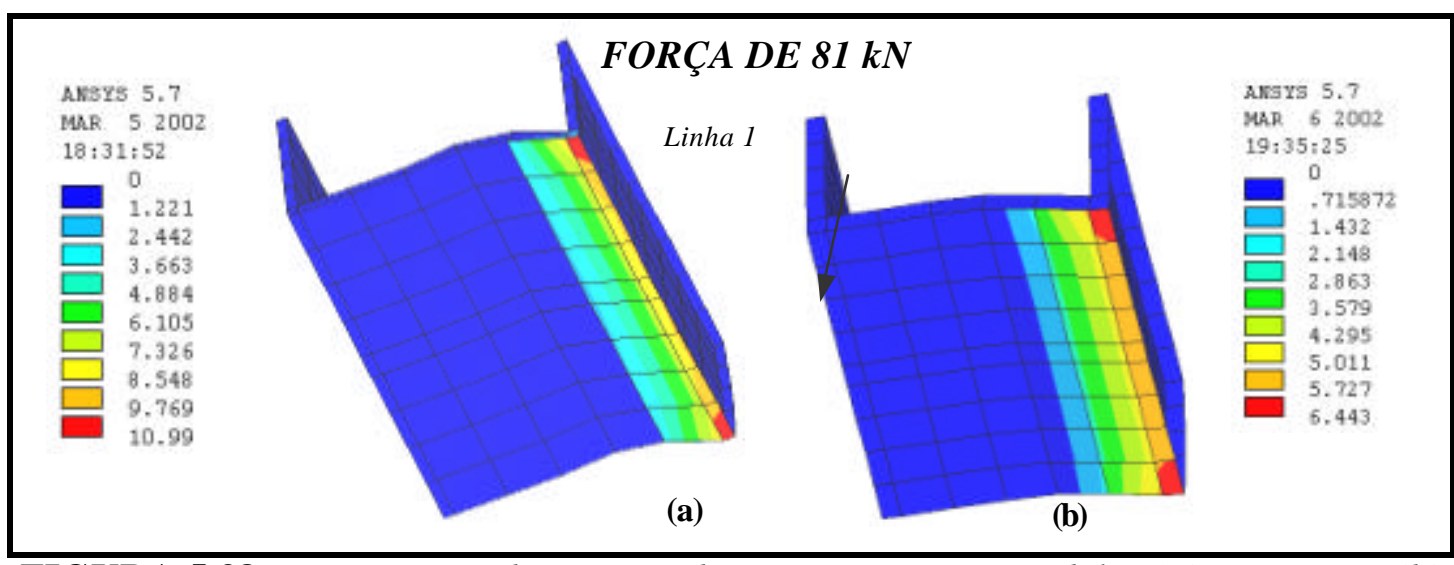

FIGURA 5.38: Comparação da pressão de contato entre os modelos (a) PHU-EII e (b) 
O gráfico 5.26 ilustra o comportamento da pressão de contato entre conector e laje de concreto ao longo da solicitação para o modelo PHU-EII, o qual os valores foram tomados a partir dos nós indicados na linha 1 (figura 5.38).

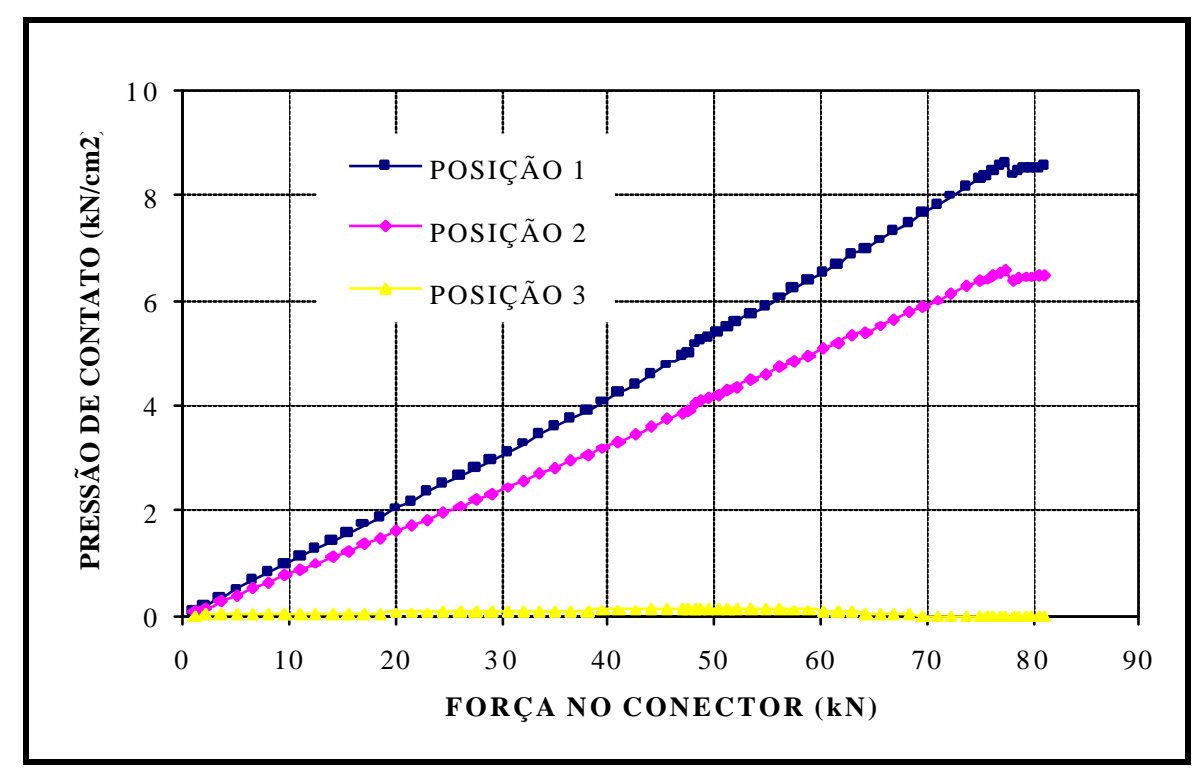

GRÁFICO 5.26: Relação pressão de contato $x$ força, modelo PHU-EII

Essas mesmas análises não serão feitas para os modelos PHU-EI e PHU-FI, uma vez que existem algumas diferenças nos modelos numéricos, quanto à porção da laje com o modelo concreto e o modelo elástico não-linear. 


\section{CONSIDERAÇÕES FINAIS}

A proposta do presente trabalho objetivou pesquisar aspectos referentes às vigas mistas aço-concreto, bem como realizar pesquisas e simulações numéricas, com base em código de cálculo previamente escolhido, referentes ao ensaio experimental do tipo "Push-out", bastante empregado na determinação da resistência de conectores tipos pino com cabeça (stud) e perfil " $U$ " formado a frio, comumente utilizados em vigas mistas açoconcreto.

Para tanto, tomou-se como ponto de partida a realização de uma ampla pesquisa bibliográfica, com referência ao assunto em questão, objetivando conhecer o comportamento, tanto de vigas mistas aço-concreto, como o comportamento do modelo isolado para o ensaio tipo "Push-out".

Como fruto de uma pesquisa bibliográfica inicial, foram identificados conectores de cisalhamento classificados, em função da resposta entre força no conector e deslocamento relativo laje-perfil, como rígidos e flexíveis, destacando-se como aspecto de interesse que, no caso de vigas mistas que contenham conectores de cisalhamento do tipo flexível, a ruptura desta mesma viga será do tipo dúctil.

Um outro aspecto de interesse abordado e que também merece destaque se refere à determinação da resistência do conector de cisalhamento, por meio do ensaio tipo "Push-out", cujo valor final depende da resistência e rigidez do material do conector e do concreto na zona de compressão triaxial, também denominada de zona de influência, região localizada próximo ao conector, em que são observadas tensões elevadíssimas, conforme constatado, descrito e ilustrado por alguns dos mais renomados pesquisadores no assunto.

Como caminho para a determinação da resistência do conector é proposta a modelagem numérica do ensaio tipo "Push-out". Sendo a geometria e a solicitação do 
modelo experimental para o ensaio experimental tipo "Push-out" simétricas, modelou-se apenas metade do modelo experimental para construir o modelo numérico, adotado-se elementos finitos com apenas três graus de liberdade, referentes às translações em x, y e z, uma vez que não houve o interesse imediato na quantificação da rotação dos elementos.

Para a obtenção de uma resposta satisfatória das não-linearidades físicas do aço e do concreto optou-se, para a representação do aço do perfil e do conector, o comportamento elasto-plástico com encruamento isótropo, enquanto que para o aço das armaduras da laje, o comportamento elasto-plástico perfeito.

Já o comportamento não-linear do concreto foi representado, tanto pelo modelo concreto, quanto pelo modelo elástico não-linear. O modelo de não-linearidade concreto é indicado pelo ANSYS, dentre aqueles disponibilizados por esse mesmo código de cálculo, como sendo o mais adequado para a representação do comportamento de materiais frágeis, como o concreto. Porém o ANSYS só permite a utilização do modelo de nãolinearidade concreto ao elemento finito SOLID 65, restringindo a sua utilização.

A consideração de elementos de contato entre o conector e o concreto teve um papel de fundamental importância no comportamento dos modelos numéricos, uma vez que o contato permite o descolamento do conector em relação ao concreto. Por meio de alguns testes realizados, a não consideração do elemento de contato resultou em deslocamentos bem menores quando comparados aos valores experimentais dos deslocamentos. Nesse caso, o modelo numérico resultou bem mais rígido que o modelo experimental, e com uma resistência última menor.

Os resultados numéricos, de uma maneira geral, representaram satisfatoriamente o ensaio experimental de ambos os tipos de conectores de cisalhamentos, no caso, os tipos pino com cabeça (stud) e perfil "U" formado a frio. Todos os modelos numéricos apresentaram, com relação à curva força-deslocamento do conector, duas fases distintas. Em uma primeira etapa, a rigidez da curva foi governada basicamente pela rigidez normal de contato $(\mathrm{FKN})$, até um valor de força aplicada em que a curva começou a ter a rigidez penalizada em função do comportamento não-linear do aço do conector e do concreto.

O modelo numérico PHS-1 (conector tipo pino com cabeça - 13mm) apresentou resultados satisfatórios, tanto no comportamento global, como na avaliação das tensões dos seus componentes. O conector apresentou deformações consideráveis principalmente na região da ligação com a mesa do perfil, porém nenhuma região do conector atingiu a tensão de escoamento do aço $\left(f_{y}\right)$. 
Por outro lado, o modelo PHS-2 (conector tipo pino com cabeça - 19mm), para a relação força-deslocamento do conector, apresentou resultados satisfatórios até uma força de aproximadamente $50 \mathrm{kN}$, a partir do qual o modelo numérico começou a apresentar deslocamentos ligeiramente maiores quando comparados aqueles do modelo experimental. Porém, de um modo geral, o modelo numérico representa satisfatória e coerentemente o comportamento do modelo experimental, tanto no aspecto das tensões no conector como nas fissuras da laje de concreto.

A tabela 6.1 apresenta uma análise comparativa de valores da resistência última numérica $\left(\mathrm{Q}_{u}\right)$ e da resistência última do modelo experimental $\left(\mathrm{Q}_{\mathrm{u}}\right)_{1}$, juntamente com valores obtidos por meio das expressões para cálculo da resistência do conector propostas pela NBR-8800 (1986) e EUROCODE 4 (1994), adotando-se como parâmetros de interesse para as expressões de ambas as normas as propriedades dos modelos PHS-1 e PHS-2.

TABELA 6.1: Comparação da resistência última para os modelos PHS-1 e PHS-2

\begin{tabular}{|c|c|c|c|c|}
\hline \multirow{2}{*}{ MODELO } & $\left(\mathbf{q}_{\mathbf{n}}\right)$ & $\left(\mathbf{q}_{\mathbf{r d}}\right)$ & $\left(\mathbf{Q}_{\mathbf{u}}\right)_{\mathbf{1}}$ & $\left(\mathbf{Q}_{\mathbf{u}}\right)$ \\
& NBR-8800 & EUROCODE 4 & EXPERIMENTAL & NUMÉRICO \\
& $(\mathbf{k N})$ & $(\mathbf{k N})$ & $(\mathbf{k N})$ & $(\mathbf{k N})$ \\
\hline PHS-1 & 40,45 & 42,11 & 45,00 & 37,75 \\
\hline PHS-2 & 128,21 & 94,13 & 113,25 & 82,12 \\
\hline \\
$\left(\mathbf{Q}_{\mathbf{u}}\right)_{\mathbf{1}}$ : Média da resistência última do conector, a qual mediu-se o deslocamento
\end{tabular}

É importante observar que, com relação ao valor obtido para resistência do conector em questão, o resultado numérico, principalmente do modelo PHS-1, está muito próximo do experimental como também das normas. Porém, com relação ao modelo PHS-2, a expressão do EUROCODE 4 (1994) apresenta um valor muito próximo do numérico, porém ambos encontram-se distantes dos valores experimentais e da NBR-8800 (1986).

Os modelos com conectores de cisalhamento tipo perfil " $U$ " formados a frio (PHU-EI, PHU-EII, PHU-FI e PHU-FII), de um modo geral, também apresentaram resultados satisfatórios em todos as fases, quanto à relação entre a força-deslocamento do conector.

Os dois tipos de comportamentos adotados para representar o concreto foram aplicados simultaneamente, objetivando diminuir a rigidez do modelo e, conseqüentemente, melhorar a convergência nas fases em que os materiais já apresentavam um comportamento não-linear. Vale mencionar que quando se adotava apenas o modelo concreto, os modelos 
numéricos não apresentavam convergência para aplicação de força bem abaixo daquele obtido experimentalmente. Acredita-se que com a consideração do modelo elástico nãolinear em algumas regiões da laje, nos modelos com perfil "U", não implica em alterações no comportamento global do modelo, podendo com isso realizar uma análise criteriosa das tensões tanto na laje de concreto como no conector.

Assim como identificado e descrito para os modelos experimentais, nos modelos numéricos a posição do conector perfil " $U$ " em ambas as espessuras influenciou basicamente na ductilidade do modelo, ou seja, para modelos com o conector na posição I (PHU-EI e PHU-FI) a força última do conector deu-se para deslocamentos maiores que os modelos com o conector na posição II (PHU-EII e PHU-FII), sendo esta força última praticamente igual entre os modelos PHU-EI e PHU-EII, assim como nos modelos PHU-FI e PHU-FII.

A tabela 6.2 apresenta, com vistas a uma análise comparativa, valores das resistências últimas dos modelos numéricos perfil " $U$ " formados a frio, dos resultados experimentais e das expressões propostas.

TABELA 6.2: Comparação da resistência última para os modelos com conector perfil " $U$ "

\begin{tabular}{|c|c|c|c|c|c|}
\hline MODELO & $\begin{array}{c}\left(q_{n}\right)_{1} \\
\text { MALITE et al. } \\
(1998)(k N)\end{array}$ & $\begin{array}{c}\left(q_{n}\right)_{2} \\
\text { NBR-8800 }\end{array}$ & $\begin{array}{l}\left(\mathbf{Q}_{\mathbf{u}}\right)_{1} \\
\text { EXPERIMENTAL } \\
(\mathbf{k N})\end{array}$ & $\begin{array}{c}\left(\mathbf{P}_{\mathbf{u}}\right) \\
\text { EXPERIMENTAL } \\
(\mathbf{k N})\end{array}$ & $\begin{array}{c}\left(Q_{u}\right) \\
\text { NUMÉRICO } \\
(k N)\end{array}$ \\
\hline PHU-EI & 96,57 & 74,12 & 100,00 & 124,70 & 84,00 \\
\hline PHU-EII & 96,57 & 74,12 & 106,66 & 121,70 & 81,00 \\
\hline PHU-FI & 176,80 & 134,66 & 181,66 & 203,30 & 147,00 \\
\hline PHU-FII & 176,80 & 134,66 & 156,67 & 168,30 & 139,00 \\
\hline \multicolumn{6}{|c|}{$\begin{array}{l}\left(q_{n}\right)_{1}: E_{c} \text { calculado por meio da expressão } 3.18 \text { (capítulo 3), onde adotou-se } \gamma_{c}=24 \mathrm{kN} / \mathrm{m}^{3} \\
\left(Q_{u}\right)_{1}: \text { Média da Resistência última do conector, a qual mediu-se o deslocamento } \\
\left(P_{u}\right): \text { Média da força de colapso, sem medição de deslocamento }\end{array}$} \\
\hline
\end{tabular}

As resistências últimas dos modelos numéricos ficaram próximas das expressões propostas tanto por MALITE et al. (1998) como pela NBR-8800 (1986). Em relação aos resultados experimentais, as resistências últimas dos modelos numéricos ficaram em média $20 \%$ abaixo de $\left(\mathrm{Q}_{\mathrm{u}}\right)_{1}$ e em torno de $39 \%$ abaixo de $\left(\mathrm{P}_{\mathrm{u}}\right)$. Segundo MALITE (1993), não foi possível medir os deslocamentos a partir de $\left(Q_{u}\right)_{1}$. 
As armaduras na laje de concreto em todos os modelos numéricos apresentaram tensões muito inferiores à tensão de escoamento do aço, confirmando como função desse elemento, a de apenas confinar o concreto, aumentando assim a sua resistência, conforme constatado e descrito em trabalhos publicados por outros pesquisadores.

Com base numa análise criteriosa da pressão e penetração de contato entre o concreto e o conector, acredita-se que a perturbação que ocorre na relação tensão x força para algumas posições no conector, deve-se ao fato de nessas regiões a pressão e a penetração de contato serem elevadas, quando comparado com o restante do conector.

Ao contrário de ensaios experimentais em que é possível detectar o modo de falha por meio do aspecto visual, nos modelos numéricos não foi possível constatar o modo de falha, ou seja, no concreto ou no conector de cisalhamento, apesar de inúmeras informações que os resultados numéricos fornecem. A tabela 6.3 apresenta os tipos de modos de falha detectados nos ensaios experimentais para os respectivos modelos numéricos.

TABELA 6.3: Tipos de modos de falha detectados nos ensaios experimentais dos respectivos modelos numéricos

\begin{tabular}{|c|c|}
\hline MODELO & MODO DE FALHA \\
\hline $\boldsymbol{P H S}-\mathbf{I}$ & CONECTOR \\
\hline $\boldsymbol{P H S}-\mathbf{2}$ & CONCRETO \\
\hline $\boldsymbol{P H U}$-EI & CONECTOR \\
\hline $\boldsymbol{P H U}-\boldsymbol{E I I}$ & CONECTOR \\
\hline $\boldsymbol{P H U}-\boldsymbol{F I}$ & CONCRETO \\
\hline $\boldsymbol{P H U}-\boldsymbol{F I I}$ & CONCRETO \\
\hline
\end{tabular}

Como a proposta do trabalho foi a desenvolver um modelo numérico que representasse o ensaio tipo "Push-out", bem como analisar mais detalhadamente o comportamento do conjunto concreto-conector, buscou-se um modelo mais sofisticado com um número significativo de elementos finitos e a consideração da não-linearidade física e geométrica (elemento de contato). Porém, toda essa sofisticação resultou em um tempo de processamento elevado, em torno de quatro dias.

O elevado tempo requerido para a elaboração e simulações de todos os modelos numéricos analisados impossibilitou a simulação numérica de um número de maior, e conseqüentemente, mais representativo, de modelagens. Desta forma, fica como proposta do autor desse trabalho que um número maior de exemplos sejam futuramente analisados, 
com base no procedimento de modelagem proposto nesse trabalho, com vistas à obtenção de melhorias na técnica de modelagem, objetivando um ganho na confiabilidade dos resultados obtidos.

Um outro aspecto que também deve ser levado em conta para futuras pesquisas, objetivando maior eficiência nas simulações numéricas, está relacionado à utilização de outros códigos de cálculo que necessariamente disponibilizem ao usuário uma gama maior de elementos finitos que representem o comportamento do concreto, uma vez que as maiores dificuldade encontradas na obtenção da convergência para os modelos numéricos, nesse trabalho, foram identificadas quando da consideração da não-linearidade imposta ao material da laje.

Ainda com relação à continuidade dos estudos, o autor deste trabalho propõe a análise numérica de vigas mistas, para que possa representar o comportamento do conector de cisalhamento numa estrutura real, possibilitando assim avaliar melhor o efeito do grupo de conectores. 


\section{REFERÊNCIAS BIBLIOGRAFICAS}

ALVA, G.M.S. (2000). Sobre o projeto de edifícios em estrutura mista aço-concreto. São Carlos. Dissertação (Mestrado) - Escola de Engenharia de São Carlos, Universidade de São Paulo.

AMERICAN CONCRETE INSTITUTE (1993). ACI manual of concrete practice. Parte 1: Material and general properties of concrete. Detroit, ACI.

AMERICAN INSTITUTE OF STEEL CONSTRUCTION (1994). AISC-LFRD - Load and resistance factor design. Chicago.

AN, L.; CEDERWALL, K. (1996). Push-out tests on studs in high strength and normal strength concrete. Journal of Construction Steel Research, v.36, p.15-29.

ASSOCIAÇÃO BRASILEIRA DE NORMAS TÉCNICAS (1980). NBR 6120 - Cargas para o cálculo de estruturas de edificações. Rio de Janeiro.

ASSOCIAÇÃO BRASILEIRA DE NORMAS TÉCNICAS (1986). NBR 8800 - Projeto e execução de estruturas de aço de edifícios. Rio de Janeiro.

ASSOCIAÇÃO BRASILEIRA DE NORMAS TÉCNICAS (2000). Projeto de revisão e comentários da NBR 6118/78 - Projeto e execução de estruturas de concreto armado. Rio de Janeiro. 232p.

BRITISH STANDARD INSTITUTION (1979). BS 5400 - Steel, concrete and composite bridges. Part 5: Code of pratice for design of composite bridges. London. 
BRITISH STANDARD INSTITUTION (1990). BS 5950 - Structural use of steelwork in building. Part 3: Section 3.1: Code of pratice for design of simple and continuous composite beams. London.

CANADIAN STANDARDS ASSOCIATION (1994). CAN/CSA-S16.1-94 - Limit states design of steel structures. Toronto, Ontario.

CHEN; SALEEB (1982). Constitutive equations for engineering materials: elasticity and modeling. Wiley Interscience Publication. v.1

CODEME ENGENHARIA S.A. (1997). Steel deck CE-75: noções de utilização e dimensionamento. Betim.

COMITE EURO-INTERNATIONAL DU BETON (1991). CEB-FIP model code 1990. Bulletin dÏnformation, n.203-205.

EUROPEAN COMMITTEE FOR STANDARDIZATION (1991). ENV 1992-1 -1: Eurocode 2 - Design of concrete structures. Part 1-1: General rules and for buildings. Brussels.

EUROPEAN COMMITTEE FOR STANDARDIZATION (1992). ENV 1993 -1-1: Eurocode 3 - Design of steel structures. Part 1-1:General rules and rules for buildings. Brussels.

EUROPEAN COMMITTEE FOR STANDARDIZATION (1994). ENV 1994-1-1: Eurocode 4 -Design of composite steel and concrete structures. Part 1-1: General rules and rules for buildings. Brussels.

EUROPEAN CONVENTION FOR CONSTRUCTION STEELWORK (ECCS) (1993). Composite beams and columns to Eurocode 4. Brussels.

GATESCO, N. (1999). Analytical modeling of nonlinear behavior of composite beams with deformable connection. Journal of Construction Steel Research, v. 52, p.195-218.

GATESCO, N.; GIURIANI, E. (1996). Experimental study on shear connectors subjected to cyclic loading. Journal of Construction Steel Research, v.38, p.1-21. 
GESCHWINDNER, L.; DISQUE, R.; BJORHVDE, R. (1994). Load and resistance factor design of steel structures. Englewood Cliffs, New Jersey, Prentice Hall.

GHALI, A.; FAVRE, R. (1994). Concrete structures: stresses and deformations. 2.ed. Chapman \& Hall.

GHAVAMI, K. (1998). Ultimate load behaviour of flexible and rigid connectors in composite beams. Journal Construction Steel Research, v.46, p.208-210.

HACKETT \& ASSOCIATES (1998). Products: shear connectors. http://www.hacckettassociates.com. (19 ago/1999).

INTERNATIONAL SPECIALTY CONFERENCE, $14^{\text {th }}$, St. Louis, USA (1998). Recent research and developments in cold-formed steel: design and construction. Rolla, University of Missouri-Rolla.

JAYAS, B.S.; HOSAIN, M.U. (1988). Behaviour of headed studs in composite beams: pushout tests. Can. J. Civ. Eng., v.15, p.240-253.

JOHNSON, R.P. (1994). Beams, slabs, columns, and frames for buildings. 2.ed. Blackwell Scientific Publications. v.1.

JOHNSON, R.P.; BUCKBY, R.J. (1986). Composite structures of steel and concrete: bridges. 2.ed. Colins. v.2.

KALFAS, C. et al. (1997). Inelastic behaviour of shear connection by a method based on FEM. Journal of Construction Steel Research, v.44, p.107-114.

KLINSKY, G.E. 1999). Uma contribuição ao estudo das pontes em vigas mistas. São Carlos. 186p. Dissertação (Mestrado) - Escola de Engenharia de São Carlos, Universidade de São Paulo.

MALITE, M. (1990). Sobre o cálculo de vigas mistas aço-concreto: ênfase em edifícios. São Carlos. 144p. Dissertação (Mestrado) - Escola de Engenharia de São Carlos, Universidade de São Paulo. 
MALITE, M. (1993). Análise do comportamento estrutural de vigas mistas aço-concreto constituídas por perfis de chapa dobrada. São Carlos. 253p. Tese (Doutorado) - Escola de Engenharia de São Carlos, Universidade de São Paulo.

MANUAL brasileiro para cálculo de estruturas metálicas (1986). Brasília, MIC/STI. v.2.

MISTAKIDIS, E.S.; THOMOPOULUS, K.; AVDELAS, A.; PANAGIOTOPOLOUS, P.D. (1994). Shear connectors in composite beams: a new accurate algorithm. Thin-Walled Structures, v.18, p.191-207.

NARAYANAN, R., ed. (1987). Composite steel structures: advances, design and construction. London, Elsevier Applied Science.

OEHLERS, D.J. (1989). Splitting induced by shear connectors in composite beams. Journal of Structural Engineering, v.115, p.341-362.

OEHLERS, D.J.; COUGHLAN, C.G. (1986). The shear stiffness of shear connections in composite beams. Journal Construction Steel Research, v.6, p.273-284.

OEHLERS, D.J.; NGUYEN, N.T.; AHMED, M.; BRADFORD, M.A. (1997). Partial interaction in composite steel and concrete beams with full shear connection. Journal of Construction Steel Research, v.41, p.235-248.

OEHLERS, D.J.; PARK, S.M. (1992). Shear connectors in composite beams with longitudinally cracked slabs. Journal of Structural Engineering, v.118, p.2004-2022.

OEHLERS, D.J.; SVED, G. (1995). Composite beams with limited-slip-capacity shear connectors. Journal of Structural Engineering, v.121, p.932-938.

OGUEIJIOFOR, E.C.; HOUSAIN, M.U. (1997). Numerical analysis of push-out specimens with perfobond rib connectors. Computers \& Structures, v.62, p.617-624.

OVEN, V. A.; BURGESS, I.W.; PLANK, R. J.; ABDUL WALI, A.A (1997). An analytical model for the analysis of composite beams with partial interaction. Computers \& Structures, v.62, p.493-504. 
PROENÇA, S.P.B. (1988). Sobre modelos matemáticos do comportamento não-linear do concreto: análise crítica e contribuições. São Carlos. 163p. Tese (Doutorado) - Escola de Engenharia de São Carlos, Universidade de São Paulo.

QUEIROZ, G.; PIMENTA, R.J.; MATA, L.A. (2001). Elementos das estruturas mistas açoconcreto. Belo Horizonte, Editora O Lutador. 336p.

SALARI, M.R. (1999). Modeling of bond-slip in steel-concrete composite beams and reinforcing bars. PhD Thesis - University of Colorado at Boulder.

SALES, J.J. (1995). Estudo do projeto e construção de edifícios de andares múltiplos com estruturas de aço. São Carlos. 257p. Tese (Doutorado) - Escola de Engenharia de São Carlos, Universidade de São Paulo.

SHIM, C.S.; KIM, J.H.; CHANG, S.P.; CHUNG, C.H. (2000). The behaviour of shear connections in a composite beam with a full-depth precast slab. Proc. Instn. Civ. Engrs. Structs \& Bldgs, v.140, p.101-110.

SMITH, J.C. (1996). Structural steel design (LFRD approach). 2.ed. North Carolina State University.

VERREAUlT, C.; BEAULIEU, D.; PICARD, A. (1997). Évaluation expérimentale de connecteurs pour le renforcement de ponts. Can. J. Civ. Eng., v.24, p.705-715.

WRIGHT, H.D.; FRANCIS, R.W. (1990). Tests on composite beams with low levels of shear connection. The Structural Engineer, v.68, p.293-298. 


\section{DETERMINAÇÃO DO \\ COEFICIENTE DE REDUÇÃO
PARA LAJES COM FORMA DE \\ AÇO INCORPORADA}

- NBR - 8800 (1986), AISC-LFRD (1994)

a) Para fôrmas dispostas com as nervuras paralelas à viga de aço:

$$
\mathrm{C}_{\text {red }}=0,6\left(\frac{\mathrm{b}_{\mathrm{F}}}{\mathrm{h}_{\mathrm{F}}}\right)\left(\frac{\mathrm{h}_{\mathrm{cs}}}{\mathrm{h}_{\mathrm{F}}}-1\right) \leq 1,0
$$

Para a NBR 8800 , se $b_{F} / h_{F}$ for maior que 1,5 , usa-se $C_{\text {red }}$ igual à 1,0 .

b) Para fôrmas dispostas com as nervuras perpendiculares à viga de aço:

$$
\mathrm{C}_{\mathrm{red}}=\frac{0,85}{\sqrt{\mathrm{n}_{\mathrm{cs}}}}\left(\frac{\mathrm{b}_{\mathrm{F}}}{\mathrm{h}_{\mathrm{F}}}\right)\left(\frac{\mathrm{h}_{\mathrm{cs}}}{\mathrm{h}_{\mathrm{F}}}-1\right) \leq 1,0
$$

onde

$\mathrm{h}_{\mathrm{F}}$ é a altura nominal da nervura $(\mathrm{mm})$;

$\mathrm{h}_{\mathrm{cs}}$ é a altura total do conector depois de soldado, não superior a $\mathrm{h}_{\mathrm{F}}+7,5 \mathrm{~mm}$ nos cálculos;

$\mathrm{b}_{\mathrm{F}}$ é a largura da nervura (mm);

$\mathrm{n}_{\mathrm{cs}}$ é o número de conectores de cisalhamento na viga, por nervura, não excedendo a 3 nos cálculos, embora mais que três conectores podem ser instalados. 
- EUROCODE 4 (1994)

Apresentam-se expressões análogas às I.1 e I.2, porém substituindo-se o fator 0,85 por 0,7 na expressão I.2, a qual não deverá ser utilizada para conectores tipo pino com cabeça (stud) com diâmetro maior que $20 \mathrm{~mm}$.

A figura I.1 esquematiza as dimensões correspondentes aos parâmetros utilizados na equação I.1 e I.2.
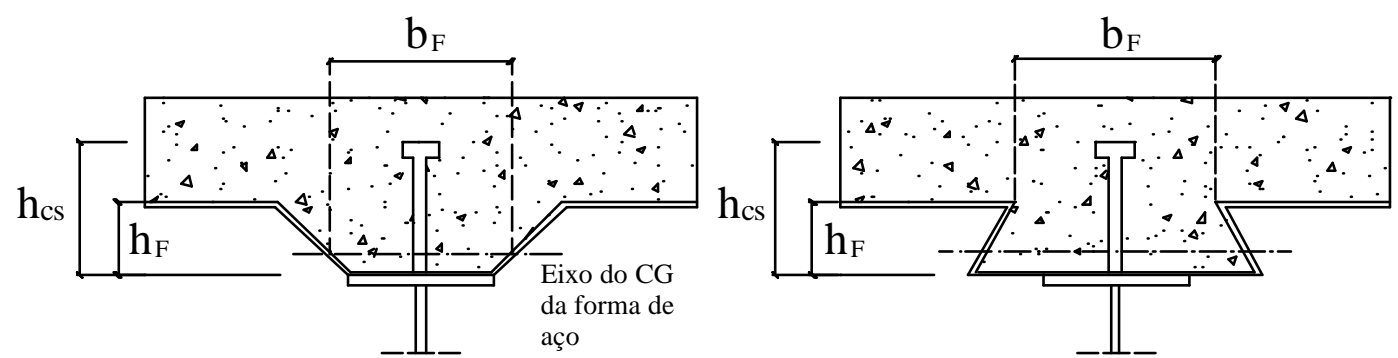

FIGURA I.1: Tipos de fôrmas de aço incorporadas

- $\quad$ BS 5950 (1990)

Para nervuras paralelas à viga de aço e relação $b_{F} / h_{F}$ (figura I.1) menor que 1,5, o coeficiente $C_{\text {red }}$ deve ser determinado a partir da expressão I.1. Para relações $b_{F} / h_{F}$ maiores que $1,5, \mathrm{C}_{\mathrm{red}}=1,0$. Para nervuras perpendiculares à viga de aço, o coeficiente de redução é calculado de acordo com as expressões I.3, I.4 e I.5.

a) Para um conector por nervura:

$\mathrm{C}_{\text {red }}=0,85\left(\frac{\mathrm{b}_{\mathrm{F}}}{\mathrm{h}_{\mathrm{F}}}\right)\left(\frac{\mathrm{h}_{\mathrm{cs}}}{\mathrm{h}_{\mathrm{F}}}-1\right) \leq 1,0$

b) Para dois conectores por nervura

$\mathrm{C}_{\text {red }}=0,6\left(\frac{\mathrm{b}_{\mathrm{F}}}{\mathrm{h}_{\mathrm{F}}}\right)\left(\frac{\mathrm{h}_{\mathrm{cs}}}{\mathrm{h}_{\mathrm{F}}}-1\right) \leq 0,8$ 
c) Para três ou mais conectores por nervura

$$
\mathrm{C}_{\text {red }}=0,5\left(\frac{\mathrm{b}_{\mathrm{F}}}{\mathrm{h}_{\mathrm{F}}}\right)\left(\frac{\mathrm{h}_{\mathrm{cs}}}{\mathrm{h}_{\mathrm{F}}}-1\right) \leq 0,6
$$

Vale ressaltar, que os resultados obtidos nas expressões I.3, I.4 e I.5 conduzem aos mesmos coeficientes de redução obtidos na equação I.2.

\section{- CAN/CSA-S16.1 (1994)}

Para fôrmas dispostas com suas nervuras paralelas à viga de aço: adota-se a expressão I.1, bem como repete-se a condição do item (a) da NBR-8800 (1986).

Nessa norma a determinação da resistência ao cisalhamento do conector tipo pino com cabeça (stud) em lajes de fôrmas dispostas com suas nervuras perpendiculares à viga de aço, se dá de modo diferente das outras normas apresentadas.

Como na maioria das vezes a ruptura para esta situação se dá pelo chamado efeito "Pull-out", há uma redução na resistência do conector em comparação às situações em laje maciça (mesma geometria e espaçamento). No efeito "Pull-out", ocorre uma separação entre o conector tipo pino com cabeça (stud) e a fôrma de aço, sendo que o conector permanece conectado à viga de aço junto com concreto com o formato da nervura.

Desta forma, a norma canadense apresenta duas expressões para determinação da resistência de cálculo do conector tipo pino com cabeça (stud) em lajes de fôrmas colocadas com nervuras perpendiculares à viga.

$$
\begin{aligned}
& \mathrm{q}_{\mathrm{rr}}=0,35 \phi_{\mathrm{sc}} \rho \mathrm{A}_{\mathrm{p}} \sqrt{\mathrm{f}_{\mathrm{ck}}}\left(\operatorname{para~}_{\mathrm{F}}=75 \mathrm{~mm}\right) \\
& \mathrm{q}_{\mathrm{rr}}=0,61 \phi_{\mathrm{sc}} \rho \mathrm{A}_{\mathrm{p}} \sqrt{\mathrm{f}_{\mathrm{ck}}}\left(\operatorname{para~}_{\mathrm{F}}=38 \mathrm{~mm}\right)
\end{aligned}
$$

onde

$\mathrm{q}_{\mathrm{rr}}$ é a resistência de cálculo do conector $(\mathrm{N})$;

$\phi_{\text {sc }}$ é o coeficiente de resistência, igual à 0,8 ; 
$\rho$ é um coeficiente para o peso específico do concreto, igual a 1,0 para concretos de densidade normal $\left(2150\right.$ a $\left.2500 \mathrm{Kg} / \mathrm{m}^{3}\right)$ e 0,85 para concretos de baixa densidade (1850 a $\left.2150 \mathrm{Kg} / \mathrm{m}^{3}\right)$;

$\mathrm{f}_{\mathrm{ck}}$ é o resistência característica à compressão do concreto (MPa);

$\mathrm{A}_{\mathrm{p}}$ é área de "Pull-out" do concreto $\left(\mathrm{mm}^{2}\right)$.

Ambas as expressões I.6 e I.7 devem ser menor ou igual ao valor $\mathrm{q}_{\mathrm{rd}}$, obtido por meio da expressão 3.7 (capítulo 3). 


\section{CRITÉRIO DE RUPTURA DO MODELO DE NÃO-LINEARIDADE CONCRETO}

De acordo com o ANSYS, os coeficientes $\mathrm{f}_{\mathrm{cb}}, \mathrm{f}_{1}$ e $\mathrm{f}_{2}$ podem ser tomados conforme as expressões I.1, I.2, I.3. Esses valores são considerados padrão.

$\mathrm{f}_{\mathrm{cb}}=1,2 \mathrm{f}_{\mathrm{c}}$

$\mathrm{f}_{1}=1,45 \mathrm{f}_{\mathrm{c}}$

$\mathrm{f}_{2}=1,725 \mathrm{f}_{\mathrm{c}}$

Os valores obtidos nas expressões I.1, I.2, I.3 representam satisfatoriamente o material quando a expressão I.4 é verificada. Caso contrário, a resistência do material pode ser incorretamente avaliada.

$\left|\sigma_{h}\right| \leq \sqrt{3} f_{c}$

$\mathrm{Na}$ expressão I.4, $\sigma_{\mathrm{h}}=\frac{1}{3}\left(\sigma_{\mathrm{xp}}+\sigma_{\mathrm{yp}}+\sigma_{\mathrm{zp}}\right)$ é $\mathrm{o}$ estado de tensão hidrostática, bem como $\sigma_{\mathrm{xp}}, \sigma_{\mathrm{yp}}$ e $\sigma_{\mathrm{zp}}$ as tensões principais segundo as direções principais.

A superfície de ruptura obtida para o material pode ser especificada apenas com $\mathrm{f}_{\mathrm{t}}$ e $\mathrm{f}_{\mathrm{c}}$ sendo $\sigma_{\mathrm{h}}{ }^{\mathrm{a}}, \mathrm{f}_{\mathrm{cb}}, \mathrm{f}_{1}$ e $\mathrm{f}_{2}$ tomados como padrão pelos códigos de cálculo do ANSYS. 
Com vista à expressão 4.1 (capítulo 4), ambas as funções F e S são expressas em termos das tensões principais denominadas de $\sigma_{1}, \sigma_{2}$ e $\sigma_{3}$, a qual são funções de $\sigma_{x p}, \sigma_{y p}$ e $\sigma_{\text {zp. }}$

$\sigma_{1}=\max \left(\sigma_{\mathrm{xp}}, \sigma_{\mathrm{yp}}, \sigma_{\mathrm{zp}}\right)$

$\sigma_{3}=\min \left(\sigma_{\mathrm{xp}}, \sigma_{\mathrm{yp}}, \sigma_{\mathrm{zp}}\right)$

Como $\sigma_{1} \geq \sigma_{2} \geq \sigma_{3}$, a ruptura do concreto pode ser classificada dentro de quatro domínios:

I. $\quad 0 \geq \sigma_{1} \geq \sigma_{2} \geq \sigma_{3}$ (compressão-compressão-compressão)

II. $\quad \sigma_{1} \geq 0 \geq \sigma_{2} \geq \sigma_{3}$ (tração-compressão-compressão)

III. $\quad \sigma_{1} \geq \sigma_{2} \geq 0 \geq \sigma_{3}$ (tração-tração-compressão)

IV. $\quad \sigma_{1} \geq \sigma_{2} \geq \sigma_{3} \geq 0$ (tração-tração-tração)

A seguir são demonstradas expressões para determinação de F e $\mathrm{S}$ dentro de cada domínio.

\section{1) DOMÍNIO I (COMPRESSÃO-COMPRESSÃO-COMPRESSÃO)}

Neste domínio o critério de William-Warnke estabelece as expressões I.7 e I.8 para determinação de $\mathrm{F}$ e S.

$$
\begin{aligned}
& \mathrm{F}=\mathrm{F}_{1}=\frac{1}{\sqrt{15}}\left[\left(\sigma_{1}-\sigma_{2}\right)^{2}+\left(\sigma_{2}-\sigma_{3}\right)^{2}+\left(\sigma_{3}-\sigma_{1}\right)^{2}\right]^{\frac{1}{2}} \\
& S=S_{1}=\frac{2 r_{2}\left(r_{2}^{2}-r_{1}^{2}\right) \cos \eta+r_{2}\left(2 r_{1}-r_{2}\right)\left[4\left(r_{2}{ }^{2}-r_{1}{ }^{2}\right) \cos ^{2} \eta+5 r_{1}^{2}-4 r_{1} r_{2}\right]^{\frac{1}{2}}}{4\left(r_{2}^{2}-r_{1}^{2}\right) \cos ^{2} \eta+\left(r_{2}-2 r_{1}\right)^{2}}
\end{aligned}
$$

Onde os termos que definem S são: 


$$
\begin{aligned}
& \cos \eta=\frac{2 \sigma_{1}-\sigma_{2}-\sigma_{3}}{\sqrt{2}\left[\left(\sigma_{1}-\sigma_{2}\right)^{2}+\left(\sigma_{2}-\sigma_{3}\right)^{2}+\left(\sigma_{3}-\sigma_{1}\right)^{2}\right]^{\frac{1}{2}}} \\
& \mathrm{r}_{1}=\mathrm{a}_{0}+\mathrm{a}_{1} \xi+\mathrm{a}_{2} \xi^{2} \\
& \mathrm{r}_{2}=\mathrm{b}_{0}+\mathrm{b}_{1} \xi+\mathrm{b}_{2} \xi^{2} \\
& \xi=\sigma_{\mathrm{h}} / \mathrm{f}_{\mathrm{c}}
\end{aligned}
$$

A figura I.1 ilustra a superfície de ruptura no espaço das tensões principais, onde o ângulo de similaridade $\eta$ estabelece as dimensões relativas das tensões principais. Da expressão I.9, $\eta=0^{\circ}$ refere-se ao estado de tensão tal que $\sigma_{3}=\sigma_{2}>\sigma_{1}$. Por outro lado, $\eta=60^{\circ}$ refere-se ao estado de tensão tal que $\sigma_{3}>\sigma_{2}=\sigma_{1}$. Todos os outros estados de tensões multiaxiais têm ângulos de similaridade tal que $0^{\circ} \leq \eta \leq 60^{\circ}$.

Quando $\eta=0^{\circ}, S_{1}$ iguala $r_{1}$, enquanto se $\eta=60^{\circ}, S_{1}$ iguala a $r_{2}$. Portanto, a função $r_{1}$ representa a superfície de ruptura de todos os estados de tensões com $\eta=0^{\circ}$.

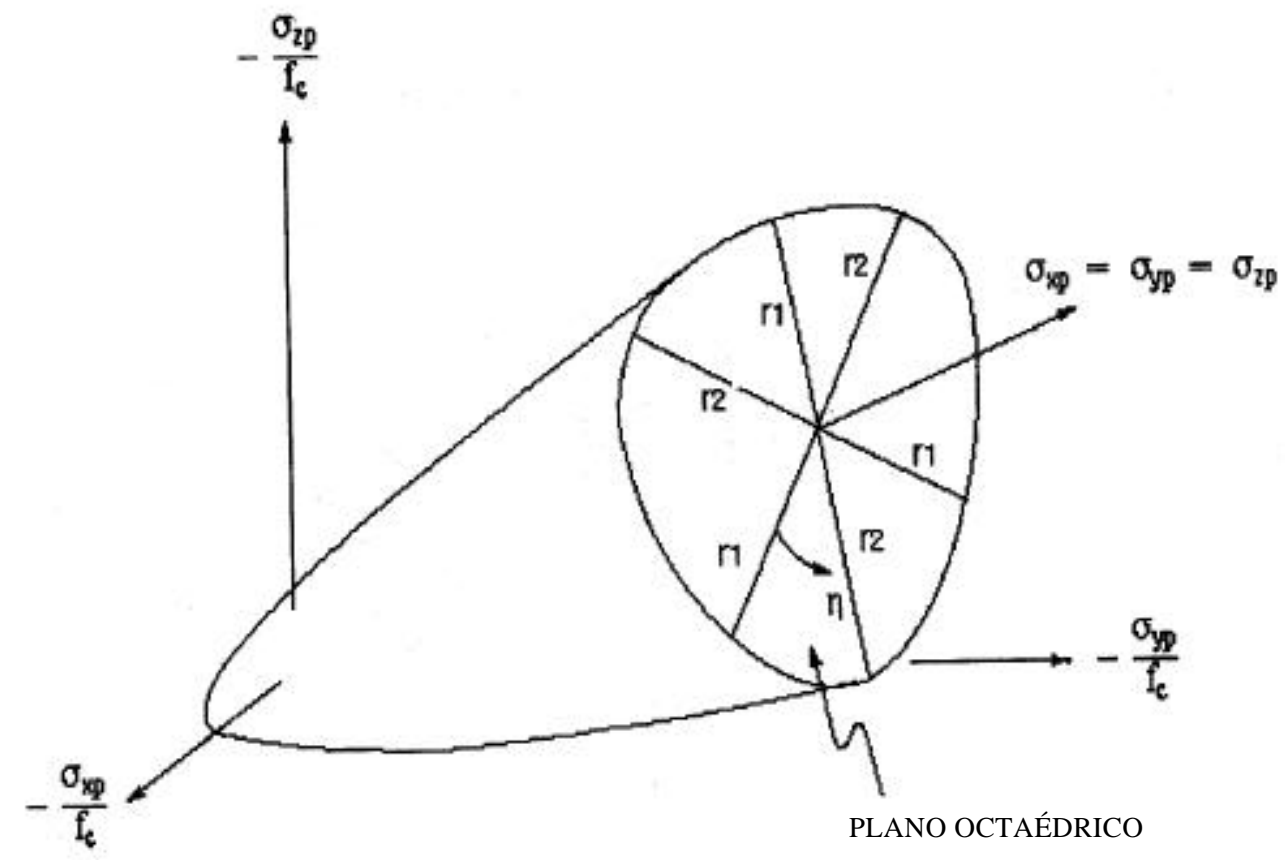

FIGURA I.1: Superfície de ruptura no espaço das tensões principais 
Na figura I.1, a seção transversal do plano de ruptura tem simetria a cada $120^{\circ}$.

A função $r_{1}$ é determinada pelo ajuste de $a_{0}, a_{1}$ e $a_{2}$, tal que $f_{t}, f_{c b}$ e $f_{1}$ estejam na superfície de ruptura. Os valores propostos para esses coeficientes são determinados por meio da solução do sistema abaixo.

$$
\left\{\begin{array}{l}
\frac{F_{1}}{f_{c}}\left(\sigma_{1}=f_{t}, \sigma_{2}=\sigma_{3}=0\right) \\
\frac{F_{1}}{f_{c}}\left(\sigma_{1}=0, \sigma_{2}=\sigma_{3}=-f_{c b}\right. \\
\frac{F_{1}}{f_{c}}\left(\sigma_{1}=-\sigma_{h}^{a}, \sigma_{2}=\sigma_{3}=-\sigma_{h}^{a}-f_{1}\right.
\end{array}\right\}=\left[\begin{array}{ccc}
1 & \xi_{t} & \xi_{t}^{2} \\
1 & \xi_{c b} & \xi_{c b}^{2} \\
1 & \xi_{1} & \xi_{1}^{2}
\end{array}\right]\left\{\begin{array}{l}
a_{0} \\
a_{1} \\
a_{2}
\end{array}\right\}
$$

onde:

$\xi_{\mathrm{t}}=\frac{\mathrm{f}_{\mathrm{t}}}{3 \mathrm{f}_{\mathrm{c}}}$

$\xi_{c b}=-\frac{2 f_{c b}}{3 f_{c}}$

$\xi_{1}=-\frac{\sigma_{h}^{a}}{f_{c}}-\frac{2 f_{1}}{3 f_{c}}$

A função $\mathfrak{r}_{2}$ é calculada pelo ajuste de $b_{b}, b_{1}$ e $b_{2}$, a qual satisfazem as condições do sistema I.16.

$$
\left\{\begin{array}{l}
\frac{F_{1}}{f_{c}}\left(\sigma_{1}=\sigma_{2}=0, \sigma_{3}=-f\right) \\
\frac{F_{1}}{f_{c}}\left(\sigma_{1}=\sigma_{2}=-\sigma_{h}^{a}, \sigma_{3}=-\sigma_{h}^{a}-\frac{f_{2}}{3 f_{c}}\right. \\
0
\end{array}\right\}=\left[\begin{array}{ccc}
1 & -\frac{1}{3} & \frac{1}{9} \\
1 & \xi_{2} & \xi_{2}^{2} \\
1 & \xi_{0} & \xi_{0}^{2}
\end{array}\right]\left\{\begin{array}{l}
b_{0} \\
b_{1} \\
b_{2}
\end{array}\right\}
$$

onde:

$$
\xi_{2}=-\frac{\sigma_{\mathrm{h}}^{\mathrm{a}}}{\mathrm{f}_{\mathrm{c}}}-\frac{\mathrm{f}_{2}}{3 \mathrm{f}_{\mathrm{c}}}
$$


$\varepsilon_{0}$ é a raiz positiva da expressão I.18.

$\mathrm{r}_{2}\left(\varepsilon_{0}\right)=\mathrm{a}_{0}+\mathrm{a}_{1} \varepsilon_{0}+\mathrm{a}_{2} \varepsilon_{0}{ }^{2}=0$

onde, $\mathrm{a}_{0}, \mathrm{a}_{1}$ e $\mathrm{a}_{2}$ são determinados pelo sistema I.12.

Os coeficientes $a_{0}, a_{1}, a_{2}, b_{0}, b_{1}$ e $b_{2}$ precisam satisfazer as seguintes condições:

$\mathrm{a}_{0}>0, \mathrm{a}_{1} \leq 0, \mathrm{a}_{2} \leq 0$

$\mathrm{b}_{0}>0, \mathrm{~b}_{1} \leq 0, \mathrm{~b}_{2} \leq 0$

Portanto, ocorre um fechamento da superfície de ruptura e a ruptura acontecerá sob pressão hidrostática elevada. O fechamento da superfície de ruptura não é verificado experimentalmente e a forma cilíndrica de Von Mises é a superfície de ruptura mais apropriada para valores de compressão $\sigma_{\mathrm{h}}$ elevados. Conseqüentemente, recomenda-se que valores de $f_{1}$ e $f_{2}$ sejam adotados, em níveis de tensão hidrostátic a $\left(\sigma_{\mathrm{h}}{ }^{\mathrm{a}}\right)$, na vizinhança ou acima das tensões hidrostática máxima encontrada na estrutura.

A superfície ruptura tem os meridianos representados por parábolas (figura I.2), e estão em função da tensão de cisalhamento $\left(\tau_{\mathrm{ct}}\right)$ e de um parâmetro adimensional $(\xi)$.

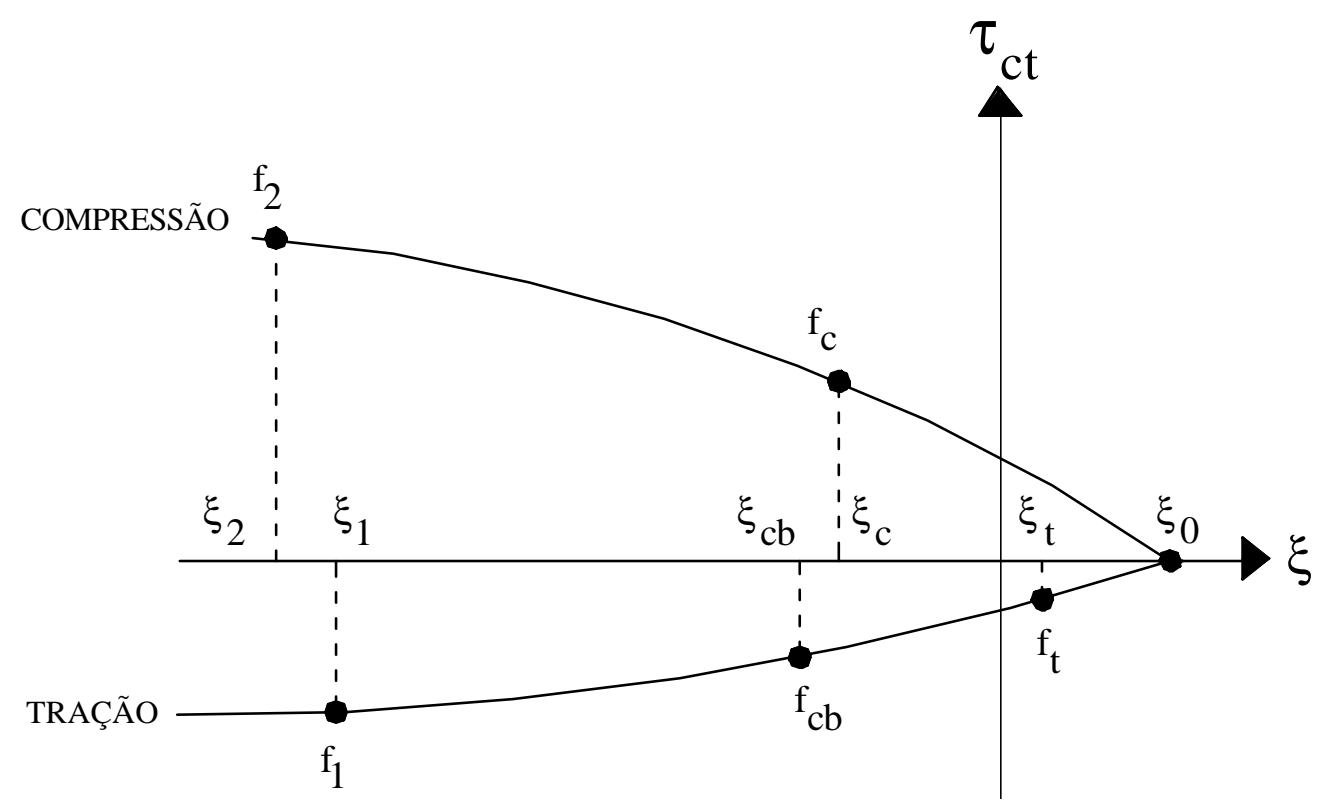

FIGURA I.2: Superfície de ruptura associado ao modelo concreto, em função de $\varepsilon$ 
Neste domínio, se o critério de ruptura for satisfeito, o material é assumido como esmagado.

\section{2) DOMÍNIO II (TRAÇÃO-COMPRESSÃO-COMPRESSÃO)}

Neste domínio F e S são definidos pelas expressões I.21 e I.22.

$$
\begin{aligned}
& \mathrm{F}=\mathrm{F}_{2}=\frac{1}{\sqrt{15}}\left[\left(\sigma_{2}-\sigma_{3}\right)^{2}+\left(\sigma_{2}\right)^{2}-\left(\sigma_{3}\right)^{2}\right]^{\frac{1}{2}} \\
& \mathrm{~S}=\mathrm{S}_{2}=\left(1-\frac{\sigma_{1}}{\mathrm{f}_{\mathrm{t}}}\right) \frac{2 \mathrm{p}_{2}\left(\mathrm{p}_{2}{ }^{2}-\mathrm{p}_{1}{ }^{2}\right) \cos \eta+\mathrm{p}_{2}\left(2 \mathrm{p}_{1}-\mathrm{p}_{2}\right)\left[4\left(\mathrm{p}_{2}{ }^{2}-\mathrm{p}_{1}{ }^{2}\right) \cos ^{2} \eta+5 \mathrm{p}_{1}^{2}-4 \mathrm{p}_{1} \mathrm{p}_{2}\right]^{\frac{1}{2}}}{4\left(\mathrm{p}_{2}{ }^{2}-\mathrm{p}_{1}{ }^{2}\right) \cos ^{2} \eta+\left(\mathrm{p}_{2}-2 \mathrm{p}_{1}\right)^{2}}
\end{aligned}
$$

onde:

$\cos \eta$ é definido pela expressão I.9

$\mathrm{p}_{1}=\mathrm{a}_{0}+\mathrm{a}_{1} \chi+\mathrm{a}_{2} \chi^{2}$

$\mathrm{p}_{2}=\mathrm{b}_{0}+\mathrm{b}_{1} \chi+\mathrm{b}_{2} \chi^{2}$

$\chi=\frac{1}{3}\left(\sigma_{2}+\sigma_{3}\right)$

Os coeficientes $\mathrm{a}_{0}, \mathrm{a}_{1}, \mathrm{a}_{2}, \mathrm{~b}_{0}$, $\mathrm{b}_{1}$ e $\mathrm{b}_{2}$ são definidos pelos sistemas I.12 e I.16.

Neste domínio se o critério de ruptura for satisfeito, ocorrerão fissuras no plano perpendicular a tensão principal $\sigma_{1}$.

\section{3) DOMÍNIO III (TRAÇÃO-TRAÇÃO-COMPRESSÃO)}

As expressões I.26 e I.27 definem as funções F e S.

$\mathrm{F}=\mathrm{F}_{3}=\sigma_{\mathrm{i}} ; \mathrm{i}=1,2$ 
$\mathrm{S}=\mathrm{S}_{3}=\frac{\mathrm{f}_{\mathrm{t}}}{\mathrm{f}_{\mathrm{c}}}\left(1+\frac{\sigma_{3}}{\mathrm{~S}_{2}\left(\sigma_{\mathrm{i}}, 0, \sigma_{3}\right)}\right) ; \mathrm{i}=1,2$

Se o critério de ruptura para $\mathrm{i}=1,2$ for satisfeito, ocorrerão fissuras nos planos perpendiculares as tensões principais $\sigma_{1}$ e $\sigma_{2}$. Se o critério de ruptura é satisfeito somente para $\mathrm{i}=1$, ocorrerão fissuras somente no plano perpendicular a tensão principal $\sigma_{1}$.

\section{4) DOMÍNIO IV (TRAÇÃO-TRAÇÃO-TRAÇÃO)}

No domínio quatro F e S são determinados pelas expressões I.28 e I.29.

$\mathrm{F}=\mathrm{F}_{4}=\sigma_{\mathrm{i}}, \mathrm{i}=1,2,3$

$\mathrm{S}=\mathrm{S}_{4}=\frac{\mathrm{f}_{\mathrm{t}}}{\mathrm{f}_{\mathrm{c}}}$

Se o critério de ruptura for satisfeito nas direções 1, 2 e 3, ocorrerão fissuras nos planos perpendiculares as tensões principais $\sigma_{1}, \sigma_{2}$ e $\sigma_{3}$.

Se o critério de ruptura for satisfeito nas direções 1 e 2, ocorrerão fissuras no plano perpendicular as tensões principais $\sigma_{1}$ e $\sigma_{2}$.

Se o critério de ruptura for satisfeito somente na direção 1 , ocorrerão fissuras no plano perpendicular a tensão principal $\sigma_{1}$. 